Erster Beratungsgegenstand:

\title{
Die staatsrechtliche Stellung der Ausländer in der Bundesrepublik Deutschland
}

\author{
1. Bericht von Professor Dr. Karl Doehring, Heidelberg
}

Der Status der Fremden im Verfassungsrecht der Bundesrepublik Deutschland unter dem Gesichtspunkt der normativen Verschränkung von Völkerrecht und Verfassungsrecht

\section{Inhalt}

Vorbemerkung . . . . . . . . . . . . . . . . 8

I. Der Begriff des Fremden . . . . . . . . . . . . . . . . 9

1. Der „Fremde" im Völkerrecht . . . . . . . . . . . 10

2. Der „Fremde“ im Verfassungsrecht . . . . . . . . . . 11

II. Die Gebote des Völkerrechts für die Behandlung von Fremden im innerstaatlichen Recht . . . . . . . . . . . . . 12

1. Das völkerrechtliche Gewohnheitsrecht . . . . . . . . 12

2. Bilaterale Verträge . . . . . . . . . . . . . . . . 14

3. Kollektivverträge . . . . . . . . . . . . . . . . 15

4. Die allgemeinen Rechtsgrundsätze . . . . . . . . . . 16

5. Die Gegenseitigkeit . . . . . . . . . . . . . . . . . 17

6. Die Repressalie . . . . . . . . . . . . . . . . . . . 18

7. Die Beachtung der heimatlichen Rechtsordnung des Fremden . . . . . . . . . . . . . . . . 19

III. Das System des Grundgesetzes zur Erfüllung völkerrechtlicher Gebote im innerstaatlichen Recht . . . . . . . . . 21

1. Das völkerrechtliche Gewohnheitsrecht und Art. 25 GG 22

2. Das Vertragsrecht . . . . . . . . . . . . . . 27

IV. Die Auswirkung völkerrechtlicher Normen auf die Grundrechte von Fremden ... . . . . . . . . . . . . 32

1. Rechtsvergleichende Ubersicht . . . . . . . . . . . . 32

2. Grundrechte und politische Beteiligung der Fremden . 34

3. Einzelne Grundrechte und Systematik des Grundgesetzes 37

Schlußbemerkung . . . . . . . . . . . . . . 43 43 


\section{Vorbemerkung}

Wir leben in einer Welt, die sich immer noch aus koordinierten Gemeinwesen, aus Staaten, zusammensetzt. Zwar ist eine gewisse Abkehr vom sogenannten nationalistischen Denken feststellbar, daneben aber, gerade bei sogenannten neuen Staaten, auch eine Zuwendung zur Betonung der alten Souveränität vorhanden. Keine nationalen und keine internationalen Träume können über den realen Status der Völkergemeinschaft hinweghelfen. Vor allem, ein Staat gäbe sich auf und würde seiner Totalverantwortung für seine Bürger nicht mehr genügen, wollte er in den Traum eines Weltbürgertums versinken.

Das heißt aber auch, daß die Unterscheidung von Staatsangehörigen und Fremden (noch?) ein Prinzip ist, dem sich ohne Verfehlung seiner noch bestehenden Aufgabe kein Staat entziehen kann; täte er es, dann würde er die ihm zuvorderst anvertrauten Menschen in gewisser Weise einer noch nicht kompensierten Unsicherheit aussetzen.

Diejenigen, die sich in neuerer Zeit dafür einsetzen, daß auf Grund des Demokratiegebotes die Gleichstellung von Staatsangehörigen und Fremden zu perfektionieren sei, sollten sich die Begriffe Demokratie und Volksherrschaft in ihrer Substanz in das Gedächtnis zurückrufen. Demokratie ist nicht nur Mitbestimmung aller, sondern vor allem Mitverantwortung der Mitglieder des Staatsvolkes ${ }^{\mathbf{1}}$ ).

Ein konkretes Beispiel sei hier erlaubt. Nimmt ein Staat auf Grund eines verfassungsmäßig verbürgten Asylrechts jeden Asylsuchenden auf, auch den Gegner jeder Rechtsstaatlichkeit, und gibt ihm - in meinem Sinne pseudodemokratisch - die Mitbestimmung, dann mag es eine Frage der Zeit sein, wie lange dieser Staat seine eigene Verfassung zu schützen vermag. Wenn eine freiheitliche demokratische Grundordnung diejenigen mit Rechten ausstattet, die diese Grundordnung zu zerstören trachten, hebt sie sich auf. Eine sich selbst aufhebende Verfassung und ein sich aufgebender freiheitlicher Staat kann niemanden mehr schützen und in ihm würde gerade der Mensch, der die Freiheit sich bewahren will, auch kein Asyl mehr suchen. Die Erkenntnis ist nicht neu, daß ein Ubermaß an Humanität und Liberalität die größte Brutalität erzeugen kann; Freiheit hat eben Bestand nur in der Bindung. Das hat

1) Uber die Entstehung des Instituts der Staatsangehörigkeit gerade auch im Hinblick auf Rechte und Verantwortlichkeiten $A$. $N$. Makarov, Allgemeine Lehren des Staatsangehörigkeitsrechts, 2. Aufl., 1962, S. 5 ff. 
mit nationalistischem Denken nichts zu tun sondern ist gerade eine Frage des Schutzes der Menschenrechte, die bisher und wohl noch lange ihren besten Hort in Verbänden und nicht in der Staatsauflösung finden.

So gesehen ist die Aufhebung der Unterscheidung von Staatsbürgern und Fremden nicht die Perfektionierung der Menschlichkeit, sondern in der noch bestehenden Welt eher ihre Zerstörung. In Frage steht nur das $\mathrm{Maß}$ der Differenzierung. Weder muß eine allgemeine Umarmung geboten sein, noch müssen die Fremden stets an ihre Fremdheit erinnert werden. Verfassungsrecht und Völkerrecht haben dieser maßvollen Sicht auch Rechnung getragen. Daß dabei Sein und Sollen divergieren können, ist bekannt.

Das Thema bedarf der Abgrenzung, insbesondere der Eingrenzung. Es soll im Folgenden nicht darum gehen, jede denkbare Rechtsbeziehung des Fremden zum deutschen Recht darzustellen und zu untersuchen, sondern der Schwerpunkt des zu behandelnden Themas liegt in der Betrachtung des Status eines Fremden, der sich legal im Geltungsbereich des Grundgesetzes aufhält.

Diejenigen Fragen also, die sich auf Aufenthaltsrecht, Ausweisung, Abweisung, Auslieferung, Asylrecht, Einbürgerung u. ä. beziehen, werden nicht als selbständige Probleme behandelt, sondern nur dann, wenn die Untersuchung des Status des legal in der Bundesrepublik lebenden Fremden für die Abgrenzung seiner Rechte und Pflichten das unbedingt notwendig macht.

In der gleichen Weise wird thematisch der Sonderstatus von Staatsangehörigen der europäischen Gemeinschaften nur berührt werden, wenn Abgrenzungen von und Vergleiche zum Status des „normalen“ Fremden unbedingt notwendig erscheinen. Ebenso ist auf die Besonderheiten der rechtlichen Behandlung der Bürger der DDR nur in dieser mittelbaren Weise einzugehen, obwohl, wie ich das früher schon ausgeführt habe, die analoge Anwendung der allgemeinen Fremdenrechtsregeln geboten sein kann.

Das heißt also, Statusbegründung, Statusbeendigung und Sonderstatus gehören nicht $\mathrm{zu}$ den eigentlichen Gegenständen der folgenden Betrachtung.

\section{Der Begriff des Fremden}

Den Terminus "Fremder" ziehe ich der Bezeichnung „Ausländer" vor, was sich aus den nun zu gebenden Hinweisen erklärt. 


\section{Der „Fremde" im Völkerrecht}

Zwar kann man heute an der lange Zeit geradezu als eine der Grundlagen des Völkerrechts geltenden Auffassung nicht mehr festhalten, wonach das Individuum nur "im Lichte" einer Staatsangehörigkeit $\mathrm{zu}$ einem völkerrechtlich relevanten $\mathrm{Ob}-$ jekt wird²). Diese Auffassung ist seit der Entstehung allgemeiner völkerrechtlicher Menschenrechte und für diejenigen, die den Bestand solcher Rechte anerkennen, nicht mehr haltbar ${ }^{3}$ ), denn auch Staatenlose sind Menschen als Inhaber von Menschenrechten. Aber auch, wenn man dieser modernen und wohl auch überwiegend akzeptierten Auffassung ${ }^{4}$ ) folgt, behält der Begriff des Fremden im Völkerrecht seine hervorragende Bedeutung. Allerdings meint er im wesentlichen etwas negatives und wird in dieser mehr negativen Beziehung vor allem rechtlich relevant.

Der Fremde im Völkerrecht ist nämlich ein Individuum, das nicht die Staatsangehörigkeit desjenigen Staates innehat, zu dem seine Rechtsbeziehungen Gegenstand der Betrachtung sind $^{5}$ ). Das kann der Inhaber einer anderen Staatsangehörigkeit als derjenige des Aufenthaltsstaates sein und es kann der Staatenlose sein; es kann auch derjenige sein, dessen Staatsangehörigkeit ungeklärt ist, oder auch für manche Belange der Doppelstaater.

Diese negative Abgrenzung - die Nichtinhaberschaft der Staatsangehörigkeit des auf sein Verhalten zu prüfenden Staates - drückt sich in den Rechtsregeln auch weitgehend negativ aus: Der Fremde kann nicht gegenüber dritten Staaten geschützt werden (nationality rule); ein Schadensersatz kann nicht für Fremde gefordert werden; ein Staat ist nicht verpflichtet, Fremde aufzunehmen; ein Staat ist nicht berechtigt, einen

7 F. Stoerk, Staatsuntertanen und Fremde, Handbuch des Volkerrechts, hrsg. von $F$. v. Holtzendorff, Bd. 2, 1887, S. 589.

s) G. Dahm, Die Stellung des Menschen im Völkerrecht unserer Zeit, Recht und Staat, Nr. 238, 1961, S. $11 \mathrm{ff}$.

9) Die Veränderung der Stellung des Individuums im allgemeinen Völkerrecht drückte sich insbes. in einer Anderung der Auffassungen über die materiell-rechtliche Inhaberschaft von Ansprüchen im Rahmen des diplomatischen Schutzes aus, wie sie etwa von $\boldsymbol{H}$. Lauterpacht (International Law and Human Rights, 1950, S. 27) zum Ausdruck gebracht wird: „.. . the correct way of stating the legal position is not that the State asserts its own exclusive rights but enforces in substance the right of the individual ....

5) $J$. Gilissen, Le statut des étrangers à la lumière de l'histoire comparative (Recueil de la société Jean Bodin, Bd. IX, 1. Tell, 1958, S. 10): "Est étranger celui qui ne fait pas partie du groupe sociale politique par rapport auquel son statut est envisagé ..." 
Fremden zum Treuebruch mit seinem Heimatstaat zu veranlassen; ein Staat ist nicht berechtigt, den Fremden in jedem Falle wie einen eigenen Staatsangehörigen $\mathrm{zu}$ behandeln und anderes mehr.

Anders gewendet bedeutet diese Abgrenzung: der Staat kann regelmäßig - nämlich abgesehen von allgemeinen auch völkerrechtlichen Menschenrechten ${ }^{6}$ ) - die eigenen Staatsangehörigen nach reiner Maßgabe des nationalen Rechts behandeln, für eigene Staatsangehörige und nur für sie die diplomatische Protektion ausüben und anderes mehr.

Die Unterscheidung zwischen Fremden und eigenen Staatsangehörigen ist also in vielen völkerrechtlichen Beziehungen strikt geboten.

\section{Der "Fremde“ im Verfassungsrecht}

Etwas anders ist die Rechtslage im Verfassungsrecht. Ob eine nationale Rechtsordnung und wie weit sie zwischen Staatsangehörigen und Nichtstaatsangehörigen oder zwischen Angehörigen verschiedener Staaten differenziert, ist regelmäßig innere Angelegenheit des jeweiligen Staates, solange und soweit die völkerrechtlichen Gebote beachtet sind, die noch aufgezeigt werden sollen.

Sicherlich würde ein Staat völkerrechtswidrig handeln, wenn er sich weigern würde, den Kreis seiner Staatsangehörigen überhaupt zu bestimmen ${ }^{7}$ ); insoweit muß - aus völkerrechtlichen Gründen - die nationale Rechtsordnung zwischen fremden und eigenen Staatsangehörigen differenzieren. Jedoch innerhalb der völkerrechtlichen Gebote kann eine Differenzierung auch unterbleiben, bzw. sie steht in ihrer Ausgestaltung jedem Staat frei. Es gibt wohl keinen Staat als Mitglied der Völkerrechtsgemeinschaft, der den Kreis seiner Staatsangehörigen nicht abgrenzt und also den Begriff des Fremden auch für den nationalen Bereich negiert.

Wie das Grundgesetz die Ausgestaltungen und Abgrenzungen vornimmt, wird noch gezeigt werden. Nur auf einen Gesichtspunkt sei hier schon hingewiesen. Wenn Artikel 25 GG die allgemeinen Regeln des Völkerrechts zu innerstaatlichem Recht

9) W. Wengler, Völkerrecht, Bd. 2, 1964, S. 1004.

7) Wenn ein abgrenzbares Staatsvolk als unabdingbares Merkmal des Staates in seiner Eigenschaft als Völkerrechtssubjekt angesehen werden muß (H. Mosler, Völkerrechtsfähigkeit, Wörterbuch des Völkerrechts, Bd. III, 1962, S. 668 ff.), müßte die Rechtsfolge mangelnder Bestimmung des Kreises der Staatsangehörigen der Verlust der Rechtspersönlichkeit sein. 
erklärt, dann gibt es nicht nur ein völkerrechtliches Gebot, eine Unterscheidung zwischen Staatsangehörigen und Fremden zu vollziehen ${ }^{8}$ ), sondern die Verfassung selbst gebietet diese Unterscheidung, soweit das Völkerrecht sie zwingend fordert ${ }^{\mathrm{p}}$ ).

II. Die Gebote des Völkerrechts für die Behandlung von Fremden im innerstaatlichen Recht

Bei dieser Betrachtung kann es nicht darum gehen, die völkerrechtlichen Gebote in ihrer subtilen Einzelausgestaltung darzustellen, sondern es kann nur das System gezeigt werden. Dieses System kann auf wenige fundamentale Grundsätze reduziert werden. Die Subtilitäten werden allerdings eine Rolle spielen bei der Frage, ob und wie das Grundgesetz die völkerrechtlichen Forderungen erfüllt.

Die folgende Betrachtung ist nach den Rechtsquellen des Völkerrechts geordnet, da diese zueinander in einer gewissen Rangordnung stehen können, die nicht übersehen werden darf ${ }^{10}$ ).

\section{Das völkerrechtliche Gewohnheitsrecht}

Die Kontroverse, ob in der Rechtsquellenhierarchie das Gewohnheitsrecht oder das Vertragsrecht den ersten Platz einnimmt, übergehe ich hier, denn auch die sowjetische Völkerrechtslehre, die der Auffassung von einem Vorrang des Vertragsrechts zuneigte, leugnet den Bestand von Gewohnheitsrecht nicht mehr in der früheren Art $^{11}$ ).

Das Gewohnheitsrecht soll hier als erste Rechtsquelle deshalb betrachtet werden, weil nur in seinem Rahmen von zwingendem Recht zu sprechen sinnvoll ist; soweit es zwingende Rechtssätze enthält, sind sie der Abänderung durch Vertragsrecht entzogen $\left.{ }^{12}\right)$.

Nach einigem Schwanken in der Rechtsentwicklung, das zum Teil besonders regional bedingt war, hat sich ein relativ fester

9) So darf eine Reihe von Pflichten, die von den Staatsbürgern zu erfüllen sind, den Fremden gerade nicht auferlegt werden ( $W$. Wengler, a. a. O., S. 988).

p) So auch eindeutig BGH v. 23. 10. 1963, MDR 1964, S. 218.

10) Auch dann, wenn man eine Rangordnung weitgehend ablehnt (vgl. dazu G. Jaenicke, Völkerrechtsquellen, Wörterbuch des Völkerrechts, Bd. III, 1962, S. 773 f.), muß doch im Falle des Normenkonflikts - z. B. Vertrag gegen Gewohnheitsrecht oder umgekehrt über den „Rang“ entschieden werden.

11) G. I. Tunkin, Völkerrechtstheorie, 1970 (deutsche Ubersetzung 1972), S. $143 \mathrm{ff}$.

12) G. Dahm, völkerrecht, Bd. 3, 1961, S. 60. 
Bestand an Rechtsgrundsätzen herausgebildet, denen das Verhalten der Staaten bei der Behandlung von Fremden zu folgen hat. Man spricht in dieser Beziehung vom völkerrechtlichen Mindeststandard ${ }^{13}$ ), dessen Unterschreitung ein völkerrechtliches Delikt bedeuten würde.

Dieser Mindeststandard deckt sich inhaltlich zum Teil mit den völkerrechtlichen Menschenrechten, wobei aber darauf hinzuweisen ist, daß letztere nicht schlechthin der Deklaration der Vereinten Nationen von 1948, den Vertragsentwürfen über die Menschenrechte der Vereinten Nationen von 1966 oder der Europäischen Menschenrechtskonvention entnommen werden können; diese Kodifikationen oder Kodifikationsversuche übersteigen den Mindeststandard und die allgemeinen Menschenrechte in vieler Hinsicht, was hier nicht weiter ausgeführt werden soll.

Der fremdrenrechtliche Mindeststandard ist ungeschriebenes Recht, er ist zwingendes Recht, zumindest soweit er sich mit den Menschenrechten deckt ${ }^{14}$ ), und kann theoretisch durch die sogenannte Inländergleichbehandlung sowohl unterschritten werden - was rechtswidrig wäre - oder überschritten werden - was zulässig wäre $-{ }^{15}$ ), wenn auch mit Grenzen, auf die zurückzukommen ist.

Der Mindeststandard hat keinen endgültig festgelegten Inhalt, sondern unterliegt dem Wandel des Gewohnheitsrechts' ${ }^{16}$ ). So könnte z. B. der Eigentumsschutz der Fremden unter weltweitem Wechsel der Sozialbindungen sich verändern. Die Substanz des Mindeststandards soll hier nicht in ihren Einzelheiten dargestellt werden; auf sie ist für Einzelfragen bei $\mathrm{Be}-$ trachtung der Regeln des Grundgesetzes gegebenenfalls zurückzukommen.

Der so charakterisierte Standard ist aber eben auch nur zum Teil ein zwingendes Mindesterfordernis ${ }^{17}$ ). Das fremdenrecht-

13) So schon E. Borchard, Diplomatic Protection of Citizens Abroad, 1919, S. 39: „. . . standard of treatment which the State cannot violate without incurring international responsability".

14) G. Dahm, a. a. O., Bd. 1, 1958, S. 506.

15) A. Verdross - S. Verosta - K. Zemanek, Völkerrecht, 5. Aufl., 1964, S. 361.

16) So auch BVerfG v. 14. 5. 1968, BVerfGE 23, 316, wo daraufhingewiesen ist, daß die Fortentwicklung des völkerrechtlichen Gewohnheitsrechts zu immer neuen Kollisionen mit innerstaatlichem Recht führen könne.

17) $H$. Kraus, Staats- und völkerrechtliche Betrachtungen zur Rechtsstellung des Fremden - Ein Beitrag zum Gleichheitsproblem, Gedächtnisschrift für Walter Jellinek, 1955, S. 92, meint, nur 
liche Gewohnheitsrecht kennt auch Regeln, die nicht zwingendes Recht und also durch Verträge abdingbar sind ${ }^{18}$ ). Der Gewohnheitsrechtssatz z. B., daB Fremde als politische Delinquenten oder auch als Desserteure nicht ausgeliefert werden, könnte vertraglich aufgehoben werden. Nur dann, wenn durch eine solche Auslieferung eine unmenschliche Behandlung im Empfangsstaat ermöglicht würde, wäre der Mindeststandard verletzt in seiner Schutzfunktion für die Menschenrechte.

Wir haben also zwei Kategorien von Gewohnheitsrechtssätzen vor uns: solche, die den Mindeststandard ausfüllen und zwingend sind, und solche, die nicht zum menschenrechtlichen Kern des Mindeststandards zählen und vertraglich abdingbar $\left.\operatorname{sind}^{10}\right)$.

\section{Bilaterale Verträge}

Damit ist über das fremdenrechtliche Vertragsrecht auch schon wesentliches gesagt. Die Staaten als Vertragspartner können den Status der beiderseitigen Staatsangehörigen oberhalb des zwingenden Mindeststandards ausgestalten; sie können Rechte erteilen, die das Gewohnheitsrecht nicht kennt und sie können Rechte aufheben, die ohne diese Aufhebung zum Gewohnheitsrecht zählen würden, solange der zwingende Mindeststandard nicht berührt ist.

Der Klarheit halber sei angemerkt, daß die Frage, ob und inwieweit die völkerrechtlichen Rechtssätze über die Behandlung von Fremden zu deren subjektiven Rechten zählen, hier nicht zu behandeln ist; die Untersuchung der Artikel 25 und 59 GG wird diese Probleme weitgehend lösen.

Wie und auf welche Weise die Vertragseinhaltung zur Fremdenbehandlung innerstaatlich gesichert ist, interessiert das Völkerrecht nicht, falls nicht der Vertrag selbst die Sicherung zum Gegenstand hat, wie das z. B. bei ausdrücklicher Vereinbarung über einen den Mindeststandard überschreitenden Ge-

eine "geringe Anzahl von Regeln zwingender Natur“ im Rahmen des Mindeststandards feststellen zu können.

18) Unklar ist die Auffassung des BVerfG (7. 4. 1965, BVerfGE 18, 448) in dieser Beziehung, wenn es heißt: „Das Völkergewohnheltsrecht ist durchweg nachgiebiges Recht"; diese Rechtsauffassung wird dann in den weiteren Ausführungen wieder eingeschränkt, da "einige elementare Rechtsgebote“ als der Vertragsfreiheit entzogen anerkannt werden.

19) $H$. Kelsen - R. W. Tucker, Principles of International Law, 2. Auflage, 1967, S. $366 \mathrm{ff}$. 
richtsschutz der Fall wäre $\left.{ }^{20}\right)$. Wenn das Rechtsmittel der Verfassungsbeschwerde nur Deutschen zur Verfügung stünde was durchaus völkerrechtlich zulässig wäre - könnte ihre Inanspruchnahme durch Fremde doch vereinbart werden, wogegen die vereinbarte Ausschließung von Fremden von jedem innerstaatlichen Gerichtsschutz den zwingenden Mindeststandard verletzen würde und daher rechtswidrig wäre ${ }^{21}$ ).

Ein allgemeines Diskriminierungsverbot kennt das Vertragsrecht nicht. Ebenso, wie im Rahmne des Gewohnheitsrechts oberhalb des zwingenden Mindeststandards klassifiziert werden darf, dürfen Verträge den Fremden einen ungleichen Status geben. Nur in extremen Grenzfällen könnte eine willkürliche Ungleichbehandlung gerügt werden ${ }^{22}$ ). Regelmäßig bedarf es des Nachweises eines sachlichen Grundes zur Ungleichbehandlung jedenfalls nicht. Der Gleichheitssatz gehört in das System der Subordination. Natürlich kann die Gleichbehandlung - von Fremden untereinander und von Fremden und Staatsangehörigen - vereinbart werden, wie das z. B. durch Meistbegünstigungsklauseln und andere rechtstechnische Mittel geschieht.

\section{Kollektivverträge}

Derartige Verträge werden meist gerade die Frage der Gleichbehandlung der Individuen zum Gegenstand haben, wie etwa das europäische Gemeinschaftsrecht und ähnliche Vereinbarungen es zeigen ${ }^{23}$ ).

Interessant und in gewisser Weise neu ist dabei das Phänomen, daß auch der Status von solchen Fremden einbezogen wird, die keine Staatsangehörigkeit irgendeiner der Vertrags-

80) Der Freundschafts-, Handels- und Schiffahrtsvertrag zwischen der BRD und den USA v. 29. 10. 1954 (BGBl. 1956 II, S. 488) enthält in Art. VI Abs. 1 die selten zu findende Zusicherung des Zuganges zu den "Verwaltungsgerichten“, im englischen Text zu den "administrative tribunals and agencies".

21) $\mathrm{Zu}$ Lehre und Staatenpraxis auf diesem Gebiet $\mathrm{K}$. Doehring, Fordert das allgemeine Völkerrecht innerstaatlichen Gerichtsschutz gegen die Exekutive? Gerichtsschutz gegen die Exekutive, Beiträge zum ausländischen öffentlichen Recht und Völkerrecht, Nr. 52, Bd.3, S. $234 \mathrm{ff}$.

27) Um derartige Erwägungen handelt es sich in der Entscheidung des OLG Bremen (Bremer Tabakstreit) v. 21. 8. 1959, Arch. d. Völkerrechts Bd. 9, 1961/62, S. 318 ff. (359 f.).

25) Vertrag zur Gründung der Europäischen Wirtschaftsgemeinschaft v. 25. 3. 1957, Art. 7 Abs. 1: „Unbeschadet besonderer Bestimmungen dieses Vertrages ist in seinem Anwendungsbereich jede Diskriminierung aus Gründen der Staatsangehörigkeit verboten ${ }^{\star}$. 
partner innehaben. Die Mitglieder der Europäischen Menschenrechtskonvention haben sich verpflichtet, alle Menschen in der vereinbarten Art zu schützen ${ }^{24}$ ). Soweit die Staaten die Individualbeschwerde akzeptiert haben, handelt es sich um die Konstruktion eines „Vertrages zu Gunsten Dritter“.

Es wäre theoretisch denkbar und bei Kollektivverträgen, die verfassungsartig Organisationsstatuten aufstellen, vielleicht zweckmäßig, wenn die Partner schon im völkerrechtlichen Vertrag die Verpflichtung begründen würden, den aus dem Vertrag herzuleitenden Rechten der Individuen einen bestimmten Rang in den nationalen Rechtsordnungen einzuräumen. Das geschieht aber nicht. So unterscheiden sich letztlich die Rechte der Fremden als Inhalt von Kollektivverträgen in dieser Beziehung nicht von denjenigen aus bilateralen Verträgen.

\section{Die allgemeinen Rechtsgrundsätze}

Sie haben für das völkerrechtliche Fremdenrecht eine - zum Teil noch nicht genügend erkannte - hervorragende Bedeutung.

Das völkerrechtliche Gewohnheitsrecht - beruhend auf Utbung und Rechtsüberzeugung - konnte für das Fremdenrecht Regeln nur durch die Praxis entwickeln. Es bleiben also Freiräume für alle diejenigen Sachverhalte, die bisher nicht zum Gegenstand der Staatenpraxis wurden ${ }^{25}$ ). Man könnte nun sagen, insofern bestehe eben keine rechtliche Regelung.

Wenn man jedoch der m. E. richtigen Auffassung folgt, wonach als Rechtsquelle auch des Völkerrechts eine Rechtsregel zu gelten hat, die sich in vielen, bedeutenden innerstaatlichen Rechtsordnungen parallel gebildet hat ${ }^{26}$ ), können diese „Freiräume" weitgehend durch die Aufdeckung der allgemeinen Rechtsgrundsätze ausgefüllt und aufgefüllt werden. Diese allgemeinen Rechtsgrundsätze können den fremdenrechtlichen Mindeststandard im Hinblick auch auf seine zwingenden Teile ausfüllen; sie können auch als abdingbare Rechtsregeln das übrige Gewohnheitsrecht ergänzen. Sie können daher im er-

24) K. J. Partsch, Die Rechte und Freiheiten der europäischen Menschenrechtskonvention, Die Grundrechte, Bd. 1, Halbband 1, 1966, S. 294.

25) Zum Verhältnis von Gewohnheitsrecht zu allgemeinen Rechtsgrundsätzen $D$. O'Connell, International Law, 2. Aufl. 1970, Bd. I, S. $5 \mathrm{ff}$.

26) Die zahlreichen Definitionen der allgemeinen Rechtsgrundsätze sind zusammengestellt von F. Berber, Lehrbuch des Völkerrechts, Bd. I, 1960, S. $66 \mathrm{ff}$. 
sten Fall nicht durch Verträge beeinträchtigt werden, im zweiten Falle haben sie Verträgen zu weichen.

Diese allgemeinen Rechtsgrundsätze sind positives Völkerrecht ${ }^{27}$ ), d. h. sie wären vom Internationalen Gerichtshof als unmittelbar anwendbar bei einer Entscheidung über die Behandlung von Fremden zu beachten, woran das Statut des Internationalen Gerichtshofs keinen Zweifel läßt'9). Die Bedeutung dieser Rechtsquelle des Völkerrechts wird bei der Frage der Völkerrechtskonformität des Grundgesetzes eine besondere Rolle spielen.

\section{Die Gegenseitigkeit}

Dieser völkerrechtliche Grundsatz bedarf im hier hergestellten Zusammenhang mit dem Fremdenrecht besondere Beachtung ${ }^{20}$ ).

Der Mangel der Gegenseitigkeit bedeutet in den völkerrechtlichen Beziehungen einen Rechtfertigungsgrund zur Einschränkung des Fremdenstatus. Das ist unproblematisch in denjenigen Fällen, in denen auch vertraglich das Gewohnheitsrecht eingeschränkt werden darf.

$\mathrm{Da} \beta$ aber auch $u$. U. von der Einhaltung des zwingenden Mindeststandards wegen mangelnder Gegenseitigkeit dispensiert werden kann, zeigt das Kriegsrecht. Daß Fremde nicht ohne Gerichtsurteil getötet werden dürfen, gehört sicherlich zum Inhalt des zwingenden Mindeststandards. Im Kriegsrecht aber gilt dieser Satz nicht, sondern es gilt dann nur der Mindeststandard des ius in bello, wie er in den Genfer Konventionen von 1949 zum Ausdruck kommt. Die Gegenseitigkeit bedeutet eben, daß die Beteiligten unter bestimmten Umständen das gleiche Mittel anwenden dürfen.

Sieht man den Kriegszustand als Rechtsausnahme an, bleibt die Frage, ob bei Nichteinhaltung des Mindeststandards im völ-

27) Die grundsätzliche Ablehnung, die allgemeinen Rechtsgrundsätze, definiert nach der überwiegenden Lehre als fundamentale Regein zunächst innerstaatlichen Rechts, als normativen Bestandteil des Völkerrechts zu qualifizieren, wie sie bei G. I. Tunkin, a. a. O., S. 234, zum Ausdruck kommt, hat wohl Bedeutung nur für das "sozialistische" Recht.

28) "Uber die Entstehung und Auslegung der Statuten des StIGH und des IGH in dieser Hinsicht eingehend Verdross - Verosta Zemanek, a. a. O., S. $146 \mathrm{ff}$.

29) Auf diesen Grundsatz macht das BVerfG (23. 3. 1971, BVerfGE 30, 409) mit besonderem Nachdruck aufmerksam, wobei es allerdings übersieht, daß das bei Anwendung des Art. 3 GG gar nicht notwendig gewesen wäre und im Grunde nur ein Zusatzargument bedeutet. 
kerrechtlichen Friedensrecht auch der betroffene Staat hiervon dispensiert ist ${ }^{30}$ ). Ich möchte das insoweit verneinen, als der Mindeststandard Menschenrechte enthält. Das leitet dann über zu einem weiteren Problemkreis.

\section{Die Repressalie}

Die Repressalie bedeutet die Verwendung eines Mittels, das rechtswidrig wäre, wenn es nicht zur Abwehr einer Rechtswidrigkeit benutzt würde ${ }^{31}$ ). Das Recht zur Repressalie hat viele Begrenzungen, hier aber kommt es nur auf einen dieser Gesichtspunkte an. Es erhebt sich nämlich die Frage, ob auch das Recht zur Repressalie im Fremdenrecht an die Begrenzung durch den Mindeststandard gebunden ist. Auch das möchte ich im Hinblick auf den menschenrechtlichen Gehalt des Mindeststandards bejahen ${ }^{32}$ ).

Wenn z. B. Fremde unter Mißachtung des notwendigen Existenzminimums expropriiert werden, wäre das gleiche Verhalten ihres Heimatstaates gegenüber den Staatsangehörigen des expropriierenden Staates m. E. nicht gerechtfertigt. Es könnte aber die Ausweisung aller dieser fremden Staatsangehörigen als Repressalie erfolgen, nur als „Repressalie“ deswegen, weil die Massenausweisung ohne zureichenden Grund als völkerrechtliches Delikt angesehen werden könnte ${ }^{\text {s9)}}$.

Der uns aus dem nationalen Verfassungsrecht so geläufige Satz, daß das Individuum nicht zum reinen Objekt, zum reinen Mittel der Zweckverfolgung gemacht werden darf ${ }^{34}$ ), besteht in dieser Allgemeinheit im Völkerrecht mit Sicherheit nicht; auch für das nationale Recht bestehen Zweifel, denn viele Regeln des

so) W. Schaumann, Gegenseitigkeit, Wörterbuch des Völkerrechts, 1958 Bd. I, S. 630: „Die umfassendste Bedeutung als Rechtsprinzip hat die Gegenseitigkeit im Bereich des Fremderechts und des Internationalen Privatrechts".

s1) K. J. Partsch, Repressalie, Wörterbuch des Völkerrechts, Bd. III, 1962, S. 106, zeigt die Abgrenzung zu anderen Rechtsinstituten.

92) Ahnlich K. J. Partsch, a. a. O., S. 104; daß die Pflicht zu humanem Verhalten das Recht zur Repressalie begrenzt, wird schon betont von Strupp, Das völkerrechtliche Delikt, 1920, S. 192.

83) Bedenken gegen Massenausweisungen als Repressalie hat $G$. $D a h m$, a. a. O., S. 429 f., ebenfalls nur im Hinblick auf den Grundsatz der Verhältnismäßigkeit.

34) Maunz-Dürig, Grundgesetz, Kommentar, zu Art. 1, Abs. I GG, Rdn. 28: „Die Menschenwürde ist getroffen, wenn der konkrete Mensch zum Objekt, zu einem bloßen Mittel, zur vertretbaren Größe herabgewürdigt wird". Die folgenden Außerungen zeigen dann, daß die Objektstellung allein wohl nicht gemeint ist, sondern nur eine solche entwürdigender Natur; auch ist eingeräumt, daß auf diesem Gebiet nur simplifizierend argumentiert werden kann. 
nationalen Fremdenrechts beruhen auf dem Ziel, den fremden Staat zu einem anderen Verhalten $\mathrm{zu}$ veranlassen.

Der Staat besteht aus Menschen. Staatsbeziehungen sind Beziehungen zu Staatsvölkern, also Menschen. Will man zum Schutze der eigenen Staatsbürger auf einen anderen Staat einwirken, wird man eine Einwirkung auf die fremden Staatsbürger nicht vermeiden können. Das ist auch immer im internationalen Recht anerkannt worden ${ }^{35}$ ).

Die repressalienhafte Wehrpflicht von Fremden ${ }^{36}$ ) und der Ausschluß der Staatshaftung bei mangelnder Verbürgung der Gegenseitigkeit seien hier als nur zwei Beispiele genannt. Auch hier aber wäre die Grenze des zwingenden Mindeststandards zu beachten. So habe ich Bedenken, den Fremden mit der Waffe für den Aufenthaltsstaat im Kriegsfalle kämpfen zu lassen und gegebenenfalls das Opfer des Lebens zu verlangen, oder die Staatshaftung soweit auszuschließen, daß der Fremde in echte Existenznot gerät.

Soweit die Repressalie den zwingenden Mindeststandard nicht angreift, ist sie zulässig ${ }^{37}$ ). Die Auswirkungen dieser Feststellung haben im Rahmen des Grundgesetzes durchaus Bedeutung.

7. Die Beachtung der heimatlichen Rechtsordnung des Fremden

Ein letzter Hinweis auf die völkerrechtlichen Regeln zur Behandlung von Fremden im nationalen Recht sei hier noch gegeben.

Zwar wird mit Recht behauptet, der Fremde unterliege der Rechtsordnung des Aufenthaltsstaates $\left.{ }^{38}\right)$. Damit ist aber noch nichts darüber gesagt, wie weit die nationale Rechtsordnung zu respektieren hat, daß der Fremde seinem Heimatstaat verpflichtet bleibt im Rahmen der Personalhoheit ${ }^{30}$ ).

35) BVerfG v. 23. 3. 1971 (BVerfGE 30, 409) führt aus, daß es ein legitimes Anliegen des Staates sei, „auch außerhalb seiner Grenzen den Schutz der eigenen Staatsbürger nach Möglichkeit zu gewährleisten"; deshalb sei es "nicht unangemessen, ihm (dem Fremden) die Haltung seines Staates ... zuzurechnen ...."

30) $D$. Walz, Die Wehrpflicht von Ausländern, Sowjetzonenflüchtlingen und Mehrstaatern nach dem Wehrpflichtgesetz der Bundesrepublik Deutschland als Problem des internationalen und des nationalen Rechts, 1969, S. $122 \mathrm{ff}$.

37) So auch F. Berber, a. a. O., S. 381.

s8) D. P. O'Connell, International Law, 2. Aufl. Bd. 2, 1970, S. 703.

39) Richtig weist das BayObLG (8. 3. 1971, Z 1971, 94 ff.) auf die Bedeutung der bestehenbleibenden Personalhoheit des Fremden im Ausland hin. 
So wäre es rechtswidrig, dem Fremden Pflichten aufzuerlegen, die ihn in Widerspruch zu dem Treue- und Schutzverhältnis $^{40}$ ) zu seinem Heimatstaat bringen würden ${ }^{41}$ ). Die Bestrebungen zur Milderung der Rechtsfolgen doppelter Staatsangehörigkeit beruhen auf diesem Grundgedanken ${ }^{42}$ ); d. h. das Völkerrecht geht von dem Grundsatz aus, daß der Mensch regelmäßig nur einem Staate zugehören sollte, denn niemand kann zwei Herren dienen. Am deutlichsten zeigt sich das in den Regelungen der Genfer Kriegsrechtskonventionen ${ }^{\text {(5) }}$ ). Aber auch im Friedensvölkerrecht lassen sich Beispiele anführen. So beruht die Regelung des $\S 4$ des Deutschen Strafgesetzbuches, wonach die Auslandstat eines Ausländers dann nicht strafbar ist, wenn sein Heimatrecht keine Bestrafung vorsieht oder gar das entsprechende Verhalten gebietet, auf diesem vorwiegend völkerrechtlichen Prinzip.

Dieses so grob umrissene Prinzip kann natürlich in Einzelfällen Probleme erzeugen; insgesamt aber ist es recht klar zu fassen. Viel ungeklärter aber ist eine Frage, die erst in neuerer Zeit sich in zunehmendem Maße stellt, und die lautet: Darf ein Staat den Fremden unbegrenzt Rechte und Vorteile bieten, die geeignet sind, ihn seinem Heimatstaat nachhaltig zu entfremden, seine Treuepflicht zum Heimatstaat zu korrumpieren ${ }^{4}$ ), den Heimatstaat meßbar zu schädigen oder zu Maßnahmen zu veranlassen, die wirtschaftskriegsähnlich sich auswirken?

Die Abwerbung von Facharbeitern durch das Anbieten besonders günstiger Bedingungen könnte sich in dieser Art auswirken. Es könnte auch sein, daß der Heimatstaat Ausreiseerlaubnis nur erteilt unter der Verpflichtung der Rückkehr nach einer bestimmten Zeit. Das Rückrufsrecht zur Ableistung

40) Die gegenseitigen Beziehungen von Schutz- und Treuepflicht im Rahmen der Staatsangehörigkeit werden eindringlich dargelegt in der Entscheidung des KG v. 1. 2. 1965, OLGZ 1965, S. 212 f.

41) G. Dahm, a. a.O., S. 521, weist daraufhin, daß die Inpellichtnahme des Ausländers durch den Aufenthaltsstaat ihre Grenze dort findet, wo sie mit der Treuepflicht gegenüber dem Heimatstaat nicht mehr vereinbar ist und einen Eingriff in dessen Rechte bedeuten würde.

2) A. N. Makarov, a. a. O., S. 291 ff.; Europäisches Ubereinkommen über die Verringerung der Mehrstaatigkeit und über die Wehrpflicht von Mehrstaatern v. 6. 5. 1963, Série des Traitées et Conventions europeens No. 43.

43) Vgl. III Genfer Abkommen v. 12. 8. 1949 über die Behandlung der Kriegsgefangenen, BGBl. 1954 II, S. 838, Art. 17 betr. Auskunftserteilung durch Kriegsgefangene.

4) Verdross-Verosta-Zemanek, a. a. O., S. 369 betonen die Pflicht des Aufenthaltsstaates, "das Treueverhältnis des Ausländers zu seinem Heimatstaat zu achten". 
des Wehrdienstes ist mit völkerrechtlichen Grundsätzen immer als vereinbar angesehen worden ${ }^{45}$ ). Eine Rückkehrverpflichtung zur Behebung nationalen Notstandes scheint mir auch nicht den allgemeinen völkerrechtlichen Menschenrechten zu widersprechen. Wenn derartige staatsbürgerliche Pflichten des Fremden als zulässig angesehen werden, wird die Frage unumgänglich, ob der Aufenthaltsstaat diese Pflichten unterlaufen darf.

Sicherlich ist es ein schönes Ideal, den Menschen zu helfen, in der ganzen Welt und wo immer sie wollen frei ihren Aufenthalt wählen zu können $\left.{ }^{46}\right)$. Die Frage ist nur, ob auch insoweit Rechte ohne Pflichten ein internationales Gemeinschaftsleben noch möglich machen. Eine Entwicklungshilfe, die darin besteht, die besten und aktivsten Staatsbürger eines unterentwickelten Gebietes endgültig diesem Staate zu entziehen, würde in ihr Gegenteil verkehrt.

Das positive Völkerrecht scheint hier - das ist zuzugeben eine klare Grenze nicht anzugeben. Immerhin spricht man in derartigen Fällen von den Grundsätzen der comity of nations $\left.{ }^{46^{8}}\right)$, deren Nichteinhaltung zumindest einen unfreundlichen Akt darstellt und die Retorsion nach sich ziehen kann. Doch würde ich meinen, daß es eine Extrem- und Evidenzgrenze auch hier gibt. Würde eine derartige „Abwerbung“ den anderen Staat in meßbare Existenznot bringen, wäre wohl eine Rechtswidrigkeit vorhanden.

Der Vollständigkeit halber sei nur noch bemerkt, daß die Ausreisefreiheit der Fremden - unter den bekannten Begrenzungen ${ }^{47}$ ) - zu den völkerrechtlichen Regeln des Fremdenrechts zählt. Da es aber hier um den Status während des Aufenthalts im fremden Staat geht, sollen diese Fragen der Ausweisung und Ausreisefreiheit nicht vertieft werden.

III. Das System des Grundgesetzes zur Erfüllung völkerrechtlicher Gebote im innerstaatlichen Recht

Die Regeln des völkerrechtlichen Fremdenrechts, wie sie hier nur in ihren Grundzügen und in grober Weise skizziert

45) G. Dahm, a. a. O., S. 523.

10) Protokoll Nr. 4 zur Europäischen Menschenrechtskonvention v. 16. 9. 1963 (BGBl. 1968 II S. 423) Art. 2, Abs. 2; in Abs. 3 findet sich aber dann ein umfassender Gesetzesvorbehalt für das nationale Recht.

402) G. Dahm, a. a. O., Bd. 1, 1958: „Darunter werden Konventionalregeln, Normen der Verkehrssitte verstanden, die die Staaten im Verkehr miteinander aus dem Gefühl der gegenseitigen Achtung und mit dem Willen zur Rücksichtnahme aufeinander befolgen".

47 W. Wengler, a. a. O., S. 1003. 
wurden, verpflichten die Bundesrepublik als Völkerrechtssubjekt.

Nun geht es um die Frage, wie diese Regeln in das System des innerstaatlichen deutschen Rechts überführt werden. Das allgemeine Völkerrecht überläßt das System des Vollzuges von einzelnen völkerrechtlichen Normen dem nationalen Verfassungsrecht. Andererseits steht dem nicht entgegen, daß im Rahmen des Vertragsrechts eine bestimmte Art des Vollzuges vereinbart wird, wie dies der Fall ist, wenn sich die Partner zur innerstaatlichen Gesetzgebung verpflichten ${ }^{48}$ ). Diese Grundsätze gelten auch für das völkerrechtliche Fremdenrecht.

1. Das völkerrechtliche Gewohnheitsrecht und Art. 25 GG

Den Anwendungsbefehl für das völkerrechtliche Fremdenrecht, soweit es auf Gewohnheitsrecht beruht, gibt das Grundgesetz in Artikel 25 ${ }^{\text {(9)}}$.

Die Tatsache, daß die allgemeinen Regeln des Völkerrechts ihre Erwähnung in der Verfassung gefunden haben und daß sie den Gesetzen vorgehen, scheint mir ihren vollen Verfassungsrang zu gewährleisten. Die Behauptung, das Bundesverfassungsgericht habe diesen Rang nicht anerkannt, ist falsch ${ }^{50}$ ). Nur der Uberverfassungsrang und die Grundrechtseigenschaft dieser Normen wurden abgelehnt ${ }^{51}$ ). Die Frage soll aber hier

49) So z. B. in der Konvention über die Verhütung und Bestrafung des Völkermordes v. 9. 12. 1948, UNTS Bd. 78, S. 277, Art. V: „Die vertragsschließenden Parteien verpflichten sich, in Ubereinstimmung mit ihren jeweiligen Verfassungen die notwendigen gesetzgeberischen Maßnahmen zu ergreifen ..."

$\left.{ }^{4}{ }^{\circ}\right) \mathrm{Zu}$ der gesamten Frage vgl. die Arbeiten der 1. Studienkommission der Deutschen Gesellschaft für Völkerrecht, Bericht von $K$. J. Partsch, Die Anwendung des Völkerrechts im innerstaatlichen Recht, Heft 6 der Berichte der Deutschen Gesellschaft für Völkerrecht, 1964, S. 56 it.

so) So behauptet $M$. Zuleeg (Zur staatsrechtlichen Stellung der Ausländer in der Bundesrepublik Deutschland, DOV 1973, S. 364) einmal mehr, das BVerfG (BVerfGE 6, 363) habe den Verfassungsrang der allgemeinen Regeln des Völkerrechts i. S. des Art. 25 GG "bekanntlich" nicht anerkannt. Wörtlich heißt es aber in der zitierten Entscheidung: „... und dem deutschen innerstaatlichen Recht nicht dem Verfassungsrecht - im Range vorgehen". Ausdrücklich ist also nur der sog. Uberverfassungsrang abgelehnt und nicht mehr. Auch mit der Entscheldung, wonach auf Art. 25 GG eine Verfassungsbeschwerde nicht gestützt werden kann (BVerfG v. 18. 11. 1954, BVerfGE 4, 111 f.) ist über den Rang des Art. 25 GG nichts ausgesagt worden, denn die Nichtaufnahme in die Bestimmung des § 90 BVerfGG war allein maßgebend.

s1) DaB Art. 25 GG nach Auffassung des BVerfG keine Grundrechte enthält (BVerfG v. 10. 5. 1957, BVerfGE 6, 440; v. 7. 4. 1965, 
nicht vertieft werden. Ich gehe jedenfalls davon aus, daß nicht nur der Anwendungsbefehl für die allgemeinen Regeln sondern auch diese Regeln selbst Verfassungsrang innehaben, was dann auch für das völkerrechtliche Fremdenrecht gilt.

Die „Erzeugung" von Rechten und Pflichten für die Fremden auf diese Weise bedeutet zunächst, daß der Fremde subjektive Berechtigungen mit Verfassungsrang geltend machen kann und persönliche Pflichten, ebenfalls mit Verfassungsrang, zu erfüllen hat. „Pflichten mit Verfassungsrang" bedeutet hier keine Besonderheit, sondern sie existieren auch für Staatsbürger, wobei als Beispiel auf die Sozialbindung im Rahmen des Artikel 14 GG zu verweisen ist. Einer ähnlichen Bindung Fremdenrechtsbindung mit Verfassungsrang - unterliegt der Fremde auch. Die Staatsgewalt ist berechtigt, diese Pflichtenbindung durchzusetzen. Dieser Gesichtspunkt wird in der weiteren Untersuchung noch eine Rolle spielen.

Die allgemeinen Regeln des Völkerrechts im Sinne des Artikel 25 GG umfassen den fremdenrechtlichen Mindeststandard, wie er aus Gewohnheitsrecht und allgemeinen Rechtsgrundsät$z^{2 n^{52}}$ ) sich ergibt. Der menschenrechtliche Mindeststandard darf als zwingendes Recht vom nationalen Gesetzgeber weder durch Erlaß eines einseitigen nationalen Gesetzes eingeschränkt werden, noch auf Grund eines Vertragsgesetzes nach Artikel 59 II GG. Das Völkerrecht verbietet eine Einschränkung und das Grundgesetz übernimmt dieses Verbot mit Verfassungsrang.

Wenig untersucht aber ist die Frage, ob und inwieweit der dispositive Teil des Mindeststandards im Ubrigen der Einschränkung durch den nationalen Gesetzgeber unterliegen kann. Das soll an zwei Beispielen demonstriert werden. Das Recht der Staaten, auf hoher See frei zu fischen, zählt zum völkerrechtlichen Gewohnheitsrecht. Artikel 25 GG „erzeugt" aus diesem den Staaten zustehenden Recht ein Individualrecht mit

BVerfGE 18, 451; v. 14. 5. 1968, BVerfGE 23, 300) besagt nichts über seinen "Rang" in der Verfassung.

s2) W. Rudolf, Völkerrecht und deutsches Recht, 1967, S. 255 ff., will die allgemeinen Rechtsgrundsätze nicht als Inhalt der allgemeinen Regeln i. S. des Art. 25 GG ansehen, ein Ergebnis, das m. E. aber doch eine noch eingehendere Auseinandersetzung mit der Gegenmeinung erfordert hätte; wie hier B. Schmidt-Bleibtreu $-F$. Klein, Kommentar zum Grundgesetz für die Bundesrepublik Deutschland, 2. Aufl., 1969, S. 317 unter Berufung auf das BVerfG (30. 10. 1962, BVerfGE 15, 35), nach dessen Auffassung allgemeine Rechtsgrundsätze das Völkergewohnheitsrecht i. S. des Art. 25 GG ergänzen. In gleichem Sinne dazu dann BVerfG v. 30. 4. 1963, BVerfGE 16, 33, und v. 14. 5. 1968, BVerfGE 23, 317. 
Verfassungsrang ${ }^{53}$ ). Ein Gesetz, das die Begrenzung des Fischfangs auf hoher See vorsieht, würde gegenüber dem völkerrechtlichen Satz zurücktreten müssen, soweit er Fremde betrifft, während im Rahmen der Personalhoheit den Staatsbürgern eine solche Pflicht auferlegt werden könnte. So wäre die Verhinderung des Auslaufens eines fremden Schiffes zum Fischfang aus dem deutschen Hafen auch mit einfachgesetzlicher Grundlage verfassungswidrig, denn die allgemeinen Regeln gehen dem Gesetz vor.

Der völkerrechtliche Satz aber, der den freien Fischfang garantiert, ist dispositiv, d. h. er trägt schon in sich die Einschränkung, daB die Staaten ihn - z. B. durch Uberfischungsabkommen $^{54}$ ) - für ihre jeweiligen Staatsangehörigen beschränken können. Ein Vertragsgesetz nach Artikel 59 II GG also wäre völkerrechtsgemä $B$ und also auch verfassungsrechtlich nicht zu beanstanden, während ein „einseitiges“ Gesetz jedenfalls gegenüber Fremden nicht standhalten würde.

Ein ähnliches Beispiel läßt sich dem Eigentumsschutz Fremder entnehmen. Das völkerrechtliche Gewohnheitsrecht lautet, dem Fremden sei bei Expropriation prompte, effektive und angemessene Entschädigung zu leisten ${ }^{55}$ ). Dieser Grundsatz ist auch Inhalt des Mindeststandards, jedoch handelt es sich um dispositives Recht, denn es darf vertraglich insofern davon abgewichen werden, als der Heimatstaat des Fremden auf eine Entschädigung verzichten kann $^{\text {s0 }}$ ). Ob der Fremde durch seinen Heimatstaat dann eine Entschädigung erhält, ist Sache des nationalen Rechts, bzw. des Verfassungsrechts.

s3) Mißverständlich ist in diesem Sinne die Auffassung des BVerfG (v. 3. 12. 1969, BVerfGE 27, 274, unter Berufung auf BVerfGE 18, 448) wonach die Funktion des Art. 25 GG jedenfalls nicht in der Anderung des „Adressaten" der Völkerrechtsregel liege, obwohl das Grundgesetz mit Art. 25 GG den Bewohnern des Bundesgebietes das Recht gebe, "sich auf diese innerstaatliche Geltung der Regeln zu berufen". So wird dann doch ein "Adressatenwechsel“ vorgenommen, denn im Rahmen des Völkerrechts kann sich eben abgesehen von allgemeinen Menschenrechten und auch da bestritten - nur ein Staat oder ein staatsähnliches Rechtssubjekt auf diese Regeln "berufen". Eingehend und überzeugend dazu die Kritik von A. Bleckmann, Deutsche Rechtsprechung in völkerrechtlichen Fragen 1969 - 1970, ZaORV Bd. 32, S. 76 f.

s4) Ubereinkommen über die Fischerei im Nordostatlantik v. 24. 1. 1959, BGBl. 1963 II, S. 157, Art. 13: „Jeder Vertragsstaat trifft in seinem Hoheitsgebiet in Bezug auf seine eigenen Staatsangehörigen und Schiffe geeignete Maßnahmen ....

*) D. P. O'Connell, a. a. O., S. $780 \mathrm{ff}$.

se) G. Dahm, a. a. O., Bd. 1, S. 507 f. 
Nach Art. 25 GG ergibt sich nun, daß ein einfaches Gesetz der Bundesrepublik einen Entschädigungsanspruch eines Fremden bei Enteignung nicht einseitig aufheben könnte. Abgesehen von Fragen des Artikels 14 GG, die hier einmal außer Betracht bleiben sollen, würde der Verfassungsrang des Art. 25 GG die völkerrechtsgemäße Entschädigung gebieten und ein solches Gesetz nicht zulassen.

Würde der Verzicht auf Entschädigung durch völkerrechtlichen Vertrag vereinbart, dann würde Art. 25 GG dem nicht entgegenstehen, obwohl das Vertragsgesetz nach Artikel 59 GG auch nur den Rang eines einfachen Gesetzes hat, denn der - dispositive - Satz des völkerrechtlichen Gewohnheitsrechts, wonach Fremde nicht ohne Entschädigung enteignet werden dürfen, trägt die Hypothek mit sich, daß ein solcher Rechtssatz durch Vertrag eben doch abgedungen werden darf. Insofern stimmt das Vertragsgesetz mit dem Völkerrecht überein und widerspricht ihm nicht.

Eine andere Frage ist es, ob ein Vertrag des Inhalts, daß der Fremde im Aufenthaltsstaat Bundesrepublik keine Entschädigung für Eigentum bekommt, dem Artikel 14 GG widersprechen würde. Ich möchte das ablehnen, da Artikel 25 GG für die Behandlung von Inhabern fremder Staatsangehörigkeit gerade als verfassungsrechtliche Ergänzung des Artikels 14 GG angesehen werden kann. Ein allgemeiner völkerrechtlicher Satz, daß der Heimatstaat auf Rechte seiner Staatsangehörigen im fremden Staat völkerrechtswirksam verzichten kann, ist nachweisbar ${ }^{57}$ ). Eine Verletzung des Artikel 14 GG ist bei Verzicht auf Entschädigung - ausgesprochen durch die „völkerrechtlich" Geschädigten - wohl nicht anzunehmen.

Ein solches Ergebnis ist auch völlig folgerichtig, denn die Verantwortung hat der Heimatstaat des Fremden durch Vertragsschluß übernommen, und dieser Heimatstaat ist in erster Linie verpflichtet, für seine Staatsangehörigen zu sorgen. Der Staatenlose bleibt geschützt, denn es gibt keinen Heimatstaat, der die Verantwortung nun innehätte und für ihn einen Verzicht aussprechen könnte.

57) Richtig daher die Auffassung des BGH (22. 6. 1960, RzW 1960 554): "Es hat sich im Völkerrecht der Satz herausgebildet, daß es im Belieben der Staaten steht, private Rechtsbeziehungen ihrer Staatsangehörigen auch ohne deren Zustimmung zum Gegenstand von vertraglichen Vereinbarungen mit anderen Staaten zu machen, und daß dieses Recht auch das Recht des vertragsschließenden Staates umfaßt, auf Forderungen seiner Staatsangehörigen ohne thre Zustimmung zu verzichten..." 
Würde man hier anders entscheiden, wären - entgegen der Staatenpraxis - Verträge über Verzicht auf Vermögensrechte von Fremden überhaupt rechtlich ausgeschlossen. Die Schweiz etwa hätte - unter Verfassungsregeln der Bundesrepublik den deutsch-schweizerischen Vermögensvertrag mit Verzicht auf erhebliche Teile des deutschen Auslandsvermögens nicht abschließen dürfen ${ }^{58}$ ); entsprechende Regelungen im italienischen Friedensvertrag ${ }^{59}$ ) hätten vor dem innerstaatlichen Recht der Bundesrepublik keinen Bestand.

Es sei aber auch darauf hingewiesen, daß ein solcher Verzichtvertrag dann völkerrechtswidrig wäre, wenn zwei Staaten in Art einer Kollusion beiderseits unbeliebte Individuen schädigen wollten.

Ich fasse die Ergebnisse noch einmal zusammen:

a) Zwingende Regeln des fremdenrechtlichen Mindeststandards (z. B. Verbot der Folterung oder Ausschluß von jedem Gerichtsschutz) haben nach Artikel 25 GG Verfassungsrang. Sie können weder durch einseitiges Gesetz noch durch Vertragsgesetz der Bundesrepublik eingeschränkt werden.

b) Regeln des völkerrechtlichen Mindeststandards, soweit sie dispositiv sind, genießen ebenfalls Verfassungsrang; sie können daher durch einseitiges Gesetz der Bundesrepublik nicht eingeschränkt werden, da sie ebenfalls den Gesetzen gemäß Artikel 25 GG vorgehen. Sie können jedoch durch Vertrag mit dem Heimatstaat des Fremden - aber auch nur auf diese Weise - eingeschränkt werden, da das Völkerrecht - und damit auf Verfassungsebene Artikel 25 GG - eine solche Einschränkung zuläßt. Die Einschränkung ist also völkerrechtsgemäß und damit auch verfassungsgemäß.

Diese Einordnung des Artikels 25 GG in das System des Grundgesetzes bedeutet natürlich nicht, daß die innerstaatliche Rechtsordnung gehindert wäre, dem Fremden auf Grund nationalen Rechts mehr an Rechten zu gewähren als das Völkerrecht fordert. Das ist auch vielfältig geschehen und wird bei Betrachtung der Grundrechte noch $\mathrm{zu}$ beachten sein. Ich weise aber nochmals darauf hin, $\mathrm{da} B$ auch ein Uberma $B$ an Wohltaten dann völkerrechtlich bedenklich sein und dann auch mit Artikel 25 GG in Widerspruch stehen könnte, wenn damit korrumpierend in das Schutz- und Treueverhältnis zwischen Fremdem und seinem Heimatstaat eingewirkt würde. Schon auf der

s9) Abkommen vom 7. 3. 1953 (BGBl. $1953 \mathrm{II}$, S. 15) und v. 26. 8. 1952 (BGBl. 1853 II, S. 17).

s9) V. 10. 2. 1947, UNTS Bd. 49, S. 3 ff. Bd. 79. 
Verfassungsebene könnte sich dann ein Normenkonflikt ergeben, der m. E. zugunsten des Artikel 25 GG als einer lex specialis $\mathrm{zu}$ lösen wäre.

Ein Beispiel soll das verdeutlichen. Frankreich hatte eine Strafnorm erlassen, wonach Franzosen, die sich fremden Staaten - gedacht war wohl vor allem an die neuen afrikanischen Staaten - für militärische Zwecke zur Verfügung stellten, bestraft würden. Der fremde Staat würde sich zwar völkerrechtsgemäß verhalten, wenn er dennoch die Dienste eines solchen Franzosen annähme; er würde sich aber wohl völkerrechtswidrig verhalten, wenn er nachhaltig eine Werbung, gestützt auf erhebliche Vorteile, betreiben würde ${ }^{60}$ ), denn er hätte die Völkerrechtsregel mißachtet, wonach das Band der Personalhoheit zwischen Staatsbürger und Heimatstaat zu respektieren ist.

\section{Vertragsrecht}

Im Zusammenhang mit den Regeln des Gewohnheitsrechts wurde über die Wirkung von völkerrechtlichen Verträgen im Grundgesetz schon einiges dargelegt. Es bleiben aber noch einige Gesichtspunkte zu erwähnen.

Verträge, abgeschlossen gemäß den Regeln des Artikel 59 GG, stehen im Rang einfacher Gesetze. Auf die dogmatischen Unterschiede zwischen Transformationstheorie und Vollzugslehre kommt es dabei nicht an. Auch der - völkerrechtliche Satz pacta sunt servanda erhebt sie nicht in den Verfassungsrang ${ }^{61}$ ), wobei ich mir die Begründung - aus Zeitgründen hier ersparen muß; jedenfalls lautet so die überwiegende Auffassung. Verträge also auch, die den Status des Fremden betreffen, wirken wie einfache Gesetze.

Denkbar wäre die vertragliche Verpflichtung, Rechte der Fremden verfassungsfest zu gestalten. Die Vertragspartner hätten dann - soweit notwendig - ihre Verfassungen zu ändern. Wollte man etwa das Versammlungsrecht des Artikel 8 GG den Fremden in gleicher Weise garantieren wie den Deutschen, müßte der Wortlaut des Artikel 8 GG verändert werden. Mir ist aber ein solcher Vorgang nicht bekannt, es sei denn, man

00) Darüber, daß zwar die französische Fremdenlegion keine völkerrechtswidrige Institution war und ist, ihre Anwerbungsmethoden jedoch im Einzelfall rechtswidrig erscheinen konnten, vgl. $K$. Doehring, Fremdenlegion, Wörterbuch des Völkerrechts, Bd. I, 1960, S. 564.

61) Ebenso W. Rudolf, a. a. O., S. 260, mit eingehenden Nachweisen aus Lehre und Rechtsprechung; weitere Nachweise bei $A$. Bleckmann, Deutsche Rechtsprechung in völkerrechtlichen Fragen 19581965, ZaöRV, Bd. 28, S. 62; 1969-1970, ZaöRV Bd. 32, S. 77 f. 
bezieht die Pflicht einer Verfassungsänderung in die in Verträgen oft genannte Pflicht ein, die entsprechenden gesetzgeberischen Maßnahmen zu treffen. Auch die Europäische Menschenrechtskonvention rangiert bei aller Dignität im Rahmen des Grundgesetzes nur mit Gesetzesrang ${ }^{62}$ ). Allein das Recht der Europäischen Gemeinschaft soll nach wohl heute überwiegender Auffassung nicht am nationalen Recht und auch nicht am Verfassungsrecht sich brechen können $\left.{ }^{69}\right)$; das aber würde für den Bereich des Grundgesetzes jedenfalls auf der Wirkung des Artikels 24 GG beruhen. $\mathrm{Zu}$ erinnern ist hier an das Recht auf Freizügigkeit gemäß dem Grundrecht des Artikel 11 GG, das Deutschen reserviert ist.

Dieser einfache Gesetzesrang der Verträge bedeutet, daß auch bei Regelungen des Fremdenstatus die nationale lex posterior für den Richter jeweils das anwendbare Recht wäre, vor allem aber die höherrangige Verfassung selbst. Weiter ist zu beachten, daß der Fremde ein subjektives Recht aus dem Vertrag, bzw. dem Vertragsgesetz nur dann herleiten kann, wenn es sich um eine Bestimmung handelt, die als self-executing wirkt ${ }^{64}$ ).

Für den auf Vertrag beruhenden Status des Fremden spielt die Zusage der Inländergleichbehandlung eine besondere Rolle und bietet besondere Probleme. Es können hier nicht alle Varianten dieser meist gegenseitigen Vertragszusage dargestellt werden ${ }^{65}$ ), nur ein Problem sei besonders betrachtet. Uberwiegend wird in Handels- und Niederlassungsverträgen die Inländergleichbehandlung im Bezug auf bestimmte Rechte zugesagt. So enthält das europäische Niederlassungsabkommen z. B. die Gleichbehandlungsklausel in bezug auf bürgerliche Rechte, auf Ausübung einer Erwerbstätigkeit und auf Gewährung von Gerichtsschutz ${ }^{86}$ ). Die Problematik dieser so allgemein gehaltenen Klausel liegt in folgender Erwägung.

62) H. Guradze, Die Europäische Menschenrechtskonvention, 1968, S. 13, der ein anderes Ergebnis anstrebt, jedoch die $h$. L. eindeutig wiedergibt.

68) Dazu ausführlich $H$. P. Ipsen, Europäisches Gemeinschaftsrecht, 1972, S. 263 ff., mit umfassenden Hinweisen auf die Rechtsprechung.

64) Rechtsprechung zur self-executing-Wirkung von Verträgen findet sich bei $A$. Bleckmann, Deutsche Rechtsprechung in völkerrechtlichen Fragen 1966-1968, ZaöRV Bd. 31, S. 282 ff.

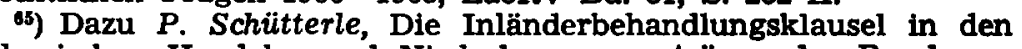
klassischen Handels- und Niederlassungsverträgen der Bundesrepublik Deutschland, 1970, S. 7 if.

o6) Europäisches Niederlassungsabkommen v. 13. 12. 1955 (BGB1. 1959, II, S. 998), Art. 4, 7, 10. 
Es könnte so erscheinen, als sei die Inländergleichbehandlung z. B. im Hinblick auf die Erwerbstätigkeit nur dann als voll hergestellt anzusehen, wenn der Fremde nun - entgegen dem Wortlaut des Artikel 12 GG - sich auf das Grundrecht der Berufsfreiheit berufen könnte. Die Frage ist also, vermittelt der völkerrechtliche Vertrag auf diese Weise die Inhaberschaft von Grundrechten? Bejaht man diese Frage, dann schlösse sich sogleich die weitere Frage an, ob der Fremde nun - im Rahmen der Inländergleichbehandlung - zur Durchsetzung seiner so erworbenen Grundrechte auch Antragsberechtigter für eine Verfassungsbeschwerde wird.

Diese zunächst schlüssig erscheinende Konstruktion möchte ich dennoch ablehnen. Die völkerrechtliche Verpflichtung zur Inländergleichbehandlung wird von den Vertragsparteien als mit immanenten Schranken ausgestattet vereinbart. Dem Fremden soll im jeweiligen Aufenthaltsstaat das versprochene Recht gesichert werden; wie und wodurch diese Sicherung erfolgt, bleibt dem Aufenthaltsstaat überlassen.

Entscheidend ist also das Ergebnis, nicht die Methode seiner Erreichung. Eine Parallele bildet hier die sogenannte Verbürgung der Gegenseitigkeit, bei der auch nicht nach der Methode, sondern nur nach dem Erfolg zu fragen ist ${ }^{67}$ ). Wird die Inländergleichbehandlung im Hinblick auf die Erwerbstätigkeit zugesagt, so ist damit nicht die Berufsfreiheit im Sinne des Grundrechts des Artikels 12 GG versprochen, sondern nur eine - allerdings gegebenenfalls durch die Gesetzgebung zu sichernde - partielle Berufsausübungsgarantie ${ }^{88}$ ). Hätten die Vertragspartner Grundrechtserteilungen an Fremde herstellen wollen, so hätten sie dies angesichts gefestigter Staatenpraxis ausdrücklich vereinbaren müssen. Ein Beispiel bilden hier die Auslieferungsverträge. Ist das politische Delikt nicht genannt, dann ist es Auslieferungshindernis, nicht etwa Auslieferungsverpflichtung, weil nach gefestigter Staatenpraxis eine Rechtsvermutung für ein solches Auslieferungshindernis besteht ${ }^{69}$ ).

Auch Verträge, die grundrechtsähnliche Rechte vermitteln sollen, werden nicht so ausgelegt, daß nunmehr der Fremde Inhaber von nationalen Grundrechten sein soll, die er vorher

${ }^{67}$ Daher ist auch W. Schaumann, a. a. O., S. 630 zuzustimmen, wenn er im Hinblick auf die Gegenseitigkeit ausführt, sle habe "vorwiegend tatsächlichen" Charakter.

6) Beispiele bei P. Schütterle, a. a. O., S. $84 \mathrm{ff}$.

6) G. Dahm, a. a. O., Bd. 1, S. 287, meint allerdings in der neueren Entwicklung die Tendenz feststellen zu können, wonach die Privilegierung der politischen Verbrechen eingeschränkt werde. 
nicht innehatte. Das zeigt auch das Modell der Europäischen Menschenrechtskonvention, die über den "jedermann" zustehenden Gerichtsschutz in den Artikeln 5, 6 und 1.3 entsprechende Vorschriften enthält. Es genügt danach, wenn ein unabhängiges Gericht entscheidet, bzw. eine nationaln Instanz.

Daher bleibt auch die Auffassung, daß zur Erschöpfung des Rechtsweges - Voraussetzung zur Anrufung der Europäischen Menschenrechtskommission und des Gerichtshofes - gegebenenfalls auch die Erhebung einer Verfassungsbeschwerde zählt ${ }^{70}$ ), entgegen der überwiegenden Lehre $m$. E. zweifelhaft. Die Grundrechte der Konvention sind eben nicht Grundrechte des Grundgesetzes, auch wenn sie zum Teil inhaltlich kongruent erscheinen mögen. Sie beruhen auf verschiedenen Rechtsquellen, was dann relevant wird, wenn man bedenkt, daß beide „Grundrechte" selbst bei völlig gleichem Wortlaut doch nach verschiedenen - entweder internationalen oder nationalen Grundsätzen ausgelegt werden müßten ${ }^{71}$ ). Auch wenn also der Beschwerdeführer gleichzeitig in einem Grundrecht des Grundgesetzes verletzt wäre, kann doch seine Beschwerde in Straßburg nur auf die Verletzung der Konvention gestützt werden; er könnte - genau gesehen - in einem Grundrecht des Grundgesetzes verletzt sein, ohne daß die Konvention verletzt wäre, und er könnte in einem Recht aus der Konvention verletzt sein, ohne daß gleichzeitig eine Verletzung eines Grundrechts des Grundgesetzes vorliegt. Es ist nicht einzusehen, daß ein Beschwerdeführer, der eine Verletzung der Grundrechte aus dem Grundgesetz gar nicht geltend machen will, die Verfassungsbeschwerde erheben muß. Der Gedanke, der dem System der Erschöpfung des nationalen Rechtsweges zugrundeliegt, daß nämlich der Staat Gelegenheit zur Korrektur des eigenen Verhaltens erhalten soll, wäre überstrapaziert, wenn man dem Rechtsschutzsuchenden aufbürden würde, sich auf ein Recht zu berufen, das er gar nicht in Anspruch nehmen will.

Selbstverständlich wäre es denkbar, daß die Vertragspartner sich verpflichten, Fremden verfassungsmäßig verbürgte Grund-

70) H. Guradze, a. a. O., S. 219 ff. gibt die Auffassung der Europäischen Menschenrechtskommission wieder; vgl. auch $W . K$. Geck, Die Erschöpfung der domestic remedies gemäß Art. 26 der EMRK, DVBl. 1957, $41 \mathrm{ff}$.

11) Uber die Unterschiede der Auslegung von internationalen Verträgen und von innerstaatlichen Gesetzen gerade auch im Hinblick auf die Europäische Menschenrechtskonvention und mit Nachweisen aus Literatur und Rechtsprechung $K$. J. Partsch, Die Rechte und Freiheiten der europäischen Menschenrechtskonvention, a. a. $O$., S. $316 \mathrm{ff}$. 
rechte zu garantieren, wobei die nationalen Verfassungen dann auf Grund völkerrechtlicher Verpflichtung ergänzt werden müßten; nur ist mir ein solcher Vorgang bisher nicht bekannt geworden ${ }^{72}$ ). Die Verbürgung supranationaler Individualrechte im Rahmen der Europäischen Gemeinschaften, von denen man behauptet, sie haben eine Art von therverfassungsrang, da sie nicht an der nationalen Verfassung zu messen seien, beruht soweit man dieser Konzeption folgt - auf der besonderen Rechtsnatur des Artikel 24 GG.

Mehr über die Subtilitäten der Einwirkung des völkerrechtlichen Vertragsrechts auf den Status der Fremden hier vorzutragen, verbietet die faktische Begrenzung der Themenbehandlung.

Nur auf einen Gesichtspunkt sei noch hingewiesen. Wird die Inländergleichbehandlung für einzelne Rechte im Rahmen der Gegenseitigkeit zugesagt, so ist auch dies eine vom deutschen Richter zu beachtende Voraussetzung für die jeweils beanspruchbare Rechtsposition des Fremden. Das bedeutet: entfällt die Ausfüllung des Merkmals "Gegenseitigkeit" im fremden Vertragsstaat, besteht auch kein Anspruch des Fremden im Rahmen des deutschen Rechts mehr; es kann sich dabei um eine Vertragsverletzung handeln, die für die Anwendbarkeit des Vertrages entscheidend ist. Beruft sich der Fremde auf den Inhalt des Vertragsgesetzes, kann ihm entgegengehalten werden, in seinem Heimatstaat bestehe die Gegenseitigkeit nicht mehr. Die Entscheidung, ob das so ist, hat aber im Rahmen des Grundgesetzes der Richter selbst zu fällen ${ }^{73}$ ), wobei er sich der Regierung als Auskunftsmittel bedienen darf und gegebenenfalls muß. In fremden Staaten ist häufig der Richter an die Regierungsauskunft gebunden. Eine Utbernahme dieses Systems in das deutsche Recht stünde jedoch der Verfassungsgrundsatz der Unabhängigkeit der Gerichte entgegen ${ }^{74}$ ). Der Verwaltungsbeamte könnte zwar und müßte gegebenenfalls z. B. die Gewerbeerlaubnis entziehen, wenn er meint, die Ge-

72) Dabei ist daran zu erinnern, daß zunächst, wenn auch vereinzelt, die Auffassung auch vertreten wurde, ein Gesetz gem. Art. 24 GG bedürfe dann einer Zustimmung von 2/3 der gesetzgebenden Körperschaften, wenn die Verfassung durch Ubertragung von Hoheitsrechten materiell-rechtlich geändert würde; so jedenfalls $W$. Schätzel, Rechtsgutachten betreffend Rechtsfragen einer Wiederbewaffnung Deutschlands, Kampf um den Wehrbeitrag, 1. Halbb., 1952 , S. 348.

78) BGH v. 25. 6. 1969, BGHZ 52, 219.

74) Dazu weitere Hinweise bei $A$. Bleckmann, Deutsche Rechtsprechung in völkerrechtlichen Fragen 1969-1970 ZaöRV Bd. 32, S. $104 \mathrm{f}$. 
genseitigkeit sei nicht mehr gegeben; entscheiden würde im Streitfall aber das Gericht. Ǎhnlich läge es mit der Zulässigkeit von Repressalien.

IV. Die Auswirkung völkerrechtlicher Normen anf die Grundrechte von Fremden

Eine Regel des Völkerrechts, wonach auch Fremden im Aufenthaltsstaat verfassungsmäßig verbürgte Grundrechte mit Vorrang vor der Gesetzgebung zu gewähren sind, ist nicht feststellbar. Wäre das der Fall, dann wären ungeschriebene Verfassungen, wie diejenigen Großbritanniens ${ }^{75}$ ), völkerrechtlich bedenklich. Es bleibt auch insoweit bei dem allgemeinen fremdenrechtlichen Mindeststandard, wobei das Völkerrecht die Methode der rechtlichen Sicherung dem nationalen Recht überläßt.

Die tatsächlich erfolgte Zuteilung von Grundrechten in den nationalen Verfassungen kann aber auf andere Weise als rechtserheblich gelten. Eine Parallelentwicklung auf diesem Gebiet könnte als Nachweis für den Bestand von allgemeinen Rechtsgrundsätzen als Quelle des Völkerrechts angesehen werden und zwar im Hinblick auf das materielle Recht.

Wird z. B. die Meinungsfreiheit in den meisten Verfassungen auch Fremden garantiert, könnte man vielleicht - mit aller Vorsicht - von einem den Mindeststandard ausfüllenden allgemeinen Rechtsgrundsatz sprechen. Wird die Ausübung von politischen Rechten überwiegend nur den eigenen Staatsangehörigen reserviert, wäre wohl ein in gewisser Weise für den Fremden negativer allgemeiner Rechtsgrundsatz festgestellt, der sich auch im Vertragsrecht geltend machen ließe. Würde die Inländergleichbehandlung undifferenziert zugesagt, dann spräche doch eine Vermutung dafür, daß das politische Recht nicht mitgemeint ist.

\section{Rechtsvergleichende Ubersicht}

Die Durchsicht der Verfassungen der Welt $^{78}$ ) zeigt folgendes Bild.

75) W. J. Mackenzie - H. Street, Grundfreiheiten im Vereinigten Königreich von Großbritannien und Nordirland, Die Grundrechte Bd. 1, Halbb. 2, 1967, S. 805, zeigen, wie die Grundrechte "durch die Tradition und nicht durch konstitutionelle Garantien" geschützt werden.

79) Die folgende Aufstellung ist angefertigt auf der Grundlage des Werkes von $A$. J. Peaslee, Constitutions of Nations, 7 Bände, letztes Erscheinungsdatum 1970. Die hier gebotene Auswertung kann notwendigerweise nur ein grobes Bild bieten und die Materie ist ständigem Wechsel unterworfen. 
Abgesehen von Differenzierungen, die jedenfalls hier nicht im einzelnen wiedergegeben werden können, enthalten 118 Verfassungen von 131 untersuchten Verfassungen in irgendeiner Weise ausdrücklich Grundrechte. 7 Verfassungen erledigen die Grundrechtserteilung durch einen einfachen Verweis auf die Menschenrechte. 24 Verfassungen sprechen im Zusammenhang mit Grundrechten nur von Staatsbürgern; Fremde erhalten also keinen Grundrechtsschutz. 31 Verfassungen erteilen Grundrechte ohne zwischen Staatsangehörigen und Fremden zu unterscheiden, wobei aber das politische Wahlrecht regelmäßig ausgenommen und den Staatsbürgern reserviert ist. 56 Verfassungen erteilen Grundrechte teils an Staatsbürger und teils an Fremde.

$\mathrm{Zu}$ vermerken ist hier, daß die Reservierung von Grundrechten nur für Staatsbürger insbesondere ein Merkmal kommunistischer Verfassungen ist, so auch die UdSSR ${ }^{77}$ ) und die Volksrepublik China ${ }^{78}$ ). Typisch für einen undifferenzierten Grundrechtsschutz, also ohne Unterschied zwischen Staatsbürgern und Fremden, sind die Verfassungen von Lateinamerika. Auch weitere regionale Einteilungen könnten gefunden werden. Wenn man den allgemeinen Verweis auf Menschenrechte unbeachtet läßt, zeigt sich, daß 87 Verfassungen von 131 Verfassungen Grundrechte auch Fremden einräumen, jedoch - wie schon vermerkt - nur 31 Verfassungen ohne Differenzierung.

Einige spezielle Hinweise seien noch gegeben:

a) Das Wahlrecht wird den Fremden - jedenfalls ausdrücklich - in keinem Staat der Welt garantiert. Dort aber, wo ein Unterschied zwischen Fremden und Staatsbürgern nicht gemacht wird, ist das Wahlrecht regelmäßig ausdrücklich ausgenommen.

b) Die Gleichheit vor dem Gesetz wird von nur 15 Staaten auch Fremden garantiert. Zählt man die nicht differenzierenden Verfassungen hinzu, sind es 46 Verfassungen.

c) Die Versammlungsfreiheit verbürgen 16 Verfassungen auch Fremden. Zählt man die nicht differenzierenden Verfassungen hinzu, sind es 47 Verfassungen.

d) Die Meinungsfreiheit wird von 41 Staaten den Fremden verbürgt. Zählt man die nicht differenzierenden Verfassungen hinzu, sind es 72 Verfassungen.

$\left.{ }^{77}\right)$ Verfassung v. 5. 12. 1936, Peaslee, a. a. O., Bd. III, S. 989, Art. $118 \mathrm{ff}$

${ }^{78}$ ) Verfassung v. 20. 9. 1954, Peaslee, a. a. O., S. 261 If. Bd. II, Art. 85 ff. 
e) Die Vereinigungsfreiheit wird von 16 Staaten den Fremden gewährt. Zählt man die nicht differenzierenden Verfassungen hinzu, sind es 47 Verfassungen.

Das Bild wäre aber falsch, wenn nicht beachtet würde, daß ein hinzugefügter Gesetzesvorbehalt, der nicht durch eine Wesensgehaltsgarantie (Art. 19 Abs. II GG) beschränkt ist, geradezu den Normalfall darstellt.

\section{Grundrechte und politische Beteiligung der Fremden}

Diese Ubersicht zeigt wohl, daß das System des Grundgesetzes im Hinblick auf die Zuerteilung von Grundrechten dem Völkerrecht nicht widerspricht. Die vom Grundgesetz den Deutschen reservierten Grundrechte sind also nicht etwa völkerrechtswidrig den Fremden vorenthalten. Eher könnte man umgekehrt sagen, die auch den Fremden zuerkannten Grundrechte übersteigen fremdenrechtlich den vom Völkerrecht gebotenen Standard schon deshalb erheblich, weil sie in ihrer Bestandskraft gegenüber dem Gesetzgeber Garantien enthalten, die das Völkerrecht selbst nicht fordert, wobei nur an die Garantie des Wesensgehaltes und des Gerichtsschutzes zu erinnern ist ${ }^{70}$ ).

Bevor auf einzelne Grundrechte einzugehen ist, soll noch eine allgemeine Betrachtung zu der Frage angestellt werden, inwieweit Fremde an der politischen Willensbildung im Staat beteiligt werden können.

Es ist symptomatisch, daß in neuerer Zeit immer wieder Erwägungen darüber angestellt werden, ob es rechtliche Hindernisse gäbe, Fremden das aktive Wahlrecht einzuräumen ${ }^{80}$ ). Aus der Sicht des Völkerrechts präsentiert sich die Antwort etwa folgendermaßen. Für den Inhaber doppelter Staatsangehörigkeit - einer fremden und der deutschen - besteht ein Problem nicht. Bei doppelter Staatsangehörigkeit ist jeder Staat berechtigt denjenigen, der seine Staatsangehörigkeit besitzt, ohne Einschränkung als eigenen Staatsbürger zu behandeln, was sich im internationalen Verkehr dahin auswirkt, daß der diplomatische Schutz vom Staat der einen Staatsangehörigkeit gegenüber demjenigen der zweiten Staatsangehörigkeit nicht ausge-

70) V. Erdmann, Das Ausländergesetz von 1965 im internationalen Vergleich, Verwaltungsarchiv, Bd. 59, 1968, S. 329: "Die dem Ausländer durch das deutsche Recht eingeräumten Kontrollmöglichkeiten sind ... (denjenigen) in den anderen Vergleichsstaaten überlegen“.

80) M. Zuleeg, a. a. O., S. 369 f.; K.-P. Dolde, Zur Betelligung von Ausländern am politischen Willensbildungsprozeß, DOV 1973, S. 371 f. 
übt werden kann $\left.{ }^{81}\right)$. Im Grunde handelt es sich auch nicht um einen Fremden, sondern um ein Mitglied des Staatsvolkes.

Bei einem Inhaber ausschließlich fremder Staatsangehörigkeit erheben sich dann Bedenken, wenn sein Heimatstaat mit der Ausübung des Wahlrechts im Ausland belastende Rechtsfolgen verbindet, etwa strafrechtliche Verfolgung, Verlust der Staatsangehörigkeit oder anderes ${ }^{82}$ ). Derartige Sanktionen durch das nationale Recht halte ich nicht schlechthin für völkerrechtswidrig, da sie Ausdruck der Personalhoheit sind, Menschenrechte nicht verletzen und das Schutz- und Treueverhältnis zwischen Staat und Staatsbürger zu bewahren geeignet sein können ${ }^{83}$ ). Das gleiche würde gelten für das Verbot, sich als Abgeordneter in einem fremden Staat wählen zu lassen. Die Annahme des Staatsdienstes im fremden Staat ist vielfältig und ohne Widerspruch zum Völkerrecht von nationalen Rechtsordnungen mit Sanktionen ausgestattet worden.

Sind die nationalen Regeln völkerrechtsgemäß, erhebt sich einmal mehr die Frage, ob es auch völkerrechtsgemäß ist, wenn eine fremde Staatsgewalt sozusagen von außen die Personalhoheit des Heimatstaates unterminiert. Eine exakte Grenze wird schwer zu finden sein; von einem völkerrechtsfreundlichen Verhalten wird man aber auch nicht sprechen können. Die Intervention in die Personalhoheit eines fremden Staates wird nach meiner Auffassung nur gerechtfertigt, wenn es um den Schutz der Menschenrechte geht; den stärksten Ausdruck dieses Grundsatzes bildet die im extremsten Falle zulässige humanitäre Intervention.

Das Verfassungsrecht veranlaßt noch zu weiteren Erwägungen über die Möglichkeit eines Wahlrechts für Fremde. $\mathrm{DaB}$ alle Staatsgewalt vom Volke auszugehen hat, bedeutet wohl eine exklusive Kompetenz nur des Staatsvolkes $\left.{ }^{84}\right)$. In neuerer

81) So auch BGH v. 12. 7, 1963, RzW 1964, S. $76 \mathrm{ff}$.

82) Vgl. als Beispiel USA Nationality Act of 1940, Sec. 401 (b), wonach der Verlust der amerikanischen Staatsangehörigkeit bei Abgabe einer Treueerklärung gegenüber einem fremden Staat eintritt; ähnlich das Staatsangehörigkeitsgesetz von Polen (19. 1. 1951, Gbl. 1951, Nr. 4, Art. 12, Abs. 1, Ziff. 1), wonach der Verlust der Staatsangehörigkeit bei Verletzung der Treuepflicht gegenüber dem polnischen Staat wegen Annahme eines öffentlichen Amtes u. ä. eintritt.

8) Uber die Aberkennung der Staatsangehörigkeit als "Strafe" für Verletzung der Treuepflicht im Rahmen der Personalhoheit W. Schätzel, Staatsangehörigkeit, Die Grundrechte Bd. 2, 1954, S. $573 \mathrm{f}$.

8) K.-P. Dolde, a. a. O., S. 372. 
Zeit scheint das nicht mehr selbstverständlich zu sein, obwohl die Rechtsvergleichung zeigt, daß eine solche Exklusivität in nahezu allen Staaten der Welt für eine Selbstverständlichkeit gehalten wird. Wenn das Grundgesetz je einer Lückenfüllung in dieser Frage bedürfte, würde das Argument der Verfassungsvergleichung schlagend sein. Ernstlich mag ich mir diese Frage kaum stellen.

Nahezu grotesk aber muten die modernen Erwägungen an, ob denn eigentlich das Grundgesetz voraussetze, daß der Abgeordnete die deutsche Staatsangehörigkeit innehaben müßte $\left.{ }^{86}\right)$. Man stelle sich vor, ein Abgeordneter mit nur fremder Staatsangehörigkeit müßte an der vielleicht umstrittenen Abstimmung über den Abschluß eines Staatsvertrages mit seinem Heimatstaat teilnehmen. Müßte er sich dann für befangen erklären? Völlig grotesk würde die Lage, wenn überhaupt kein Abgeordneter mehr die deutsche sondern alle nur noch fremde Staatsangehörigkeiten innehätten. Da sie im Rahmen des freien Mandats an Aufträge und Weisungen nicht gebunden sind, würde deutsche Staatsgewalt wohl nicht mehr ausgeübt. Das Korrelat zum "freien" Mandat kann doch wohl nur die Zugehörigkeit zum Staatsvolk herstellen; das gleiche gilt für die Freiheit der Gewissensentscheidung. Das freie Mandat und die Freiheit der Gewissensentscheidung setzen im System der Repräsentation das Parlament frei, anstelle des Staatsvolkes zu handeln; das Parlament ist dann das Staatsvolk. Das gilt jedenfalls in funktionalem Sinne, wobei Betrachtungen über die rechtstheoretischen Grundlagen der Repräsentation hier außer Betracht bleiben können.

Merkwürdig nehmen sich auch die Hinweise aus, die Beteiligung von Fremden an Wahlen, insbesondere Kommunalwahlen, sei ein Gebot der Verfassung, ihr Ausschluß also verfassungswidrig( $\left.{ }^{86}\right)$. Wenn es soweit käme, daß die Entscheidungen über

85) K.-P. Dolde, a.a. O., S. 372: „Die Beschränkung des passiven Wahlrechts auf Deutsche (\$16 Abs. 1 Nr. 1 BWahlG) rechtfertigt Art. 20 Abs. 2 GG allerdings nicht". Es soll eine "Legitimation" durch das Staatsvolk genügen; ähnlich schon ders., Die politischen Rechte der Ausländer in der Bundesrepublik, 1972, S. 72 ff., wobel dann auch die Ansicht vertreten wird (S. 81), auch die Mitglieder der Bundesregierung bedürften nur der "Legitimation" durch das Staatsvolk und könnten demnach Ausländer sein.

$\left.{ }^{86}\right)$ M. Zuleeg, a. a. O., S. 370, hält die Ausschließung des Wahlrechts von Fremden bei längerem Aufenthalt in der BRD geradezu für verfassungswidrig und ihre Zulassung für ein „verfassungsrechtliches Gebot", beruhend auf demokratischem und sozialstaatlichem Denken; F. Franz, Fremdenrecht und Fremdarbeiterpolitik, DVB1. 1973, S. 673, ist offenbar ähnlicher Auffassung. 
die Gestaltung der Gemeinden im streitigen Fall von dem Votum fremder Staatsangehöriger abhängen, die jederzeit bei Scheitern ihrer Absicht sich in ihren eigenen Heimatstaat zurückziehen könnten, wäre wohl eben das Prinzip zerstört, mit dem dieser Zustand als allein verfassungsmäßig bezeichnet wurde, nämlich die sozialstaatliche Demokratie. Die soziale Gemeinschaft verliert ihren Sinn, wenn sie Zufalls- und Opportunitätsgemeinschaft ist; die Demokratie verliert ihren Sinn, wenn der Demos die Folgen der eigenen Entscheidung nicht tragen muß. Fremde können unseren Staat in der Krise verlassen, wir selbst nicht.

Bedenklich ist die Mitwirkung von fremden Staatsangehörigen in den Gewerkschaften dann, wenn man diesen einen sogenannten öffentlichen Auftrag zuerkennt ${ }^{87}$ ), wogegen ich allerdings starke Bedenken habe. Wenn der Streik nicht zum Erfolg führt und die Wirtschaft ruiniert, kann sich der Fremde, vielleicht maßgebend an der Entscheidung beteiligt, doch in seine Heimat zurückziehen ${ }^{88}$ ), der Deutsche kann sich dann dem Wiederaufbau zuwenden. Das gleiche gilt für die Mitwirkung in politischen Parteien.

Diesem Demokratiebegriff liegt das so moderne Bestreben nach Mitbestimmung zugrunde und das wird auch deutlich gesagt. Der Demokratiebegriff ist mit guten Gründen aus dem Willen zur Mitverantwortung entstanden. Das wird übersehen, oder gilt als reaktionärer Rückfall.

\section{Einzelne Grundrechte und Systematik des Grundgesetzes}

Es soll nun an einzelnen besonders bedeutsamen Grundrechten, die vom Grundgesetz auch Fremden zuerkannt sind, gezeigt werden, wie eine systematische Handhabung der Bestimmung des Grundgesetzes das Völkerrecht und das Verfassungsrecht in Ubereinstimmung zu bringen vermag. Ich muß hier die von mir früher schon vertretene Konzeption ${ }^{88}$ ) wiederholen, denn ich möchte trotz aller Kritik an ihr festhalten. Ich werde mich aber auch bemühen, diese Konzeption noch klarer zu machen und zu ergänzen.

87) E.-R. Huber, Wirtschaftsverwaltungsrecht, 2. Aufl. 1954, Bd. 2, S. 376, führt aus, die Arbeitgeber- und Arbeitnehmerverbände seien heute "in die öffentliche Ordnung einbezogen“, sie seien mit "öffentlichen Aufgaben und Befugnissen ausgestattet" und Inhaber des Rechtsstatus „beliehener Verbände“.

88) Ch. Tomuschat, Zur politischen Betätigung des Ausländers in der Bundesrepublik Deutschland, Völkerrecht und Außenpolitik, Nr. 4, 1968, S. 60.

$\left.{ }^{89}\right) \mathrm{K}$. Doehring, Die allgemeinen Regeln des völkerrechtlichen Fremdenrechts und das deutsche Verfassungsrecht, 1963, S. 122 ff. 
Das Bekenntnis zur Menschenwürde und den allgemeinen Menschenrechten in Artikel 1 GG bietet kein hier besonders zu behandelndes Problem.

a) Die allgemeine Freiheitsgarantie des Artikel 2 Abs. 1 GG jedoch bedarf der näheren Untersuchung. Eine Differenzierung zwischen Staatsbürgern und Fremden ist nicht ersichtlich. Die Frage ist nur, ob die Schranken dieser allgemeinen Freiheit für Staatsbürger und für Fremde unterschiedlich angesetzt werden dürfen.

Die Rechte anderer und das Sittengesetz mögen hier außer Betracht bleiben; einer näheren Prüfung aber bedarf die Schranke der verfassungsmäßigen Ordnung. Gleichgültig, ob man der Formel des Bundesverfassungsgerichts folgt, wonach jedes formell und materiell mit der Verfassung übereinstimmende Gesetz diese Schranke konkretisiert ${ }^{\text {} 0}$ ), scheint es doch so, daß jedenfalls die Verfassung im übrigen die Freiheit des Artikels 2 Abs. 1 GG begrenzt. Wenn also das Grundgesetz im übrigen zwischen Staatsbürgern und Fremden differenziert, kann die Schranke der verfassungsmäßigen Ordnung für beide Gruppen verschieden ausfallen. Das ist keine Frage des Gleichheitssatzes - auf die noch einzugehen ist -, sondern die vom Grundgesetz selbst angegebenen Unterschiede stehen der Prüfung am Gleichheitssatz nicht mehr zur Verfügung. Sicherlich kann also die Nichterteilung der sogenannten DeutschenGrundrechte an Fremde auch der freien Entfaltung der Persönlichkeit der Fremden nicht entgegenstehen.

Zur verfassungsmäßigen Ordnung im engsten und direkten Sinne gehört aber auch Artikel 25 GG'1). Auch diese Bestimmung begrenzt die verfassungsmäßige Freiheit, so da B die Inanspruchnahme der persönlichen Freiheit sich über die allgemeinen Regeln des Völkerrechts nicht hinwegsetzen darf.

Hält ein Fremder sich in der Bundesrepublik auf, so hat er - ebenso wie der Deutsche - die allgemeinen Regeln des Völkerrechts einzuhalten. Die allgemeinen Regeln des Völkerrechts erzeugen gemäß Artikel 25 GG nämlich nicht nur Rechte, sondern auch Pflichten. Der Terminus „erzeugen“ hat nur dann einen Sinn, wenn die allgemeinen Regeln des Völkerrechts, deren Einhaltung in Frage steht, ohne diese besondere Erzeu-

\footnotetext{
90) BVerfG v. 16. 1. 1957, BVerfGE 6, 38.

01) BVerfG v. 14. 5. 1968, BVerfGE 23, 300: „Wegen Art. 25 GG gehört es zur verfassungsmäßigen Ordnung, daß bei der Gestaltung und Anwendung des Bundesrechts den durch Art. 25 GG inkorporierten allgemeinen Regeln des Völkerrechts Rechnung getragen wird".
} 
gung nur eine völkerrechtliche Pflicht der Staaten wären, was für die meisten Rechtsregeln des Völkerrechts zutrifft ${ }^{92}$ ).

Das heißt also: gemäß Anordnung der Verfassung soll das Individuum nichts unternehmen, was das Völkerrecht selbst den Staaten verbietet. Hier nun setzt die vom Grundgesetz selbst angegebene Differenzierung zwischen Staatsangehörigen und Fremden ein, denn, was der Staatsbürger gegenüber seinem eigenen Staat unternehmen darf, ist entweder gar keine Frage des Völkerrechts, oder ist als vom Völkerrecht dem Staat überlassen anzusehen; was aber der Fremde in der Bundesrepublik zu tun oder zu unterlassen hat, kann eine Frage des Völkerrechts sein.

Die von Artikel 25 GG erzeugte Individualpflicht, sich völkerrechtsgemäß $\mathrm{zu}$ verhalten, trifft also den Fremden in besonderer Art. Diese Pflicht ist dann gleichzeitig auch die Schranke der verfassungsmäßigen Ordnung des Artikels 2 Absatz 1 GG.

Ein Beispiel mag das verdeutlichen: das allgemeine Völkerrecht verbietet es den Staaten, durch Einwirkung auf die inneren Angelegenheiten eines anderen Staates zu intervenieren. Diese Pflicht der Staaten, derartige Interventionen zu unterlassen, überträgt das Grundgesetz auf das Individuum ${ }^{93}$ ). Auch die Meinungsfreiheit des Artikel 5 GG findet dann hier ihre Grenze. Wenn schon die allgemeinen Gesetze gemäß Artikel 5 Absatz 2 GG die Meinungsfreiheit einschränken können, dann sicherlich auch die Verfassung selbst durch die Pflichten des Artikel 25 GG. Daher stimmt die Vorschrift des $\S 6$ des Ausländergesetzes, der die politische Betätigung von Fremden einschränkt, auch nicht nur mit dem Grundgesetz überein ${ }^{94}$ ), son-

92) Das hat das BVerfG (30. 10. 1962, BVerfGE 15, 33 f.) nicht klar erkannt und bleibt selbst widersprüchlich, wenn es ausführt, die "Erzeugung" von Rechten und Pflichten gem. Art. 25 GG habe "lediglich deklaratorischen Charakter", erzeugten aber auch subjektive Rechte und Pflichten für das Individuum; ebenso BVerwG v. 22. 1. 1971, BVerwGE 37, 116; die Kritik von A. Bleckmann (Deutsche Rechtsprechung in völkerrechtlichen Fragen 1958-1965, ZaöRV Bd. 28 , S. 63 f.) vermerkt richtig, daß ohne diese „Erzeugung" das unveränderte Völkerrecht überwiegend eben nur Rechte und Pflichten der Staaten enthält. Zur gesamten Problematilk $K$. Doehring, a. a. O., S. 133 ff.

23) Auch das BVerfG (30. 10. 1962, BVerfGE 15, 34) spricht ausdrücklich von "Pflichten“.

M) Auch die Europäische Menschenrechtskonvention (4. 11. 1950, BGB1. 1952 II, S. 686) läßt in Art. 16 trotz aller Gleichbehandlungsgebote die Einschränkung der politischen Betätigung von Fremden zu. 
dern füllt es sachgerecht aus und ist in gewisser Weise sogar vom Grundgesetz geboten ${ }^{03}$ ), soweit Verhältnismäßigkeit und Wesensgehaltsgarantie - beides auch Grundsätze der Verfassung - beachtet sind.

Die Artikel 2 und 5 GG finden so in Artikel 25 GG für Fremde ihre besonderen Begrenzungen aufgrund der Verfassungsordnung, zu der nach Verfassungsbefehl auch die allgemeinen Regeln des Völkerrechts zählen ${ }^{96}$ ). Selbstverständlich kann das Grundgesetz den Fremden mehr an Rechten erteilen, als das Völkerrecht fordert. Wo derartige Differenzierungen aber nicht zum Ausdruck kommen, setzt sich Artikel 25 GG mit Verfassungsrang durch ${ }^{\mathbf{0 7}}$ ).

b) Âhnlich steht es mit dem Gleichheitssatz. Die Frage, inwieweit zwischen Fremden und Staatsbürgern differenziert werden darf, ist zunächst unter Zuhilfenahme der Verfassung im übrigen $\mathrm{zu}$ entscheiden. Insoweit, als das Grundgesetz die Differenzierung klar verbietet, gibt es kein Gleichheitsproblem. Auch das Völkerrecht verbietet dem Staat nicht, den Fremden mehr Rechte zu erteilen als nach Völkerrecht zwingend geboten ist. Daß die übermäßige Erteilung von Rechten an Fremde ein - wie ich es genannt habe - Korruptionsproblem bilden kann, wurde schon erwähnt.

Der Gleichheitssatz des Artikel 3 Absatz 1 GG kann formell von jedem Menschen in Anspruch genommen werden; er läßt insbesondere eine Differenzierung zwischen Staatsangehörigen und Fremden selbst nicht erkennen.

95) W. Marxen, Deutsches Ausländerrecht, 1967, S. 118 f., gibt Beispiele für die hier gemeinten Begrenzungen.

9) Ch. Tomuschat, a.a.O., lehnt die Auffassung ab, wonach das Ausländergesetz als allgemeines Gesetz den Erfordernissen des Art. 5 Abs. 2 GG genügen soll (S. 53 ff.). Wenn er aber gewisse Betätigungen im Rahmen des Art. 5 Abs. 1 GG der Gruppe der Ausländer wegen ihrer Nichtzugehörigkeit zum Staatsvolk dennoch und mit Recht nicht zubilligen will (S. $56 \mathrm{ff}$.), kommt diese Konstruktion der direkten Anwendung des Art. 5 Abs. 2 GG dann gleich, wenn man Verhältnismäßigkeit und Wesensgehaltsgarantie als Grenzen des Gesetzesvorbehaltes sinnvoll einsetzt. $\mathrm{Zu}$ beachten ist aber auch, daß diese Konstruktion für den Fremden letztlich weniger Schutz bedeutet, da der Gesetzgeber nicht zur klaren Aussage gezwungen wird.

${ }^{77}$ Andererseits kann ein Bundesgesetz, das die allgemeinen Regeln des Art. 25 GG unbeachtet läßt, keine rechtmäßige Eingriffsgrundlage enthalten und das Freiheitsrecht aus Art. 2 Abs. 1 GG verletzen (BVerfG v. 14. 5. 1968, BVerfGE 23, 313, unter Berufung auf frühere Entscheidungen). 
Das ist aber keine Besonderheit gerade im Rahmen dieser Differenzierungsfrage, denn - es sei mit aller Klarheit gesagt - der Gleichheitssatz hat überhaupt keinen materiellrechtlichen Inhalt. Er sagt nur: Wenn Unterschiede nicht sachgerecht erscheinen, sind sie als nicht vorhanden zu fingieren und wenn Unterschiede sachgerecht erscheinen, darf die Gleichheit nicht fingiert werden. Der Gleichheitssatz sagt nichts darüber, wo und wann Unterschiede relevant sind oder übergangen werden müssen. Der Gleichheitssatz wird verwendet zur Negierung oder zur Beachtung von Wertungen, die er selbst gar nicht enthält. Als Willkürverbot setzt er den Begriff der Willkür voraus, aber er enthält nicht dessen materielle Kriterien ${ }^{98}$ ).

Für das Fremdenrecht lautet die Frage also ganz simpel: Unter welchen Umständen dürfen oder müssen gar die unleugbaren Unterschiede zwischen Staatsbürgern und Fremden, die Fremdeigenschaft also, als relevantes Kriterium im Rahmen des Gleichheitssatzes eingesetzt werden? Der Gleichheitssatz selbst kann darüber gar nichts aussagen. Die Relevanz der Fremdeigenschaft muß sich also aus der Rechtsordnung im übrigen ergeben. Entweder die Rechtsordnung zeigt, daß die Fremdeigenschaft irrelevant sein soll, oder sie zeigt, daß sie relevant ist.

Irrelevanz der Fremdeigenschaft liegt prima facie insoweit vor, als Grundrechte bewußt unterschiedslos allen Menschen erteilt sind, also z. B. bei der Gewissensfreiheit des Artikel 4 GG. Sind Grundrechte nur Deutschen erteilt, erhebt sich die Frage der Gleichheit zwischen Fremden und Staatsangehörigen - wie schon bemerkt - gar nicht.

In all denjenigen Rechtsbeziehungen aber, in denen das Grundgesetz nicht die genannte Irrelevanz der Fremdeigenschaft zum Ausdruck bringt, ist es jedenfalls zulässig, die Fremdeigenschaft als sachliches Kriterium der Ungleichbehandlung einzusetzen ${ }^{99}$ ). Dieses Ergebnis folgt aus Artikel 25 GG, der mit Verfassungsrang jedenfalls die allgemeinen Regeln des völkerrechtlichen Fremdenrechts ausgestattet hat. Wenn Völkerrecht gleich Verfassungsrecht ist, enthält also die Verfas-

08) Leibholz-Rinck, Grundgesetz, 4. Aufl. S. 87: „Maßstab für die Willkürprüfung im Rahmen des allgemeinen Gleichheitssatzes ist vielmehr die vom GG aufgerichtete Ordnung".

00) Wegen der großen Zahl der entsprechenden deutschen Gerichtsentscheidungen wird verwiesen auf die Zusammenstellung von $A$. Bleckmann, Deutsche Rechtsprechung in völkerrechtlichen Fragen 1966-1968, ZaöRV Bd. 31, S. 317 f.; 1969-1970, ZaöRV Bd. 32, S. 130 f.; 1971, ZaöRV Bd. 32, S. 607 f. 
sung die Zulässigkeit einer Differenzierung zwischen Fremden und Staatsangehörigen gemäß Völkerrecht.

Das heißt also: Inländergleichbehandlung ist - da sie vom Völkerrecht nicht geboten ist - zwar zulässig; der Gesetzgeber darf - alle anderen Gesichtspunkte der Verfassung hier einmal außer acht gelassen - die Inländergleichbehandlung herstellen, aber muB es nicht ${ }^{100}$ ), sondern er ist insoweit frei. Der Gesetzgeber handelt nicht willkürlich, wenn er die Fremdeigenschaft als sachliches Kriterium beachtet, soweit das Grundgesetz sie nicht klar negiert und soweit das Rechtsverhältnis durch sie geprägt wird.

Setzt der Gesetzgeber die Fremdeigenschaft - soweit sie zulässig ist - als sachliches Kriterium ein, darf die Differenzierung zu Inländern doch niemals so weit gehen, daß der völkerrechtliche Mindeststandard unterschritten wird. Der Mindeststandard ist Inhalt des Artikels 25 GG und also des Verfassungsrechts.

Eine Verfassungsbeschwerde kann nach der Rechtsprechung des Bundesverfassungsgerichts zwar nicht auf die Verletzung des Artikels 25 GG unmittelbar gestützt werden, da es sich um kein Grundrecht handelt ${ }^{101}$ ); sie kann aber dann auf Artikel 3 Absatz 1 GG beruhen, wenn und soweit eine Diskriminierung des Fremden - gemessen an der Behandlung eigener Staatsbürger - den Mindeststandard unterschreitet ${ }^{102}$ ), denn der Gleichheitssatz gebietet, nur sachliche und also auch nicht völkerrechtlich unzulässige Differenzierungen vorzunehmen.

Nochmals zusammengefaßt bedeutet das: die Differenzierung zwischen Staatsbürgern und Fremden muß nicht stattfinden, aber sie darf stattfinden ${ }^{103}$ ), soweit das Grundgesetz das nicht erkennbar außerhalb des Gleichheitssatzes verbietet ${ }^{104}$ ).

100) Daß Inländergleichbehandlung vom Völkerrecht nicht gefordert wird, hat auch die deutsche Rechtsprechung immer anerkannt, z. B. BVerwG v. 10. 12. 1958, JR 1959, 436; v. 24. 9. 1965, E 22, 69.

101) Da aber die Nichtvorlage gem. Art. 100 Abs. 2 GG wegen Verletzung des Art. 101 GG zur Verfassungsbeschwerde führen kann (BVerfG v. 14. 5. 1968, BVerfGE 23, 319), kann durchaus eine Verfassungsbeschwerde den Art. 25 GG zum Prüfungsgegenstand haben.

102) Im Urteil des BVerwG v. 24. 9. 1965, E 22, 69 wird unter Berufung auf die Rechtslehre darauf hingewiesen, daß die an sich bestehende Diskriminierungsbefugnis ihre Schranke am internationalen Mindeststandard findet.

103) OLG Frankfurt v. 21. 9. 1970, NJW 1970, S. 2172 im Hinblick auf die Staatshaftung.

104) Eingehend dazu die Entscheidung des BFH v. 17. 1. 1967, E 88, $61 \mathrm{ff}$., in der auch die bisher ergangene Rechtsprechung zusammengefaßt ist. 
Bei Grundrechten mit Gesetzesvorbehalt, die nicht nur Deutschen gewährt wird, erhebt sich die Frage, ob und inwieweit der Gesetzgeber bei der Grundrechtsbeschränkung die Fremdeigenschaft beachten darf.

$\mathrm{DaB}$ die Wesensgehaltsgarantie „in keinem Falle“ außer acht gelassen werden darf und also auch Fremden gegenüber gilt, ist selbstverständlich. Oberhalb aber des Wesensgehalts kann eine Differenzierung durchaus vorgenommen werden; auch der Gleichheitssatz ist „allen" Menschen garantiert, aber dennoch können und müssen Unterschiede beachtet werden.

Das Grundgesetz läßt auch in anderen Beziehungen, als den hier behandelten, Gruppendifferenzierungen bei Sachgerechtigkeit zu. So wie für die Gruppe der Beamten die Zulässigkeit im Rahmen der Sachgerechtigkeit dem Artikel 33 Abs. 5 GG entnommen werden kann, ist sie für diejenigen Rechtsbeziehungen, die durch die Fremdeigenschaft geprägt sind, dem Artikel 25 GG zu entnehmen, da das Verfassungsrecht die völkerrechtlich relevanten Unterschiede zwischen Fremden und Staatsbürgern auf der Ebene der Verfassung zumindest für verwendbar erklärt.

Auf Artikel 3 Abs. 3 GG will ich hier nur mit einer kurzen Bemerkung eingehen. Mit guten Gründen ist die fremde Staatsangehörigkeit nicht zum Inhalt der strikten Klassifizierungsverbote gezählt worden $\left.{ }^{105}\right)$. Man stelle sich vor, was die Gegenansicht im Ergebnis bedeuten würde. Es wäre dann z. B. zweifelhaft, ob es überhaupt ein Einreiseverbot für Fremde geben dürfte. Es sei noch bemerkt, daß das System der Europäischen Menschenrechtskonvention hier bewußt nicht behandelt wurde, da es für die Rechtsanwendung ohnehin hinter das Verfassungsrecht zurücktreten muß und im übrigen die Gesetzesvorbehalte für das nationale Recht eine Kollision jedenfalls mit dem jetzt geltenden Recht der Bundesrepublik nahezu ausgeschlossen erscheinen lassen.

\section{Schlußbemerkung}

Mit diesen Hinweisen will ich schließen. Es sei nochmals betont, daß diese meine Konstruktion des Fremdenrechts im Rahmen des Verfassungsrechts mit Nationalismus nichts zu tun hat.

105) Unklar in dieser Beziehung H. Kraus, a. a. O., S. 91 t. Ebenso unklar ist die Erwähnung des Art. 3 Abs. 3 GG durch den BGH (28. 7. 1972, NJW 1973, S. 2191) unter Berufung auf OLG Celle, NJW 1953, S. 1603), wenn auch das Ergebnis zu billigen ist. 
Es ist gesagt worden, hinter meiner Konstruktion stehe nationalstaatliches Denken $\left.{ }^{106}\right)$. Ich möchte daran erinnern, daß die meisten der 131 von mir betrachteten Verfassungen erheblich nationalstaatlicher angelegt sind, als ich es hier für das deutsche Recht vorgeführt habe. Völkerrecht und Rechtsvergleichung sollten etwas bekannter sein.

Würde man denn - mit einem gewissen soupçon - von "Vereinsdenken" sprechen, wenn die Vereinsmitglieder ihre Vereinsrechte auf Gäste nicht ausdehnen möchten? Oder wäre die volle Erstreckung auf Nichtmitglieder ein Gebot der Demokratisierung des Vereinsrechts?

Wenn man - wie das vorgeschlagen wurde ${ }^{107}$ ) - Artikel 3 Abs. 3 GG sogar als Begrenzung des Ermessens für die Einbürgerung ansieht, dürfte man einem Bewerber aus der Volksrepublik China etwa die Einbürgerung nicht versagen, weil man ihn sonst unter Umständen wegen politischer Auffassung, wegen Rasse und wegen Staatsangehörigkeit diskriminieren würde. Man sollte einmal in der Volksrepublik China nachfragen, wie es mit einem Anspruch auf Einbürgerung von Staatsangehörigen der BRD dort stünde.

Solange die Völkergemeinschaft aus selbständigen Staaten in einem System der Koordination besteht, kann auch das Verfassungsrecht auf Schutzvorkehrungen nicht verzichten.

${ }^{100)} M$. Zuleeg, a. a. O., S. 364.

107) M. Zuleeg, a. a. O., S. 365, will Art. 3 Abs. 3 GG als Hinderungsgrund ansehen, bei der Einbürgerung nach der Staatsangehörigkeit zu differenzieren. 
Leitsätze des Berichterstatters über:

\section{Die staatsrechtliche Stellung der Ausländer in der Bundesrepublik Deutschland}

Der Status der Fremden im Verfassungsrecht der Bundesrepublik Deutschland unter dem Gesichtspunkt der normativen Verschränkung von Völkerrecht und Verfassungsrecht

Zur Vorbemerkung:

1. Die rechtliche Unterscheidung von Staatsangehörigen und Fremden ist ein völkerrechtliches Prinzip, dem sich kein Staat entziehen darf. Würde ein Staat in seiner Rechtsordnung eine solche Abgrenzung unterlassen, käme er seinen auch von der Völkergemeinschaft ihm auferlegten Pfichten nicht nach, die jeweilige Personalhoheit erkennbar zu machen und auf ihrer Grundlage die Totalverantwortung für die eigenen Staatsbürger zu übernehmen.

2. Die allgemein anerkannten Menschenrechte finden derzeit (noch?) ihren relativ stärksten Schutz in Staatsverbänden, die den Kreis ihrer Staatsbürger zu Fremden eindeutig abgrenzen.

Zu I, Der Begriff des Fremden.

3. Einen eindeutigen Hinweis auf die Pficht der Staaten zur Abgrenzung der Staatszugehörigkeit gibt das Völkerrecht mit der sog. nationality rule, die eine konkrete Definition auch des "Fremden" unumgänglich macht.

4. Wenn Art. 25 GG die allgemeinen Regeln des Völkerrechts $z u$ innerstaatlichem Recht erklärt, besteht nicht nur ein völkerrechtliches Gebot, eine Unterscheidung zwischen Staatsangehörigen und Fremden zu vollziehen, sondern die Verfassung selbst gebietet das.

Zu II, Die Gebote des Völkerrechts für die Behandlung von Fremden im innerstaatlichen Recht

5. Das völkerrechtliche Gewohnheitsrecht gebietet den Staaten, bei der Behandlung von Fremden einen Mindeststandard einzuhalten, dessen Unterschreitung ein völkerrechtliches Delikt bedeuten würde. Der Inhalt des Mindeststandards ist dem Wandel des Gewohnheitsrechts unterworfen. 
6. Dieser völkerrechtliche Mindeststandard ist zwingendes Recht, soweit sein Inhalt in etwa den allgemeinen völkerrechtlichen Menschenrechten entspricht. Diejenigen Regeln des Mindeststandards, die nicht zwingender Natur sind, können durch Vertragsschluß mit dem Heimatstaat des Fremden eingeschränkt werden.

7. Ein allgemeines Verbot unterschiedlicher Behandlung von Staatsbürgern und Fremden und von Fremden untereinander kennt das Völkerrecht nicht. Nur in extremen Grenzfällen könnte eine willkürliche Ungleichbehandlung rechtswidrig sein. Verträge können die Gleichbehandlung von Fremden untereinander und von Fremden und Staatsbürgern weitgehend herstellen; eine Verpflichtung zum Abschluß solcher Verträge besteht nicht.

8. Die sog. allgemeinen Rechtsgrundsätze - d. h. Regeln fundamentaler Bedeutung, die sich parallel in den nationalen Rechtsordnungen gebildet haben - ergänzen das völkerrechtliche Gewohnheitsrecht gerade auch im Hinblick auf das Fremdenrecht.

9. Die Nichteinhaltung des Grundsatzes der Gegenseitigkeit durch den einen Staat berechtigt den anderen noch nicht, den fremdenrechtlichen Mindeststandard zu unterschreiten, soweit dieser den allgemeinen Menschenrechten entspricht. Nur das staatliche Selbsterhaltungsrecht könnte im extremen Fall auch insoweit eine Rechtfertigung bedeuten. Das gleiche gilt für das Recht zur Repressalie.

10. Zwar unterliegt der Fremde der Rechtsordnung des Aufenthaltsstaates; diese hat jedoch zu respektieren, daß die Personalhoheit des Heimatstaates vielfältig über dessen Staatsgrenzen hinauswirken darf.

11. Der Aufenthaltsstaat darf dem Fremden keine Pflichten auferlegen, die mit dem Fortbestand des Treue- und Schutzverhältnisses zu seinem Heimatstaat unvereinbar sind.

12. Weitgehend ungeklärt ist die Frage, ob und inwieweit der Aufenthaltsstaat dem Fremden Rechte und Vorteile anbieten darf, die geeignet wären, sein Treueverhältnis zum Heimatstaat zu korrumpieren. Es bestehen jedoch Anzeichen für die Annahme, daß auf diese Weise nicht nur die comity of nations sondern auch Rechte des Heimatstaates als verletzt angesehen werden könnten. 
Zu III, Das System des Grundgesetzes zur Erfüllung völkerrechtlicher Gebote im innerstaatlichen Recht

13. Den Anwendungsbefehl für das völkerrechtliche Fremdenrecht soweit es auf Gewohnheitsrecht und allgemeinen Rechtsgrundsätzen beruht, gibt das Grundgesetz durch Art. 25 . Anwendungsbefehl und anzuwendende völkerrechtliche Normen haben Verfassungsrang. Die von Art. 25 GG "erzeugten" Rechte und Pfichten der Fremden nehmen an diesem Verfassungsrang teil.

14. Die Regeln des fremdenrechtlichen Mindeststandards können durch einfaches Gesetz nicht eingeschränkt werden. Soweit sie dispositive Regeln des Völkerrechts sind, können sie aufgrund eines völkerrechtlichen Vertrages mit dem Heimatstaat des Fremden durch einfaches Vertragsgesetz eingeschränkt werden.

15. Im Verhältnis zwischen fremdenrechtlichem Gesetz und fremdenrechtlichem Vertragsgesetz gemäß Art. 59 Abs. 2 GG gilt die Regel, daß das spätere Gesetz dem früheren vorgeht. Diese Regel wäre nur dann ausgeschaltet, wenn die Vertragspartner den Verfassungsrang von Vertragsbestimmungen vereinbaren würden und der Gesetzgeber die Verfassung entsprechend ändert.

16. Die vertragliche Zusicherung der Inländerbehandlung vermittelt dem Fremden nicht auch die Inhaberschaft entsprechender Grundrechte, es sei denn, der völkerrechtliche Vertrag und das Verfassungsrecht würden das ausdrücklich bestimmen.

$\mathrm{Zu}$ IV, Die Auswirkung völkerrechtlicher Normen auf die Grundrechte von Fremden

17. Ein Vergleich mit den Verfassungen fremder Staaten zeigt, daß das Grundgesetz den allgemeinen Standard im Hinblick auf die Erteilung von Grundrechten an Fremde erheblich übersteigt, und zwar sowohl in bezug auf deren materiellrechtlichen Gehalt als auch und vor allem in bezug auf die Bestandskraft der zugesicherten Grundrechte.

18. Der Gesetzgeber darf den Fremden mehr an Rechten zuteilen als das Völkerrecht es gebietet, es sei denn, eine solche Rechtserteilung beeinträchtigt die Personalhoheit des Heimatstaates des Fremden. Der Gesetzgeber darf aber auch - soweit das Grundgesetz nicht selbst schon den völkerrechtlichen Standard überschreitet - bei der Zuteilung von Rechten sich auf den völkerrechtlichen Mindeststandard beschränken.

19. Inhaber des aktiven und passiven Wahlrechts können nach den Regeln des Grundgesetzes nur deutsche Staatsangehörige 
sein. Die Rechtsvergleichung zeigt darüber hinaus, daß die Beschränkung des Wahlrechts auf Staatsangehörige als ein allgemeiner Rechtsgrundsatz angesehen werden muß. Den allgemeinen Regeln des Völkerrechts ist auch zu entnehmen, daß die Erteilung des nationalen Wahlrechts an Fremde unter Umständen geeignet sein kann, die Personalhoheit fremder Staaten zu beeinträchtigen.

20. Die allgemeine Freiheitsverbürgung des Art. 2 Abs. 1 GG läßt eine Differenzierung zwischen Staatsbürgern und Fremden insoweit zu als die Schranke der verfassungsmäßigen Ordnung, die auch von Art. 25 GG gebildet wird, eine Ungleichbehandlung rechtfertigt oder auch gebietet.

21. Bei Anwendung des Gleichheitssatzes (Art. 3 Abs. 1 GG) darf die Fremdeigenschaft eines Menschen als sachliches Unterscheidungskriterium dann zu einer Ungleichbehandlung führen, wenn das rechtlich einzuordnende Lebensverhältnis durch diesen tatsächlichen und rechtlichen Unterschied entscheidend geprägt ist. Soweit das Grundgesetz diese Unterscheidung erkennbar verbietet, darf sie als Rechtfertigungsgrund für eine Ungleichbehandlung nicht verwendet werden; soweit das nicht der Fall ist, darf bis zur Grenze des völkerrechtlichen Mindeststandards differenziert werden.

22. Enthält ein Grundrecht, das nicht nur deutschen Staatsangehörigen erteilt ist (z. B. Art. 5 Abs. 1 GG) die Beschränkungsmöglichkeit aufgrund eines Gesetzesvorbehaltes (z. B. Abs. 2 des Art. 5 GG), ist eine Ungleichbehandlung von Fremden gegenüber Staatsangehörigen durch den Gesetzgeber noch insoweit zulässig als die oben angeführten Kriterien des Gleichheitssatzes eingreifen; diese Grundrechte sind dennoch für den Fremden nicht "leerlaufend", weil der Grundsatz der Verhältnismäßigkeit und die Wesensgehaltsgarantie gegen Willkür und Aushöhlung schützen.

23. Die so aufgezeigten Einschränkungen gegenüber einer nicht differenzierenden Inländerbehandlung entsprechen nicht nur den Regeln des Völkerrechts, sondern, gemessen an den meisten Verfassungen der Welt, ändern sie nichts daran, daß das Grundgesetz den allgemeinen Standard durchaus übersteigt. Das Grundgesetz übersteigt auch die Forderungen der Europäischen Menschenrechtskonvention, die den nationalen Rechtsordnungen einen weitgehenden Gesetzesvorbehalt reservieren und besondere Einschränkungen für Fremde zulassen. 


\section{Die staatsrechtliche Stellung der Ausländer in der Bundesrepublik Deutschland}

2. Mitbericht von Professor Dr. Josef Isensee, Saarbrücken

\section{Inhalt}

Selte

A. Das Problem . . . . . . . . . . . . . . . . . . . . . . . 50

I. Das Grenzgebiet der Verfassungsdogmatik . . . . . . 50

II. Die Herausforderung der Verfassungswirklichkeit . . . 51

III. Die Verfassungsfrage der Gleichheit . . . . . . . . . 53

B. Det verfassungsdogmatische Horizont . . . . . . . . . . . 55

I. Das Modell des Rechts-Dreiecks . . . . . . . . . . . 55

II. Die unentrinnbare Staats-Abhängigkeit als StatusKriterium . . . . . . . . . . . . . . 58

C. Die aufenthaltsrechtlichen Status-Bedingungen . . . . . 60

I. Die Vorfrage des Verfassungs-Kollisionsrechts . . . . 60

II. Status-Begründung durch Gebietskontakt - die Zulassung des Aufenthalts ................ 61

III. Status-Sicherheit durch Beschränkung der Ausweisungskompetenz . . . . . . . . . . . . . . 71

D. Der rechtsstaatliche Status . . . . . . . . . . . . . . 73

I. Die Vermutung für die Rechtsgleichheit . . . . . . . 73

II. Absolute Gleichstellungsgebote . . . . . . . . . . . . 75

III. Die Schlechterstellung im Vorbehaltsbereich der Deutschenrechte . . . . . . . . . . . . . 76

IV. Die Möglichkeit fortschreitender Status-Angleichung . 81

V. Grundrechtsstandard der Verfassung und Mindeststandard des völkerrechts . . . . . . . . . . . 85

E. Der sozialstaatliche Status . . . . . . . . . . . . . 86

I. Das soziale Staatsziel und der Angehörige eines fremden Staatsverbandes .. . . . . . . . . . . . . . . . . . 86

II. Das soziale Staatsziel und der Angehörige eines fremden Kulturkreises . . . . . . . . . . . . . . 87

F. Der demokratische Status . . . . . . . . . . . . . . . . 91

I. Teilhabe an der Entscheidungsmacht des Staatsvolkes . 91

II. Ausübung staatlicher Ämter . . . . . . . . . . . . . 95

III. Mitbestimmung in unterstaatlichen Verbänden . . . . 96

IV. Demokratischer Aspekt der Freiheitsgrundrechte . . . . 99

G. Schluß - Ordnungsdefizit und Verfassung . . . . . . . . 101

4 Ver\&fentl. Dt. Staatsrechtslehrer, Heft 32 
Josef Isensee

\section{A. Das Problem}

\section{Das Grenzgebiet der Verfassungsdogmatik}

Die Frage nach der staatsrechtlichen Stellung des Ausländers führt in das Spannungsfeld zwischen Liberalität und Souveränität, zwischen Weltbürgertum und nationalstaatlicher Selbstbehauptung ${ }^{1}$ ). Es scheint, als erreiche die Verfassung hier nicht die normative Stärke, um diese Spannungen aufzuheben, und als müsse sie vorrechtlichen, elementaren Kräften Raum belassen: einer Staatsraison, die sich noch nicht hat verfassungsrechtlich domestizieren lassen, und auf der Gegenseite ursprunghaften Geboten der Menschlichkeit, die noch nicht Rechtsgestalt angenommen haben.

1) Die Position der reinen Souveränität des Verfassungsstaates gegenüber dem Fremden repräsentiert Max von Seydel: Es bestehe den Fremden gegenüber „,keine rechtliche Schranke der Gesetzgebung, sondern nur eine solche, welche die Staatsgewalt sich selbst zieht. Wohl sind Rücksichten der Gesetzgebungspolitik und des Staatenverkehrs vorhanden, welche eine Selbstbeschränkung der Staatsgewalt gegenüber dem Fremđen als innerlich oder politisch notwendig erscheinen lassen, allein es gibt keinen allgemeinen Rechtsgrundsatz, und kann keinen geben, nach welchem mit Bestimmtheit und unbedingter Giltigkeit gesagt $\mathrm{zu}$ werden vermöchte, welche Rechte oder Pflichten für den Fremden bestehen und welche nicht. Es läßt sich lediglich der Satz aufstellen, daß die Bedingung, unter welcher der Fremde mit seiner Person oder seinen rechtlichen Verhältnissen in den Machtbereich der Staatsgewalt zugelassen wird, der Gehorsam gegen diese Staatsgewalt ist, ein Gehorsam, der soweit reicht, als die Staatsgewalt ihn zu fordern für gut findet". (Bayerisches Staatsrecht I, 18962, S. 342).

Die Gegenposition der kosmopolitischen Liberalität vertritt Robert von Mohl: „Es können ... die künstlich gezogenen Striche auf der Landkarte kein grundsätzliches Hindernis sein, die vom Schöpfer der Weltordnung gestellte Aufgabe des Daseins zu erreichen. Es muß vielmehr der Satz aufgestellt werden, daB jedem menschlichen Individuum, als Regel, das Recht zusteht, an und für sich vernünftige, also erlaubte Lebenszwecke überall $\mathrm{zu}$ verfolgen, wo er die geeigneten Mittel hierzu zu finden glaubt, zu dem Ende aber namentlich auch die Gebiete fremder Staaten $\mathrm{zu}$ betreten und sich die seinen Zwecken entsprechende Zeit hindurch daselbst aufzuhalten". (Staatsrecht, Völkerrecht und Politik I, 1860, S. 627). - Eine geradezu idealtypische Darstellung der weltbürgerlichen Forderung bietet auch Silvester Jordans Artikel "Gastrecht (Fremdenrecht)" im Rotteck-Welcker'schen Staatslexikon (Bd. VI, 1838, S. 291-317, insbes. S. 315-317).

Zur geschichtlichen Entwicklung des Fremdenrechts: Jordan a. a. O., S. 291-315; von Frisch, Das Fremdenrecht, 1910, S. 5-90; Friedrichsen, Die Stellung des Fremden in deutschen Gesetzen und völkerrechtlichen Verträgen seit dem Zeitalter der französischen Revolution, Diss. Göttingen 1967. 
Die Staatsrechtslehre hat bisher wenig Neigung gezeigt, das unwegsame Gelände des deutschen Verfassungsrechts an der Grenze zu ausländischen Staatsordnungen und zum internationalen Recht dogmatisch zu vermessen. Der Ausländer tritt in das verfassungsdogmatische Blickfeld zumeist nur bei der Unterscheidung zwischen "Menschenrechten" und "Bürgerrechten" - pflichtübungsmäßiger Reverenz vor einem Bildungserbe ${ }^{2}$ ). Die Rechtsfragen des Ausländers sind herkömmlich zumeist den Disziplinen des Ausländerpolizeirechts und des völkerrechtlichen Fremdenrechts überlassen geblieben.

\section{Die Herausforderung der Verfassungswirklichkeit}

In diesem bislang nur beiläufig und akademisch gelassen erörterten Fragenkreis stößt die Staatsrechtslehre heute auf die Herausforderung der Verfassungswirklichkeit, seit sich Millionen Ausländer im Bundesgebiet aufhalten ${ }^{3}$ ), seit das Provisorium des Gastarbeiters sich als dauerhaft zu erweisen scheint und die deutsche Bevölkerung in ihrer Mitte erstmals größere nationale Minderheiten aus heterogenen Kulturkreisen entstehen sieht ${ }^{4}$ ). Das geltende Gesetzesrecht ist auf diese Lage

2) Verfassungshistorische Analyse und verfassungsdogmatische Kritik der Begriffspaare "Menschenrechte - Bürgerrechte" sowle "Bürgerliche und politische Rechte": von Frisch, (N 1), S. 225-308.

3) Am 31. 12. 1971 wurden im Bundesgebiet 3,439 Millionen Ausländer registriert. Hinzu kommt ein unabsehbarer (auf mehrere hunderttausend Personen geschätzter) Kreis von Ausländern, die sich illegal in der Bundesrepublik aufhalten. Die Vergleichszahl für das Jahr 1933, bezogen auf das Gebiet des Deutschen Reiches, beträgt 0,757 Millionen; die Vergleichszahl für das Jahr 1900: 0,779 Millionen. - Zahlenangaben nach: Wirtschaft und Statistik 1972, S. 435-447; Statistisches Jahrbuch für das Deutsche Reich 1936, S. 16; Statistisches Jahrbuch für das Deutsche Reich 1908, S. 9.

1971 stieg die Zahl der im Bundesgebiet (legal) beschäftigten ausländischen Arbeitnehmer auf 2,128 Millionen an. Im Jahr 1967 hatte die Zahl 1,014 Millionen, im Jahre 1962 0,629 Millionen betragen. Zahlenangaben nach: Statistisches Jahrbuch für die Bundesrepublik Deutschland 1972, S. 129 und 1967, S. 151.

4) Amtliche Berichte jüngsten Datums über die Lebensverhältnisse der ausländischen Arbeitnehmer, mit empirischen Belegen und Problemanalysen: Bayerisches Staatsministerium für Arbeit und Sozialordnung, Ausländische Arbeitnehmer in Bayern, Sonderdruck eines Berichts v. 23. 5. 1973 an den Bayerischen Landtag über Probleme der Arbeits- und Wohnverhältnisse der Familienzusammenführung und der gesellschaftlichen Integration der ausländischen Arbeitnehmer in Bayern, 1973 (zit. Bay. Bericht); Stadt Nürnberg (Sozial- und Gesundheitsreferat), Ausländische Arbeitnehmer in Nürnberg, März 1973 (unveröffentl. Typoskript); Stadt München, Ausländerstudie (Zusammenfassung in: Bay. Bericht, S. 57-59); Präsident der Bundesanstalt für Arbeit, Erste vorläufige Ergebnisse 
nicht zugeschnitten. Die staatlichen Stellen greifen zu hektischen Improvisationen, ohne bisher zu einer Konzeption gelangt zu sein $\left.{ }^{5}\right)$. Der amtliche Pragmatismus wird bedrängt von

aus der Ausländerbefragung durch die Arbeitsämter vom Frühjahr 1972 (Typoskript v. 17. 12. 1972); Bundesminister für Arbeit und Sozialordnung, Sozialbericht 1973, S. 11-14.

Sonstige Berichte mit Statistiken, Dokumenten, Analysen: Bingemer, Meistermann-Seeger, und Neubert (Hrsg.), Leben als Gastarbeiter, 1970 (Lit.); Höpfner, Ramann und Rürup, Ausländische Arbeitnehmer, 1973 (Lit.); Nikolinakos, Politische Okonomie der Gastarbeiterfrage, 1973; Geiselberger (Herausgeber im Auftrag des Bundesvorstandes der Jungsozialisten), Schwarzbuch: Ausländische Arbeiter, 1972 (Lit.); Klee (Hrsg.), Gastarbeiter - Analysen und Berichte, 1972.

5) Die amtliche Ratlosigkeit wird sichtbar, wenn der Präsident der Bundesanstalt für Arbeit seinen Bericht vom 17. 12.1972 (N 4) mit der Feststellung einleitet, daß die in der Bundesrepublik Deutschland verfügbaren Informationen "für eine umfassende Beurteilung der wirtschaftlichen, arbeitsmarktlichen und sozialen Aspekte der Ausländerbeschäftigung “ nicht ausreichten. Die Regierungserklärung des Bundeskanzlers vom 18. 1.1973 verheißt, das Gastarbeiterproblem „nicht dem Gesetz des augenblicklichen Vorteils allein" zu überlassen, „diese Dinge im Zusammenhang darzustellen und Lösungsvorschläge daraus abzuleiten"; die Zielvorstellungen für diese "riesenhafte und komplexe Aufgabe" erschöpfen sich vorerst in Formeln wie "solidarischer Geist", "gute Nachbarschaft mit diesen Minderheiten" und "Reifeprüfung" des „demokratischen Bewußtseins" aller Bürger (Bulletin des Presse- und Informationsamtes der Bundesregierung v. 19. 1. 1973, Nr. 6/S. 54).

Allenfalls als erste Ansätze zu einer ausländerpolitischen Konzeption lassen sich die "Leitlinien" der Bundesregierung zur Ausländerbeschäftigung werten (dem Bundestag in seiner Sitzung vom 6. 6. 1973 mitgeteilt durch den Bundesminister für Arbeit und Sozialordnung als „Bericht der Bundesregierung aus der Kabinettsitzung", Bulletin v. 8. 6. 1973, Nr. 70/S. 693). Zögernde Versuche zu einer bundespolitischen Ziel- und Wegfindung werden erkennbar in: Antwort der Bundesregierung auf eine Kleine Anfrage der CDU/CSU-Fraktion, „Politik der Bundesregierung gegenüber den ausländischen Arbeitnehmern in der Bundesrepublik Deutschland" v. 31. 1. 1972 (BT-Drucks. VI/3085). „Grundsätze zur Eingliederung ausländischer Arbeitnehmer und ihrer Familien“ v. 20. 4. 1972, beschlossen von den „im Koordinierungskreis und im Länderausschuß ,Ausländische Arbeitnehmer' beim Bundesministerium für Arbeit und Sozialordnung vertretenen Stellen und Organisationen" (BArbBl. 1972, 380-382).

Zusammenfassungen politischer und rechtlicher Vorstellungen auf Länderebene geben der Beschluß des Bayerischen Ministerrats v. 3. 4. 1973 (Bay. Bericht, [N 4], S. 37 f.) und die Antwort des Ministerpräsidenten von Rheinland-Pfalz v. 27. 4. 1973 auf die Große Anfrage der CDU-Landtagsfraktion zur "Situation der ausländischen Arbeitnehmer in Rheinland-Pfalz" Landtags-Drucks. 7/1781). - Besondere Initiativen werden vor allem von einzelnen Gemeinden entwickelt; hervorgehoben seien die Städte Nürnberg, Opladen und Troisdorf. Die z. T. gründlich erarbeiteten Planungs-Unterlagen dieser Städte sind nicht veröffentlicht. 
einer wachsenden rechtspolitischen Bewegung, die auf Gleichstellung der Ausländer ausgeht, bis in die letzten Konsequenzen der Zuweisung des unbegrenzten Aufenthaltsrechts und des Wahlrechts $\left.{ }^{6}\right)$. Die Befreiung des Gastarbeiters aus seinem Heloten-Dasein ist zu den Fortschrittsprogrammen des Neuen Naturrechts geworden, das die Mittel der Verfassungsauslegung in den Dienst der Emanzipationszwecke stellt ${ }^{7}$ ). Wer sich jetzt mit der staatsrechtlichen Stellung des Ausländers befaßt, findet wie in allen Rechtsbereichen, die vom Neuen Naturrecht bewegt worden sind, tabula rasa vor: Die Selbstverständlichkeiten des herkömmlichen Rechtsverständnisses sind abgeräumt.

\section{Die Verfassungsfrage der Gleichheit}

Die Frage nach dem verfassungsrechtlichen Status des Ausländers nötigt eigentlich (wie Max von Seydel es für das Staatsangehörigkeitsrecht, die Korrespondenzmaterie des Ausländerrechts, gesagt hat) „zu einer Rundreise durch das gesammte Be-

7) Als Beispiele gesetzespolitischer Programme, die auf volle oder weitgehende Gleichstellung des Ausländers mit dem Deutschen ausgerichtet sind, seien genannt: Franz-Heldmann-Kasprzyk-MajerPätzoldt, „Alternativentwurf 1970 zum Ausländergesetz 1965“ Petition der Humanistischen Union an den Bundestag v. März 1970 - (zit. Alternativentwurf AuslG 1970) in: Studentische Politik 1970, 5-25 (dazu: Franz, ebd. S. 27-32; ders., ZRP 1970, 229-237; ders., JIR 15 [1971], 319-334); Stadt München (N 4), S. 59; Geiselberger (N 4), S. 193-209; Klee (N 4), S. 25-35.

Das Gleichstellungs-Ziel leitet mehr oder weniger deutlich auch die - oft schrille - Kritik am geltenden Ausländerrecht und seiner Vollzugspraxis. Eine Auswahl heterogener Stellungnahmen: Franz, JIR 15 (1971), 319-334; ders., in: Klee (N 4), S. 36-57; ders., DVBl. 1973, 662-675; Diemut Majer, ZRP 1969, 125-128; dies., Anm. zu OVG Lüneburg, NJW 1970, 1515-1517; dies., Das Standesamt 1971, 38-44; Pätzoldt, in: Studentische Politik 1970, 83-88; Riege und Tietz, in: Staat und Recht, 1966, 988-1001; Schuster, Blätter für deutsche und internationale Politik 1972, 1140-1144; Rittstieg, NJW 1972, 2153-2163; ders., JZ 1971, 113-118; Rolvering, Die Rechtsgarantien für eine politische Betätigung von Ausländern in der Bundesrepublik Deutschland, Diss. Tübingen 1970; Zuleeg, DOV 1973, 361-370. - Auf derselben Linie: Asta-Auslandsreferat Universität Stuttgart u. a., Dokumentation zum Ausländerrecht 1972.

Beispiele der Antikritik und der Verteidigung des ausländerrechtlichen status quo: Kanein, NJW 1973, 729-735; Rose JZ 1971, 721-725; Wirtz ZRP 1970, 247-250.

7) $\mathrm{Zu}$ analogen Ausprägungen der emanzipatorischen Verfassungsauslegung, die sich an verfassungstranszendenten Fortschrittszielen ausrichtet und den Unterschied zwischen Rechtsdogmatik und Rechtspolitik aufhebt, für den Bereich des Beamtenrechts: Isensee, Beamtenstreik, 1971, S. $177 \mathrm{f}$. 
reich des Staatsrechts“8). Statt dieses aufwendigen Unternehmens soll hier nur der Versuch einer ersten verfassungsdogmatischen Orientierung gewagt werden - bei Konzentration auf systematische Hauptlinien und markante Punkte, unter Beschränkung auf eine teleskopische Rechtsbetrachtung auch dort, wo die Schwierigkeiten der Materie an sich eine mikroskopische verlangen. Die Zeitökonomie gebietet die Reduzierung des Themas auf den Regeltypus des ausländischen Individuums unter Verzicht auf die Sondertatbestände des nationalen und internationalen Rechts ${ }^{9}$ ), insbesondere des Europarechts ${ }^{10}$ ).

Die Komplexität der Verfassungsfragen des Ausländers läßt sich auf eine einzige Frage zurückführen: die Verfassungsfrage der Gleichheit. Während das Völkerrecht in der Vielzahl der Staatsordnungen mit unterschiedlichem Individualrechtsniveau dem Fremden einen weltweit gleichen Mindeststandard ge-

9) Zitat: von Seydel (N 1), S. 294 (s. auch die ähnlichen Feststellungen zum Fremdenrecht, ebd. S. 342). Im gleichen Sinne: Georg Jellinek, System der subjektiven öffentlichen Rechte, $1905^{2}$ (2. Nachdr. 1963), S. 117 f. Eine Enzyklopädie des ausländerrechtlichen Stoffs aus den verschiedenen Rechtsgebieten: Schiedermair, Handbuch des Ausländerrechts der Bundesrepublik Deutschland, 1968.

D) Das Grundgesetz regelt im negativ abgegrenzten Kreis der Nichtdeutschen expressis verbis nur den Sonderfall des Asylberechtigten (Art. 16 II 2). Das Verfassungsrecht ist insoweit undifferenziert - verglichen mit dem völkerrechtlichen Fremdenrecht, das eine reiche Typologie der Sonderstatus entwickelt hat. (S. etwa die Ubersicht über die "privilegierten Fremden" des Friedensrechts: Berber, Lehrbuch des Völkerrechts I, 1960, S. 401-405. Zusammenstellung der Status-Differenzierungen des internationalen und nationalen Fremdenrechts - mit Rechtsquellen -: Schiedermair, N 8, S. 14-19, 288-290, 625-741). Soweit die Sonderstatus aus ,allgemeinen Regeln des Völkerrechtes" folgen, werden sie über "Art. 25 GG von Verfassungs wegen rezipiert. Im übrigen hält sich das Grundgesetz in seinen Integrations- und Vertragsschluß-Ermächtigungen (Art. 24, 32, 59) unterschiedlichen internationalrechtlichen Lösungen offen. Die mangelnde Differenziertheit des Verfassungstextes ermöglicht gerade differenzierende Lösungen durch völkerrechtlichen Vertrag und durch Gesetz.

19) Grundsattzlich verbleiben außerhalb des Blickfeldes der Untersuchung

— das Sonderrecht des europäischen „Marktbürgers" (dazu mit Nachw. Ipsen, Europäisches Gemeinschaftsrecht, 1972, S. 715770; Grabitz, Europäisches Bürgerrecht zwischen Marktbürgerschaft und Staatsbürgerschaft, 1970, S. 65-116; Materialien: Erdmann, Europäisches Fremdenrecht, 1969);

- der Sonderstatus des Asylberechtigten und des Staatenlosen (dazu mit Bibliographie Kimminich, in: Bonner Kommentar zit. BK - Zweitbearb. 1964, Art. 16/Rn. 92-202);

- die Rechtslage der ausländischen juristischen Personen (dazu mit Nachw.: Walther Wieland Schmidt, Grundrechte und Nationalität juristischer Personen, 1966; Meessen JZ 1970, 602-605). 
währleistet ${ }^{11}$ ), stellt sich in der hochentwickelten Grundrechtlichkeit der deutschen Verfassung nur das Problem, wieweit sie Gleichstellung des Ausländers mit dem Deutschen gebietet, zuläßt oder ausschließt.

Der Deutschenstatus als Vergleichstatbestand ist allerdings selbst verfassungsrechtlich mehrdeutig. Die Identitätsnot der geteilten Nation führt zur Ausbildung unterschiedlicher, wenngleich konzentrischer Rechtskreise: der Deutschen i. S. des Art. 116 GG, der deutschen Staatsangehörigen und der Träger der aktuellen Bürgerrechte der Bundesrepublik Deutschland ${ }^{\mathbf{1 2}}$ ). Die intern-deutschlandrechtlichen Statusunterschiede dürfen vernachlässigt werden, weil es um die externe Stellung dessen geht, der auch dem weitesten der drei Rechtskreise nicht angehört $\left.{ }^{13}\right)$.

\section{B. Der verfassungsdogmatische Horizont}

\section{Das Modell des Rechts-Dreiecks}

Die verfassungsdogmatischen t'berlegungen müssen von der apriorischen Besonderheit des Ausländerstatus ausgehen, die jeder möglichen Regelung des Verfassunggebers vorausliegt. Der Status des Ausländers ${ }^{14}$ ) fügt sich nicht in das konventio-

11) Zum Stand der völkerrechtlichen Lehre vom internationalen Minimumstandard und ihrem Verhältnis zur Theorie der Inländerbehandlung - mit Nachw.: Guggenheim, in: Friedenswarte 1949, 177-190; Berber (N 9), S. 380-383; Doehring, Die allgemeinen Regeln des völkerrechtlichen Fremdenrechts und das deutsche Verfassungsrecht, 1963, S. 68-109; Schindler, Gleichberechtigung von Individuen als Problem des Völkerrechts, 1957, S. 28-54.

12) $\mathrm{Zu}$ den deutschlandrechtlichen Statusfragen s. die Grundsatzentscheidung des BVerfG im "Grundvertrags-Urteil" v. 31. 7. 1973, JZ 1973, 588 (593). - Z Zu der materiell bestehenden, nicht aber formell institutionalisierten Staatsbürgerschaft der Bundesrepublik Deutschland s. Böckenförde, Festgabe für Carl Schmitt, 1968, S. 423463; Meesen JZ 1973, 673-679.

19) Die Abgrenzung des Themas deckt sich mit der Legaldefinition von \$ 1 II AuslG: „Ausländer ist jeder, der nicht Deutscher im Sinne des Artikels 116 Abs. 1 des Grundgesetzes ist". - Zu dem schwankenden Gebrauch der Begriffe „Fremder" und "Ausländer" im Staats- und im Völkerrecht: Doehring (N 11), S. 19-22.

14) Am Begriff "Status" des Ausländers braucht sich nicht eine ähnlich überflüssige Kontroverse zu entzünden, wie sie herkömmlich das Staatsangehörigkeitsrecht bewegt: ob nämlich die Staatsangehörigkeit eine Rechtsbeziehung oder eine Eigenschaft (Status) sei (Nachw. bei Makarov, Allgemeine Lehren des Staatsangehörigkeitsrechts, 1962 , S. 21-28). Die Unterscheidung hat weder praktische Bedeutung noch wissenschaftlichen Erkenntniswert. Es handelt sich lediglich um zwei unterschiedliche dogmatische Perspektiven - bezogen auf denselben Rechtsgegenstand. 
nelle Modell zweiseitiger Rechtsbeziehungen zwischen Individuum und Staat $\left.{ }^{15}\right)$. Der Ausländer ist zwei öffentlichen Gewalten zugeordnet - der des Aufenthaltsstaates, unter dessen Gebietshoheit, und der des Heimatstaates, unter dessen Personalhoheit er steht ${ }^{16}$ ). Die staatsrechtliche Stellung des Ausländers läßt sich nur mit einem dreiseitigen Modell erfassen, das die (staatsrechtlichen) Bindungen des Individuums an zwei Herrschaftssysteme und die (völkerrechtliche) Beziehung der konkurrierenden Herrschaftsordnungen zueinander als Zusammenhang erkennen läßt.

Inländisches Staatsrecht, ausländisches Staatsrecht und Völkerrecht bilden ein System der Wechselwirkungen ${ }^{17}$ ). In diesem

15) Die neueren Versuche, die Gleichstellung des Fremden mit dem Deutschen für einen bestimmten Lebensbereich verfassungsrechtlich zu begründen, bewegen sich zumeist innerhalb des zwelseitigen Status-Modells, ohne daß dieses Modell des näheren hinterfragt oder gar dogmatisch gerechtfertigt würde. Das gilt etwa für: Dolde, Die politischen Rechte des Ausländers in der Bundesrepublik, 1972; Zuleeg DOV 1973, 361-370.

10) Auf die Zuordnung des Ausländers zu zwei Staaten weisen hin: Tomuschat, Zur politischen Betätigung des Ausländers in der Bundesrepublik Deutschland, 1968, S. 60; Bordewin, Das Aufenthaltsrecht der Ausländer, Diss. Köln 1962, S. 83; von der Heydte, Art. "Ausländer", in: Staatslexikon I, 1957', Sp. 696; Milke, Rechtsprobleme der ausländischen Arbeitnehmer in der Bundesrepublik Deutschland, Diss. Würzburg 1966, S. 18, 21.

Im gleichen Sinn die Amtl. Begründung des Regierungsentwurfs zum AuslG (BT-Drucks. IV/868, S. 9).

17) Der Zusammenhang der staatsrechtlichen Beziehungen mit den völkerrechtlichen wird spürbar, wenn der Aufenthaltsstaat zu Vergeltungsmaßnahmen greift (vgl.: $\$ 31$ EGBGB und $\$ 25$ I 2 AusiG. - Grundsätzlich zu Repressalie und Retorsion: Tomuschat ZaöRV 33 [1973], 179-221). Das gleiche gilt, wenn dem Ausländer bestimmte Rechte nur unter dem Vorbehalt der Gegenseitigkeit eingeräumt werden (dazu u. N 70).

Die auswärtigen Belange der Bundesrepublik werden dem ausländischen Individuum gegenüber in mehrfachen Bezlehungen zur Geltung gebracht. So dürfen nach § 9 I RuStG erhebliche Belange der „zwischenstaatlichen Beziehungen" nicht der Ehegatten-Einbürgerung entgegenstehen (zur Intervention des Heimatstaates gegen eine Einbürgerung: OVG Berlin, U. v. 2. 8. 1967, JZ 1967, 751 [753]; dazu kritische Anm. Wengler ebd. S. 754). Zur gebotenen Rücksicht auf die Personalhoheit des anderen Staates bei der Ertellung eines Fremdenpasses nach § 4 I AuslG: BVerwG, U. v. 3. 5. 1973, DOV 1973, 862 f. VGH Bad.-Württ., U. v. 7. 8. 1972, DOV 1973, 4161. - Zu den "Belangen der Bundesrepublik", von denen nach dem AuslG die Aufenthaltserlaubnis ( $\$ 2 \mathrm{I}$ ), die Ausweisungsmöglichkeit (\$ 10 I 11) und die zulässige politische Betätigung (8 6 II) abhängen, gehören auch die auswärtigen Beziehungen der Bundesrepublik zum Heimatstaat: s. etwa VGH Mannheim, U. v. 14. 7. 1969, DOV 1970, 95 (96); Kanein, Ausländergesetz, 1966, S. 76, 84, 124 und passim; 
Rechts-Dreieck waltet weder prästabilierte Harmonie noch schicksalhafter Interessengegensatz. Jeder der drei Beteiligten ist möglicher Verbündeter und möglicher Widersacher des anderen. So kann der Heimatstaat, der den diplomatischen Schutz seiner Bürger wahrnimmt, sowohl auf Liberalisierung als auch auf Disziplinierung durch den Aufenthaltsstaat drängen - je nachdem, ob er ihre Freiheit fördert oder fürchtet.

Ein Aufenthaltsstaat, der diese doppelte Zuordnung des Ausländers ignorieren und ihn schematisch gleichbehandeln wollte, schüfe die Möglichkeit von Mehrfachbegünstigungen, Doppelbelastungen und Pflichtenkollisionen. Falls der Staat des Grundgesetzes dem Ausländer Rechtsgleichheit einräumen muß (quod erit demonstrandum), so ist er bereits aufgrund dieses inneren Staatszieles zu differenzierender völkerrechtlicher $\mathrm{Ab}$ stimmung mit dem Heimatstaat verpflichtet. Um der Lastengleichheit willen ist er zum Abschluß von Doppelbesteuerungsabkommen und um der gleichen sozialen Sicherung willen zum Abschluß von Sozialversicherungsverträgen gehalten.

Das Grundgesetz trägt dieser doppelten Zuordnung des Ausländers Rechnung:

- Es öffnet sich dem Völkerrecht und entsagt damit nationaler Rechtsautarkie ${ }^{18}$ ).

- Es bekennt sich zu der Idee universaler Menschenrechte ${ }^{10}$ ).

Kloesel-Christ, Deutsches Ausländerrecht, Stand 1972, AuslG § 6/2; Tomuschat (N 16), S. 49; Dolde (N 15), S. 182 mit weit. Nachw.; vgl. auch Bordewin (N 16), S. 83. - Nach der Amtlichen Begründung zum AuslG ist die Regelung des Aufenthalts der Ausländer im Bundesgebiet "ein Spiegelbild der politischen Beziehungen der Bundesrepublik Deutschland zu anderen Staaten und zur Völkergemeinschaft" (N 16, S. 10). -

Ohne spezifisch fremdenrechtlichen Bezug genießen die auswärtigen Beziehungen der Bundesrepublik explicite gesetzlichen Schutz gegen Störungen durch Individuen: in \$§ 7 I 2, 8 II AWG und \$6 II 1 AusführungsG zu Art. 26 II GG (KriegswaffenG). Dazu Bayer DOV 1968, 717; Häberle, Offentliches Interesse als Juristisches Problem, 1970, S. 152 Anm. 258.

18) Der Verfassungsgrundsatz der „Völkerrechtsfreundlichkeit" kommt etwa zum Ausdruck in: der Präambel (S. 1: „... als gleichberechtigtes Glied in einem vereinten Europa dem Frieden der Welt zu dienen"), Art. 1 II (Menschenrechte "als Grundlage jeder menschlichen Gemeinschaft, des Friedens und der Gerechtigkeit in der Welt"), Art. 9 II (,Völkerverständigung"), Art. 24-26, 32, 59 GG.

Zur „Völkerrechtsfreundlichkeit" des Grundgesetzes: BVerfGE 6, 309 (362); 18, 112 (121); 31, 58 (75 f.); Doehring (N 11), S. 122-125 (Nachw.).

19) Das Bekenntnis zur Menschenrechtsidee (Art. 1 II GG) verbindet sich mit dem Prinzip der Völkerrechtsfreundlichkeit zur Ver- 
- Es sieht von einer pauschalen Gleichstellung des Fremden mit dem Deutschen ab. Wo die Verfassung den Ausländer von bestimmten Grundrechtsverbürgungen ausnimmt, läßt sie erkennen, daß sie nicht die ausschließliche und umfassende Verantwortung für seine Freiheitsverwirklichung übernehmen will. Das Grundgesetz hält sich hier differenzierenden Lösungen offen ${ }^{20}$ ).

\section{Die unentrinnbare Staats-Abhängigkeit als Status-Kriterium}

Ein Status-Vergleich, der auf den Rechtfertigungszusammenhang der Einzelregelungen abstellt und sich am regelungsmotivierenden typischen Fallmaterial ausrichtet ${ }^{21}$ ), stößt auf Unterschiede zwischen der Stellung des Staatsangehörigen und

fassungsmaxime der Weltoffenheit und zur Absage zu nationalstaatlicher Abkapselung. Gleichwohl ist das Verhältnis der Verfassungsgrundsätze der Menschenrechtsbindung und der Völkerrechtsfreundlichkeit dialektisch:

- Das völkerrechtsfreundliche Prinzip steht im Dienst des menschenrechtlichen, soweit das Völkerrecht den Schutz der Individuen übernommen hat (dazu Friesenhahn, Art. „Menschenrechte", in: Strupp-Schlochauer, Wörterbuch des Völkerrechts II zit. WbVR - 1962' ${ }^{2}$ S. 503-511; Berber [N 9], S. 373-375; Doehring [N 11], S. 70_85, 120; Verdro $\beta$, Völkerrecht 19645, S. 363 f.).

- Das völkerrechtsfreundliche Prinzip relativiert aber auch das menschenrechtliche, soweit das Völkerrecht auf den Schutz der souveränen Staaten angelegt ist. Das völkerrechtsfreundliche Prinzip muß sich daher nicht durchgehend zu Gunsten des ausländischen Individuums auswirken. Ein aufschluBreiches Beispiel dafür, daß der Respekt vor einer fremden Staatsordnung Rechtseingriffe legitimieren kann, bildet der Fall der Auslieferung elnes Ausländers wegen eines Verbrechens, das im ersuchenden Staat mit der Todesstrafe geahndet werden kann (BVerfGE 18, 112-121, dazu Geck JuS 1965, 221-232).

20) Dazu näher u. D III.

21) Die typologische Methodenlehre zeigt, daß jeder Norm ein Anschauungsbild des Normalfalles zugrundeliegt und daß die Normauslegung sich an diesem zu orientieren hat (dazu Arthur Kaufmann, Analogie und "Natur der Sache", 1965, S. 35-42; Hassemer, Tatbestand und Typus, 1968, S. 109-149). Diese normalfall-bezogene Auslegung ist in gesteigertem Maße geboten, wenn eine normativ typisierte Rolle wie die des Staatsangehörigen und des Fremden zu erfassen ist. Diese läßt sich daher auch nicht vom atypischen Fall her begreifen und ad absurdum führen, wie es in der Statusdiskussion oft versucht wird. So kritisiert von Frisch den AusschluB des Fremden vom Wahlrecht damit, daß Fremde, die Jahrzehnte lang im Staate leben, oft viel mehr Interesse und Verständnis für die Bedürfnisse des Landes hätten als die "Masse der politisch indifferenten Eingeborenen" (N 1, S. 353). Auf vergleichbarer Linie: Rolvering (N 6), S. 95-104; Dolde (N 15), S. 75-78; Marqués in: Klee (N 4), S. 175-183. 
des Staatsfremden, die von der Verfassung nicht geschaffen, sondern vorgefunden worden $\sin ^{22}$ ):

- Die Beziehung des Ausländers zum Aufenthaltsstaat ist nicht wie die des Staatsangehörigen auf Lebenszeit angelegt ${ }^{23}$ ). Dem Fremden kommt lediglich ein status temporarius $\mathrm{zu}^{\mathbf{2 4}}$ ).

- Der Ausländer ist nicht unentrinnbar auf den Aufenthaltsstaat angewiesen ${ }^{25}$ ). Er kann die bestehende Bindung lösen, wenn er es für angebracht hält. Er darf jederzeit in seinen Heimatstaat zurückkehren ${ }^{26}$ ).

Die Verfassung der Bundesrepublik vermag dieses Ausländerprivileg nicht dadurch aufzuwiegen, daß sie dem Staats-

22) Das Grundgesetz setzt die Institution der Staatsangehörigkeit (wie, mutatis mutandis, die Fremden-Qualität) als gegeben voraus, wenn es unmittelbar auf sie verweist (Art. $16 \mathrm{I}, 73 / 2,74 / 8,116$ ) oder wenn es mittelbar an sie anknüpft (Art. 19 III — „inländische“ juristische Personen -; Art. 20 II — „Volk“). Die Staatsangehörigkeit wird verfassungsrechtlich akzeptiert als Einrichtung, die dem heutigen Stand der Staatenentwicklung entspricht, in der Gestalt, die sie im gegenwärtigen Völkerrecht und im vorkonstitutionellen deutschen Gesetzesrecht, insbesondere im RuStG, gefunden hat. Das schließt nicht aus, daß sich die Verfassung völkerrechtlichen Entwicklungen und staatsrechtlichen Fortbildungen offen hält. Diese Offenheit wird im Rezeptionsblankett des Art. 25 GG wie in den Kompetenznormen der Art. 73/2 und Art. 74/8 GG deutlich.

23) Zur Beständigkeit der Staatsangehörigkeits-Beziehung: Grawert, Staat und Staatsangehörigkeit, 1973, S. 232-235.

24) Mit der Ausprägung der neuzeitlichen Vorstellung von der Gebietshoheit im 17. Jahrhundert wird der Fremde als „subditus temporarius" angesehen (dazu Jordan, N 1, S. 306 f.; Grawert, $\mathbf{N} 23$, S. 120 f.). Georg Jellinek sieht im Fremden zudem den "civis temporarius" wegen der Ansprüche, die ihm kraft seines status positivus gegen den Aufenthaltsstaat zukommen (N 8, S. 116 f.).

${ }^{25}$ ) Die Unentrinnbarkeit gilt auch für den deutschen Staatsangehörigen, der im Ausland lebt. Sie manifestiert sich in der PaBhoheit, der er unterworfen bleibt, wie im diplomatischen Schutz, auf den er angewiesen Ist. Gerade die Fälle des Staatsangehörigen im Ausland wie des Staatsfremden im Inland zeigen, daß die Lehre von der Ausschließlichkeit der Staatsangehörigkeit nur bedingten $\mathbf{A b}-$ grenzungswert hat. Denn die Lehre von der „Einzigkeit der Untertanschaft im Verhältnis zu anderen Staaten" (Herbert Krüger, Allgemeine Staatslehre, 1966², S. 954-958; s. auch schon Zachariae, 40 Bücher vom Staate, 1841, S. 267-271) vermag die zwiefache Staatszuordnung des Fremdenrechts nicht zu erfassen. - Zum Merkmal der „AusschlieBlichkeit" kritisch: Grawert (N 23), S. 235244.

20) Die Ausreisefreiheit des Fremden ist völkerrechtlich anerkannt - vgl. Berber (N 9), S. 384; Hartmann, JOR i. F. 17 (1968), 463; Schnitzer, Art. "Fremdenrecht", in: WbVR I, 1960 (N 19), S. 568. Sie genießt über Art. 25 GG Verfassungsschutz und über \& 19 AuslG gesetzliche Anerkennung. 
angehörigen die freie Ausreise im Rahmen der Allgemeinen Handlungsfreiheit grundrechtlich gewährleistet ${ }^{27}$ ). Denn das Grundgesetz vermag dem ausreisewilligen Deutschen keinen Aufnahmeanspruch gegenüber einem fremden Staat sicherzustellen.

\section{Die aufenthaltsrechtlichen Status-Bedingungen}

\section{Die Vorfrage des Verfassungs-Kollisionsrechts}

Da den Ausländer kein dauerhaftes, personales Band mit dem Staat des Grundgesetzes verbindet, muß ein territorialer Anknüpfungspunkt gegeben sein, damit eine staatsrechtliche $\mathrm{Be}-$ ziehung entstehen kann. Welche Inlandsberührungen in Betracht kommen, ist eine kollisionsrechtliche Vorfrage.

Hier wird eine (bisher selten erkannte) Zukunftsaufgabe der Verfassungsdogmatik sichtbar: ein Verfassungskollisionsrecht zu entwickeln, das vor allem die Grenznormen der Grundrechte aufzuweisen hat ${ }^{28}$ ). Das Kollisionsrecht ist vom Völkerrecht nicht schon vorgegeben $\left.{ }^{29}\right)$. Es kann auch vom einfachen Gesetzesrecht nicht nachgeholt werden ${ }^{30}$ ). Die Grenznormen der Verfassung sind aus ihren Sachnormen zu erschließen ${ }^{31}$ )

27) Als grundrechtlicher Standort der Ausreisefreiheit für Staatsangehörige wird Art. 2 I GG anerkannt von: BVerfGE 6, 32 (3442); Merten, Der Inhalt des Freizügigkeitsrechts, 1970, S. 106-116 (Nachw.). Dagegen wird die Ausreisefreiheit dem Schutzbereich des Art. 11 GG zugeordnet von Scheuner, in: Festschrift für Thoma, 1950, S. 222 f.; Dürig, in: Maunz-Dürig-Herzog, Grundgesetz, Stand $1971^{2}$ (zit. M-D-H), Art. 11/Rn 104-106.

28) Die rechtswissenschaftliche Aufgabe wird klar gesehen von BVerfGE 31, 58 (77). Ahnlich: Wengler JZ 1965, 101 f.; Jochem, Das Erbrecht des nichtehelichen Kindes nach deutschem Recht bei Sachverhalten mit Auslandsberührung, Diss. Saarbrücken 1971, S. 155162; Sturm FamRZ 1972, 20. - Zu Unterschied wie Zusammenhang der kollisionsrechtlichen und der materiellrechtlichen Seiten des deutschen Fremdenrechts: Isay, Das deutsche Fremdenrecht, 1923, S. 4-19, 36-115; Friedrichsen (N 1), S. 15 t.

29) Zum vergleichbaren Problem des Verhältnisses des Internationalen Privatrechts zum Völkerrecht: s. Kegel, Internationales Privatrecht, $1971^{3}$, S. 4-B. Vgl. auch Wengler, Völkerrecht II, 1964, S. 933-949; Bauer, Das Internationale Privatrecht im Rechtssystem, Diss. Erlangen 1967, S. 277-510.

so) Die Erkenntnis, daß die Normen des Internationalen Privatrechts die Reichweite der Grundrechte nicht abstecken, sie vielmehr ihrerseits an die Grundrechte gebunden sind, hat sich mit der Entscheidung BVerfGE 31, 58 (73 f.) durchgesetzt. Im gleichen Sinne: Wengler JZ 1964, 623; ders., JZ 1965, 101-103; Sturm FamRZ 1972, $16-20$.

s1) Das BVerfG entwickelt das Programm einer "aus der Verfassung selbst zu entwickelnden Bestimmung der Reichweite der Grundrechte"; dabei sei „jeweils durch Auslegung der entsprechen- 
(eine Aufgabe, die durch den emphatischen Charakter der meisten Verfassungsbestimmungen und ihre unterentwickelte Rechtstechnizität erschwert wird). Ein System des Verfassungskollisionsrechts läßt sich nur durch differenzierende Analyse der einzelnen Verfassungsregelungen gewinnen ${ }^{32}$ ). - Dieses anspruchsvolle Vorhaben kann nicht in diesem Rahmen in Angriff genommen werden. Die Status-tberlegungen müssen sich auf eine grobe Abgrenzung im praktisch bedeutsamsten Problemkreis beschränken, wenn sie nicht schon in ihrem aporienreichen Vorfeld steckenbleiben wollen.

II. Status-Begründung durch Gebietskontakt - Die Zulassung des Aufenthalts

1. Der Ausländer kann in bestimmte verfassungsrechtliche Beziehungen eintreten, ohne in das Bundesgebiet einzureisen. So erlangt er, wenn er ein Grundstück im Inland erwirbt, den Schutz des Eigentumgrundrechts; uno actu rückt er auch in die korrespondierende Pflichtenstellung des Eigentümers ein $\left.{ }^{33}\right)$. Es entsteht allerdings nur ein rollenspezifischer, sachbegrenzter, partieller Verfassungsstatus $\left.{ }^{34}\right)$. - Der umfassende Status setzt

den Verfassungsnorm festzustellen, ob sie nach Wortlaut, Sinn und Zweck für jede denkbare Anwendung hoheitlicher Gewalt innerhalb der Bundesrepublik gelten will oder ob sie bei Sachverhalten mit mehr oder weniger intensiver Auslandsbeziehung eine Differenzierung zuläßt oder verlangt“ (E 31, 58 [77] — im Anschluß an Wengler JZ 1965, 101 f.). Im gleichen Sinne: Sturm FamRZ 1972, 20.

a2) Beisp. einer verfassungskollisionsrechtlichen Studie: Walther W. Schmidt (N 10), S. 56-176.

3s) Die vormärzliche Staatsrechtslehre sprach in solchen Fällen von einer "dinglichen Untertänigkeit" - dazu: Zachariae (N 25), S. 271, 273; Jordan (N 1), S. 308. - Zur Geltung von Grundrechten (Gewerbefreiheit, Eigentum, Briefgeheimnis) für gebietsfremde Ausländer: Isay (N 28), S. 88; vgl. auch S. 65-81 (zur Anwendbarkeit des Polizeirechts auf Ausländer im Ausland).

34) Die partiellen Verfassungsbeziehungen, die in der vorliegenden Darstellung vernachlässigt werden müssen, erschließen sich in ihren Besonderheiten nur einer norm-differenzierenden Untersuchung. Gleichwohl gilt die unten im Text entwickelte Zwei-PhasenUnterscheidung zwischen grundrechtsfreier Gebietszulassung und grundrechtlichem Status - mutatis mutandis - auch für partielle Gebietskontakte. Wenn ein gebietsfremder Ausländer ein Grundstück im Inland erworben hat, so hat er auch eine partielle, sachbezogene Grundrechtsposition gewonnen. Er hat jedoch keinen grundrechtlich gesicherten Anspruch darauf, daß er ein inländisches Grundstück erwerben darf. Wird das Veräußerungsgeschäft von Staats wegen unterbunden, gemäß $\S 23$ I 1 AWG oder gemäß einer landesrechtlichen Regelung, die Art. 88 EGBGB fortgelten läßt, so scheitert das Zulassungsbegehren, das sich auf keinen grundrechtlichen Titel stützen kann. Abweisung ist kein Grundrechtseingriff. Ein solcher könnte allerdings den gebietszugehörigen Veräußerer 
dagegen den Aufenthalt im Bundesgebiet voraus. Der Schritt über die Grenze muß noch nicht einmal rechtmäßig erfolgen. Auch der illegale Grenzgänger, der sogleich in Abschiebehaft genommen wird, gelangt in den unverkürzten Schutz der Habeas-Corpus-Grundrechte.

Der Aufenthalt ist die wesentliche Entstehungsvoraussetzung der meisten Ausländergrundrechte ${ }^{35}$ ). Aber er ist selber nicht grundrechtlich gewährleistet. Ein unbeschränkter Anspruch auf Einreise und Aufenthalt steht allein dem Deutschen zu - als ungeschriebenes Grundrecht, das sich von selbst versteht, in einem Gemeinwesen, das in einer Epoche der Vertreibung und Flucht als Refugium der Deutschen erstanden ist Das Deutschenrecht der Freizügigkeit setzt das Aufenthaltsgrundrecht voraus, erfaßt es aber nicht und unterwirft es nicht seinem sicherheitsrechtlichen Beschränkungsvorbehalt. Die Unbeschränkbarkeit des Aufenthaltsrechts wird sichtbar im Auslieferungsverbot, das die am meisten gefährdete Stelle des Grundrechts ausdrücklich abschirmt und damit mittelbar seinen positiv-rechtlichen Standort erkennen läßt $\left.{ }^{36}\right)$.

2. Das Grundgesetz gibt den Ausländern nur im Rahmen des Asylrechts einen Aufnahmeanspruch. Diese grundrechtliche Offerte für Fälle extremer Menschenrechtsnot kann nicht auf alle Fremden ausgeweitet werden, die Einreise begehren - auch nicht auf jene, denen ihr Heimatland die angemessene men-

treffen. Soweit dessen Grundrechtsschutz mittelbar dem gebietsfremden Erwerber zugute kommt, empfängt er einen Grundrechtsreflex.

35) Die Regelungen des Aufenthaltsrechts der Ausländer haben daher die analoge staatsrechtliche Bedeutung wie die des Erwerbs oder Verlusts der Staatsangehörigkeit. Sie sind ihrer Rechtsqualität nach materielles Staatsrecht, auch wenn ihnen kein förmlicher Verfassungsrang zukommt.

s6) Die grundrechtliche Ortsbestimmung des Aufenthaltsrechts der Deutschen im Umkreis des Art. 16 II 1 GG, der eine Teilregelung enthält, unterscheidet sich

- von der Zuweisung zum Schutzbereich des Art. 11 GG dadurch, daß die Konsequenzen des Schrankenvorbehalts (Art. 11 II GG) nicht eintreten;

- und von der Zuweisung zur Staatsangehörigkeitsgarantie des Art. 16 I GG dadurch, daß das Aufenthaltsrecht nicht nur den deutschen Staatsangehörigen, sondern allen Deutschen im Sinne des Art. 116 GG zukommt.

Begründung der heute herrschenden Gegenmeinung - Ortung bei Art. 11 GG - mit Nachw.: Merten (N 27), S. 87-105 (S. 94-96: Ablehnung einer Analogie zu Art. 11 II GG; S. 96-101: Ablehnung der Deduktion aus der Staatsangehörigkeit; S. 103-105: Ubernahme. des Schrankenvorbehalts aus Art. 11 II GG). 
schenrechtliche Entfaltung verwehrt ${ }^{37}$ ). Der gebietsfremde Ausländer befindet sich noch nicht im grundrechtlichen Verantwortungsbereich der Bundesrepublik. Die grundgesetzliche Garantenpflicht ist nicht weltumspannend; sie kann es schon deshalb nicht sein, weil eine universale Grundrechtslast die realen Kräfte Deutschlands unendlich übersteigen müßte. Die territoriale Begrenzung des Grundrechtsschutzes ist ebenso Gebot staatlicher Selbstbehauptung wie staatlicher Selbstbescheidung. Der Staat des Grundgesetzes hütet sich, grundsätzlich jedenfalls, fremde Rechtsordnungen an der deutschen Verfassungselle zu messen und sich als Folge eines gutgemeinten Grundrechts-Paternalismus am Ende den Vorwurf eines teutonischen Grundrechts-Imperialismus zuzuziehen ${ }^{88}$ ). Wer aus den Grund-

37) Das Grundgesetz hat die staatsrechtliche Materie des Aufenthaltsrechts für Ausländer nicht geregelt, sondern sie dem Gesetzgeber zur Regelung zugewiesen (Art. 74/4 GG: „das Aufenthaltsund Niederlassungsrecht der Ausländer"; Art. 73/3 GG: „Einwanderung").

Ein verfassungsrechtlicher Anspruch auf Einreise und Aufenthalt für Nichtdeutsche - außerhalb des Asylrechts - wird abgelehnt von: $B$ VerwGE 3, 235 f.; VGH Stuttgart VerwRspr. 8 (1956), 355 (357 f.); OVG Berlin, B. v. 15. 4. 1969, in: Schüler/Wirtz, Rechtsprechung zum Ausländerrecht, 1971, AuslG \& 2 Nr. 5; Amtl. Begründung zum AuslG (N 16), S. 10, 12; Bordewin (N 16, S. 35 - gute Begründung des argumentum a contrario zu Art. 16 II 2 GG); Doehring, ZaöRV 25 (1965), 486; Kanein (N 17), S. 29-31, 40 f.; Rose JZ 1971, 721 f.; Schiedermair (N 8), S. 36 f.; Schnapp DOV 1973, 594; Weißmann, Ausländergesetz, 1966, S. 40 f. Ahnlich die Rechtsauffassung der Weimarer Zeit: Heinze, Die Grundrechte der Ausländer nach der deutschen Reichsverfassung v. 11. 8. 1919, Diss. Marburg 1929, S. 27 f.; Voigt, Gesetzliche Schranken für Ausländer bei der Einwanderung in Deutschland, Diss. Gießen 1932, S. 10, $54 \mathrm{f}$.

Ein Ausländergrundrecht auf Einreise und Aufenthalt über den Fall des "politisch Verfolgten" (Art. 16 II 2 GG) hinaus postulieren: Dïrig, in: GR II, 1954, S. 522 f.; ders. in M-D-H Art. 11/Rn 116, 119; Franz DVBl. 1963, 799; Zuleeg DOV 1973, 366. S. auch BVerfGE 9, 174 (180 - für extensive Auslegung der Asylvoraussetzungen).

s8) Die Versuchung, heute am deutschen Grundrechtswesen die Welt genesen zu lassen, wird vom BVerfG abgewiesen. Es spricht der deutschen Rechtsordnung die Legitimation ab, die grundgesetzliche Entscheidung gegen die Todesstrafe unbedingt durchzusetzen, damit eine rechtsstaatlich-sittliche Superiorität in Anspruch zu nehmen und fremde Rechtsordnungen zu diskriminieren $(E 18,112$ [117 f.]). Das BVerfG weist den „Oktroi deutscher Wertvorstellungen gegenüber dem Ausland" und die generelle grundrechtliche Zensur fremder Regelungen von sich (E 31, 58 [74 f.]). - Ein Beispiel deutscher Rechtsüberheblichkeit liefert dagegen das LG Frankfurt, das die Auswanderung nach Israel für unzumutbar hält und die Lebensverhältnisse in Israel arrogant beurteilt (U. v. 21. 8. 1968, NJW 1969, 385 [386], mit krit. Anm. von Wirtz, NJW 1969, 21082110). 
rechten einen Anspruch auf Gebietszulassung herleiten will, kehrt die Beziehung von Grundrechtsvoraussetzung und Zulassungsfolge um: Der Ausländer wird nicht deshalb zugelassen, damit er einen grundrechtlichen Status gewinne, sondern er erhält einen grundrechtlichen Status, weil er zugelassen worden ist. So ist die Abweisung kein Grundrechtseingriff gegenüber dem Gebietsfremden ${ }^{39}$ ).

Sie kann sich allerdings als Grundrechtseingriff gegenüber einem gebietsansässigen Ausländer oder einem Deutschen auswirken, der mit dem Abgewiesenen durch eine grundrechtlich geschützte Familienbeziehung verbunden ist. Die Grundrechtsgarantie der Ehe und Familie fordert auch Sicherstellung ihrer

39) Die Abweisung greift auch nicht in die Allgemeine Handlungsfreiheit des Betroffenen ein (im Ergebnis zutreffend: BVerwGE 3, 235 [236]). Denn Art. 2 I GG übt nur dort seine Funktion als subsidiäres allgemeines Freiheitsrecht (Auffanggrundrecht) aus, wo eine Herrschaftsbeziehung zwischen der deutschen Staatsgewalt und dem ausländischen Individuum besteht. Wenn Art. 2 I GG auch in seinem gegenständlichen Schutzbereich umfassend ist, so ist es doch nicht grenzenlos in kollisionsrechtlicher Hinsicht. Die kollisionsrechtliche Dimension wird von Zuleeg völlig übersehen, wenn er dem einreisewilligen Ausländer das Grundrecht aus Art. 2 I GG zuspricht (DOV 1973, 363, 366; ähnlich: Begründung zum Alternativentwurf 1970 [N 6], S. 10 f.). Zutreffend dagegen: OVG Berlin, B. v. 15. 4. 1969, in: Schüler/Wirtz (N 37), AuslG \& 2 Nr. 5 .

Die Abweisung kann auch nicht an Art. 3 GG gemessen werden, weil dieses Grundrecht ebenfalls eine bestehende Subordinationsbezlehung voraussetzt. Der Aufenthaltsstaat darf im Verhältnis zum Gebietsfremden noch Unterscheidungen treffen, die thm gegenüber dem Gebietszugehörigen durch Art. 3 GG verwehrt sind. Wenn die Bundesrepublik mit ihren ausländerpolizeilichen Regelungen den Kreis ihrer Bevölkerung definiert, so kann sie Frauen bevorzugen, falls nur für Frauen freie Arbeitsplätze zur Verfügung stehen; sie darf auch darauf abstellen, wer von den Einreisewilligen sich nach Sprache, Heimat und Herkunft am leichtesten in die deutsche Gesellschaft einfügt.

Die rechtsstaatliche Grenze des aufenthaltspolizellichen Ermessens bildet dagegen das objektivrechtliche Willkürverbot, das die Rechtfertigung der Differenzierungen vor dem Gemeinwohl fordert und individuelle Schikane ausschließt. Dieses objektive Willkürverbot, das der Rechtsstaat um seiner selbst willen einhalten muß, ist vom Grundrecht des Art. 3 GG, das dem Individualinteresse eines Betroffenen dient, $\mathrm{zu}$ unterscheiden.

Der Ausschluß des Art. 3 III GG vom vergleichbaren Tatbestand der Einbürgerung wird begründet von Hans Schneider, Festgabe für Makarov, ZaöRV 19 (1958), 463; Doehring (N 11), S. 201 (a. A. Zuleeg DOV 1973, 365). Dagegen wird die Anwendbarkeit des Art. 3 GG bei der Entscheidung über die Gebietszulassung bejaht, mit kollisionsrechtlicher petitio principii, von: Rittstieg JZ 1971, 114; ders., NJW 1972, 2155, 2159; Begrüindung zum Alternativentwurf 1970 (N 6), S. 11. 
aufenthaltsrechtlichen Voraussetzungen. Damit erwächst allerdings dem Einreisewilligen kein selbständiger Anspruch auf Gebietszulassung. Die familienrechtliche Beziehung ist nur um des deutschen Gebiets- oder Staatsangehörigen willen zu berücksichtigen. Der Gebietsfremde empfängt einen Grundrechtsreflex ${ }^{40}$ ).

Im Verhältnis zum Gebietsfremden, ist die Entscheidung über die Gebietszulassung noch nicht grundrechtsgebundene Herrschaftsausübung, sondern grundrechtsfreie Herrschaftsbegrün-

\footnotetext{
40) Art. 6 I GG gewährt keinen materiellen Einreiseanspruch, sondern nur ein formelles subjektives Recht auf Berücksichtigung der grundrechtlich geschützten Lebensbeziehung im Rahmen der Ermessensentscheidung über die Aufenthaltserlaubnis. Die Befugnis, den Grundrechtsschutz aus Art. 6 I GG prozessual geltend zu machen, steht ausschließlich dem inländischen Familienangehörigen zu, in dessen Person der kollisionsrechtliche Anknüpfungspunkt für das deutsche Grundrecht gegeben ist. Die Abweisung (wie auch die Ausweisung) des ausländischen Ehegatten stürzt den inländischen Ehegatten in die Zwangslage, zwischen dem ehelichen Zusammenleben und dem Aufenthalt in Deutschland zu wählen. Damit kann auch nur der inländische Partner darüber befinden, ob er seine Ehe im Bundesgebiet führen und für sie den Schutz des Grundrechts beanspruchen will. Der (gebietsfremde) Ausländer partizipiert nur mittelbar an dieser Begünstigung aus Art. 6 I GG. Wenn damit die Verteidigung der aufenthaltsrechtlichen Grundlagen der Ehe und Familie dem inländischen Partner vorbehalten ist, verringert sich die Gefahr, daß eine nur nominell bestehende familiäre Beziehung lediglich als Vorwand zur Erlangung der Einreiseerlaubnis mißbraucht wird (zur Mißbrauchsgefahr: BVerwG, U. v. 3. 5. 1973, JZ 1973, 732 [733]).

Soweit Rechtsprechung und Rechtsschrifttum den inländischen Familienangehörigen überhaupt als grundrechtlich Betroffenen anerkennen (ablehnend: BayVGH, U. v. 5. 11. 1969, BayVBl. 1970, 186 f.), wird ihm allenfalls neben dem Ausländer die Berufung auf Art. 6 I GG zugesprochen, also nicht als dem eigentlichen Grundrechtsträger, sondern praktisch nur als dem Grundrechts-Sekundanten des Ausländers (so etwa bei BVerwG, U. v. 3. 5. 1973, DÖV 1973, 859; VGH Mannheim, ESVGH 21, 80-85; Rittstieg JZ 1971, 117; Schickedanz NJW 1973, 1534 Anm. 21; Tomuschat AöR 97 [1972], 141).

Der Zusammenhang der Abweisung (bzw. Ausweisung) eines ausländischen Familienangehörigen mit Art. 6 I GG wird - mit Bezug auf den Ausländer - mit unterschiedlicher Akzentuierung bejaht von: Rittstieg JZ 1971, 116 f.; dems., NJW 1972, 993 f. („abgeleitetes Aufenthaltsrecht" des fremden Partners); dems., NJW 1972, 2157 f.; Rose JZ 1971, 724 f.; Schickedanz NJW 1972, 366-371; dems., NJW 1973, 1533 f.; Stange ZRP 1971, 172-174; Tomuschat AöR 97 (1972), 140-142; Zuleeg DOV 1973, 367. Vgl, auch Walter Jellinek, in: Festschrift für Bilfinger, 1954, S. 119 (bezogen auf Art. 3 Europ. MRK). Auf gleicher Linie die (neuere) höchstrichterliche Rechtsprechung zur Ausweisung: BVerfGE 19, 394 (396-398); BVerfG, B. v. 18. 7. 1973, DVBl. 1974, 79 (83); BVerwG, U. v. 3. 5. 1973 JZ 1973, 732734; U. v. 3. 5. 1973 DƠV 1973, 859; U. v. 3. 5. 1973 DOV 1973, 862 f.
} 
dung: Kooptation eines Gebietszugehörigen - als Analogon zur Einbürgerung, der Kooptation eines Staatsangehörigen ${ }^{\mathbf{4}}$ ).

Daher fehlt auf Verfassungsebene der Ansatz für grundrechtsakzessorische Gewährleistungen wie das Ubermaßverbot und das Erfordernis gesetzlicher Eingriffsbestimmtheit ${ }^{42}$ ). Dem Ausländer erwächst auch daraus kein Zulassungsanspruch, daß die allgemeinen Regeln des Völkerrechts, die über Art. 25 GG innerstaatliche Verbindlichkeit erlangen, verbieten, die Grenzen gänzlich zu schließen ${ }^{43}$ ). Der Staat muß zwar die Grenzen

41) Silvester Jordan versucht, die Begründung der „zeitlichen Untertanschaft" mit einer quasi-staatsvertraglichen Konstruktion zu erfassen. Er sieht „eine stillschweigende Vertragung zwischen dem Fremden und dem Staate . ..., in welchem er sich befindet, indem sich jener durch die Betretung des Staatsgebietes zur Beobachtung der Gesetze des Staates verpflichtet, dieser dagegen durch die $\mathbf{Z u}-$ lassung des Fremden sich verbindlich macht, ihn wie jeden anderen Untertan zu schützen“ (N 1, S. 307). - Eine koordinationsrechtliche Deutung der Einbürgerung gibt Doehring (N 11, S. 199 f.). - Die Besonderheit der Gebietszulassung wird dagegen von vornherein verfehlt, wenn sie in den Assoziationskreis des Gnadenakts gestellt wird (Kanein, [N 17], § 2/A 2 b: „... dicht an den Rand des Gnadenakts gerückt"). Die Möglichkeit einer "Gnade" setzt den äußersten Grad von Herrschaftsunterworfenheit voraus - bei der Kooptation des Gebietszugehörigen fehlt jeglicher Ansatz dazu.

12) Der Vorbehalt des Gesetzes und das Bestimmtheitsgebot setzen bestehende Herrschaftsverhältnisse voraus und erfassen damit nicht die herrschaftsfreie Kooptations-Phase. Daher können diese verfassungsrechtlichen Postulate nicht gegen die Regelung der Gebietszulassung in \$2 I AuslG ins Feld geführt werden, obwohl hier das weite ausländerpolizeiliche Ermessen nur an einen Blankett-Tatbestand (Vereinbarkeit mit den staatlichen „Belangen“) geknüpft wird und praktisch ein Blankoscheck der Legislative an die Exekutive vorliegt (vgl. OVG Lüneburg, U. v. 17. 2. 1970, NJW 1970, 1515 [1517]). Die Grenzen des Bestimmtheitserfordernisses werden von der Kritik am AuslG verkannt - so etwa von Franz DVBl. 1963, 801; dems., ZRP 1970, 230; Rittstieg, JZ 1971, 113 f.; dems., NJW 1972, 2153 f.; Stange ZRP 1971, 173; Zuleeg DOV 1973, 366; Begrïdung zum Alternativentwurf 1970 (N 6), S. 10 f. Im Ergebnis zutreffend dagegen: Schnapp DOV 1973, $593 \mathrm{f}$.

45) Das Völkergewohnheitsrecht verbietet den Mitgliedern der Staatengemeinschaft, sich schlechthin gegen Fremde abzuriegeln (Verbot "chinesischer Mauern"), ohne daß aber den einzelnen Fremden ein "Zulassungsanspruch zugestanden würde. Zum völkerrechtlichen Gebot der Offenheit, das Francisco de Vitoria mit dem Staatengrundrecht auf Verkehr begründen wollte: von Mohl (N 1), S. 627; Bluntschli, Das moderne Völkerrecht der zivilisierten Staaten, 1878, Art. 381 f.; Oppenheim-Lauterpacht, International Law I, London $1955^{8}$ (Neudruck 1963), S. 615-617, 675; Fauchille-Bonfils, Traité de droit international public I, Paris 1922, S. 889-893; von Frisch (N 1), S. 131 f.; Verdroß (N 19), S. 362; Doehring (N 11), S. 58-60; Schnitzer (N 26), S. 566 f. 
offenhalten; er bleibt doch frei darin, wen er passieren läßt. Der rechtsstaatliche Argumentations-Automatismus, der von der Gewährung einer staatlichen Begünstigung auf einen Anspruch des Begünstigten folgert, greift im Außenverhältnis des Staates nicht ein ${ }^{44}$ ). In der koordinationsrechtlichen Phase der

41) Das völkerrechtliche „Offenheits"-Gebot begründet nur Pflichten zwischen den Staaten (zum Ausnahmefall einer individualbezogenen Aufnahmepflicht bei Lebensgefahr: Doehring, N 11, S. 59 f.). Die staatsrechtliche „Erzeugung“ eines Individualanspruchs über Art. 25/2 GG kann nicht Personen zugute kommen, die (noch) nicht Bewohner des Bundesgebietes sind; im übrigen läßt auch der Sinn dieser Völkerrechtsregel den Individualbezug nicht zu (vgl. Doehring a. a. O., S. 152-172).

Auch andere verfassungsrechtliche Ansätze zur Begründung eines (materiellen oder formellen) Zulassungsanspruchs versagen: Die allgemeine rechtsstaatliche „Vermutung" für das subjektive öffentliche Recht greift nur ein, wenn die maßgebende Norm wenigstens auch dem Interesse des Begünstigten zu dienen bestimmt ist (grundlegend BVerwGE 39, 235-239; dazu Hoffmann-Becking JuS 1973, 615-619). Im Außenverhältnis des Staates zu gebietsfremden Ausländern ist ein derartiger Individualschutz (außerhalb des Asylrechts) nicht gegeben. Wo noch keine Herrschaftsbeziehung begründet ist, besteht auch keine rechtsstaatliche Fürsorgepflicht gegenüber Individualinteressen. Es fehlt hier das rechtsstaatliche Bindungs- und Vertrauensverhältnis, an das eine ermessensverengende "Vermutung" anknüpfen kann (verfehlt daher die verfassungsrechtlichen Deduktionen von Ermessensschranken bei Rittstieg JZ 1971, 113-115). Ein grundrechtlicher Ansatz in Art. 2 I und 3 GG kommt in der Kooptations-Phase nicht in Betracht (s. o. N 39).

Da das Grundgesetz keine materielle Individualrechtsposition gewährleistet, greift auch bei der Abweisung der formelle Rechtfertigungszwang, wie er in Begründungspflicht und Rechtsschutzgarantie (Art. 19 IV GG) enthalten ist, noch nicht verfassungsnotwendig ein (unzutreffend: Franz DVBI. 1973, 801; Rittstieg JZ 1971, 114). Das Absehen von einer Begründungspflicht in $\$ 23$ II AuslG ist daher unbedenklich. - Mit dieser Feststellung wird aber nicht auf die Doktrin vom gerichtsfreien Hoheitsakt zurückgegriffen (wie bei Schiedermair [N 8], S. 38 f.; s. auch S. 421 f., 444). Hier soll nicht die um den mythischen „Bereich der Regierung“ wabernde Lohe ermeut entfacht werden, die kein gerichtliches Kontrollorgan durchschreiten darf. Art. 19 IV GG scheidet nur deshalb aus, weil auf Verfassungsebene das subjektive Recht fehlt. Soweit der Gesetzgeber dem Gebietsfremden ein solches einräumt, kann und muß der Gerichtsschutz nach Art. 19 IV GG einsetzen.

Wenn die Verwaltungsgerichtsbarkeit dem Gebietsfremden im Rahmen des \& 2 I AuslG einen nicht gesetzlich formulierten, klagbaren, formellen Anspruch darauf zuspricht, daß seine Individualinteressen bei der Gebietszulassung berücksichtigt werden, so hat sie nicht Verfassungsdirektiven vollzogen, sondern das Gesetz richterrechtlich fortgebildet (Beisp.: BVerwGE 9, 235 f.; 36, 45-53; 38, 90-92). Diese Gerichtskontrolle ohne vorgegebene gesetzliche Maßstäbe beschwört die Gefahr herauf, daß das von den demokratischen Entscheidungsinstanzen unabhängige Gericht souverän die 
Gebietszulassung fordert die Verfassung lediglich die Beachtung der objektiven Gebote der Rechtsstaatlichkeit, insbesondere der Maximen eines geordneten Verwaltungsverfahrens. Es muß gewährleistet bleiben, was Robert von Mohl in seinem Plädoyer für kosmopolitische Freizügigkeit - angesichts der in diesem Bereich "vielfachen Verschlungenheit der Verhältnisse" - als das feststehende Gebot erkennt: „daß keine Willkür stattfinden darf, noch eine neidische Verkümmerung fremden Vorteils"46). - Diese relative Indifferenz des Grundgesetzes hält die Möglichkeit offen, daß einfache Gesetze oder supranationale Rechtsquellen dem Ausländer die Option des Aufenthaltsrechts verschaffen, wie es im Rahmen der Europäischen Gemeinschaften durch die Gewährung der Freizügigkeit für europäische Marktbürger erreicht ist ${ }^{\mathbf{4}}$ ).

Der Verfassungsstaat hat sich in der Entscheidung über die Zulassung Staatsfremder weiteste Freiheit und damit Elastizität im Wechsel der Lagen erhalten. Er darf sich an allen legitimen Staatszwecken ausrichten: an Außenpolitik wie an Wirtschaftssteuerung, an Kulturpflege wie Entwicklungshilfe; er kann Bedarfs- wie Kapazitätsgesichtspunkte berücksichtigen. Das Grundgesetz zwingt die Bundesrepublik nicht, sich als Einwanderungsland zu definieren ${ }^{47}$ ); verwehrt es ihr aber auch

„Belange der Bundesrepublik Deutschland" definiert und sich bevölkerungspolitische Kompetenzen anmaßt. Auf der anderen Seite wird die Ausländer-Exekutive leicht dazu neigen, außenpolitisch und bevölkerungspolitisch brisante Entscheidungsgründe vor Gericht zu tarnen, notfalls unter Berufung auf $\S 99$ VwGO; am Ende zeitigt der Rechtsschutz ein würdeloses Versteckspiel der Motive und die Flucht in die Floskeln.

45) Zitat: von Mohl (N 1), S. 627. - von Mohl verwirft in diesem Zusammenhang auch die "tadelnswerte Quälerei“ schwierig zu erfüllender Einreiseformalitäten (ebd. S. 631).

46) Zur Freizügigkeit der Europäischen Marktbürger: Ipsen (N 10), S. 636-647 (mit Nachw.); Grabitz (N 10), S. 69-87; Oppermann, Der Beitrag der Rechtsprechung zur Freizügigkeit innerhalb der Gemeinschaft und zu den sozialen Fragen, Luxemburg 1963.

47) Die Indifferenz des Grundgesetzes zeigt sich bereits in der Gesetzeskompetenz über die „Einwanderung“ in Art. 73/3. - Die Bundesrepublik wird nach geltendem Gesetzesrecht als "kein Einwanderungsland" qualifiziert von: Bay. Staatsministerium für Arbeit und Sozialordnung, in: Bay. Bericht (N 4), S. 27, 34; Beschluß des Bay. Ministerrats (N 5), S. 37; Bundesminister fïr Bildung und Wissenschaft, Antwort auf Kleine Anfrage v. 30. 3. 1971, BT-Drucks. VI/2071, S. 2; BayVGH, U. v. 4. 6. 1969, NJW 1970, 1012 (mit Anm. Wirtz NJW 1970, 2178); Wirtz ZRP 1970, 249. Dagegen wird die Qualität des „Einwanderungslandes" als vorgegeben oder (zumindest) als aufgegeben erachtet von: Stadt Mïnchen, Ausländerstudie 
nicht. Im gegenwärtigen Kampf der Konzeptionen um den Aufenthalt der Gastarbeiter - Rotation, Integration, Kontraktion, Einwanderung etc. ${ }^{48}$ ) - trifft keine die besondere Gunst oder die Ablehnung der Verfassung. Die auswärtige Gewalt darf differenzierende Lösungen in Aufenthalts- und Niederlassungsabkommen treffen, ohne daß sich der Gleichheitsgrundsatz als universale Meistbegünstigungsklausel auswirkt.

Die Verfassung läßt in der Zulassungsphase den Vitalwerten staatlicher Selbstbehauptung und Selbstgestaltung( ${ }^{49}$ ) gerade deshalb weiten Raum, weil in dem Augenblick, in dem der Fremde zum Gebietszugehörigen geworden ist, die Entscheidungsflexibilität endet. Mit der Aufnahme wandelt sich das koordinationsrechtliche Außenverhältnis in ein subordinationsrechtliches Innenverhältnis. Der Fremde wird mit der Einreise zum Untertan des Aufenthaltsstaates. Mit der Herrschaft des Gesetzes beginnt nunmehr auch der Schutz des Gesetzes ${ }^{50}$ ). Der Aufenthaltsstaat tritt aus der Grundrechtsindifferenz in die Grundrechtsbindung ein ${ }^{51}$ ). Die Stellung des Gebietszugehöri-

(in: Bay. Bericht, N 4, S. 58); Franz, NJW 1970, 1013; Kanein NJW 1973, 731; Nikolinakos (N 4), S. 9, 14, 22; Zuleeg DOV 1973, 366; Rose JZ 1971, 723; Rittstieg NJW 1972, 2155.

48) $\mathrm{Zu}$ den bevölkerungspolitischen Modellen in der Gastarbeiterfrage: Stadt Nürnberg (N 4), S. 54-58; Höpfner, Ramann und Rürup (N 4), S. 63-92.

49) Die Notwendigkeiten staatlicher Selbstbehauptung werden als Leitgedanken des Aufenthaltsrechts anerkannt von: von Frisch (N 1), S. 110; Fauchille-Bonfils (N 43), S. 892 f.; Stier-Somlo, Art. 109 - Gleich heit vor dem Gesetz, in: Nipperdey (Hrsg.), Die Grundrechte und Grundpflichten der RV I, 1929, S. 162; Walter Jellinek (N 40), S. 121; Doehring ZaöRV 25 (1965), 486-488; Bordewin (N 16), S. 35 .

Zur Bedeutung staatlicher Vitalinteressen im Fremdenrecht: Isay (N 28), S. 49-51; ders., Internationales Finanzrecht, 1934, S. 36; Doehring (N 11), S. 125, 192 f.; Walther W. Schmidt (N 10), S. 167 f.; Thieme, Die Rechtsstellung des Ausländers nach dem BGG, Diss. Göttingen 1951, S. 64. - Zur Existenzsicherung des Staates als Grundrechtsschranke: Gallwas, Der Mißbrauch von Grundrechten, 1967, S. 87 f., 90 f.

s0) Dieser Rechtsvorgang wird konzis dargestellt in der Verfassungsurkunde für das Königreich Sachsen vom 4. 9. 1831, \& 24: „Der Aufenthalt innerhalb der Grenzen des Staats verpflichtet zur Beobachtung der Gesetze desselben und begründet dagegen den gesetzlichen Schutz". Ahnliche Formulierungen finden sich in: Verfassungsurkunde für das Kurfürstentum Hessen vom 5. 1. 1831, § 19; Verfassung Belgiens vom 7. 2. 1831, Art. 128.

51) Die Feststellungen zum Grundrechtsschutz gelten nicht für Amtsträger fremder Staaten - gleich, ob sie hoheitliche oder fiskalische Funktionen wahrnehmen (als Konsul oder als Vertreter eines staatlichen Wirtschaftsunternehmens). Die Reichweite der deutschen Grundrechte endet notwendig dort, wo die (offene oder getarnte) dienstliche Abhängigkeit von einem ausländischen Ent- 
gen ist weitgehend verfassungsrechtlich vorgeprägt und der Gestaltung durch Legislative und Exekutive entzogen.

3. Der Unterschied zwischen der vorgrundrechtlichen Statusbegründung und dem grundrechtlichen Status wird wichtig, wenn die Aufenthaltserlaubnis mit einer bestimmten Auflage verbunden wird, etwa dem Verbot bestimmter wirtschaftlicher oder politischer Betätigung. Die Auflage ist eine antizipierte Grundrechtsbeschränkung. Sie kann nicht pauschal mit dem argumentum a maiore ad minus gerechtfertigt werden: da der Staat den Fremden sogar hätte a limine abweisen können, so dürfe er erst recht, wenn er ihn schon zulasse, ihm einen Status minderen Rechts geben. Zwischen vorgrundrechtlicher Statusverweigerung und grundrechtsgebundener Statusminderung besteht keine quantitative, sondern eine qualitative Differenz. Nebenbestimmungen der Aufenthaltserlaubnis müssen sich daher an den Grundrechten messen lassen und dem Vorbehalt des Gesetzes genügen. Eine Blanko-Ermächtigung der Legislative an die Ausländerpolizei ist unzulässig ${ }^{52}$ ).

scheidungszentrum beginnt. Die Grundrechte gewähren zwar ausländischen Individuen Freiheitsschutz, nicht aber ausländischen Staaten einen Rechtstitel zur Einmischung in innerdeutsche Angelegenheiten und zur Umgehung des völkerrechtlichen Interventionsverbotes (etwa durch Aufbau auslands-gesteuerter Presse- oder Wirtschaftsmacht). In den zwischenstaatlichen Beziehungen fehlt auch die Subordination, die von den Grundrechten vorausgesetzt wird (exemplarisch zur Rechtsstellung eines ausländischen Konsuls: $B$ VerwGE 15, 59 [62]; vgl. auch Herbert Krüger [N 25], S. 958). Der Status ausländischer Amtsträger beurteilt sich allein nach Völkerrecht, das über Art. 25, 59 GG innerstaatlich bedeutsam wird.

Der Grundrechtsausschluß fremder Staaten und ihrer Organwalter entspricht der Regelung für ausländische juristische Personen überhaupt (Begründung des argumentum e contrario zu Art. 19 III GG: Walther W. Schmidt [N 10], S. 168-175; Meesen JZ 1970, 603). Im übrigen steht der deutschen Staatsgewalt ihrerseits der Schutz der Grundrechte nicht zu (Nachw. bei Isensee, Subsidiaritätsprinzip und Verfassungsrecht, 1968, S. 210-212).

62) Die pauschalen Ermächtigungen des \& 7 AuslG entsprechen bereits nicht dem rechtsstaatlichen Bestimmtheitserfordernis. Soweit sich die Ermächtigungsblankette nicht durch ergänzende inhaltliche Regelungen näher ausfüllen lassen (etwa §6 II AuslG), können sie nicht herangezogen werden, um die verfassungsrechtliche Eingriffsreserve gegenüber Ausländern, wie sie im Bereich der Deutschengrundrechte besteht (s. u. D III), zu aktualisieren. - Hinreichend bestimmt sind dagegen die ausländerrechtlichen Ermächtigungen zu Bedingungen und Auflagen in $\$ \S 18$ I 3, 19 I 3 ArbeitsförderungsG.

Für die Grundrechtsbindung der Ausländerbehörden ist es gleichgültig, ob eine Nebenbestimmung (Auflage, Bedingung, Beschränkung) gemäß $\S 7$ AuslG von vornherein mit der Aufenthaltserlaub- 
Im Ergebnis erweist sich der Grundrechtsstatus des Ausländers als das Werk souveräner Selbstbindung des Verfassungsstaates. Der Staat ist Herr über die Grundrechtsvoraussetzungen, nicht mehr über die Grundrechtsfolgen. Für ihn gilt das Gesetz Mephistos: „Das erste steht uns frei, beim zweiten sind wir Knechte".

\section{Status-Sicherheit durch Beschränkung der Ausweisungs- kompetenz}

Eine Versuchung, der grundrechtlichen Knechtschaft zu entrinnen, kann darin liegen, daß der Staat den Ausländer bei an sich legaler, aber unbequemer Grundrechtsbetätigung (etwa politisch mißliebiger Meinungsäußerung oder wirtschaftlich lästiger Koalitionsbetätigung) mit Ausweisung bedroht; er also dort, wo er Grundrechte nicht beschränken darf, die aufenthaltsrechtliche Grundrechtsvoraussetzung entzieht ${ }^{53}$ ). Ohne die Freiheit von Furcht vor unberechenbarer Ausweisung ist jede Freiheitsgarantie wertlos. Der aufenthaltsberechtigte Ausländer wäre nicht besser gestellt als der illegal Einreisende. Rechtsstaatliche Ironie! Der Verfassungsstaat stellte sich selbst in Frage, wenn er als Fundament der Grundrechtsfreiheit die aufenthaltsrechtliche Vogelfreiheit genügen ließe ${ }^{84}$ ).

Die Beschränkung der Ausweisungskompetenz ist elementares rechtsstaatliches Gebot. Die erste Folge der Selbstbindung

nis verbunden oder $\mathrm{ihr}$ nachträglich hinzugefügt wird. Die Wirkung der antizipierenden Grundrechtsbeschränkung wird verkannt, wenn Schnapp die vorgängigen oder gleichzeitigen Nebenbestimmungen im Gegensatz zu den nachträglichen vor den grundrechtsabhängigen Verfassungspostulaten $\mathrm{zu}$ "retten" versucht (DOV 1973, 594). (Uberzogene) verfassungsrechtliche Kritik an \& 7 AuslG: Rittstieg JZ 1971, 117 f.; ders., NJW 1972, 2156 f.; Zuleeg DOV 1973, 367. Die Verwaltungsrechtsprechung geht von der Zulässigkeit der Nebenbestimmungen nach $\S 7$ AuslG aus: $B V$ erwGE 36, 45 (47 f.); BVerwG, U. v. 18. 12. 1969, DVBl. 1970, 623; VGH Mannheim, U. v. 14. 7. 1969, DOV 1970, 95 (96); OVG Rheinland-Pfalz, U. v. 30.6. 1969, GewArch. 1969, 284.

63) Dagegen meint Isay, die Freiheitssphäre des Ausländers werde durch Ausweisung „tatsächlich, nicht jedoch rechtlich" geschmälert; die Drohung mit der Ausweisung sei „ein rechtlich nicht zu beanstandenes Mittel, dem Ausländer manche Freiheiten tatsächlich zu versagen, die ihm rechtlich verbürgt sind“ (N 28, S. 90, 262).

54) Isay hält den Ausländer im Blick auf die Ausweisung für "vogelfrel, wie er es in ältesten Zeiten war" (N 28, S. 363). Im Recht der Ausweisung habe sich „ein Stück Polizeistaat bis auf den heutigen Tag erhalten" (S. 100; s. auch S. 214). Vgl. auch Heinze (N 37), S. 61; Grabitz (N 10), S. 52 f.; Tomuschat (N 16), S. 24-26, 63-65 ("größte Schwierigkeiten“ der korrekten Grenzziehung des Ausweisungsermessens). 
durch Gebietszulassung muß ein Mindestmaß an aufenthaltsrechtlicher Statussicherheit sein ${ }^{55}$ ).

Diese Selbstbindung verschafft dem Ausländer allerdings kein unbeschränktes Aufenthaltsrecht, eine Einwanderungsfreiheit oder gar einen Einbürgerungsanspruch. Die Entscheidungsfreiheit des Staates, die Aufenthaltserlaubnis zeitlich zu begrenzen oder aufzukündigen, wird durch die rechtsstaatlich gebotene Statussicherheit nicht aufgehoben ${ }^{68}$ ).

s5) Mit der Gebietszulassung gewinnt der Ausländer Grundrechtsschutz für sein Aufenthaltsrecht im Rahmen des Art. 2 I GG. Dieser Grundrechtsschutz ist auf der einen Selte durch den Vorbehalt des verfassungsmäßigen Gesetzes relativiert, auf der anderen Seite durch den Eingriffsvorbehalt des bestimmten Gesetzes und durch das Ubermaßverbot (verfassungsgebotene Güterabwägung der staatlichen Belange mit denen des Ausländers) objektivrechtlich ergänzt. Zum Grundrechtsschutz gegen Ausweisungsakte nach $\S 10$ I 11 AuslG: BVerfG, B. v. 18. 7. 1973, DVBl. 1974, 79-83.

Bo) Die rechtsstaatlich gebotene Stabilisierung des Aufenthaltsrechts sprengt jedoch nicht die zeitlichen und sonstigen Grenzen der Aufenthaltserlaubnis. Wer den kleinen Finger des Touristenvisums erhält, kann nicht die ganze Hand der Einwanderungserlaubnis erwarten. Der Staat ist in der Entscheidung über die Aufenthaltsverlängerung grundsätzlich ebenso frei wie bei der ersten Zulassung. Der Ausländer kann die Verlängerung nicht dadurch ertrotzen, daß er sich in den Aufenthaltsstaat durch eigene Tätigkeit integriert und grundrechtlich geschützte Positionen erwirbt (etwa Eigentum an einem eingerichteten und ausgeübten Gewerbebetrieb). Der Fortbestand des Eigentumsschutzes hängt nicht vom Aufenthalt $a b$, ebenso wie der ("effektive") Rechtsschutz nicht unbedingt den Aufenthalt erfordert (zur Rechtsschutzgarantie des Aufenthaltsrechts in Art. 19 IV GG: BVerfG, B. v. 24. 1. 1973, DOV 1973, 170 f.; B. v. 18. 7. 1973, DVBl. 1974, 79 [81 f.]; vgl. auch OVG Bremen, B. v. 19. 7. 1971, DVBl. 1972, 519).

Solange die öffentliche Hand nicht spezifische Vertrauenstatbestände gegenüber bestimmten Ausländern setzt (wie im Fall $B V$ erwG, U. v. 14. 12. 1972, DOV 1973, 417 f.), entfällt jeder Ansatz dazu, den Fortbestand des Aufenthaltsrechts auf den rechtsstaatlichen Vertrauensschutz zu stützen (Gegenansicht mit Selbstwiderspruch: Zuleeg DOV 1973, 366; im Ergebnis ähnlich: Rittstieg JZ 1971, 116; ders., NJW 1972, 993; ders., NJW 1972, 2156; Rose JZ 1971, 723; Dolde DOV 1973, 375). Der Umstand, daß eine befristete Aufenthaltserlaubnis mehrfach verlängert worden ist, schafft jedenfalls keinen Vertrauenstatbestand (auch nicht mittels der gewaltsamen Hilfskonstruktion eines "Kettenverwaltungsakts"). Im Gegenteil: Die Befristung und die jeweils neue Entscheidung über die Verlängerung verhindern gerade, daß eine rechtserhebliche Erwartung auf die Verleihung einer unbegrenzten Aufenthaltsberechtigung entstehen kann (verfehlt: Dolde DOV 1973, 375; zutreffend: $B V$ erwG, B. v. 29. 8. 1972, DOV 1973, 414).

Die Verfassung liefert auch dann keine Gründe für eine Verlängerung oder Verewigung des Aufenthaltsrechts, wenn der Ausländer in ein Heimatland mit niedrigerem Wirtschafts- und niedrigerem 


\section{Der rechtsstaatliche Status}

Erst wenn der Ausländer zum Bewohner des Bundesgebietes geworden ist, hat er den Zustand der ursprünglichen aufenthaltsrechtlichen Ungleichheit überwunden. Damit ist eine Analogie-Ebene mit dem Staatsangehörigen hergestellt, auf der sich nunmehr sinnvoll die Frage der rechtsstaatlichen Gleichheit stellen läßts7.

\section{Die Vermutung für die Rechtsgleichheit}

Wenn das Grundgesetz die Rechtsgleichheit "aller Menschen" (Art. 3 Abs. 1) proklamiert, setzt es sich von der Weimarer Reichsverfassung ab, die ihren Zweiten Hauptteil "Grundrechte und Grundpflichten der Deutschen" mit der „Gleichheit aller Deutschen" (Art. 109 Abs. 1 RV) einleitet. Zwar sollte der Ausländer damit nicht von der Teilhabe an den Grundrechten ausgeschlossen werden. Die Grundrechte waren, wie Anschütz repräsentativ für die Weimarer Lehre formulierte, nicht „nationalistisch, sondern individualistisch" gedacht $^{58}$ ). Der nationale Gedanke war Träger der liberal-weltbürgerlichen Idee ${ }^{58}$ ).

Freiheitsstandard zurückkehren müßte. Denn die Grundrechtsgarantien der Verfassung, ebenso die Sozialstaatsklauseln, beziehen sich nicht auf die Zustände in fremden Staaten. Von den Grenzfällen, die in den Bereich des Asylrechts gehören, abgesehen, verbietet es das Grundgesetz, daß die deutsche Staatsgewalt sich zum grundrechtlichen und sozialstaatlichen praeceptor mundi aufschwingt und die „Unzumutbarkeit" der Rückkehr in die heimischen Rechts- und Lebensverhältnisse dekretiert (so aber Zuleeg DOV 1973, 366; LG Frankfurt, U. v. 21. 8. 1968, NJW 1969, 385 [386]).

$\left.{ }^{57}\right)$ Der Gleichheitsmaßstab verändert seinen Inhalt, je nach der Staatsform- und Staatszielbestimmung, der er zugeordnet wird. Gleichheit erscheint

- aus der Sicht des Rechtsstaats als (liberale) Rechtsgleichheit: Gleichheit in der grundrechtlich gewährleisteten Individualfreiheit;

- aus der Sicht der Sozialstaatlichkeit als soziale Gleichheit: Gleichheit in den realen Möglichkeiten der Freiheitsverwirklichung;

- aus der Sicht der Demokratie als politische Gleichheit: Gleichheit in der Teilhabe am staatlichen Entscheidungsverfahren.

Die Gleichheitsfrage wird daher gesondert für jeden der drei Verfassungsbereiche gestellt.

58) Zitat: Anschîtz, Die Verfassung des Deutschen Reiches - zit.: Komm. -, $1933^{14}$ (Nachdr. 1965), S. 513. - Anschütz geht allerdings nicht von einer materialen Gleichstellung der Ausländer mit den Deutschen aus, sondern nur von der formalen unter dem rechtsstaatlichen Prinzip der Gesetzmäßigkeit der Verwaltung. Die Gleichstellung ist nicht „reichsverfassungskräftig“; sie gilt nur, soweit nicht das Gesetz (oder ein gesetzesgleicher Rechtssatz) ein anderes bestimmt oder eine Abweichung sich aus dem Wesen der Sache ergibt (ebda, S. 511-513; ebenso bereits ders., Die Verfassungsur- 
Im Grundgesetz besitzt er dazu nicht mehr die Kraft. Die gebrochene Nation des Grundgesetzes sucht gerade im Anschluß an den menschenrechtlichen Universalismus ihre geistige Einheit und ihr Selbstbewußtsein zu finden. Die universalen Rechtswerte füllen das Rückzugsgebiet der nationalen auf. Die Grundrechtsdogmatik geht heute den Weg vom menschenrechtlichen Universalismus zur nationalen Besonderheit - in umgekehrter Richtung wie die Weimarer Lehre. Die Individualrechte des Fremden leben nunmehr nicht von der Gnade einer Analogie zu den Deutschenrechten; vielmehr muß sich jedes Staatsbürgerprivileg vor dem Gebot der Rechtsgleichheit rechtfertigen $\left.{ }^{60}\right)$.

kunde für den preußischen Staat I, 1912, S. 92, 99-103). Im wesentlichen halten die gleiche Linie wie Anschütz: Aldag, Die Gleichheit vor dem Gesetz in der Reichsverfassung, 1925, S. 56-59; Hatschek, Deutsches und preußisches Staatsrecht I, 1922, S. 189; Isay (N 28), S. 89-91; Carl Schmitt, Verfassungslehre, 1928 (Nachdr. 1965), S. 164 f.; ders., in: Anschütz-Thoma (Hrsg.), Handbuch des Deutschen Staatsrechts II, 1932, S. 591; Strupp, in: Anschütz-Thoma a. a. O., I, 1930, S. 278 f.; Thoma, in: Nipperdey (Hrsg.), Die Grundrechte I (N 49), S. 25-29; ders., in: Festgabe zur Feier des 50-jähr. Bestehens des PreuBOVG, 1925, S. 198 f. (vorsichtig).

Die mehr nominelle als substantielle Gegenauffassung, die dem Ausländer nicht den Schutz der Grundrechte, wohl den Schutz des Gesetzmäßigkeitsprinzips zuerkennt, vertreten: Giese, Die Grundrechte, 1905, S. 87 (zur Preuß. Verfassungsurkunde); ders., Die Verfassung des Deutschen Reiches, 19318, S. 244; Walter Jellinek, Verwaltungsrecht, 1931', S. 171; Friedrichs, Art. "Ausland, Ausländer“, in: Handwörterbuch der Rechtswissenschaft I, 1926, S. 418 f.; Stier, Zur Frage des Petitionsrechts der Ausländer, Gruchots Beiträge 64 (1920), 710-716; Stier-Somlo (N 49), S. 160-164. Die praktische Bedeutungslosigkeit der Kontroverse wird von Anschütz gesehen (Komm., S. 512 Anm. 1).

${ }^{60)}$ Die nationale Komponente in den Weimarer Grundrechten "der Deutschen" wird von Smend hervorgehoben, der den "Doppelsinn" der Grundrechte als Kultursystem und als Volksintegration erfaßt: Der Grundrechtskatalog normiere das Kultursystem „als nationales, als das System gerade der Deutschen, das allgemeinere Werte national positiviert, eben dadurch aber den Angehörigen dieser Staatsnation etwas gibt, einen materialen Status, durch den sie sachlich ein Volk, untereinander und im Gegensatz gegen andere, sein sollen" (Verfassung und Verfassungsrecht, 1928, in: Staatsrechtliche Abhandlungen, 19682, S. 264). - Ahnlich Herbert Krüger (N 25), S. 549; Walther W. Schmidt (N 10), S. 167.

${ }^{80}$ Mit dem dogmatischen Ansatz der Rechtsgleichheit scheiden von vornherein zwei klassische Topoi des Fremdenrechts aus der Betrachtung aus: die Souveränität und die Gastfreundschaft.

a) Wenn Schiedermair die Souveränität des Aufenthaltsstaates bemüht, um ein unbeschränkbares Herr-im-Haus-Recht gegenüber dem Fremden zu begründen (N 8, S. 27 f., 36 f., 129 und passim), so wird Souveränität als materiale Kompetenz (statt als formale Kompetenz-Kompetenz) sowie als Unfähigkeit zur Selbstbindung miß- 


\section{Absolute Gleichstellungsgebote}

1. Das Grundgesetz verbietet allerdings nicht schlechthin die Unterscheidung nach der Staatsangehörigkeit. Die absoluten Differenzierungsverbote des Art. 3 Abs. 3 GG erfassen die Staatsangehörigkeit nicht. Sprache, Rasse, familiäre Abstammung, Heimat (als Ortsverbundenheit), soziale Herkunft (als Beziehung zu einer Gesellschaftsschicht) - diese tabuisierten Unterscheidungsmerkmale liegen auf anderer Ebene als das Staatsangehörigkeitskriterium $\left.{ }^{61}\right)$. Sie können für Deutsche wie Nichtdeutsche gleichermaßen erheblich werden. Sie hängen nicht von der Staatsangehörigkeit ab, wie umgekehrt die Staatsangehörigkeit nicht notwendig an sie anknüpft ${ }^{62}$ ).

deutet. Die Institutionen des Rechtsstaates, insbesondere die Grundrechte, schließen ein solches Souveränitätsverständnis aus. Die Fähigkeit zu rechtlicher Selbstbindung ist gerade Ausdruck des innerstaatlichen Zu-Höchst-Seins wie der zwischenstaatlichen Unabhängigkeit. (Kritik am "apokryphen Souveränitätsbegriff" Schiedermairs: Tomuschat ZaöRV 33 [1973], 396-398; zum Verhältnis Souveränität - rechtsstaatliche Bindung: Isensee [N 51], S. 180-183 mit Nachw.).

b) Das Kriterium des Gastrechts kann den Ausländerstatus nicht klären, weil es unabsehbare Implikationen enthält. Das Gastrecht ist geschichtlich vieldeutig (zur Geschichte des Gastrechts: Jordan, N 1, S. 291-317; von Frisch, $\mathbf{N} 1$, S. 5-36). Auch die gesetzliche Apostrophierung der "Gastfreundschaft" als Grundlage des Aufenthaltsrechts in $\S 1$ Ausländerpolizeiverordnung v. 22. 8. 1938 stiftet nicht die Klarheit, auf die eine Status-Bestimmung im Rechtsstaat angewiesen ist. Der Hinweis auf das Gast-Sein könnte geradezu die verfassungsrechtlichen Unterscheidungen verwischen und müßte offen lassen, ob die Rechte des Fremden ausgeweitet oder eingeschränkt werden sollen (verfehlt: Tomuschat [N 16], S. 61 f.).

In der Kategorie des Gastes wird letztlich die private HausherrnGast-Beziehung auf das öffentliche Staat-Bürger-Verhältnis übertragen - eine Analogie, für die seit dem Tod der Patrimonialstaatlichkeit keine Grundlage mehr besteht. Besonders verfehlt ist die Analogie im Grundrechtsbereich; denn im Zeichen der Menschenrechte genießt der Fremde nicht Gast-, sondern Heimatrecht.

Eine ganz andere Frage ist die, ob die Kategorie des Gast-Seins nicht auf außerrechtlicher Ebene Bedeutung hat: als Richtmaß des Taktes und der Courtoisie.

o1) Zum staatsangehörigkeits-neutralen Inhalt der Differenzierungsverbote des Art. 3 III GG: BVerfGE 5, 17 (22); 9, 124 (128); 23, 258 (262); BVerwGE 22, 66 (69 f.); Ipsen, Gleichheit, in: GR II, 1954, S. 140; Kraus, in: Gedächtnisschrift für Jellinek, 1955, S. 91 f.; Doehring (N 11), S. 195-201; ders., ZaöRV 25 (1965), 484; Dolde (N 15), S. 55 f.; ders., DOV 1973, 373.

62) Die These, daß Art. 3 III GG die Unterscheidung nach der Staatsangehörigkeit verbiete, vertritt mit widerspruchsvoller, unschlüssiger Begründung Zuleeg (DOV 1973, 363 f.). Ahnlich auch Brinkmann, Grundrechts-Kommentar zum GG, 1967, Art. 3, Anm. I 3 b; Art. 8 zu Abs. 1, Anm. 1 a. 
2. Dagegen enthalten alle Freiheitsgrundrechte, die nicht ausdrücklich den Deutschen vorbehalten sind, für ihren jeweiligen Sachbereich absolute Gleichstellungsgebote. In den Grundrechtsräumen der Religionsfreiheit, des Eigentums, des Rechtsschutzes darf nicht nach der Staatsangehörigkeit unterschieden werden. Hier hat der menschenrechtliche Universalismus des Grundgesetzes seinen Ausdruck gefunden ${ }^{63}$ ).

Gleichwohl ist es mißverständlich, diese allgemeinen Grundrechte mit erborgtem Pathos als „Menschenrechte" zu bezeichnen $\left.^{64}\right)$. Die Menschenrechte jedenfalls, zu denen sich das Grundgesetz in Art. 1 Abs. 2 als naturrechtlichen Vorgegebenheiten bekennt, brauchen die allgemeinen Grundrechte nicht abzudecken, müssen sich in ihnen aber auch nicht erschöpfen.

\section{Die Schlechterstellung im Vorbehaltsbereich der Deutschen- rechte}

Die Besonderheit des Ausländerstatus wird dort spürbar, wo das Grundgesetz bestimmte Grundrechte nur den Deutschen zuerkennt: nämlich in der Versammlungs- und Vereinsfreiheit, der Freizügigkeit, der Freiheit des Berufs und im gleichen Zugang zum öffentlichen Dienst. Hier gewinnt der Gesetzgeber gegenüber den ausländischen Gebietszugehörigen einen Planungs- und Steuerungsspielraum, der ihm gegenüber den Deutschen durch kategorische Grundrechtsschranken entzogen ist $\left.{ }^{85}\right)$.

63) Bei den Beratungen des Grundgesetzes entwickelte von Mangoldt das Konzept der strikten Rechtsgleichheit „aller Menschen“, von dem die Verfassung in besonderen Bestimmungen Ausnahmen vorsehe (42. Sitzung des Hauptausschusses des Parlamentarischen Rates am 18. 1. 1949, in: Parlamentarischer Rat, Verhandlungen des Hauptausschusses, 1948/49, S. 538). - Im Ergebnis ähnlich wie der Text zu den sachbezogenen Differenzierungsverboten in den allgemeinen Grundrechten: BVerfGE 31, 58 (67 - zu Art. 6 I GG).

64) Die gängige Unterscheidung zwischen „Menschenrechten“ und "Bürgerrechten" (wobei "Menschenrechte“ die positiv-rechtlich gewährleisteten allgemeinen Grundrechte, „Bürgerrechte“ die Vorbehaltsrechte der Deutschen sind) findet sich etwa bei: Anschiitz, Die Verfassungsurkunde für den preuß. Staat I, 1912, S. 101; dems., Komm. (N 58), S. 511; Hesse, Grundzüge des Verfassungsrechts der Bundesrepublik Deutschland, $1973^{\circ}$, S. 119; Kraus (N 61), S. 91; Maunz, Deutsches Staatsrecht, 1973'10, S. 104; Zippelius, BK (Zweitbearb.), Stand 1972, Art. 4/Rn 52.

$\left.{ }^{65}\right)$ Dadurch, daß die Berufstreiheit (Art. 12 I GG) den Deutschen vorbehalten ist, fällt gegenüber Ausländern auch das Tabu der Bedürfnisprüfung als objektiver Zulassungssperre fort. Nunmehr können die Erfordernisse der Gesamtwirtschaft und einzelner Berufszweige, des Arbeitsmarktes und der Regionalplanung vorrangige Rücksicht erfahren. Hier kommt die Primärverantwortung des Staates für die deutsche Bevölkerung zum Tragen, die unentrinn- 
1. Die grundrechtliche Benachteiligung der Ausländer fordert den dogmatischen Rekurs auf den höchsten Verfassungssatz von der Menschenwürde heraus. Ein Argumentationsweg geht dahin, die wirtschaftlichen, politischen und sonstigen Betätigungen, die Gegenstand der Deutschenrechte sind, als Ausprägungen der Menschenwürde auszuweisen und deshalb entweder die Deutschenvorbehalte als verfassungswidrige Verfaslungsbestandteile auszuscheiden ${ }^{60}$ ) oder aus den Deutschenrechten menschenrechtliche Kerne herauszuschälen ${ }^{67}$ ). Hier ist Differenzierung geboten.

- Die Menschenwürde enthält zunächst ein Grundrecht, das unantastbar auch dem Ausländer zusteht: Schutz der körperlichen, geistigen, sittlichen Person. Dieses Elementargrundrecht schließt aber nicht die Lücke, die mit den Deutschenvorbehalten entsteht.

- Der Schutz der Menschenwürde wirkt ferner als Direktive in alle grundrechtlichen und organisatorischen Verfassungsbereiche hinein - als das einheitstiftende Moment $\left.{ }^{88}\right)$. Jedoch dürfen die Besonderheiten der konkreten Verfassungsbereiche nicht durch undifferenzierten Rückgriff auf dieses Prinzip durchbrochen werden. Eine jede Ausprägung der Menschenwürde kann nicht mit der Menschenwürde selbst identifiziert werden. Die jeweilige positivrechtliche lex und die menschenrechtliche ratio legis sind auseinanderzuhalten.

Der Nachweis, daß bestimmte Freiheitsäußerungen Erscheinungsformen der Menschenwürde sind, liefert im übrigen noch

bar vom wirtschaftlichen Schicksal der Bundesrepublik abhängig ist. Auf der anderen Seite verbleibt der auswärtigen Gewalt eine Dispositionsmaterie für völkerrechtliche Abkommen, welche die Rechtsstellung der Deutschen im Ausland auf der Grundlage der Gegenseitigkeit verbessern. - Zur Motivation der Deutschenvorbehalte: von Mangoldt-Klein, Das Bonner Grundgesetz I, 1966², S. 99.

60) So mit unschlüssigen Begründungen, die gelegentlich an Art. 1 I oder 3 III GG anknüpfen: Brinkmann (N 62), Art. 8 Abs. 1, Anm. 1 a; Art. 9 Abs. 1 , Anm. 1 a; Art. 11 Abs. 1, Anm. 1 a; Art. 12 Abs. 1 Anm. 1 a. Ahnlich Rolsvering (N 6), S. 113-121.

o7) So Bachof, in: GR III/1, 1958, S. 177 f.; Dürig, in: GR II, 1954, S. 521-523; ders., in: M-D-H (N 27), Art. 1/Rn 85; Art. 2 I/Rn 66; Dolde (N 15), S. 62-71; ders., DOV 1973, 373 f. - Ahnlich auch Kraus (N 61), S. 91 (Unzulässigkeit eines totalen Versammlungsoder Vereinigungsverbots für Ausländer).

68) Zur Unterscheidung eines "dirigierenden" von einem (grundrechtlich-),,institutionellen" Verfassungselement: Lerche, tbermaß und Verfassungsrecht, 1961, S. 61-96, 315-318. - Zur Direktivfunktion des Art. 1 I GG im Ganzen der Verfassung: Dïrig, M-DH (N 27), Art. 1 II/Rn 4-14; Zippelius, BK (Zweitbearb.), 1966, Art. $1 / \operatorname{Rn} 26$. 
nicht die Begründung dafür, daß dem Ausländer diese Freiheitsäußerungen gerade auf dem deutschen Territorium ermöglicht werden müssen ${ }^{09}$ ). Das Grundgesetz geht bei der differenzierenden Zuerkennung der Grundrechte davon aus, daß der Ausländer primär seinem Heimatstaat zugeordnet ist; daß grundsätzlich nur die Deutschen das Rechtsschicksal der Unentrinnbarkeit $\mathrm{zu}$ tragen haben und daher die Zuordnung des Ausländers zu zwei Staaten auch eine Teilung der staatsrechtlichen Verantwortung aus der Sicht der Menschenwürde erträglich macht ${ }^{70}$ ).

(9) Dieser Gesichtspunkt wird übersehen, wenn dem Ausländer ein bestimmter Grundrechtsstandard - vor allem hinsichtlich selner politischen Betätigung - zuerkannt werden soll mit der Begründung, daß diese Betätigung um der Menschenwürde willen geboten sei (so etwa die Deduktionen Doldes [N 15], S. 62-71, 101103 und passim; DOV 1973, 373 f.).

70) Von diesem dogmatischen Ansatz aus löst sich auch die Frage, ob und wieweit die Verfassung duldet, daß dem Ausländer Rechte nur unter der Bedingung verbiirgter Gegenseitigkeit gewährt werden (Beisp.: \$\$ 110 I, II, 114 II 1 ZPO; \$ 34 c V EStG; § 7 RBHaftG; § 12 II 1 GewO; \& 49 II AuslG; \& 157 RVO; § 237 RKnG. Vgl. dazu Tomuschat ZaöRV 33 [1973], 179-221). Die Lösung muß differenzieren:

a) Der Allgemeine Gleichheitssatz steht den Gegenseitigkeitsklauseln nicht schlechthin im Wege. Die bedingte Schlechterstellung des Ausländers knüpft an rechtliche Vorgegebenheiten an: die Teilung der staatsrechtlichen Verantwortung sowie den Zusammenhang der staatsrechtlichen und der völkerrechtlichen Beziehungen. Daß der Gegenseitigkeitsvorbehalt dazu dienen soll, die Rechtsstellung der eigenen Bürger im Ausland zu verbesserm, ist nicht von vornherein eine sachwidrige Zweck-Mittel-Verknüpfung. Immerhin ist dieser Vorbehalt eines der wenigen leidlich wirksamen Druckmittel, mit denen ein Staat auf gleichgeordnete andere Staaten im Interesse seiner Auslandsbürger einwirken kann.

Die Verletzung des Allgemeinen Gleichheitssatzes durch Gegenseitigkeitsvorbehalte wird für Einzelregelungen (insbes. $\$ 7$ RBHaftG) oder allgemein verneint von: $R G Z$ 111, 375 (379); 128, 238 (240); RG U. v. 15. 4. 1930, JW 1930, 1869; BGH U. v. 1. 10. 1956, NJW 1956, 1836; OLG Frankfurt B. v. 21. 9. 1970, NJW 1970, 21722174; BVerfGE 30, 404-414 (zur Haftentschädigung). Anschiltz, Komm. (N 58), S. 512 Anm. 1; Aldag (N 58), S. 58; Doehring (N 11), S. 65; Walther W. Schmidt (N 10), S. 60. - Differenzierend: Thieme (N 49), S. 64-66, 106 f., 114, 117. - Einen Widerspruch zu Art. 3 I GG nehmen an: Rolvering (N 6), S. 104-108; Grasmann JZ 1969, 455 f.; Zuleeg DOV 1973, 363.

b) Gegenseitigkeitsklauseln verstoßen auch nicht notwendig gegen die Menschenwürde. Der Ausländer wird nicht schon dann zum bloßen Werkzeug der Staatsraison erniedrigt, wenn ihm die Bundesrepublik eine Steuervergünstigung nach \& 34 V EStG versagt, solange ihre eigenen Angehörigen nicht den entsprechenden Vorteil im Ausland erhalten. Hier wird nicht die Person als solche in den Dienst eines außenpolitischen Zwecks gestellt, sondern die Vorent- 
Das Rechtsschicksal der Unentrinnbarkeit bietet sich als menschenrechtliches Analogiekriterium dafür an, in welchem Maße dem Ausländer die Annäherung an den Grundrechtsstandard der Deutschen gewährleistet werden muß. Je nach dem Grad, in dem er auf Lebensentfaltung im Geltungsbereich des Grundgesetzes angewiesen ist, muß ihm ein Minimum an Erwerbsmöglichkeit, an räumlicher Bewegungsfreiheit, an organisierter Kommunikation zuerkannt werden. Das höchste $\mathrm{MaB}$ der Unentrinnbarkeit ist in der Regel beim Asylberechtigten und beim Staatenlosen erreicht. Hier ist weitgehende Annäherung an den Deutschenstatus menschenrechtliches Gebot ${ }^{71}$ ).

Der grundrechtliche Standort dieser menschenrechtlichen Angleichungsgebote befindet sich nicht bei den einzelnen Deutschengrundrechten ${ }^{72}$ ). Wenn jedem Deutschengrundrecht ein diffuses Schattengrundrecht für Ausländer beigegeben würde,

haltung eines bestimmten Rechtsvorteils. Wer hier bereits Art. 1 GG mit der Kant'schen Formel ins Spiel bringt (s. Doehring [N 11], S. 65 Anm. 214), läßt Sinn für verfassungsrechtliche Proportionen vermissen.

c) Jedoch steckt die Verfassung den Anwendungsmöglichkeiten des Reziprozitäts-Prinzips Grenzen. Der Gesetzgeber darf nicht solche Rechte von der Bedingung der Gegenseitigkeit abhängig machen, die von Verfassungs wegen bereits als unbedingte garantiert sind. So erheben sich Bedenken gegen die bedingte Versagung des Armenrechts ( $\$ 114$ II 1 ZPO), weil dieses Recht eine sozialstaatlich legitimierte Voraussetzung des verfassungsrechtlichen Justizgewährleistungsanspruchs bildet (zum Verhältnis Armenrecht und Verfassung: Fechner JZ 1969, 349-354). Das Entsprechende gilt für die bedingte Vorenthaltung der Staatshaftung ( 8 RBHaftG); denn die Staatshaftung ist eine Emanation der Rechtsstaatlichkeit, die nicht nach der Staatsangehörigkeit unterscheidet. Die Eigenhaftung des Beamten, die bei fehlender Schuldübernahme durch den Dienstherrn eintritt, ist für den Geschädigten nicht immer die wirksame Kompensation. Im übrigen ist die Eigenhaftung bei Ausländerschäden eine gleichheitswidrige Belastung des handelnden Beamten (vgl. Frowein JZ 1964, 410-413; Wiese DVBl. 1964, 573-576; vgl. auch Grasmann JZ 1969, 455 f.). Allerdings entsteht für den geschädigten Ausländer in der Regel neben dem (unzulässig bedingten) Ersatzanspruch ein nicht gegenseitigkeits-bedingter Entschädigungsanspruch aus enteignungsgleichem Eingriff.

71) Zu Recht sieht Bachof einen Versto $B$ gegen die Menschenwürde eines Asylberechtigten dann als gegeben, wenn diesem jegliche Berufsarbeit verwehrt und er zum Objekt staatlicher Wohltätigkeit degradiert würde (N 67, S. 178). - Den Staatenlosen ist im Vorbehaltsbereich der Deutschenrechte weitgehende InländerGleichstellung gewährleistet durch das Gesetz über die Rechtsstellung heimatloser Ausländer im Bundesgebiet v. 25. 4. 1951 (insbes. $\$ \S 12-20$ ) und durch viele Einzelgesetze (z. B. § 2 II 2 AuslG, § 3 I 1 BArzteO, § 2 I 1 ApothG).

72) Aus den einzelnen Deutschenrechten wird ein Menschenrechtsgehalt oder Wesensgehalt zugunsten der Ausländer destilliert: 
wäre die Technizität der Vorbehaltrechte gefährdet, und mit ihr die Individualisierung der menschenrechtlichen Angleichungsgebote, die nicht jedem Ausländer Anteil an jedem Deutschenrecht verschaffen wollen, und auch nicht jeweils den gleichen Anteil.

2. Der systemgerechte Ansatz liegt bei Art. 2 Abs. 1 GG, dem subsidiären allgemeinen Freiheitsrecht, das die Grundrechtsbreschen zu schließen vermag. Das Blankettgrundrecht der Allgemeinen Handlungsfreiheit füllt sich mit menschenrechtlicher Substanz ${ }^{73}$ ). Es erschließt die Möglichkeit, das menschenrechtliche Minimum über die Verfassungsbeschwerde zur Geltung zu bringen.

Die wichtigste Funktion der Allgemeinen Handlungsfreiheit ist die grundrechtliche Sanktion des objektiv-rechtlichen Vorbehalts des Gesetzes, dem im Rahmen der Deutschenrechte eine besondere formelle Sicherungsfunktion zukommt ${ }^{74}$ ). Die

Dürig, in: GR II, 1954, S. 521-523; ders., M-D-H (N 27), Art. 1/Rn 85; Art. 2 I/Rn 66; Art. 11/Rn 119; Maunz, M-D-H, Art. 9/Rn 23; Herzog, M-D-H, Art. 8/Rn 12 f. Dagegen wird das menschenrechtliche Minimum unmittelbar aus Art. 1 I GG abgeleitet unter Ablehnung einer Ortsbestimmung beim einzelnen Deutschengrundrecht: Ruppel, Der Grundrechtsschutz der Ausländer im deutschen Verfassungsrecht, Diss. Würzburg 1968, S. 54-60, 198-201.

73) Die besonderen Freiheitsgrundrechte beanspruchen gegenüber der Allgemeinen Handlungsfreiheit nur soweit Vorrang, als sie in ihrer gegenständlichen und in ihrer personellen Reichweite eingreifen. Die Subsidiarität des Art. 2 I GG (Nachw. zur Judikatur des BVerfG: Leibholz-Rinck, GG, 19714, Art. 2/Rn 4), kommt also gegenüber Ausländern im Schutzbereich der Deutschenrechte nicht zum Zuge. Dïrigs Bedenken, der Ausländer könne bei Berufung auf Art. 2 I GG besser dastehen als der grundrechtlich privilegierte Deutsche (M-D-H [N 27], Art. 2 I/Rn 66), greift nicht durch, da die allgemeine Handlungsfreiheit durch den weitesten und elastischsten Schrankenvorbehalt des Grundrechtskatalogs relativiert ist und das umfassende Freiheitsblankett mit dem umfassenden Ordnungsblankett korrespondiert (Nachw. zur Judikatur des BVerfG: Leibholz-Rinck, a. a. O., Art. 2/Rn 5-8).

Art. 2 I GG wird als Auffangsgrundrecht im Vorbehaltsbereich der Deutschenrechte anerkannt von: BVerfG, B. v. 18. 7. 1973, DVB1. 1973, 79 (80 - zum Aufenthaltsrecht der Ausländer); Bachof (N 67), S. 178; Merten (N 27), S. 83; Rolvering (N 6), S. 120 f.; Zuleeg, DOV $1973,362 \mathrm{f}$. Dagegen wird den Ausländern im Negativraum der Deutschenrechte der Grundrechtsschutz (nicht aber der objektiv-rechtliche Schutz des Art. 20 III GG) versagt von: von Mangoldt-Klein (N 65), S. 302 f. (S. 388 f.); Maunz, in: M-D-H (N 27), Art. 12/Rn 6; von Münch, BK (Zweitbearb.), 1964/66, Art. 8/II Rn 2; Art. 9/II Rn 2. - Weit. Nachw. Dolde (N 15), S. 45 f. Anm. 1.

${ }^{74)}$ Der grundrechtliche Gesetzesvorbehalt, den Art. 2 I GG in dem Blankett der „verfassungsmäßigen Ordnung" aufweist, deckt den objektiv-rechtlichen Vorbehalt des Gesetzes ab, den Art. 20 III GG - als Ausprägung der rechtsstaatlichen Demokratie - enthält. 
Deutschenrechte schließen den Ausländer nicht schlechthin aus den geschützten Bereichen aus, vielmehr enthalten sie nur eine Eingriffsreserve. Solange diese noch nicht mobilisiert ist, genießt der Ausländer im Rahmen der Gesetze die gleiche Freiheit unter dem Gesetz wie der Deutsche. Er partizipiert an der Gewerbefreiheit, wie sie die Gewerbeordnung, an der Versammlungsfreiheit, wie sie das Versammlungsgesetz, an der Vereinsfreiheit, wie sie das Vereinsgesetz ausgestaltet. Da diese allgemeinen gesetzlichen Freiheiten auf den höheren Grundrechtsstandard der Deutschen abstellen, kommt dieser Grundrechtsstandard mittelbar auch dem Ausländer zugute ${ }^{75}$ ).

\section{Die Möglichkeit fortschreitender Status-Angleichung}

1. Die Funktion des allgemeinen Gleichheitssatzes für die Rechtsstellung der Ausländer sei an einem Fall exemplifiziert, den das Bundesverwaltungsgericht 1965 entschieden hat ${ }^{76}$ ): Die Satzung eines Landkreises über die Erhebung einer Schankerlaubnissteuer erhöht den Steuersatz für Ausländer um $\mathbf{4 0 0} \%$ gegenüber dem für deutsche Steuerschuldner geltenden Satz.

a) Das Bundesverwaltungsgericht sieht keinen Versto $\beta$ gegen Art. 3 Abs. 1 GG vorliegen. Es gibt die Begründung: daß die im öffentlichen Interesse bei Gastwirten besonders notwendige Uberwachung sich gegenüber Deutschen sachgerechter und einfacher durchführen lasse als gegenüber Ausländern, denen die gleiche Verbundenheit mit der im Bundesgebiet bestehenden Rechts- und Lebensordnung fehle ${ }^{77}$ ). Das Gericht zieht hier steuerfremde Gesichtspunkte der gebührenrechtlichen Kostendeckung heran und überspringt den Anknüpfungspunkt der

$\left.{ }^{75}\right)$ Dem vom Schutz des Art. 8 GG ausgeschlossenen Ausländer erkennt Giese ein „Reflexrecht“ kraft des gesetzlichen Versammlungsrechts zu (Grundgesetz für die Bundesrepublik Deutschland, 19512, Art. 8 Anm. II 1). Die Partizipation des Ausländers „an all den einfachgesetzlichen Freiheiten und Verbürgungen, die die Deutschenrechte dem Inländerrecht eingewoben haben", stellt Rupp dar (in: Festschrift für Küchenhoff II, 1972, S. 658-661).

Im Ergebnis entspricht der Grundrechtsschutz des Ausländers im Vorbehaltsbereich der Deutschenrechte der Konzeption Anschütz' zu den Weimarer Grundrechten, die nur „reichsgesetzeskräftig“ gelten und sich im wesentlichen nur über ihre formale Seite - die Gesetzmäßigkeit der Verwaltung - zugunsten der Ausländer auswirken sollten (Nachw. N 58).

76) BVerwG, U. v. 24. 9. 1965, E 22, 66-73.

77) BVerwG (N 76), S. 71. Ahnlich die Meinung Thiemes zur Zulässigkeit höherer Besteuerung der Ausländer (N 49, S. 113 - unter Berufung auf Isay, Internationales Finanzrecht, 1934, S. 49 f., 53, 54). 
Steuer, der in einem Aspekt der wirtschaftlichen Leistungsfähigkeit des Schuldners liegen muß. Die Ausländereigenschaft ist steuerindifferent. - Der Gleichheitssatz gebietet hier Systemgerechtigkeit und Formkonsequenz, über die sich zugleich die materiale Steuergerechtigkeit verwirklicht ${ }^{78}$ ). Dem deutschen Steuerrecht ist allgemein die Staatsangehörigkeit als steuerbegründendes Merkmal fremd. Die Eigenschaft des Steuerausländers oder -inländers hängt vom Wohnsitz und gewöhnlichen Aufenthalt, nicht von der Staatsangehörigkeit $\mathbf{a b}^{79}$ ). Sondersteuern für Ausländer sind seit der Aufklärung verpönt. Die diskriminierenden Vermögenseingriffe, wie sie das feudale Fremdlingsrecht vorsah, wurden von der Französischen Nationalversammlung 1790 als Schande der Menschheit verurteilt ${ }^{80}$ ). Es besteht kein Grund dazu, dieses Urteil heute zurückzunehmen.

2. Das Bundesverwaltungsgericht unternimmt noch einen zweiten Begründungsversuch für die Sonderbelastung des Ausländers: Da dem Ausländer das Grundrecht der Berufsfreiheit nicht zustehe, dürfe ihm die Betätigung in einzelnen Gewerbezweigen auch mit dem Mittel der Steuer erschwert werden ${ }^{81}$ ).

Hier wird unzulässig a fortiori gefolgert - von der Möglichkeit der Berufsversagung auf die Möglichkeit der Diskrimi-

78) Dazu Isensee, Umverteilung durch Sozialv́ersicherungsbeiträge, 1973 , S. $65 \mathrm{f}$.

Das Verbot, Ausländern besondere Abgaben aufzuerlegen, erfährt eine zusätzliche Begründung, wenn die Abgabe als Eingriff in den Schutzbereich des Eigentumsgrundrechts aus Art. 14 GG erkannt wird (dazu mit Nachw. Vogel, Finanzverfassung und politisches Ermessen, 1972, S. 36-46; Kirchhof, Besteuerungsgewalt und Grundgesetz, 1973, S. 20-55). Denn Art. 14 GG läßt als allgemeines Grundrecht ("Menschenrecht“) keine Ausländer-Diskriminierung zu. - Zur Gleichstellung des Ausländers sub specie des Art. 14 GG: Kimminich, BK (Zweitbearb., 1964), Art. 14/Rn 162-167; Maunz, M-D-H (N 27), Art. 14/Rn 11; Ruppel (N 72), S. 205 a-210.

70) Repräsentativ für die Rechtslage des Steuerrechts: \& 1 EStG, $\S 1$ UStG. Vgl. Kruse, Steuerrecht I, 1973', S. 52 f.; Walther W. Schmidt (N 10), S. 74-81; Schiedermair (N 8), S. 610-613; Friedrichsen (N 1), S. 209-220. Für die Zulässigkeit einer Sonderbesteuerung: Isay (N 28), S. 51-57; ders. (N 77), S. 47-55. - Zum völkerrechtlichen Postulat der Gleichbehandlung im Abgabenbereich: von Liszt, Das Völkerrecht, 1904", S. 201; Schindler (N 11), S. 59 f.; a. A. Wengler, Völkerrecht II, 1964, S. 1006.

80) Dekret vom 6. 8. 1790 - dazu Jordan (N 1), S. 302. Zum Fremdlingsrecht (ius detractus, ius albinagii): von Frisch (N 1), S. 25 f., 32, 34. Postulat der Abgabengleichheit: von Mohl (N 1), S. 635.

81) BVerwG (N 76), S. 70 f. - Ahnlich auch Isay (N 77), S. 54. 
nierung in der Berufsausübung. Es wäre grundrechtlich unbedenklich gewesen, hätte die öffentliche Hand dem Ausländer den Zugang zum Beruf völlig versperrt. Hat sie sich aber in der Phase der Berufszulassung einmal über den grundrechtlichen Minderstatus des Ausländers hinweggesetzt, so kann sie nachher nicht mehr beliebig darauf zurückkommen $\left.{ }^{82}\right)$. Es ist ein Gebot rechtsstaatlicher Konsequenz, daß der Staat von seinen selbstgesetzten Prämissen nicht ohne Grund mehr abweicht. ... beim zweiten ist er Knecht!

In der Phase der Berufsausübung kann nur noch unterschieden werden nach der jeweiligen beruflichen Rolle, nicht mehr nach der Staatsangehörigkeit. Der Gleichheitssatz läßt nicht zu, $\mathrm{da} B$ sich in einem Lebensbereich eine Zwei-Klassen-Ordnung bildet. Damit fordert er die materielle Gleichstellung des zum Beruf zugelassenen Ausländers mit den Deutschen. Wenn sich der Deutsche und der Ausländer hier auf der gleichen Stufe der Berufsausübungsfreiheit treffen, so ist es für den Ausländer ein Schritt hinauf, von der Stufe der grundrechtlich ungesicherten Zulassung; für den Deutschen ein Schritt hinab von der Höhe der am stärksten geschützten Berufswahlfreiheit auf die Stufe der geringeren Grundrechtssicherung ${ }^{89}$ ).

Das System der staatlichen Selbstbindung gegenüber den Ausländern ist also mit der Zulassung zum Aufenthalt noch nicht abgeschlossen - wenn der Ausländer zu einem deutschenrechtlich geschützten Lebensbereich zugelassen wird, verfestigt sich sein Grundrechtsstatus weiter.

Die in der Ära der Gastarbeiter praktisch wichtigsten Beispiele für die Möglichkeit zunehmender Status-Angleichung liefert das Arbeitsrecht. Der Staat ist grundrechtlich frei, einem Ausländer die Arbeitserlaubnis zu erteilen oder zu versagen ${ }^{84}$ ). Hat er sie erteilt, so muß er ihm die gleichen arbeitsrechtlichen

82) Ein Parallelproblem stellt sich im Wirtschaftsverfassungsrecht: Die Möglichkeit, daß die öffentliche Hand einen Privat-Wirtschaftsbereich sozialisieren oder in ein Finanzmonopol einbeziehen darf, erlaubt nicht den Schluß a maiore ad minus, daß ihr beliebige Interventionen (etwa über staatswirtschaftliche Konkurrenztätigkeit) gegenüber den Privatunternehmern gestattet seien, solange sie von Sozialisierung oder Monopolisierung absehe. Vgl. Uber, Freiheit des Berufs, 1952, S. 160, 168; Nipperdey, Soziale Marktwirtschaft und Grundgesetz, 1961², S. 26 f.; Bachof (N 67), S. 204; Isensee (N 51), S. 214 f. (Nachw.). - Vertreter der Gegenmeinung: Lutz Richter VVDStRL 6 (1929), S. 83 f.; Wïrtt.-Bad. VGH, U. v. 31. 8. 1950, DVBl. 1950, 754-756.

83) Nachw. zur "Stufenlehre" des BVerfG: Leibholz-Rinck (N 73), Art. 12/Rn 5-15 f.

8) Vgl. die gesetzliche Regelung in \$§ 18, 19 ArbeitsförderungsG. 
Bedingungen wie dem Inländer gewährleisten $\left.{ }^{85}\right)$. Im Rahmen eines begründeten Arbeitsverhältnisses kann nur noch auf die Rolle des Arbeitnehmers abgestellt werden $\left.{ }^{86}\right)$. Der Rekurs auf die Staatsangehörigkeit ist abgeschnitten. - Die Kette der Selbstbindung kann weitergehen, je nach dem Lebensbereich, den der Staat dem Ausländer eröffnet.

3. Die Arbeitserlaubnis erschließt den Zugang zur Koalitionsfreiheit. Hier bedarf es nicht mehr des allgemeinen Gleichheitssatzes, um die Gleichstellung ausländischer und deutscher Arbeitnehmer zu begründen. Die Koalitionsfreiheit ist als allgemeines Grundrecht konzipiert $\left.{ }^{87}\right)$. Der Unterschied zwischen deutschen und ausländischen Arbeitnehmern liegt allein darin, daB der Staat gegenüber dem Ausländer über die Grundrechtsvoraussetzungen disponieren kann. Für den Ausländer lebt die Koalitionsfreiheit erst auf, wenn sich der Zugang zum Beruf geöffnet hat. Ist die Arbeitserlaubnis aber erteilt, so gilt die Koalitionsfreiheit mit allen Konsequenzen bis zu Mitbestimmung und Arbeitskampffreiheit ${ }^{88}$ ).

85) Zur Rechtsstellung des ausländischen Arbeitnehmers mit Nachw.: Schiedermair (N 8), S. 579-610; Milke (N 16); Friedrichsen (N 1), S. 183-201. S. auch Isay (N 28), S. 332-343.

80) Das Verbot rollenfremder Unterscheidung wird vom BGH für die Strafzumessung anerkannt: Es liege ein Versto $B$ gegen Art. 3 GG vor, wenn der Ausländereigenschaft straferhöhende Bedeutung beigelegt werde (B. v. 28. 7. 1972, NJW 1972, 2191).

87) Zu Art. 159 WRV: Anschütz, Komm. (N 58), S. 732; Isay (N 28), S. 181 f. - Zu Art. 9 III GG: von Mangoldt-Klein (N 65), S. 328; Maunz, in: M-D-H (N 27), Art. 9/Rn 94; von Münch BK (Zweitbearb.), 1966, Art. 9/II Rn 101 f.; Ruppel (N 72), S. 204.

88) Das sachbezogene absolute Differenzierungsverbot des Art. 9 III GG gilt nicht nur für den unmittelbaren Schutzbereich des Grundrechts auf Verfassungsebene, sondern auch für den mittelbaren auf der Ebene der einfachgesetzlichen Grundrechts-Ausgestaltungen (Tarifrecht, Streikrecht, Mitbestimmung etc.). Daher liegt ein Versto B gegen Art. 9 III G (nicht nur gegen Art. 3 I GG) vor, wenn das Mitbestimmungsrecht - eine Ausprägung der Koalitionsfreiheit im einfachen Gesetzesrecht - den Ausländer benachteiligt und die Wählbarkeit zum Betriebsrat auf Arbeitnehmer beschränkt, die das Wahlrecht zum Deutschen Bundestag besitzen (so \& 7 I 1 BetrVerfG v. 11. 10. 1952; nunmehr ersetzt durch die verfassungsmäßige Lösung in $\$ 8$ BetrVerfG v. 15. 1. 1972).

Aus dem gleichen Grunde verstößt es gegen Art. 9 III GG, wenn dem Ausländer die Koalitionsbetätigung im Rahmen der Personalvertretung verkürzt wird (s. den Ausschluß der Wählbarkeit durch \& $10 \mathrm{I}$ d BPersVertrG v. 5. 8. 1955; dagegen aber $\mathrm{Zu}-$ erkennung des passiven Wahlrechts auch an Ausländer: \& 13 I Saarl. PersVertrG v. 9. 5. 1973). Auch hier gilt, daß der Staat an sich dem Ausländer den Zugang zum öffentlichen Dienst sperren darf (Art. 33 II GG e contrario). Hat der Dienstherr jedoch einen 
In diesem Zusammenhang ist allerdings vor einem modischen Argumentations-Holzweg zu warnen: Der Umstand, daß die Koalitionsfreiheit auch den Ausländern zusteht, läßt nicht den Schluß zu, daß der Staat grundrechtlich gezwungen sei, ausländischen Gebietszugehörigen die Arbeitserlaubnis zu erteilen, um die Koalitionsfreiheit für Ausländer nicht auszuhöhlen. Von der Notwendigkeit der Grundrechtsfolge kann nicht auf die Notwendigkeit der Grundrechtsvoraussetzung geschlossen werden.

Der Staat hält mit dem Deutschengrundrecht des Art. 12 I GG den Schlüssel zu allgemeinen Grundrechten in der Hand: so zur Pressefreiheit, soweit sie der Ort beruflicher Betätigung als Journalist oder Verleger ist, oder zu den Grundrechten, die in der Universität als Berufsfeld und Ausbildungsstätte organisiert sind. Die Unterscheidung zwischen allgemeinen Grundrechten und Deutschengrundrechten bedarf also der Ergänzung durch die Unterscheidung zwischen Grundrechten, deren Entstehungsvoraussetzung mit der Einreise erfüllt ist, und solchen, deren Entstehungsvoraussetzung der Staat auch nach der Aufenthaltnahme noch in der Hand hält.

Im Ergebnis läßt sich die Stellung des ausländischen Individuums in der Grundrechtsordnung als die Ermöglichung zunehmender Status-Verfestigung kennzeichnen, dem auf der Seite des Staates ein System fortschreitender Selbstbindung entspricht.

V. Grundrechtsstandard der Verfassung und Mindeststandard des Völkerrechts

Die bisherigen Ergebnisse werden nicht von den allgemeinen Regeln des völkerrechtlichen Fremdenrechts in Frage gestellt, die über Art. 25 GG in die innerstaatliche Rechtsordnung einbezogen sind. Das gilt auch dann, wenn man den Regeln Ver-

Ausländer eingestellt, so können diesem die rollenspezifischen Mitwirkungsrechte nicht vorenthalten werden. Soweit das Personalvertretungsrecht echte grundrechtlich legitimierte KoalitionsbetätIgung ermöglicht, wird auch der Einwand hinfällig, daß die Mitgliedschaft im Personalrat ein öffentliches Amt darstelle, das der Ausländer nicht innehaben könne (so aber Molitor, Bundespersonalvertretungsgesetz, 19582, §1/Anm. 2; \$10/Anm. 8). Wenn der Ausländer die Planstelle im öffentlichen Dienst ubernehmen kann, ist auch die Ausübung des Mitbestimmungs-,Amtes" vertretbar. Sowelt sich aber Bedenken erheben, daß über die Personalvertretung sich deutsche Hoheitsgewalt auf Ausländer verlagern könne, so gelten diese Bedenken letztlich einer Hypertrophie der Mitbestimmung im öffentlichen Dienst schlechthin, nicht der Beteiligung der Ausländer. Ein begründetes MiBbehagen sucht den falschen Ausweg. 
fassungsrang zuerkennt ${ }^{80}$ ). Sie gewährleisten dem Fremden nur einen Minimumstandard, den die Verfassung überschreiten darf und durchgehend überschritten hat. Sie erteilen dem Gesetzgeber nicht die Ermächtigung, einen höheren Grundrechtsstandard, wie er etwa im Bereich der Eigentums- und der Meinungsfreiheit gilt, auf einen niedrigeren völkerrechtlichen Minimumstandard zu senken ${ }^{90}$ ). Die eigentliche Bedeutung der grundgesetzlichen Rezeption des internationalen Fremdenrechts liegt darin, daß sich das Grundgesetz für eine Zukunft weltweiter Liberalisierung bereithält.

\section{E. Der sozialstaatliche Status}

I. Das soziale Staatsziel und der Angehörige eines fremden Staatsverbandes

1. Die Sozialstaatsklausel führt das Prinzip der sozialen Gleichheit in die Verfassung ein. Während die rechtsstaatliche Gleichheit Gleichheit im Freiheitsrecht bedeutet, stellt die soziale auf die gesellschaftlichen Bedingungen zur Freiheitsverwirklichung ab. Die grundrechtlich gewährleistete gleiche Freiheit ermöglicht tatsächliche gesellschaftliche Ungleichheit. Der Sozialstaat übernimmt die Verantwortung dafür, daß die rechtliche Freiheit Aller nicht zur tatsächlichen Freiheit Weniger verkümmert. Damit werden die grundrechtlichen Verbürgungen nicht abgeschwächt; sie erhalten vielmehr eine neue $\mathrm{Di}$ mension. Der Sozialstaat übernimmt die objektiv-rechtliche Garantie dafür, daß mit der rechtlichen Freiheitschance der Grundrechte auch eine reale Freiheitschance in den gesellschaftlichen Bedingungen korrespondiert.

Diese Garantenpflicht gilt nicht gegenüber dem Staatsverband, sondern gegenüber der Gesellschaft. Sie kommt nicht nur den Staatsbürgern, sondern auch den ausländischen Gesellschaftsbürgern zugute, die am Schutz der Grundrechte teilhaben, je nach dem Grad ihrer Status-Verfestigung ${ }^{91}$ ). Die Teilhabe des Ausländers an den sozialstaatlichen Leistungen, etwa im Bereich der sozialen Sicherheit und der Daseinsvorsorge, hängt von der jeweiligen Dauer des Aufenthalts und dem

"9) These des Verfassungsranges der "allgemeinen Regeln": Doehring (N 11), S. 173-187 (mit Nachw, zu herrschender Gegenmeinung).

o) So aber Doehring (N 11), S. 167-172, 183, 187, 192 1.; ders., ZaöRV 25 (1965), 484. - Dazu kritisch Tomuschat (N 16), S. $55 \mathrm{f}$.

1) Die Geltung der Sozialstaatsgarantle zugunsten ausländischer Gesellschaftsbürger setzt voraus: BVerwG, U. v. 3. 5. 1973, DOV 1973,859 (861). 
Grad der gesellschaftlichen Integration $\mathrm{ab}^{\mathbf{9}}$ ). Jedoch kommt dem fremden Staatsangehörigen als solchem keine spezifische sozialstaatliche Rolle zu. $\mathrm{Er}$ ist nicht von vornherein besonders sozial schutzbedürftiges). Ihm ist nicht a priori in den sozialstaatlich motivierten Umverteilungsprozessen der Platz auf der Nehmens- oder auf der Gebensseite zugewiesen.

2. Wenn der Sozialstaat bei der Vergabe knapper Güter Prioritäten setzt, so muß er Deutsche in den Bereichen bevorzugen, in denen sie bereits grundrechtlich einen Vorrang genießen. Dies ist der Fall bei der Vergabe von Studienplätzen, aufgrund des Deutschenrechts der freien Wahl der Ausbildungsstätte $\left.{ }^{94}\right)$. Jedoch ergibt sich damit nicht die Verpflichtung, den Ausländern Studienplätze so lange zu versagen, bis auch der letzte deutsche Bewerber Berücksichtigung gefunden hat $\left.{ }^{\circ 5}\right)$. Der grundrechtsermöglichende Verteilerstaat hat weiteren Entscheidungsspielraum als der grundrechtsbeschränkende Eingriffsstaat. Dagegen darf bei der Vergabe von existenznotwendigen Leistungen, auf die der Ausländer wie der Deutsche unentrinnbar angewiesen ist, etwa im Elementarbereich der Sozialhilfe und der Daseinsvorsorge, nicht nach der Staatsangehörigkeit differenziert werden ${ }^{96}$ ).

II. Das soziale Staatsziel und der Angehörige eines fremden Kulturkreises

1. Die Fragestellung und mit ihr die Funktion der Sozialstaatsgarantie wandelt sich, wenn der Ausländer nicht, wie

7) Daß der Ausländer zur Nutzung der öffentlichen Einrichtungen unter den gleichen Bedingungen zuzulassen ist, wie der Staatsangehörige, gehört zu den hergebrachten Grundsätzen des deutschen Verwaltungsrechts. S. bereits Jordan (N 1), S. 307; von Mohl (N 1), S. 634.

97) Von dieser Prämisse scheint jedoch Zuleeg auszugehen (DOV $1973,364,366,368)$.

94) Zur verfassungsrechtlichen Unbedenklichkeit, Deutsche bei der Studienzulassung zu bevorzugen: Thieme, Deutsches Hochschulrecht, 1956, S. 317.

06) Das BVerfG hält Numerus-clausus-Regelungen für zulässig, die einen bestimmten Prozentsatz der Studienplätze Ausländern vorbehalten (E 33, 303 [348]). S. dazu Art. 11 II 2 Staatsvertrag über die Vergabe von Studienplätzen v. 20. 10. 1972 (Saarl. ABl. 1973, 194); \$ 8 II 2 Saarl. Zustimmungsgesetz v. 28. 2. 1973 (ABl. S. 192) und § 13 Saarl. Durchführungsvo v. 29. 5. 1973 (ABl. S. 309).

6) Diesem Erfordernis genügt \$120 I BSHG. Zur Stellung des Ausländers im Sozialrecht mit Nachw.: Schewe, Nordhorn und Schenke, Ubersicht über die Soziale Sicherung, 19708, S. 253-258; Wannagat, Lehrbuch des Sozialversicherungsrechts I, 1965, S. 395424; Friedrichsen (N 1), S. 221-250; Ruppel (N 72), S. 210-214; Schiedermair (N 8), S. 593-610. 
bisher, als Angehöriger einer fremden Rechtsgemeinschaft, sondern als Angehöriger eines fremden Kulturkreises betrachtet, wenn also das Merkmal der Fremdheit nicht als normatives, sondern als soziologisches Kriterium verstanden wird. $\mathrm{DaB}$ der Rechtsstaat niemanden benachteiligen darf, weil er sich nach Sprache, Heimat, Herkunft, Religion von der Mehrheit der deutschen Bevölkerung unterscheidet, ist nach Art. 3 Abs. 3 GG selbstverständlich. Offen ist aber, welche Impulse der Sozialstaat zur Bewältigung der Schwierigkeiten erteilt, die sich für den Fremden wie für das Gastland aus der Berührung unterschiedlicher Lebensformen ergeben können.

Bei konkreten Folgerungen aus der Sozialstaatsklausel ist Zurückhaltung geboten. Die Deduktionslust vieler SozialstaatsDeuter weckt leicht die Vorstellung, daß die Sozialstaatsklausel in kaninchenhafter Fruchtbarkeit Leistungsansprüche und institutionelle Garantien gebäre ${ }^{07}$ ). Die soziale Staatszielbestimmung ist eine unvollständige Verfassungsnorm, die der Ausfüllung und Ausführung durch den politisch Handelnden bedarf. Die Sicht des politisch Handelnden, der den Verfassungsimpuls aufnimmt und in Aktionsprogramme umsetzt, ist dem Verfassungsexegeten verwehrt, der nicht politische Spekulation, sondern juristische Reflexion zu leisten hat. Die Uberlegungen können daher eine bestimmte Abstraktionshöhe nicht verlassen.

2. a) Die sozialstaatlichen Impulse zur Integration der Ausländer sind notwendig determiniert durch die bevölkerungspolitischen Vorentscheidungen über Dauer und Ziel des Aufenthaltes. Die Sozialstaatlichkeit gibt ein gesellschaftspolitisches, kein bevölkerungspolitisches Mandat. Sie postuliert die Herstellung sozialer Gerechtigkeit in einer definierten Gesellschaft; sie leistet selbst nicht die Definition. - Eine systematische Assimilationspolitik gegenüber Fremden, die keinen Einwanderungsanspruch haben, verstöBt gegen das rechtsstaatliche Konsequenzgebot ${ }^{98}$ ).

97) So leitet das BVerwG aus der Sozialstaatsklausel den Anspruch einer spanischen Großmutter darauf ab, die Aufenthaltserlaubnis zum Zwecke der Betreuung ihrer Enkelkinder zu erhalten (U. v. 3.5. 1973, DOV 1973, 859 [861]). Proben waghalsiger Deduktions-Kunststücke bietet Zuleeg, der "aus dem Sozialstaatsgebot noch weitere Rechte des Ausländers fließen" sieht: u. a. „ein Recht auf einen Platz im Kindergarten und ein Recht auf menschenwürdige Wohnung“ (DOV 1973, 369).

$\left.{ }^{98}\right)$ Die bevölkerungs- und aufenthaltspolizeiliche Zielunsicherheit kennzeichnet insbesondere das Dilemma, eine Schulkonzeption für die Kinder ausländischer Arbeitnehmer zu finden und die sachge- 
b) Das sozialstaatliche Ziel der "Einheitlichkeit der Lebensverhältnisse" enthält auch nicht den Auftrag, die Entstehung nationaler und kultureller Minderheiten zu verhindern und dazu etwa das Integrationsmedium der Schule einzusetzen. Der Sozialstaat ist kein Fichte'scher "Zwingherr zur Deutschheit". Das sozialstaatliche Homogenitätsgebot bezieht sich nur auf die Herstellung der realen Bedingungen, unter denen individuelle Entfaltung und freie Differenzierung in einer offenen Gesellschaft möglich sind ${ }^{90}$ ).

c) Auf der anderen Seite entspricht es dem sozialen Staatsziel, daß der Staat, der dem Fremden für begrenzte Zeit Aufnahme gewährt und damit begrenzte Verantwortung übernimmt, Eingliederungshilfe leistet, dem mit deutschen Verhältnissen Unvertrauten die Selbstbehauptung in der deutschen Gesellschaft ermöglicht und zu "gesellschaftlicher Tüchtigkeit" verhilft (um das Erziehungsziel des Art. 120 WRV zu apostrophieren) ${ }^{100}$ ).

d) Die Grundrechte gewährleisten dem Fremden wie dem Einheimischen die Wahrung seiner nationalen und kulturellen Eigenart. Besondere Bedeutung kommt dabei dem Elternrecht zu, das die souveräne Entscheidung über die Erziehungsziele den Eltern vorbehält und damit das eigentliche Rechtsfunda-

mäße Lösung der Frage zu entwickeln, wieweit sich das Lehrprogramm an den Erfordernissen des Heimatstaates oder des Aufenthaltstaates auszurichten hat. Die kulturpolitische Linke des Staates scheint nicht genau zu wissen, was die ausländerpolizeiliche Rechte tut. Dokumente dieser Unsicherheit: Bundesminister für Bildung und Wissenschaft (N 47), S. 1-6; Ministerpräsident von RheinlandPfalz (N 5), S. 7 f.; Bay. Bericht (N 4), S. 32 f.; Ständige Konferenz der Konferenz der Kultusminister der Länder, B. v. 3. 12,1972 über den Unterricht für Kinder ausländischer Arbeitnehmer (Bay. GMBl. 1972, 50). Zur Schulproblematik: Bingemer (N 4), S. 130-132; Diamant, in: Klee (N 4), S. 58-103.

90) Daher läßt sich aus der Sozialstaatsklausel nicht das Gebot ableiten, der Bildung von Ausländervierteln ("Türken-Gettos") in den Städten entgegenzuwirken, solange diese Enklaven der Bevölkerungsminderheit die Wahrung ihrer eigentümlichen Lebensformen erlauben und die räumliche Absonderung nicht durch Diskriminierung oder wirtschaftliche Not erzwungen wird. Das soziale Staatsziel rechtfertigt den Schutz vor Verelendung, nicht aber den Oktroi deutscher Verhaltensmuster oder die kulturelle Absorption. - Auf der anderen Seite steht die Verfassung einer Gesellschaftspolitik nicht entgegen, die auf Integration ausgerichtet ist (s. auch $\mathrm{N}$ 103). Die Verfassung ist hier in weitem Maße offen.

100) Kataloge von Eingliederungshilfen zugunsten ausländischer Arbeitnehmer und threr Familien: "Grundsätze“ des Koordinierungskreises (N 5); Bericht des Ministerpräsidenten von RheinlandPfalz (N 5), S. $4-9$. 
ment des gesellschaftlichen Pluralismus bildet. Der Staat hat bei der Erfüllung seines eigenen Erziehungs- und Bildungsauftrags das Elternrecht der Ausländer zu achten ${ }^{101}$ ). Er folgt dem sozialstaatlichen Gebot einer wirksamen Grundrechtsermöglichung, wenn er als Träger der Schulhoheit den Bedürfnissen der ausländischen Minderheiten Rechnung trägt und für eine differenzierte Schulorganisation wie ein minderheitengemäßes Unterrichtsprogramm sorgt oder die Voraussetzungen dafür schafft, daß private Schulträger ein solches Bildungsprogramm anbieten können. Das soziale Staatsziel rechtfertigt auch die Annahme eines "besonderen prädagogischen Interesses" an einer privaten Volksschule für Kinder einer fremden Bevölkerungsgruppe $\left.{ }^{102}\right)$. Der staatlichen Schulaufsicht obliegt es, den für die deutsche Gesellschaft erforderlichen Homogenitätsstandard (im Lehrgegenstand wie im Lehrniveau) durchzusetzen ${ }^{103}$ ). - Im Ergebnis macht es keinen Unterschied für die sozialstaatliche und die grundrechtliche Fragestellung, ob sich die kulturellen Minderheiten aus Staatsfremden oder aus Deutschen zusammensetzen ${ }^{104}$ ).

101) Zum „publizistischen Schutz" der Kulturansprüche größerer Bevölkerungsgruppen innerhalb des Schulsystems der Weimarer Verfassung: Holstein AöR 51 (1927), 215-219. - Zum aktuellen Verhältnis des Elternrechts zur staatlichen Schulhoheit: BVerfG, U. v. 6. 12. 1972, NJW 1973, 133 (134, 138); OVG Berlin, U. v. 7. 12. 1972, NJW 1973, 819 f.; Oppermann, Kulturverwaltungsrecht, 1969, S. 159, 262-264; Ossenbühl AöR 98 (1973), 368-380 (Nachw.).

102) Das „besondere pädagogische Interesse“ (Art. 7 V GG) wird für private Volksschulen nationaler Minderheiten bejaht von Oppermann (N 101), S. 218. Zum Inhalt des "pädagogischen Interesses" bei Minderheitenschulen: OVG Lïneburg, U. v. 27. 1. 1954, DVBl. 1954, 255 (256 - zu einer dänischen Schule in Südschleswig). - Unzutreffend dagegen: Beschl. d. KMK (N 98), Nr. 1.1.

103) Der Vorbehalt der staatlichen Schulaufsicht (Art. 7 I GG) stellt klar, daß der Staat des Grundgesetzes nicht gewillt ist, über den Garantien der individuellen und gruppenmäßigen Differenzierung das Ziel der nationalen Integration zu vernachlässigen (noch heute grundlegend: Holstein AöR 51 [1927], 251 f.). Der grundrechtliche und sozialstaatliche Schutz der ausländischen Bevölkerungsteile begründet keinen Anspruch darauf, daß die Institutionen, die Kontinuität, Einheitsbewußtsein und Zukunftswillen Deutschlands verkörpern, aufgelöst werden, daß etwa die Spracheinheit im staatlichen Bereich aufgegeben wird.

104) Die Grundrechtskonflikte, die auftreten, wenn ein Mohammedaner türkischer Nationalität durch die Arbeitsbedingungen seines deutschen Betriebs an der Einhaltung seiner religiösen Pflichten gehindert wird (Beisp.: LAG Dïsseldorf, U. v. 14. 2. 1963, JZ 1964, 258 f.; dazu Habscheid JZ 1964, 246-249), können sich in gleicher Weise für einen deutschen Anhänger des Islam erheben. Der Ausgleich zwischen der Individualfreiheit des Ausländers und den Institutionen der deutschen Rechtsordnung, die auf die Bevölkerungs- 
3. Das Ziel des Grundgesetzes, soziale Spannungen zu verhindern, wird nicht durch die Einebnung individueller und gruppenmäßiger Besonderheiten, sondern durch Erziehung zur Toleranz erfüllt. Die sozialstaatliche Garantenpflicht umfaßt auch die Aufgabe, innergesellschaftliche Diskriminierung oder erzwungene innergesellschaftliche Isolierung zu verhindern und Tendenzen zur Xenophobie entgegenzuwirken ${ }^{105}$ ). Hier deckt sich das sozialstaatliche Programm mit den Zielen der grundrechtlichen Drittwirkung. Letztlich sind die Bedingungen für eine freie Selbstentfaltung des Fremden in der deutschen Gesellschaft nicht staatlich organisierbar. Sie hängen von der existentiellen Entscheidung jedes Gesellschaftsbürgers ab, ob er das Recht des Fremden als das Recht des Nächsten achten will. Freiheit und Gleichheit haben nur eine reale Chance, wenn das von ihrem Glanz verdunkelte dritte republikanische Ideal gesellschaftliches Leben erhält $\left.{ }^{106}\right)$.

\section{F. Der demokratische Status}

\section{Teilhabe an der Entscheidungsmacht des Staatsvolkes}

Der status activus ist bisher offen geblieben. - Wenn Demokratie fordert, daß das Volk nicht nur Objekt der Staatsherrschaft, sondern auch ihr Subjekt sei - muß sie dann nicht

mehrheit zugeschnitten sind, bildet kein spezifisch ausländerrechtliches Minderheitenproblem. Entsprechendes gilt von der rechtlichen Bewältigung der Fragen, die sich aus der mangelnden Beherrschung der deutschen Sprache ergeben (zur Sprache im Verwaltungsverfahren: Ebner DVB1. 1971, 341 345; zu Sprachschwierigkeiten bei der Ausübung des betrieblichen Wahlrechts: Schlessmann DB 1964, $586 \mathrm{f}$.; Halberstadt DB 1965, 780 f.).

105) Ein Programm, das auf diese Aufgabe ausgerichtet ist: UNKonvention zur Beseitigung jeder Form von Rassendiskriminierung v. 21. 12. 1965 (Ratifikation durch die Bundesrepublik Deutschland: BGBl. 1969 II, S. 961, 2211); dazu: Partsch, Rassendiskriminierung, 1971; Ermacora, Diskriminierungsschutz und Diskriminierungsverbot in der Arbeit der Vereinten Nationen, 1971 (Lit.). - Zu innergesellschaftlichen Diskriminierungsverboten aus völkerrechtlicher Sicht: Schindler (N 11), S. 149-153. Beispiele arbeitsrechtlicher Vorkehrungen zur betrieblichen Eingliederung ausländischer Arbeitnehmer und zum Schutz vor Benachteiligung: \$§ 75 I, 80 I 7 BetrVerfG; § 56 I 1 BPersVertrG; $\$ \$ 70$ II 1, 71 I f. Saarl. PersVertr.G. Zur rechtlichen Behandlung innergesellschaftlicher Diskriminierung ( $\mathrm{Zu}$ trittsverbot zu Gaststätten): Horstmann und Weber, Staats- und Kommunalverwaltung 1967 , S. 33-36, 63-67.

106) Zur Fraternite in verfassungsrechtlicher und verfassungshistorischer Sicht: Herbert Krüger, in: Festgabe für Maunz, 1971, S. 249265; Fritz Werner, in: Recht und Gericht in unserer Zeit, 1971, S. 78-90. - Zum „Recht des Nächsten“: Erik Wolf, in: Die AlbertLudwigs-Universität Freiburg 1457-1957, 1957, S. 43-56. 
dem Staatsfremden die volle politische Gleichstellung - vor allem im Wahlrecht - einräumen?

1. Das Grundgesetz schließt den Ausländer nicht ausdrücklich vom Wahlrecht aus, das es als "allgemeines" gewährleistet. Gleichwohl deckt sich die Allgemeinheit der Wählerschaft nicht mit dem Kreis der Untertanen und Grundrechtsträger. Die demokratische Gleichheit hängt nicht vom Umfang der rechtsstaatlichen und der sozialen Gleichheit ab. Demokratie ist Herrschaftszuständigkeit, nicht Herrschaftsziel oder Herrschaftsgrenze, wie sie die soziale Rechtsstaatlichkeit markiert. Das demokratische System rechtfertigt sich nicht aus seinem Staatszweck (weder einem liberalen noch einem sozialen), sondern aus der selbstzweckhaften, ursprunghaften Souveränität des Volkes, das als Einheit vorausgesetzt wird ${ }^{107}$ ). Demokratie empfängt ihre Identität aus dem Staatsverband ${ }^{108}$ ). Das „Volk“ als Träger der Staatsgewalt wird durch die personale Dauerbeziehung der Staatsangehörigkeit, nicht durch die fluktuierende Gebietszugehörigkeit konstituiert $\left.{ }^{109}\right)$. Die Teilhabe des Staats-

107) Dagegen hält Zuleeg das demokratische Verfassungsprinzip nur für ein Instrument der Sozialstaatlichkeit - mit der Folge, daß das Wahlrecht nach sozialen Bedürfnissen verliehen werden soll (DOV 1973, 370). Die Verleihung des Wahlrechts an Ausländer (mit unterschiedlichen Vorbedingungen) sehen als verfassungsrechtlich zulässig an: Dolde (N 15), S. $72-78$ (widersinnige Zulassung des passiven Wahlrechts, bei Ausschluß des aktiven); ders. DOV 1973, 372.

$\left.{ }^{108}\right)$ Eine Gegenlösung entwickelte die Sowjetverfassung von 1918, die an die Stelle des Staatsverbandes die "Gesellschaft aller Werktätigen in Rußland" treten ließ und die Staatsangehörigkeit als Grundlage der politischen Rechte durch die Klassenzugehörigkeit ersetzte. Wenn damit Ausländer, die sich in der Sowjetunion zwecks werktätiger Beschäftigung aufhielten, das Wahlrecht bekamen, wurde es den einheimischen Klassenfeinden entzogen $(V 10,20$, XIII $64 \mathrm{f}$. Verfassung v. 10. 7. 1918). Eine Aufhebung der politischen Abgrenzungen im kosmopolitischen Sinne wurde also nicht angestrebt. - Zu diesem Verfassungskonzept, das die geltende Verfassung von 1936 (Art. 34) nicht mehr übernommen hat: Maklerow-Timaschew u. a., Das Recht Sowjetrußlands 1925, S. 39 f.; Kelsen, Vom Wesen und Wert der Demokratie, $1929^{2}$ (Nachdr. 1963), S. 18; Carl Schmitt (N 58), S. 234.

$\left.{ }^{109}\right)$ Art. 20 II 1 GG meint in seinem „Volks"-Begriff, an den Art. 21 I 1 und Art. 38 I 2 GG anknüpfen, den Verband der Staatsangehörigen, während Art. 20 II 2 GG den engeren Kreis der stimmberechtigten Staatsangehörigen, die Aktivbürgerschaft, zum Gegenstand hat. Vgl. von Mangoldt-Klein (N 65), S. 593, 595; Maunz, in: MD-H (N 27), Art. 20/Rn 48 f.; Wernicke, in: BK, Stand 1972, Art. 20/ II 1 c; Tomuschat (N 16), S. 56-63. Das Wahlrecht wird von Verfassungs wegen den Staatsangehörigen vorbehalten: Hesse (N 64), S. 59; Schmitt Glaeser, Mißbrauch und Verwirkung der Grundrechte im politischen Meinungskampf, 1968, S. 185 f.; Maunz a. a. O., Art. 38/ 
angehörigen an der Selbstbestimmung des Staatsverbandes ist der Ausgleich für seine lebenslange, unentrinnbare Angewiesenheit auf den Verband. Die Angewiesenheit begründet wiederum die Erwartung, da $B$ der Einzelne seine demokratische Freiheit im Dienst des Gemeinschaftswesens ausüben werde, von dessen Zukunft sein eigenes Los abhängt.

Legitimation und Ethos der Demokratie entfallen, wenn das Wahlrecht von der Staatsangehörigkeit gelöst und Verbandsfremden zugestanden wird. Die Grenze zwischen demokratischer Selbstbestimmung des Staatsverbandes und demokratiewidriger Fremdbestimmung durch Außenstehende wird überschritten. - Mit der Verleihung des Wahlrechts an Ausländer bilden sich zwei Klassen von Aktivbürgern: auf der einen Seite der ausländische Transitbürger, der nicht unbedingt auf die deutsche politische Organisation angewiesen ist, und der sich den Folgen seiner Entscheidungen jederzeit durch Rückzug in sein Heimatland entziehen kannn ${ }^{110}$, auf der anderen Seite der deutsche Staatsbürger auf Lebenszeit, der diese Folgen unentrinnbar zu tragen hat ${ }^{111}$ ).

Rn 39; Tomuschat a.a. O., S. 56 f.; Papke NJW 1960, 2337; Ruppel (N 72), S. 23 f., 186-188; Rose JR 1973, 226; Schiedermair (N 8), S. 446 f.; Thieme (N 49), S. 64 (anders aber S. 88-90); Behrend DOV $1973,376 \mathrm{f}$.

Der Ausschluß der Ausländer von der Entscheidungsgewalt des Staatsvolkes entspricht der Tradition der deutschen Staatsrechtslehre und Allgemeinen Staatslehre: Jordan (N 1), S. 317; von Mohl (N 1), S. 626, 628; Georg Jellinek, Allgemeine Staatslehre, 1914, (7. Nachdr. 1960), S. 723; Anschütz, Die Verfassungsurkunde (N 58), S. 99; ders., Komm. (N 58), S. 510 f., 513; Hatschek (N 58), S. 266 f.; Laun, in: Anschütz-Thoma I (N 58), S. 244; Strupp, ebd., S. 275, 278; Sartorius, ebd., S. 281; Thoma, in: Nipperdey (N 58), S. 27; Carl Schmitt (N 58), S. 168 f.; Kelsen, Allgemeine Staatslehre, 1925 (Nachdr. 1966), S. 159; Kotthaus, Die Rechtsstellung der Ausländer in der Weimarer Verfassung . . ., Diss. Erlangen 1933, S. 25 f. Skepsis gegenüber der herkömmlichen Anknüpfung der politischen Rechte an die Staatsangehörgikeit äußern: von Frisch (N 1), S. 116 f., 352356; Kelsen (N 108), S. 17 f.; Grabitz (N 10), S. 25-54, 106-116.

Das Völkerrecht fordert die Zuweisung eines status activus an Fremde nicht: von Liszt, Das Völkerrecht, $1904^{3}$, S. 202; Berber (N 9), S. 382; Menzel, Völkerrecht, 1962, S. 203; Kimminich, Archiv des Völkerrechts $10(1962 / 63)$, S. 134-137; Schindler (N 11), S. 12 f.; Thomsen, Die politische Betätigung von Ausländern nach deutschem Verfassungs- und Verwaltungsrecht, Diss. Bonn 1968, S. 5-32 (Nachw.).

110) Vgl. Tomuschat (N 16), S. 60.

11i) Dieser Unterschied wird nicht dadurch verwischt, daß für den Deutschen, der innerhalb des Bundesgebiets umzieht, das Wahlrecht für das jeweilige Landes- oder Kommunalparlament dem Wohnsitz folgt. Der Deutsche verläßt damit nicht den gesamtstaatlichen Verband, der die Länder und Kommunen als Gliedverbände um- 
2. Wenn der ausländische Bewohner des Bundesgebiets den deutschen Gesetzen Gehorsam schuldet, so ist es kein Gebot kompensatorischer Konsequenz, daß er deshalb die Gesetze auch mitgestalten müsse. Die Kompensation für die Herrschaft der Rechtsordnung ist der Schutz durch die Rechtsordnung ${ }^{112}$ ). Der soziale Rechtsstaat wiegt den status passivus durch die Zuweisung des status positivus und negativus auf.

Allerdings dürfen dem Ausländer auch nicht die Lasten aufgebürdet werden, die aus der Mitgliedschaft im Staatsverband erwachsen und die in der demokratischen Solidarität begründet sind: wie die Pflicht zur Ubernahme öffentlicher Ehrenämter und die Wehrpflicht'119). Die Utberwälzung von Verbandslasten und die Einräumung von Verbandsvorteilen drängten den Ausländer in den Zustand faktischer Doppelstaatlichkeit, stürzten ihn in Loyalitätskonflikte und wirkten als planmäßige Desintegration von seinem Heimatstaat. Ein solches Vorgehen verletzte allgemeines Völkerrecht, das über Art. 25 GG auch staatsrechtlich wirksam ist.

schließt, sie zu einer politischen wie wirtschaftlichen Schicksalsgemeinschaft eint und ihre wechelseitige Solidarität fordert. $\mathrm{Da}$ die Gliedkörperschaften der Föderation verfassungsrechtlich homogen sind, können die Bürger ein gemeinsames Indigenat beanspruchen, wie es Art. 28, 33 I, 38 GG statuieren. Die Bedingungen der bundesstaatlichen Solidarität und Homogenität sind im Rahmen der völkerrechtlichen geordneten Staatenwelt nicht erfüllt - auch nicht im Rahmen der Europäischen Gemeinschaften nach ihrem gegenwärtigen Entwicklungsstand (zum Marktbürger ohne Aktivbürgerrecht und zur "Gemeinschaft ohne Gemeinschaftsvolk" : Ipsen [N 10], S. 252 f., 997-999; Grabitz [N 10], S. 88 f.).

112) Der Gedanke einer Rechte-Pflichten-Aquivalenz im Ausländerstatus (allerdings verdeckt unter dem finanzrechtlichen Aquivalenzprinzip) klingt an bei von Mohl (N 1, S. 635 f.); Isay (N 28), S. 55-60; dems. (N 77), S. 37. Die Kompensation der Rechtslasten gegen die Rechtsvorteile wird formuliert in § 24 Sächs. Verf. 1831 (N 50).

${ }^{113}$ ) Die Einbeziehung von Ausländern in die Wehrpflicht wird aus völkerrechtlichen Gründen (zumindest für den Regelfall) abgelehnt von: Jaenicke und Doehring, ZaöRV 16 (1955/56), 523-566; Doehring Art. "Wehrpflicht", in: WbVR I (N 19), S. 813, 816 (Bedenken gegen $\S 2$ I WehrpflichtG); ders. (N 11), S. 181; Verdroß (N 19), S. 369; Berber (N 9), S. 383. - Ahnlich aus staatsrechtlicher Sicht: Anschütz, Komm. (N 58), S. 513; Zachariae (N 25), S. 271; Thieme (N 49), S. 63; Gegenansicht: Wengler, Völkerrecht II, 1964, S. 946 f., 1006; Menzel (N 109), S. 203. Wenn über konkrete, rechtlich sanktionierte Staatsbürgerpflichten hinaus noch eine allgemeine Treupflicht des Staatsbürgers angenommen wird, der ein Fremder nicht unterliegt (s. etwa Berber, N 9, S. 382 f.; Thieme [N 49], S. 63 f.), so ist diese, bel juristischem Lichte betrachtet, "nur ein ethisch-politisches Postulat ohne rechtliche Bedeutung" (Kelsen, [N 109], S. 159; ähnlich Georg Jellinek [N 8], S. 198). 
3. Mit der Verleihung des Wahlrechts an eine Personengruppe, der kein gesichertes Aufenthaltsrecht zusteht, fiele der Exekutive, die über den Aufenthalt entscheidet, die Macht zu, über die Wählerstruktur zu verfügen. Aufenthaltspolitik könnte unkontrollierbar in den Dienst der wahlstrategischen Machtbehauptung gestellt werden - als neuartige „überlegale Prämie auf den legalen Machtbesitz" der amtierenden Exekutivspitze $\left.{ }^{114}\right)$. Die demokratische Gleichheit setzt daher notwendig die volle rechtsstaatliche Gleichheit voraus, zu der auch die grundrechtliche Gleichstellung im Aufenthaltsrecht, in der Freizügigkeit wie in der beruflichen Niederlassungsfreiheit gehört.

\section{Ausübung staatlicher Ämter}

Das Junktim zwischen der Zugehörigkeit zum Staatsverband und der Teilhabe an der demokratischen Herrschaft wird vom Grundgesetz nicht durchbrochen, wenn es dem Ausländer den Zugang zum öffentlichen Dienst nicht schlechthin versperrt und bei "dringendem dienstlichen Bedürfnis" auch der Verbeamtung nicht entgegensteht ${ }^{115}$ ). Der Amtswalter der Exekutive übt nur abgeleitete, weisungsgebundene, entziehbare öffentliche Gewalt aus - im Gegensatz zum Aktivbürger, dem originäre, souveräne Entscheidungsmacht zukommt. Im übrigen sind Organwalterstellungen auf der Ebene der Staatsorgane den Ausländern verschlossen, auch wenn das Grundgesetz nur für den Bundespräsidenten ausdrücklich die Deutscheneigenschaft vorschreibt $\left.{ }^{116}\right)$. Wenn die Identität von Regierenden und Regierten unerfüllbares Ideal bleibt, so muß mindestens das

114) Dazu Carl Schmitt, Legalität und Legitimität (1932), in: Verfassungsrechtliche Aufsätze, 1958, S. 283-293.

115) Vgl. § 4 II BRRG, \& 7 II BGB. Zur verfassungsrechtlichen Stellung des Ausländers im Negativbereich des Art. 33 II GG: Nachw. bei Dolde (N 15), S. 79.

116) Nur formalistische Verfassungsauslegung kann zu dem Umkehrschluß aus Art. 54 I 2 GG führen, daß Bundeskanzler, Bundesminister, Parlamentsabgeordnete und sonstige höchste Organwalter in Bund und Ländern nicht Deutsche sein müßten (so aber Thieme [N 49], S. 88; Friedrichsen [N 1], S. 279; Dolde [N 15], S. 72-82). Diese Auslegung verkennt die Bedingungen demokratischer Repräsentation. Insbesondere ist es in diesem Zusammenhange verfehlt, den Rechtsgedanken des Art. 33 II GG zu bemühen (so aber Dolde a. a. O., S. 74). Von der Ebene des öffentlichen Dienstes führt keine Analogiebrüicke auf die Ebene der Staatsorgane. Auf der ersten Ebene dominieren die Regeln der rechtsstaatlichen Gleichheit (Art. 33 II GG), auf der zweiten die der demokratischen Repräsentation. Die Besetzung der Staatsorgane folgt nicht den formalisierten Eignungskriterien des Art. 33 II GG, sondern den Regeln materialer Legitimation, die der souveräne Wille des Staatsvolkes verleiht, die aber auch die Zugehörigkeit zum Staasvolk voraussetzt. 
demokratische Gebot der Homogenität von Volk und Volksrepräsentanten verwirklicht werden.

Im Ergebnis bleibt nur ein Weg offen, um dem Ausländer das Wahlrecht zu verschaffen: die Einbürgerung. Mit der Einbürgerung allerdings endet auch die staatsrechtliche Stellung als Ausländer.

\section{Mitbestimmung in unterstaatlichen Verbänden}

Der Ausschluß des Fremden von demokratischen Teilhaberechten gilt auch auf der Ebene der kommunalen Gebietskörperschaften ${ }^{117}$ ). Diese sind heute gerade im Zeichen der Demokratie völlig staatshomogen strukturiert; sie verkörpern kein staatsfremdes, "gesellschaftliches" Prinzip mehr ${ }^{118}$ ).

Soweit sich Mitgliedschafts- und Repräsentationsrechte in Verbänden aus dem demokratischen Prinzip herleiten und sich in ihnen die Herrschaft des Staatsvolkes ausprägt, sind sie dem Ausländer schlechthin unzugänglich ${ }^{119}$ ). Sie stehen ihm dagegen

117) Der vom Homogenitätsgebot des Art. 28 GG vorgeschriebenen Beschränkung des kommunalen Wahlrechts auf Träger des staatlichen Wahlrechts entspricht das allgemeine deutsche Landesrecht (vgl. für Bayern: Art. 15 II, 17 GO, Art. 1 I, 5 I GemeindewahlG, für Nordrhein-Westfalen: \$\$ 6 II, 29 GO, \$\$ 7, 12 KommunalwahlG; für das Saarland: $\$ \S 17$ II, 30 I GO, $\$ \$ 12,16$ KommunalwahlG; weit. Nachw.: Dolde [N 15], S. 75).

Dagegen wird die Verleihung des kommunalen Wahlrechts an Ausländer als verfassungsrechtlich zulässig (oder sogar als geboten) dargestellt von: Dolde (N 15), S. 78; Zuleeg DOV 1973, 370. Politische Forderungen nach der Zuweisung kommunalen Wahlrechts für Ausländer nach bestimmter Aufenthaltsdauer: Geiselberger (N 4), S. 202, 209; Marqués, in: Klee (N 4), S. 175-183; Europa-Union, s. EuropaUnion-Korrespondenz 1971-1, S. 3. - Die zutreffende Gegenthese, $\mathrm{da} B$ der Ausländer verfassungskräftig vom Kommunal-Wahlrecht ausgeschlossen ist, vertritt Behrend (DOV 1973, 376-378).

118) Zur Staatshomogenität der Gemeinden als Einheiten „mittelbarer Staatsverwaltung " und zum Verlust ihres "gesellschaftlichen" Charakters: Peters: Grenzen der kommunalen Selbstverwaltung in Preußen, 1926, S. 43, 56, 60, 126; Smend (N 59), S. 271; Köttgen, in: Peters, HbKWP I, 1956, S. 194 f., 217; Forsthoff, Lehrbuch des Verwaltungsrechts I, $1973^{10}$, S. 475-524; Werner Weber, Staats- und Selbstverwaltung in der Gegenwart, 1967, S. 59, 62 f., 68; Scholz, Das Wesen und die Entwicklung der gemeindlichen öffentlichen Einrichtungen, 1967, S. 49 f.; Isensee (N 51), S. 241 f. (Nachw.); Scheuner AfK 12 (1973), 7 f., 9 f.

110) Wenn die Ausländer auch von der Ausübung der demokratischen Hoheitsgewalt im unmittelbar wie im mittelbar staatlichen Bereich ausgeschlossen sind, so ist ihnen damit nicht die organisierte Interessenwahrnehmung versagt. - Es ist von Verfassungs wegen unbedenklich, daß eine Gemeinde ihren ausländischen Einwohnern ein offiziöses Vertretungsgremium schafft und diesem Beratungsfunktionen und Anhörungsrechte zuweist (Beisp.: „Ausländerbeirat" der Stadt Nürnberg - dazu Satzung über den Ausländer- 
offen, soweit sie sich aus der Grundrechtsfreiheit legitimieren, an der er - je nach dem Grad seiner Status-Verfestigung teilhat, und soweit die Mitgliedschaftsrechte von einer bestimmten gesellschaftlichen Rolle abhängen, die er übernehmen kann.

Wenn der ausländische Arbeitnehmer der Zwangsmitgliedschaft in der Sozialversicherung und der ausländische Unternehmer der Zwangsmitgliedschaft in einer Berufskammer unterworfen wird, so ist es Gebot rechtsstaatlicher Konsequenz, daß auch die jeweiligen Selbstverwaltungsrechte unverkürzt eingeräumt werden ${ }^{120}$ ). - Die Universität ist als Institution der Forschung und Lehre organisierte Grundrechtssubstanz, nicht Stätte demokratischer Machtausübung. Folglich kann es bei den akademischen Bürgerrechten nicht auf die Staatsangehörigkeit ankommen ${ }^{121}$ ). - Die Rundfunkverfassung verwirklicht nicht Medienherrschaft des Staatsvolkes, sondern repräsentativ wahrgenommene Grundrechtsfreiheit ${ }^{122}$ ). Deshalb kön-

beirat v. 24. 5. 1973, Amtsblatt der Stadt Nürnberg v. 30. 5. 1973, S. 93; vgl. auch Erlaß des bad.-württ. Innenministeriums v. 8. 7. 1971 betr. Beteiligung von Ausländern an kommunalen Geschehen). Der Spielraum zulässiger Partizipations-Möglichkeiten ist weit. Die Grenze ist aber überschritten, wenn die unmittelbare Teilhabe an den Entscheidungen der Verbandsgewalt übertragen wird. So darf ein Gemeinderat einen Ausländer als Sachverständigen zu seinen Sitzungen beiziehen (s. $\$ 48$ SaarlGO); jedoch kann er ihm kein Stimmrecht verschaffen.

Auf der anderen Seite verbürgt die Verfassung in den allgemeinen Grundrechten den Ausländern ein unentziehbares Minimum an politischen Einflußchancen; diese liegen insbesondere in Art. 5 und 17 GG. - Zur Ausländergeltung des Art. 5 GG s. u. N 127. Zur Ausländergeltung des Art. 17 GG: Ruppel (N 72), S. 188-190 (Nachw.); Dolde (N 15), S. 155-159. Anderer Ansicht zu Art. 126 WRV: Stier (N 58), S. 713-715.

120) Unvereinbar mit diesem Gebot sind die gesetzlichen Regelungen, die den Ausländer vom passiven Wahlrecht ausschließen - so von der Wählbarkeit zur Handwerkskammer (\$§ 97 I 1 d, 99/3 HandwO), zum GesellenausschuB ( $\$ 71$ I 1 HandwO) und zu den Selbstverwaltungsorganen der Sozialversicherung (\$ 17 I 1 Gesetz über die Selbstverwaltung auf dem Gebiet der Sozialversicherung).

- S. auch o. N 88 (Wählbarkeit nach Personalvertretungsrecht).

121) Dieser Folgerung entspricht das geltende deutsche Hochschulrecht (vgl. \& 6 Hamburger UniversitätsG v. 25. 4. 1969; \& 4 Nordrhein-Westf. HochschulG v. 7. 4. 1970; $\$ 51$ Saarl. UniversitätsG v. 7. 7. 1971; Art. $1-31$ Verfassung der Universität des Saarlandes v. 6. 7. 1972 . S. auch Bussiek, Deutsche Universitätszeitung 1964/Heft 11, S. 3 f.; weit. Nachw.: Dolde [N 15], S. 83-87). - Zur Prämisse der grundrechtlichen Substanz (Art. 5 III GG) der Universitätsorganisation: BVerfG, U. v. 29. 5. 1973, JZ 1973, 456-462.

122) Die ausländischen Träger der Rundfunkfreiheit werden als Angehörige der gesellschaftlich relevanten Gruppen (als Arbeitnehmer, als Mitglied einer Religionsgemeinschaft etc.) repräsentlert. Der ausländische Bevölkerungsteil als solcher ist dagegen nicht „re- 
nen ausländische Angehörige gesellschaftlich relevanter Gruppen nicht von der Vertretung in Rundfunkgremien ausgeschlossen werden ${ }^{123}$ ).

Anders stellt sich dagegen die Rechtslage für die politischen Parteien dar. Sie erlangen ihre Sonderstellung, die sie über den schlicht grundrechtlichen Vereinsstatus emporhebt, aus ihrem demokratischen Mandat, an der politischen Willensbildung des Staatsvolkes teilzunehmen. In den Fällen, in denen diese Teilnahme bereits die Entscheidung der Aktivbürgerschaft wirksam mediatisiert und verbindlich einengt, ist dem ausländischen Parteimitglied kraft Verfassungsrecht jede Mitwirkung verwehrt; so ist es insbesondere von der Aufstellung der Wahlvorschläge ausgeschlossen ${ }^{124}$ ). Der Gesetzgeber träfe die verfassungsrechtlich angemessene Lösung, wenn er den Parteien überhaupt die Aufnahme von Ausländern versagte.

levant". Er ist sub specie der Rundfunkfreiheit auch nicht vertretungsfähig, weil er nicht hinreichende Homogenität aufweist; seine Gemeinsamkeit beschränkt sich auf ein Negativum - das Fehlen der deutschen Staatsangehörigkeit. Die Repräsentation ausländischer Grundrechtsträger kann nur in den Beziehungen erfolgen, die sie mit dem deutschen Gemeinwesen verbinden, nicht in denen, die sie von ihm trennen.

123) Die Mitgliedschaft im Rundfunkrat wird vom passiven Wahlrecht zum Landtag abhängig gemacht von Art. 6 IV BayRundfunkG i. d. F. v. 1. 3. 1972 und von 86 IV Satzung der Rundfunkanstalt "Sender Freies Berlin" v. 12. 11. 1953. - Zur Prämisse der grundrechtlichen Fundierung der Rundfunkverfassung in Art. 5 I GG: BVerfGE 12, 205 (259-264).

124) Die Beschränkung des Rechts zu Wahlvorschlägen auf die wahlberechtigten Parteimitglieder ( 822 I BWahlG) ist grundgesetzlich geboten. Von Verfassungs wegen vorgegeben ist darüber hinaus, daß eine politische Partei, die als demokratisches Kreativorgan die Vorzugsstellung nach Art. 21 GG genießen will, sich zumindest mehrheitlich aus Angehörigen des Staatsverbandes rekrutieren muB (verfehlt daher die Kritik an 82 III 1 Parteig bei Dolde [N 15], S. 142 f.; Zuleeg DOV 1973, 370).

Der Deutschenvorbehalt des Art. 21 GG duldet nicht dasselbe Maß an Gleichstellungsmöglichkeiten für Ausländer wie etwa der entsprechende Vorbehalt des Art. 12 GG, da sich die Parteifreiheit wesentlich aus der Zugehörigkeit zum Staatsvolk legitimiert. Mit diesem Status-activus-Recht stehen sowohl die Identität des demokratischen Verbandes als auch die Integrität der demokratischen Willensbildung auf dem Spiel. Wenn die Parteien dazu berufen sind, in bestimmtem Maße die Aktivbürgerschaft zu mediatisieren, so müssen sie in ihrer Mitgliedstruktur wie ihrer ninneren Ordnung" (Art. 21 I 2 GG) demokratie-konform verfaßt sein. Dazu gehört, daß die Mitgliedschaft (zumindest grundsätzlich) nur Aktivbürgern zukommt und daß die partei-interne Willensbildung gegen Fremdsteuerung vom Ausland her abgeschirmt ist. 


\section{Demokratischer Aspekt der Freiheitsgrundrechte}

1. Es ist heute ein verfassungsdogmatischer Gemeinplatz, daß alle Freiheitsgrundrechte auch eine demokratische Komponente enthalten. Dieser Ansatz erklärt den Versuch, die politischen Gehalte der allgemeinen Freiheitsrechte nur dem Staatsbürger vorzubehalten und den Ausländer, der vom demokratischen Entscheidungsverfahren ausgeschlossen ist, auch aus dem Vorraum der demokratischen Willensbildung zu verdrängen, in den ihn die allgemeinen Grundrechte, insbesondere die Meinungsfreiheit, hineinführen ${ }^{125}$ ). Immerhin hat der Verfassunggeber dem demokratischen Vorrang der Deutschen auch grundrechtlich dadurch Rechnung getragen, daß er nur ihnen die kollektiv organisierte wie die beruflich wahrgenommene Meinungsäußerung grundrechtlich gewährleistet $\left.{ }^{120}\right)$. Kann der demokratische Integrationsproze $\beta$ vor dem Einfluß Verbandsfremder abgeschirmt werden, wenn diesen etwa über die allgemeinen Grundrechte (wie die Pressefreiheit) öffentliche Meinungsmacht zuwächst?

2. Das Integrationsargument hat nicht die Kraft, rechtsstaatliche Verfassungsgewichte zugunsten der demokratischen zu verschieben. Im Grundrechtsbereich ist jede Freiheitsäußerung um ihrer selbst willen geschützt; es gilt weder das Privileg noch die Diskriminierung des Politischen. Stünden die Grundrechte der Ausländer unter dem Vorbehalt ihrer demokratischen Relevanz oder ihrer Integrationsbedeutung, wären sie praktisch hinfällig, weil schlechthin keine Grundrechtsausübung im Wirkungszusammenhang des Privaten und des Offentlichen, des Gesellschaftlichen und des Staatlichen ausgenommen werden könnte. Das Erfordernis eines „allgemeinen

125) Die „öffentliche“ („große“) Meinungsfreiheit wird als demokratisches Teilhaberecht gedeutet und dem Ausländer abgesprochen von: Ridder, Meinungsfreiheit, in: GR II, 1954, S. 269; ders., Art. „Meinungsfreiheit", in: Staatslexikon V, 1960", Sp. 651; Tomuschat (N 16), S. 57-63; Erbel, JuS 1971, 35.

126) Die differenzierte Grundrechtsgeltung verlangt die sorgfältige Klärung der Grundrechts-Konkurrenzen. Wenn dem Ausländer die Pressefreiheit als solche zusteht, so fällt die berufliche Pressetätigkeit in den Deutschenvorbehalt des Art. 12 I GG (verfehlt: Rebe, Die Träger der Pressefreiheit nach dem Grundgesetz, Diss. Berlin 1968, S. 74; Rolvering [N 6], S. 44 f.). Wenn der Staatsfremde die Meinungsfreiheit genießt, so hat er damit nicht auch die grundrechtlich gesicherte Möglichkeit, diese im Rahmen der Versammlung, des Vereins oder der politischen Partei - im Schutzbereich der Deutschenrechte der Art. 8, 9, 21 GG - auszuüben (sachgerecht zum Verhältnis des Art. 5 I zu Art. 8 I GG: OVG Münster, U. v. 13. 1. 1970, DOV 1970, 344 346). - Zum Grundrechts-Ausschluß der ausländischen Staaten und ihrer Funktionsträger s. o. N 51. 
Gesetzes" läßt ausländerspezifische Eingriffe in die politische Meinungsfreiheit nicht $\left.\mathrm{zu}^{127}\right)$. Die Reduzierung der allgemeinen Meinungsfreiheit auf ein Aktivbürgerrecht läßt sich auch nicht durch den Kunstgriff einer Analogie von den Aktivbürgervorbehalten des Wahlrechts oder der Parteifreiheit her erreichen $\left.{ }^{128}\right)$. Der Freiheitsstandard des Ausländers ist aus diesem Grunde vor den Launen der außenpolitischen Entwicklung und den Schwankungen der Machtkonjunkturen gesichert ${ }^{129}$ ). Wo Meinungsäußerungen von Fremden die außenpolitischen Beziehungen belasten, muß der demokratische Rechtsstaat diese Grundrechtslast tragen ${ }^{130}$ ).

127) § 6 II, III AuslG enthält nicht das Verbot (bzw. die Verbotsermächtigung) für bestimmte politische Meinungsbekundungen. Diese Norm erfüllt nicht die Voraussetzungen eines „allgemeinen Gesetzes" im Sinne des Art. 5 II GG - so zutreffend: Tomuschat (N 16), S. 51-53; Kanein (N 17), S. 73; Weißmann, Ausländergesetz, 1966, S. 82; Ruppel (N 72), S. 164-171; Dolde (N 15), S. 186-198; ders., DOV 1973, 369; Rolvering (N 6), S. 48-51, 86-95; Zuleeg DOV 1973, 369. Gegenthese (\$ 6 II, III AuslG als „allgemeines Gesetz"): Kloesel-Christ (N 17), 8 6/3; Thomsen (N 109), S. 67-88; Heuer, Politische Betätigung von Ausländern und ihre Grenzen, 1970, S. 2931.

128) Vgl. die von Smend inspirierte Deutung der „Offentlichen Meinungsfreiheit" im Lichte der Parteifreiheit bei Ridder (N 125), S. $249-266$.

129) Das Grundrecht des Art. 5 I GG läßt auch nicht Abstufungen danach zu, ob sich eine Meinungsäußerung des Ausländers auf das politische Leben Deutschlands oder das seines Heimatstaates bezieht. Eine solche Unterscheidung könnte in der Realität ohnehin selten trennscharf vollzogen werden. Die Stringenz und die Allgemeinheit der Meinungsfreiheit verhindern, daß die Bundesrepublik gegenüber ihren ausländischen Untertanen das $\mathrm{Maß}$ der Grundrechtsausübung nach außenpolitischer Staatsraison - willfährig gegenüber Empfindlichkeiten totalitärer Regierungen - festsetzen darf.

Dagegen übernimmt die Bundesrepublik grundsätzlich keine Schutzpflicht für den Fall, daß ein Ausländer, der sich auf deutschem Boden nach deutschem Verfassungsrecht legal betätigt, sich dafür Sanktionen seines Heimatstaates zuzieht. Dieses Risiko liegt jenseits der Regelungsmacht deutscher Staatshoheit und der Reichweite deutscher Grundrechte. Daher geben die allgemeinen Grundrechte auch dem Ausländer nicht die Möglichkeit, sich vom Bundesgebiet aus durch Provokationen des Heimatstaates die Voraussetzungen des Asylrechts zu erschleichen. Eine vorsichtige und zurückhaltende Verwaltungspraxis hat hier Grundrechtsmißbrauch zu verhindern. An eine Asylvoraussetzung, die erst während des Aufenthalts im Bundesgebiet entstanden ist, sind strengste Maßstäbe zu legen (s. BVerfGE 9, 174 [181]).

130) Das BVerwG weist für den Fall, daß die Grundrechtsausübung von Ausländern außenpolitische Ungelegenheiten heraufbeschwört, auf die Aufgabe der Bundesregierung hin, sich auf diplomatischem Wege um Verständnis für eine bindende verfassungsrechtliche Lage zu bemühen und eine einvernehmenliche Regelung der Schwierigkeiten zu suchen (U. v. 3. 5. 1973, DOV 1973, 862 f.). 
Wenn die demokratischen Verfassungsbestimmungen dem Ausländer die Freiheit der politischen Tat versagen, so müssen ihm die rechtsstaatlichen die Freiheit des politischen Wortes erst recht gewährleisten, damit die Herrschaft, an der er nicht teilhat, gemildert und erträglich wird. - Die allgemeinen Freiheitsrechte sind Vertrauensbekundungen des Verfassunggebers - auch gegenüber den Verbandsfremden. Das demokratische Prinzip gestattet nicht, den Ausländern das grundrechtliche Vertrauen zu entziehen und das Wagnis der Rechtsstaatlichkeit zu verringern.

\section{G. Schluß - Ordnungsdefizit und Verfassung}

Die kargen Ergebnisse der verfassungsrechtlichen Uberlegungen müssen den enttäuschen, der im Grundgesetz das ausländerpolitische Konzept $\mathrm{zu}$ finden hofft, das die verantwortlichen politischen Instanzen bisher schuldig geblieben sind. Das gefährliche Regelungsvakuum läßt sich nicht mit grundgesetzlichen Wertungen füllen. Der soziale Konfliktstoff kann nicht über verfassungsrechtliche Deduktionen entschärft werden. Die Verfassung richtet grundrechtliche, sozialstaatliche, völkerrechtliche Friedensziele auf; aber sie enthält nur wenige Determinanten für die jeweilige Friedensverwirklichung. $\mathrm{Zu}$ den drängenden bevölkerungspolitischen und gesellschaftspolitischen Fragen, von deren Lösung das staatliche Schicksal der Ausländer und die Zukunft des deutschen Gemeinwesens abhängen, schweigt die Verfassung. Die politischen Entscheidungsorgane haben das Wort. 
Leitsätze des Mitberichterstatters über:

\title{
Die staatsrechtliche Stellung der Ausländer in der Bundesrepublik Deutschland
}

\author{
I. \\ Das Statusproblem - ein Gleichheitsproblem
}

1. Das verfassungsdogmatische Problem der staatsrechtlichen Stellung des Ausländers ist ein Problem der Gleichheit.

2. Die Vergleichsgrößen - der grundgesetzliche Status des Staatsfremden und der des Staatsangehörigen - sind von vornherein unterschiedlich strukturiert. Der Ausländer ist der deutschen Staatsgewalt weder ausschließlich noch unentrinnbar zugeordnet. Er steht unter doppelter Herrschaftszuständigkeit: der Gebietshoheit des Aufenthalts- und der Personalhoheit des Heimatstaates. Die Rechtsstellung des Ausländers läßt sich daher nur durch ein dreiseitiges Modell erfassen, das seine (staatsrechtliche) Zuordnung zu zwei Rechtssystemen und die (völkerrechtliche) Beziehung der konkurrierenden Rechtssysteme zueinander einschließt.

II.

Die aufenthaltsrechtlichen Statusgrundlagen

3. Für den Ausländer ist der Aufenthalt im Bundesgebiet die Entstehungsvoraussetzung eines umfassenden verfassungsrechtlichen (insbesondere grundrechtlichen) Status. Die Entstehungsvoraussetzung ist ihrerseits nicht grundrechtlich gesichert.

4. a) Das Grundgesetz erkennt außerhalb des Asylrechts dem Ausländer im Unterschied zum Deutschen kein Grundrecht auf Einreise in das Bundesgebiet zu. Der gebietsfremde Ausländer steht außerhalb des grundrechtlichen Schutzbereiches. Grundrechtsreflexe sind möglich.

b) Die Begründung eines grundrechtlichen Status des Ausländers ist nicht Zweck, sondern Folge der Zulassung seines Aufenthaltes. Der Grundrechtsstatus ist das Werk grundrechtsfreier Selbstbindung des Staates.

5. Von der koordinationsrechtlichen Phase der Gebietszulassung ist die subordinationsrechtliche Phase der Gebietszugehörigkeit zu unterscheiden, die weithin verfassungsrechtlich de- 
terminiert ist. Nebenbestimmungen zur Aufenthaltserlaubnis können die Determinanten nicht verschieben.

6. Die Selbstbindung durch Gebietszulassung muß dem Ausländer ein Minimum aufenthaltsrechtlicher Statussicherheit durch rechtsstaatliche Begrenzung der Ausweisungsmöglichkeit verschaffen. Die Selbstbindung hebt aber nicht das Recht des Staates auf, den Aufenthalt zeitlich zu begrenzen. Die Verfassung vermittelt keinen Anspruch auf unbegrenzten Aufenthalt oder auf Einbürgerung.

III.

Der rechtsstaatliche Status

7. Eine rechtliche Ungleichbehandlung der ausländischen Bewohner des Bundesgebietes gegenüber den Deutschen bedarf der Rechtfertigung vor dem rechtsstaatlichen Gebot der Rechtsgleichheit.

8. Grundrechte, die nicht ausdrücklich Deutschen vorbehalten sind, enthalten absolute Differenzierungsverbote für ihren Sachbereich. Die personenbezogenen Differenzierungsverbote des Art. 3 Abs. 3 GG sind dagegen staatsangehörigkeits-indifferent.

9. a) Wo das Grundgesetz bestimmte Grundrechte nur den Deutschen zuspricht, entsteht für die Ausländer wegen Art. 2 Abs. 1 GG kein grundrechtliches Vakuum.

b) Art. 1 Abs. 1 GG verlangt nicht die undifferenzierte Gleichstellung des Ausländers. Das menschenrechtliche Gebot einer individualisierenden Angleichung an den Grundrechtsstandard des Deutschen greift dort ein, wo der Ausländer nicht auf die Verwirklichung der Menschenrechte in seinem Heimatstaat verwiesen werden kann.

10. a) Der Ausländer kann in den Sachbereichen der Deutschen-Grundrechte materielle Gleichstellung über eine Selbstbindung der öffentlichen Gewalt gewinnen. Im Fortschreiten der Selbstbindung verfestigt sich sein grundrechtlicher Status.

b) Hat der Staat dem Ausländer die Berufsaufnahme gestattet und sich damit über den grundrechtlichen Minderstatus hinweggesetzt, so kann er auf diesen bei der Regelung der Berufsausübung nicht mehr zurückkommen: Nunmehr verlangt Art. 3 Abs. 1 GG die Gleichstellung mit dem Deutschen.

11. Die Unterscheidung zwischen allgemeinen Grundrechten und Deutschen-Grundrechten wird ergänzt durch die Unterscheidung zwischen Grundrechten, deren Entstehungsvoraussetzungen mit dem Aufenthalt erfüllt sind, und solchen, deren 
Entstehungsvoraussetzungen der Staat auch nach der Gebietszulassung noch in der Hand hält. So beherrscht der Staat mit der Zulassungskompetenz im Schutzbereich des Art. 12 Abs. 1 GG auch den Zugang des Ausländers zur Koalitionsfreiheit.

12. Die über Art. 25 GG rezipierten allgemeinen Regeln des Völkerrechts senken den grundgesetzlichen Grundrechtsstandard des Ausländers nicht auf das Rechtsniveau eines niedrigeren völkerrechtlichen Minimumstandards.

IV.

\section{Der sozialstaatliche Status}

13. Das sozialstaatliche Ziel der sozialen Gleichheit stellt auf die Zugehörigkeit zur Gesellschaft, nicht auf die zum Staatsverband ab. Die Garantenpflicht des Sozialstaates dafür, daß mit der rechtlichen Freiheitschance der Grundrechte auch eine reale Freiheitschance in den gesellschaftlichen Bedingungen korrespondiert, gilt nicht nur gegenüber dem Staatsbürger, sondern auch gegenüber dem ausländischen Gesellschaftsbürger - abgestuft nach der Dauer seines Aufenthalts, seiner Integration in die Gesellschaft und dem Grad seiner grundrechtlichen Status-Verfestigung.

14. Das sozialstaatliche Ziel der „Einheitlichkeit der Lebensverhältnisse" enthält keinen Auftrag, die Entstehung nationaler und kultureller Minderheiten zu verhindern. Das Homogenitätsziel rechtfertigt Eingliederungshilfe, nicht Assimilation.

15. Die sozialstaatlichen Impulse zur Integration der Ausländer sind determiniert durch die bevölkerungspolitischen Vorentscheidungen über Dauer und Ziel des Aufenthaltes. Die Sozialstaatsklausel erteilt kein bevölkerungspolitisches, sondern ein gesellschaftspolitisches Mandat.

16. Dem Sozialstaat obliegt die Aufgabe, innergesellschaftliche Diskriminierung und innergesellschaftlichen Zwang zur Segregation zu verhindern. Das soziale Staatsziel enthält den Erziehungsauftrag zur Toleranz.

\section{$V$.}

\section{Der demokratische Status}

17. Dem Ausländer ist die Teilnahme am politischen Entscheidungsprozeß versagt. Das „Volk“ als Träger der Staatsgewalt wird durch die Staatsangehörigkeit, nicht durch die Gebietszugehörigkeit definiert. Das demokratische Prinzip des Grundgesetzes schließt es aus, daß sich verbandsfremde Personen an der Willensbildung des Staatsverbandes beteiligen. 
18. a) Der status passivus des Ausländers fordert nicht die Verleihung eines status activus. Das grundgesetzliche Aquivalent für die Herrschaft der Rechtsordnung ist der Schutz durch die Rechtsordnung.

b) Die demokratischen Mitgliedschaftsrechte des Staatsbürgers kompensieren seine unentrinnbare Angewiesenheit auf den Staatsverband. Die demokratische Egalität verbietet, das aktive wie passive Wahlrecht Personen einzuräumen, die nicht Staatsbürger auf Lebenszeit sind.

c) Die spezifischen Lasten, die aus der demokratischen Mitgliedschaft im Staatsverband erwachsen (insbesondere die Wehrpflicht), obliegen Ausländern nicht.

d) Das demokratische Gebot der Homogenität von Volk und Volksrepräsentanten fordert, daß die Organwalter der Staatscrgane dem Kreis der Staatsbürger entstammen.

19. a) Die Entscheidung darüber, ob dem Ausländer Mitgliedschafts- und Repräsentationsrechte in öffentlichrechtlichen oder privatrechtlichen Verbänden zuerkannt werden können, hängt davon $a b$,

- ob der Verband (überwiegend) demokratisch oder grundrechtlich legitimiert ist;

- ob die Verbandszugehörigkeit an die Rolle des Staatsbürgers oder an eine bestimmte "gesellschaftliche" Rolle (als Angehöriger eines bestimmten Berufs, als Sozialversicherter etc.) anknüpft.

b) Die staatshomogene kommunale Selbstverwaltung ist dem Ausländer daher verschlossen, nicht dagegen die soziale Selbstverwaltung. In den politischen Parteien ist dem Ausländer die Mitwirkung zumindest in dem Umfange versagt, in dem die Parteien Vorentscheidungen für die politische Willensbildung des "Volkes" treffen. Die Mitwirkung und Repräsentation in den grundrechtlich legitimierten Einrichtungen der Koalitionen, der Universität, der Presse, des Rundfunks etc. ist dem Ausländer als Gesellschaftsbürger - im Maße seiner grundrechtlichen Status-Verfestigung - möglich.

20. Soweit die allgemeinen Freiheitsrechte einen demokratisch relevanten Aspekt aufweisen und ihren Trägern einen status activus verleihen, steht dieser auch dem Ausländer zu. Das Grundgesetz läßt nicht zu, daß dem Ausländer auch im rechtsstaatlich geordneten Freiheitsbereich spezifisch politische Beschränkungen auferlegt werden. 


\section{VI.}

Das Fazit der Statusdiskussion als Gleichheitsfrage Die staatsrechtliche Stellung des Ausländers wird bestimmt

- auf der Ebene der aufenthaltsrechtlichen Statusbegründung und Statusdauer: durch ursprüngliche Ungleichheit;

- auf der Ebene des sozialen Rechtsstaates: durch grundsätzliche Gleichstellung bei begrenzten Differenzierungsmöglichkeiten;

- auf der Ebene der Demokratie: durch schlechthinnige Ungleichheit. 


\section{Aussprache und Schlußworte}

\section{Die staatsrechtliche Stellung der Ausländer in der Bundesrepublik Deutschland}

Vorsitzender (Lerche): Ich darf die Aussprache eröffnen und daran erinnern, daß wir, wie beschlossen, keine Rednerliste führen wollen im Sinne einer feststehenden, vorher festgelegten Liste und daß möglichst vom Platz aus gesprochen werden soll.

Thematisch würde ich vorschlagen, daß wir die mehr polizeirechtlichen und verwaltungsrechtlichen Fragen nicht in den Vordergrund schieben, damit wir dem Gewicht der Referate auch gerecht werden, die ihr Zentrum im Staatsrecht und den damit verbundenen völkerrechtlichen Fragen gefunden haben. Im übrigen wollen wir Ihnen vom Vorstand aus keine thematischen Eingrenzungen vorschreiben, um eine möglichst sachnahe Diskussion zu ermöglichen.

Herr Kewenig, darf ich Sie bitten, das Panier zu ergreifen?

Kewenig: Ich darf zunächst eine allgemeine Bemerkung zu beiden Referaten machen. Was ich in beiden Referaten vermißt habe, ist die soziologische Aufarbeitung des Begriffs und des Phänomens des „Fremden“. Ich hatte bei Herrn Doehring, aber auch bei Herrn Isensee sehr stark den Eindruck, das der Fremde hier so auftaucht, wie wir ihn aus dem 19. Jahrhundert kennen, also nicht als Gastarbeiter, sondern als „normaler“ völkerrechtlicher Fremder, der eine Kunst- oder Geschäftsreise macht oder sich aus anderen Gründen kurzfristig und vereinzelt im fremden Ausland aufhält. Bei einer grundlegenden rechtlichen Neubehandlung des Themas wäre es $\mathrm{m}$. E. nötig gewesen, sich vorweg auch um den neuen soziologischen $\mathrm{Be}-$ fund zu bemühen. Die Besonderheiten der heutigen Situation liegen nämlich nicht im eigentlich fremdenrechtlichen, im individuellen Bereich des Ausländers, sie stellen sich vielmehr als Minderheitenprobleme, als Schwierigkeiten einer oder mehrerer sozialer Gruppen unserer Gesellschaft dar. Ich würde meinen, daß man in dieser Richtung die Diskussion erheblich vertiefen müßte. Sieht man die von den Referenten behandelte Problematik unter einer "Minderheitenperspektive“ in dem angedeuteten Sinne, dann dürften einige Antworten auf die in 
den Referaten aufgeworfenen rechtlichen Grundsatzfragen doch wohl etwas anders ausfallen.

Sodann zu drei Einzelfragen der beiden Referate:

1. Ich würde der These von Herrn Doehring, daß über Art. 25 GG die allgemeinen Regeln des Völkerrechts Verfassungsrang erlangen, nicht zustimmen. Ich habe keine neuen Gründe für diese These gehört. Gegen diese These spricht vor allem das Argument aus Art. 79 Abs. 1 GG: keine Verfassungsänderung ohne Verfassungstextänderung. Außerdem aber macht gerade das Referat von Herrn Doehring deutlich, in welches Gestrüpp von Problemen man gerät, wenn man seiner These folgt und alsbald sich auf allgemeine Regeln des Völkerrechts zur Rechtfertigung der Einschränkung von Grundrechten beruft.

2. Die zweite Bemerkung gilt der Problematik des Wahlrechts der Ausländer, also der wohl wichtigsten Einzelfrage, mit der sich die beiden Referenten befaßt haben. Herr Doehring hat gesagt: Wenn man sich einmal die Verfassungen der Welt ansieht, so stellt man fest, daß die ganz überwiegende Zahl dieser Verfassungen das aktive und passive Wahlrecht auf die eigenen Staatsbürger beschränkt. Das ist sicher richtig. Herr Doehring hat aus dieser Beobachtung aber meiner Erinnerung nach weiterhin gefolgert, über Art. 25 GG verbiete es also eine allgemeine Regel des Völkerrechts den Staaten, Ausländern das aktive oder passive Wahlrecht einzuräumen. Ich halte diese Folgerung für unzulässig. Selbst wenn man, wie Herr Doehring, alle Rechtssätze, die man in einer Vielzahl von Verfassungen wiederfindet, als „principes generaux" bezeichnet und über Art. 25 GG mit Verfassungsrang ausstattet - dieses Verfahren ist für meinen Geschmack sowieso mehr als fragwürdig -, selbst dann kann man im konkreten Fall doch höchstens feststellen, daß es einen allgemein akzeptierten Rechtssatz gibt, nach dem das Wahlrecht der Ausländer ausgeschlossen werden kann. Es gibt dagegen auch dann noch immer keinen Rechtssatz, nach dem Ausländer vom aktiven und passiven Wahlrecht ausgeschlossen werden müssen.

Ich habe aber nicht nur aus formalen Gründen Bedenken gegen das Ergebnis beider Referenten, soweit das Wahlrecht der Ausländer in Frage steht. Ich halte auch materiell dieses Ergebnis für nicht ausreichend begründet - und für nicht begründbar. Herr Isensee hat hierzu vorgetragen, daß die demokratischen Mitgliedschaftsrechte des Staatsbürgers seine „unentrinnbare Angewiesenheit" auf seinen eigenen Staatsverband kompensieren. Legt man mit Herrn Isensee dieses Kriterium einmal der weiteren Betrachtung zugrunde, so muß man doch 
wohl sehr genau zwischen den verschiedenen staatlichen Ebenen, also zwischen Bund, Ländern und Gemeinden unterscheiden. Stimmt das Kriterium der „unentrinnbaren Angewiesenheit" auch noch auf der Gemeindeebene? Oder muß man nicht feststellen, daß Ausländer und Inländer sich zumindest auf dieser Ebene in einer durchaus vergleichbaren Position befinden? Ich würde meinen, der Deutsche kann und wird ebenso wie der Ausländer die Gemeinde verlassen, wenn er das Gefühl hat, daß ihm hier nicht Gerechtigkeit widerfährt. Zu einem ähnlichen Ergebnis kann man wohl auch für die Länderebene kommen. Ich möchte eine zweite Uberlegung anschließen, die m. E. ebenfalls ein Fragezeichen hinter das übereinstimmende und sehr generelle Votum beider Referenten gegen die Möglichkeit demokratischer Mitwirkungsrechte von Ausländern setzt. Lassen Sie mich diese Uberlegung in Anlehnung an eine brillante Formulierung von Herrn Isensee ausdrücken. Herr Isensee hat gesagt, es sei ein verfassungsdogmatischer Gemeinplatz, daß alle Grundrechte auch eine demokratische Komponente hätten. Könnte man nicht auch in Umkehrung dieser Formulierung sagen: Demokratische Mitwirkungsrechte haben selbstverständlich immer auch eine grundrechtliche Komponente? Man sollte etwa die Mitwirkung auf der gemeindlichen Ebene nicht nur im Hinblick auf das Demokratieprinzip sehen, sondern auch beachten, daß ein effektiver Grundrechtsschutz insbesondere im Bereich der Leistungsverwaltung durchaus etwas zu tun hat mit, ja geradezu abhängig ist von einer Berücksichtigung der Interessen der Ausländer in den Gemeindevertretungen. Eine solche Berücksichtigung aber ist nur gesichert, wenn die Ausländer auch wahlberechtigt sind. Denn sonst fragt sich doch jeder Gemeindevertreter, warum gerade er sich um die Interessen der Gastarbeiter kümmern soll, und zwar selbst dann, wenn, wie häufig, die Effektuierung dieser Interessen mit den Interessen der eigenen - deutschen - Wähler kollidiert. An dieser Stelle kommen also demokratischer Status und Grundrechtsstatus in eine sehr enge Berührung. Beide Positionen sollten bei der Beantwortung der Frage: „Können den Ausländern demokratische Mitwirkungsrechte zugebilligt werden?“ berücksichtigt werden.

3. Zum Schluß noch eine kurze Bemerkung zu Art. 3 GG. Ich würde Herrn Doehring zustimmen, daß Art. 3 Abs. 1 GG viel von einer leeren Hülse hat, würde aber doch meinen, daß sie im Hinblick auf die Ausländer nicht so leer ist, wie sie Herr Doehring gemacht hat. Das Merkmal der unterschiedlichen Staatsangehörigkeit muß m. E. als Differenzierungsmerkmal genau so behandelt werden wie alle anderen denkbaren Diffe- 
renzierungsmerkmale. Bei einer Anwendung des Art. 3 Abs. 1 GG muß also in jedem konkreten Fall gefragt werden: Ist eine unterschiedliche Behandlung auf der Basis der Staatsangehörigkeit vertretbar oder nicht, sachgerecht oder nicht, willkürlich oder nicht? Unzulässig ist es dagegen nach meiner Auffassung, das Merkmal der unterschiedlichen Staatsangehörigkeit a priori als ein in jedem Fall zulässiges Differenzierungskriterium anzuerkennen und folglich Art. 3 Abs. 1 GG insoweit als mögliche verfassungsrechtliche Grenze staatlichen Verhaltens auszuscheiden.

Zuleeg: Ich möchte an das Stichwort Minderheiten anknüpfen. Ich finde, das ist ein geglücktes Stichwort; denn wir müssen ja bedenken, daß wir eine große Zahl von Ausländern hier in unserem Lande haben, die zumindest für längere Zeit hier bleiben wollen. Dann sind die Begriffe und die Regeln, die wir von früher her überliefert bekommen haben, eben keine Selbstverständlichkeiten mehr.

Ich kann Herrn Isensee in seiner Schlußbemerkung nicht ganz zustimmen, wenn er gesagt hat, daß das Normenmaterial sehr spärlich sei und deswegen der Gesetzgeber aufgerufen sei, eine Konzeption zu entwickeln. Ich glaube, daß man auch aufgrund der Verfassung eine Konzeption entwickeln kann, trotz der Spärlichkeit des Normenmaterials. Ich meine sogar, daß wir eine Konzeption entwickeln müssen; denn schließlich muß sich der einfache Gesetzgeber daran halten, was die Verfassung in der Auslegung durch das Bundesverfassungsgericht gebietet.

Ich freue mich aber, daß Herr Isensee zumindest bei den rechtsstaatlichen Garantien die Verantwortung nicht völlig dem Gesetzgeber überlassen will oder gar der Exekutive, sondern $\mathrm{da} B$ er hier bestrebt ist, Rechte für die Ausländer zu sichern. Ich glaube, daß es verfehlt wäre, sich auszuruhen und zu sagen, andere Verfassungen hätten diese Rechte nicht; deshalb müssen wir ja nun nicht ein Ubermaß, ein tbersoll an Grundrechten im rechtsstaatlichen Bereich anbieten.

Zu Art. 25, der hier möglicherweise eine Einschränkung bringen könnte, hat Herr Kewenig schon Stellung genommen. Ich möchte nur noch kurz einiges anfügen, nämlich zu der Frage des Verfassungsrangs. Wenn Art. 25 GG wirklich lex specialis wäre, dann müßten die generellen Normen des Grundgesetzes zurücktreten, und wenn sie zurücktreten müßten, dann hätte eben Art. 25 doch die Kraft, Verfassungsregeln zu überwinden. Dementsprechend wäre das auch nicht mit dem Ausspruch des 
Bundesverfassungsgerichts zu vereinbaren, daß Art. 25 keine Rechte und Pflichten erzeugen kann, die über die Verfassung hinausgehen.

Nun ist das Wort gefallen, daß wir vielleicht durch zu große Wohltaten die Ausländer korrumpieren könnten. Ich glaube, dies ist ein Schreckgespenst, das wir zumindest bei der rechtsstaatlichen, aber auch bei der sozialstaatlichen Sicherung angesichts des gegenwärtigen Status der Ausländer bestimmt nicht an die Wand malen müssen. Allerdings könnte man sich durchaus überlegen, ob das Verhältnis zum Heimatland des Ausländers bei der demokratischen Komponente getrübt sein kann. Hier ist allerdings darauf hinzuweisen, daß das Wahlrecht im Grunde ein minderes Recht gegenüber der Staatsangehörigkeit ist und schon herkömmlich in Ländern mit Anknüpfung an den Geburtsort den Ausländern bei Geburt im Lande die Staatsangehörigkeit auferlegt worden ist, also ein stärkeres Recht als das Wahlrecht, und daß niemand bisher an dieser Konsequenz Anstoß genommen hat.

Die Bundesrepublik Deutschland folgt demgegenüber mit gewissen Ausnahmen dem ius sanguinis. Wenn man nun das Volk im Sinne von Art. 20 damit in Verbindung bringen will, dann ist der praktische Anknüpfungspunkt der demokratischen Rechte die Blutsbande. Ich meine, daß wir in der Vergangenheit mit der Anknüpfung an die Blutsverwandtschaft durchaus böse Erfahrungen gemacht haben und daß es uns wohl ansteht, wenn wir überlegen, ob wir nicht rationale Gesichtspunkte an die Stelle setzen können. Hier ist das Stichwort der Unentrinnbarkeit gefallen. Ich möchte über Herrn Kewenig hinausgehend sagen, daß es nicht nur auf der kommunalen Ebene diese Unentrinnbarkeit gar nicht so absolut gibt, sondern auch auf der staatlichen Ebene. Denn die Tatsache, daß jemand ausreisen kann, wird allenfalls durch einfaches Gesetz gehindert und nicht durch die Verfassung. Durch einfaches Gesetz können sowohl die Ausreise des Deutschen als auch die Ausreise des Ausländers verhindert werden. Ich glaube also, daß es die Unentrinnbarkeit als rationales Bild, als rationale Vorstellung nicht gibt. Und die Frage der Mitverantwortung, so glaube ich, dreht das Verhältnis auf den Kopf. Denn die Mitbestimmung beruht ja doch auf der Vorstellung, daß die Menschen selbstverantwortlich entscheiden können. Aus dieser selbstverantwortlichen Entscheidung folgt das Recht der Mitverantwortung und Mitentscheidung. Ich sehe nicht ein, weshalb wir für eine ganze Kategorie der Bevölkerung sagen könnten, diese selbstverantwortliche Entscheidung stehe ihr nicht $\mathrm{zu}$, so daß wir meiner 
Meinung nach - wenn wir uns nach rationalen Kriterien umsehen - bei dem Begriff der Schicksalsgemeinschaft landen, in der eine bestimmte Bevölkerungsgruppe auf einem bestimmten Territorium zusammenlebt und gemeinsam ihr Schicksal bestimmt. Ich bin der Ansicht, daß wir eine große Gruppe in diesem Land nicht einfach von der Mitwirkung bei der Bestimmung ihres Schicksals ausschließen dürfen. Das folgert auch aufgrund dieser Selbstverantwortlichkeit, die sich in Mitbestimmung umsetzt, aus dem Demokratieprinzip und - wie Herr Kewenig schon angedeutet hat - ebenfalls aus dem Sozialstaatsprinzip. Denn nur, wenn mit dem Stimmzettel in der Hand die Ausländer mitbestimmen dürfen, dann wird letzten Endes auch im sozialen Bereich auf ihre Interessen Rücksicht genommen werden.

Doehring: Herr Kewenig und Herr Zuleeg haben die Frage der Minderheiten angesprochen. Diesen Begriff möchte ich in diesem Zusammenhang eigentlich gerade nicht verwendet sehen. Die Minderheit, so wie wir sie als Begriff im Staats- und Völkerrecht verstehen, ist ja doch gerade die Gruppe der Menschen, die an sich zwar die Staatsangehörigkeit innehaben, die aber in besonderen Kulturbelangen geschützt sein sollen. Das ist eben etwas anderes. Die Minderheiten im klassischen Sinne können nicht wegziehen. Sie müssen also deshalb geschützt sein, weil sie bleiben müssen. Die Fremden, die wir hier haben, können zurück in ihren Heimatstaat. Die Minderheiten haben, wenn man so will, keinen zweiten Heimatstaat. Dieser Begriff machte mich doch sehr stutzig.

Die nächste Frage galt den Gründen für den Verfassungsrang des Art. 25. Ich gebe dabei auch zu - ich bin auch dafür in der Literatur schon einmal angegriffen worden - , daß sich meine Auffassung auch vom Ergebnis her trägt. Ich glaube, so darf dann verfahren werden, wenn sich nicht zwingende Vorschriften finden, die eben das Rekurrieren auf das Ergebnis verbieten. Ich muß doch Normenkonflikte auch sonst so lösen. Ich glaube, daß Art. 25 Verfassungsrang hat, weil er in der Verfassung steht und an der Bestandskraft der Verfassung teilnimmt. Sie können doch den Art. 25 nur mit verfassungsändernder Mehrheit abschaffen.

Ein Zwischenrang der aus Art. 25 resultierenden einzelnen Fremdenrechte - ein solcher Zwischenrang ist auch behauptet worden - hält nicht stand, weil die aus Art. 25 entfließenden Rechte doch auch nur mit zwei Dritteln durch Änderung des Art. 25 selbst abgeschafft werden könnten. Ich glaube, das ist eine vielleicht etwas stumpfsinnige, aber doch schlüssige An- 
nahme des Rangs. Nur wenn das Gleichgewicht besteht zwischen dem, was man aufgrund des Völkerrechts darf, und dem, was die Verfassung gebietet -, und da komme ich gleich auf einen nächsten Punkt - werden wir mit diesen Fragen fertig. Wir werden sonst mit ihnen nicht fertig.

Nun zu Herrn Kewenig: Ich glaube nicht, daß ich den Art. 25 überstrapaziert habe. Ich habe auch nicht behauptet, daß nun die Verfassung alles erlauben oder begrenzen muß, was das Völkerrecht erlaubt oder verbietet, sondern ich habe an mindestens drei Stellen meines Referates gesagt, daß die Verfassung mehr Rechte erteilen kann als das Völkerrecht. Die Frage ist nur: Wenn sie es nicht erkennbar tut, ist dann der Staat berechtigt, auf das Völkerrecht zurückzugreifen, sei es auch, wenn sich kein anderer Gesichtspunkt bietet, bis zum Mindeststandard? Mehr habe ich gar nicht gesagt. Das Völkerrecht verbietet nicht die Erteilung von Wohltaten, es sei denn, die von mir angedeuteten Wohltatsdubiositäten kämen dann ins Spiel, und ich müßte sagen, daß ein Eingriff in die Personalhoheit des eigentlichen Heimatstaates vorliegt. Aber das ist ein Grenzfall.

Ich wollte noch eine Bemerkung zu Herrn Zuleeg über die rechtlichen Bedenken gegen gewisse Wohltaten machen. Sie sagen, im gegenwärtigen Status des Fremdenrechts habe das keine große Bedeutung. Das ändert sich aber sehr schnell. Die Größenordnungen im Fremdenrecht haben sich - wie wir sehen - in einer unglaublich kurzen Zeit geradezu katastrophenartig geändert. Das wäre eigentlich das, was ich zu Herrn Zuleeg wegen des Art. 25 zu sagen hätte. Daß man damit andere Verfassungsregeln überwinden könnte, habe ich damit nicht gemeint, sondern man darf sie dort ausfüllen, wo die Regeln es zulassen. Nur so viel wollte ich damit gesagt haben.

Mosler: $\mathrm{Zu}$ der Minderheitenfrage: Ich bin der Meinung des Referenten, daß das Stichwort Minderheit hier nicht herausgegriffen werden sollte. Ich schlage vor zu sagen, es handele sich um eine sachbezogene Teilintegration, wobei die Sache, die die Integrationsbeziehung herstellt, sehr differenziert sein kann, aber von dem Terminus Minderheit nicht erfaßt wird.

Isensee: Ich darf einige ergänzende Bemerkungen machen zunächst zur Diskussion der Staatsangehörigkeit und ihres Gegenbildes, des Fremdenstatus: Eine Statusdiskussion kann nicht mit atypischem Fallmaterial bestritten werden. Ein Status ist ein typisierter Regelungskomplex, der auf das Vorstellungsbild des Normalen abgestellt ist. Wenn die Status-Zuweisung in 
concreto diesem Vorstellungsbild nicht entspricht (etwa im Falle des Ausländers, der in Deutschland geboren, beruflich wie familiär ausschließlich in die deutsche Gesellschaft eingegliedert ist), so ergibt sich damit kein Grund dafür, die Rechtsstellung des Fremden schlechthin in Frage zu stellen, sondern nur ein Grund für die Annahme, daß im Einzelfall der Fremdenstatus unsachgerecht und Einbürgerung angebracht ist.

Im Rahmen einer rechtsdogmatischen Betrachtung können die Rechtfertigungsgründe, die den verfassungsrechtlichen Unterschieden des Staatsangehörigkeits- und Ausländerstatus zugrunde liegen (insbesondere die unentrinnbare Angewiesenheit des Staatsangehörigen auf den Heimatstaat), nicht von den positivrechtlichen Regelungen abgelöst und gegen diese ausgespielt werden. Die ratio legis ersetzt nicht die lex. -

Der Fragenkreis der nationalen Minderheit liegt auf anderer Rechtsebene. Die Zugehörigkeit zu einer völkischen Minderheit hängt nicht von der Staatsangehörigkeit ab. Das Minderheitenrecht soll gerade im Raum des Staatsverbandes nationale und kulturelle Inseln ermöglichen. Der Minoritätenschutz ist ein Moment des Gruppenföderalismus. Er folgt dem föderalen Prinzip der Parität, aber nicht dem demokratischen Prinzip der Egalität. - Wenn es um die staatsrechtliche Stellung des Ausländers geht, kann es auf ethnische Kriterien des „Fremden" nur soweit ankommen, wie sie mit den normativen der Staatsangehörigkeit korrespondieren.

Den Staatsform- und Staatszielbestimmungen der Verfassung liegen Grenznormen zugrunde, die ihre Reichweite abstecken. Das gilt auch für die Regelung des Wahlrechts auf der Ebene der Bundesländer und der Kommunen. Das Wahlrecht des Ausländers kann nicht der Aufenthaltnahme folgen, wie es gemäß dem Wohnsitzprinzip für deutsche Staatsangehörige beim Wechsel der Gemeinde und des Bundeslandes der Fall ist. Der Deutsche, der von einer Gemeinde in die andere, von einem Bundesland in das andere zieht, verbleibt in demselben gesamtstaatlichen Verband. Der Verband der Länder und Gebietskörperschaften ist rechtlich homogen. Er ist über den Finanzausgleich auch zu einer finanziellen Haftungsgemeinschaft geeint. Innerhalb des gesamtstaatlichen Rahmens gilt für alle Bürger - um ein klassisches Wort zu verwenden - ein gemeinsames Indigenat.

Weltweit besteht dieses dagegen nicht, noch nicht einmal im Rahmen der Europäischen Gemeinschaften. Solange die Europäischen Gemeinschaften noch nicht den Integrationsgrad erreicht haben, von dem die Bismarck'sche Reichsverfassung mit 
ihrer Bestimmung über ein gemeinsames Indigenat ausgehen konnte, und sich kein übergreifender Europäischer Bundesstaat entwickelt hat, ist auch nicht die Voraussetzung für die Verleihung des Wahlrechts in den Mitgliedsstaaten und ihren Teilverbänden nach Maßgabe des Wohnsitzprinzips gegeben.

Vogel: Herr Zuleeg hat eben seine Bedenken gegen das ius sanguinis mit einem Hinweis auf die Uberschätzung der $\mathrm{Ab}-$ stammung in nationalsozialistischer Zeit begründet. Ich glaube nicht, daß hier ein Vergleich möglich ist (übrigens hieß es damals: "Blut und Boden"). Wenn er weiter darauf hingewiesen hat, daß die klassischen Einwanderungsländer vom ius soli ausgehen, so ist demgegenüber doch immerhin zu bemerken, daß in diesen Ländern derjenige, der im Land geboren ist, mit den Rechten des Staatsangehörigen auch dessen Pflichten erwirbt. Man könnte wohl allenfalls überlegen, ob nicht die „unentrinnbare Verknüpfung", auf die Herr Isensee abstellt, in bestimmten Fällen auch aus anderen als aus rechtlichen Gründen gegeben sein kann: der 55jährige Ausländer, der bei uns in einem langjährigen Arbeitsverhältnis steht oder Beamter ist, mag zwar rechtlich noch in seinen Heimatstaat zurückkehren können, aber doch kaum faktisch - das schiene mir jedenfalls ein erwägenswerter Gesichtspunkt. Persönlich würde ich dennoch dem Referenten darin folgen, daß, wenn man dem Ausländer die vollen Rechte des Inländers geben will, kein Weg an der Verleihung der Staatsangehörigkeit vorbeiführt. Man mag, wenn man die Bundesrepublik in Zukunft als Einwanderungsland verstehen will, vom ius sanguinis zum ius soli übergehen; das ginge sogar durch einfaches Gesetz. Doch wäre dies dann eine politische Entscheidung, die eben der Gesetzgeber treffen müßte und die man ihm nicht auf dem Wege über die Verfassungsinterpretation aus der Hand nehmen kann.

Vorsitzender: Wir sollten vielleicht nicht nur auf diesem Punkte beharren. Es liegt eine Reihe von Wortmeldungen auch noch zu weiteren Fragen vor, die einleitend von Herrn Kewenig berührt worden sind. Wir wollen versuchen, Herr Dürig, einen weiteren Problemkreis zunächst einzugrenzen, über den wir dann sprechen können.

Dürig: Ich bitte um Vergebung, es wird doch eine Tour d'horizon. Aber sie wird ganz kurz, wie immer bei mir. Erstens, auch ich bezweifle, daß wir mit dem traditionellen ausländerpolizeilichen Normenbefund des Fremdenrechts weiterkommen. Bleiben wir doch einmal bei der "Normalität", die es zu „normieren" gilt. Wir haben 2,5 Mill. Gastarbeiter; deren Angehö- 
rige sind unterschlagen worden; auch die, die unkontrolliert hier sind; das sind zusammen etwa 4,5 Mill. Da stellt sich doch die Frage, ob hier nicht allein schon aufgrund der Quantität auch die Qualität umschlägt, $d$. $h$. die materiellrechtliche Regelung dem zu folgen hat. Ich bin nun mit Ihnen der Meinung, Herr Isensee, daß tatsächlich hier vordringlich zuerst einmal eine politische Tat erfolgen muß - solange wird das Ausländergesetz und das Fremdenrecht eine verkorkste Angelegenheit bleiben - also vereinfacht gesprochen, es fehlt die Dezision, ob wir ein Einwanderungsland sind oder nicht.

Und das zweite. Wie diese Entscheidung auch ausfallen möge, wir dürfen unter keinen Umständen den Eindruck erwecken. $\mathrm{da} B$ wir jemals ohne die Rechtsfigur des generellen Verbots mit konkretem Erlaubnisvorbehalt auskommen könnten.

Denn - und jetzt kommt das dritte - eine Liberalisierung insoweit kann leicht zu noch inhumaneren Zuständen führen. Es geht um die Folgewirkungen der Grundrechte, die man ja doch kontrollierbar erhalten muß. Jetzt entfaltet eben doch entgegen Ihrer Meinung, Herr Doehring, der Gleichheitssatz mehr Kraft als die einer bloßen Leerformel. Es entstehen etwa dann nach Art. 6 die Grundrechte zur Ehe, zur Familie und Familiennachführung, über Art. 7 zur Schule, usw. Das ist also der Vorgang der Statusverfestigung, von dem Herr Isensee sprach.

Das vierte ist ein psychologischer Prozeß, der sich über Jahre erstreckt. Wir wissen doch zunächst einmal nicht, ob die Ausländer bei uns bleiben wollen, und die Ausländer wissen zunächst in der Regel auch nicht, ob sie hier bleiben wollen und zusätzlich, ob sie hier bleiben dürfen. Und so kommt es entscheidend darauf an, in diesem sich über Jahre erstreckenden Prozeß normative Fixpunkte anzusetzen. Und da bietet sich in der Tat ja wohl nur die Einbürgerung an, die Einbürgerung, die man vielleicht erleichtern könnte. Das macht ja gewissermaßen jetzt schon das Wehrpflichtgesetz, indem es einen Quasianspruch nach abgeleisteter Wehrpflicht bewirkt. Nötig sind also klar faßbare normative Daten. Und das fünfte: Ohne einen solchen Formalakt würde ich dringend warnen, hier den Ausländern mit dem status activus entgegenzukommen, etwa in der Form des aktiven oder passiven Wahlrechts für Parlamente; und zwar aus einem etwas ignorierten Gesichtspunkt, nämlich zum Schutz der betreffenden Ausländer. Die Spanier z. B. oder die Jugoslawen kommen in eine fürchterliche Zerreißprobe, wenn sie jetzt bei uns in die große Politik einsteigen, bevor sie nicht deutlich die Seile zu ihrem Heimatstaat zerschnitten haben. 
Nun könnte man sagen: Ja, aber auf der kommunalen Ebene da machen wir es, und wir machen es ja auch im Betriebsverfassungsrecht. Aber schauen Sie sich einmal in den Betrieben um. So einfach ist das gar nicht. Ich habe einmal ein Planspiel gemacht speziell über die Beteiligung von Gastarbeitern im Gemeinderat in einer Randgemeinde von Tübingen. Sie bekommen Serben und Kroaten nicht auf eine Linie. Sie bekommen Türken und Griechen nicht auf eine Linie, d. h. jede dieser nationalen Minderheiten im für uns untechnischen Sinne wollte ihren Kandidaten. Jede dieser Bevölkerungsgruppen hätte also einen Mann gestellt, wäre also im Gemeinderat überrepräsentiert gewesen. Sie haben das auch in den Betrieben, in denen die Betriebsleiter zum Teil ängstlich besorgt sein müssen, daß bestimmte Gastarbeitergruppen an bestimmten Arbeitsplätzen nicht zusammenarbeiten. Der Witz bei meinem Planspiel war übrigens, daß ich seine Ergebnisse mit Roß und Reiter gar nicht veröffentlichen konnte, eben um den Streit zwischen den Gruppen nicht noch anzuheizen, von dem ich gerade sprach.

Ich erwäge sechstens als Diagnose, ob wir nicht vor einer faktischen Unmöglichkeit stehen, den Leuten die Infrastruktur zu bieten, auf die sie ein Recht haben, und ob nicht dann von Verfassungs wegen auch eine rechtliche Unmöglichkeit eintritt, als Folge mit dem Gebot eines zu verhängenden generellen Zuzugsstopps, und sei es nur in Form einer zeitlichen Denkpause.

Nun schließlich noch eine Frage, die bewußt provozierend ist und die doch sicher von den Herren Referenten mit Zahlen beantwortet werden kann: Wieviele Wochenstunden müßten wir, die Deutschen, eigentlich mehr arbeiten - und die Zahlen, die ich gehört habe, sind verschwindend gering, und ich weiß auch, daß für die Drecksarbeit die reine Statistik eine Milchmädchenrechnung ist -, um das Ausländerproblem wieder auf eine faßbare, kontrollierbare, grundrechtlich realisierbare Größe zurückzustufen? Zur Zeit ist es uns in der Tat normativ entglitten.

Zacher: Ich bin im Augenblick etwas verwirrt; denn ich müßte Herrn Dürig auf das zuletzt Gesagte etwas schärfer antworten als mir lieb ist. Es geht ja hier nicht nur um die drei Stunden Mehrarbeit, es geht um ganz bestimmte soziale Schichtungen. Es geht darum, daß wir eine Bildungspolitik betreiben, die darauf aufgebaut ist, daß wir Gastarbeiter ausbeuten können und dergleichen mehr. 
Herzog: In den drei Stunden, die er mehr arbeitet, muß Herr Dürig dann den Müll abfahren.

Lerche: Damit können auch die Produkte der Kollegen gemeint sein.

Zacher: Aber meine Damen und Herren, lassen Sie mich das beiseite legen und zu den ursprünglichen Themen zurückkehren. Ich möchte anregen, daß wir das Problem stärker als ein dynamisches - gewissermaßen als ein Problem des nationalen Energiehaushaltes - sehen. Wir kennen die Vorstellung des souveränen Staates als eines nach innen übermächtigen, nach außen unabhängigen Gebildes. Diese Vorstellung korrespondiert mit dem ökonomischen Bild: mit dem Bild des geschlossenen Handelsstaates. Wir wissen, daß das auf Dauer gesehen so nie gestimmt hat, daß der "geschlossene" Staat ein Staat ist, der hart auf Krisensituationen, auf Ausnahmesituationen oder besondere Herrschaftsverhältnisse wie z. B. in den sogenannten sozialistischen Ländern zugeschnitten ist. Im übrigen haben wir vielmehr eine sehr verflochtene Staatenwelt, eine nach außen hin international, supranational, ökonomisch verflochtene Staatenwelt. Und im Inneren haben wir die konkurrierende Macht der Verbände, der Gruppen, der Unternehmen usw. Der Staat ist ja z. B. permanent daran, von den Verbänden überwältigt zu werden. Es kommt demgegenüber nicht darauf an auch für die Souveränität des Staates nicht - daß die tbermacht nach innen oder die Unabhängigkeit nach außen permanent realisiert werden, sondern darauf, daß sie permanent präsent - verfügbar - sind.

Das freilich beinhaltet dann besondere normative Schwierigkeiten, wenn etwa in der supranationalen Einbindung ohnedies gewisse Einlagerungen vorhanden sind, welche die nationale Kontraktion erschweren. Und wir haben neuerdings gerade im Staatsangehörigkeitsrecht ja durch das Urteil des Bundesverfassungsgerichtes über den Grundvertrag, wie ich glaube, einen ungeheuerlichen Block im Wege, dergestalt, daß wir kraft Art. 116 GG vermittels der DDR so viele Staatsangehörige haben, deren Staatsangehörigkeit wir längst nicht mehr wirksam regeln können, jedenfalls nicht mit Aussicht auf internationale Anerkennung oder wenigstens auf Anerkennung bei allen, die es angeht. Ich meine damit die "Deutschen", die nicht in der Bundesrepublik ihren Sitz haben, sondern in der DDR. Und diese Probleme der maximalen Lockerung und Verflechtung, der maximalen Kontraktion und Abschließung und der Möglichkeiten und Schwierigkeiten, aus dem Zustand der Verflech- 
tung heraus $\mathrm{zu}$ kontrahieren, scheinen mir unser Thema $\mathrm{zu}$ sein.

Für den Bürger selbst, wenn ich nun beim einzelnen Menschen ansetze, ist es das gleiche. Der Bürger braucht Freizügigkeit; auch er braucht die Möglichkeit, sich gewissermaßen international verflechten zu können. Er braucht aber auch andererseits die Möglichkeit, seinen Staat zu haben, auf den er in der Krisensituation rechnen kann. Ich glaube, daß wir deshalb die Frage „Wie kann das Ausländerrecht im Verhältnis zum Inländerrecht geregelt werden?" sehr stark auf das Problem der Kontraktionsfähigkeit hin anlegen sollen. Sind die Entwicklungen, die wir einleiten, im Konfliktsfall, im Krisenfall, revozierbar? Kontraktionsfähigkeit muß verbindbar sein mit Freizügigkeit und Verflechtung für den Dauerzustand.

Und zu dieser Problematik, so glaube ich, hat uns Herr Doehring gezeigt, wie weit die Kontraktion gehen kann, wie weit wir uns die Fähigkeit erhalten können, uns auf uns selbst zurückzuführen. Herr Isensee ist sehr viel stärker hinausgegangen in den Bereich des Dauerzustandes, der Verflochtenheit. Ich würde sogar sagen, Herr Isensee: für den ganz normalen, nicht kritischen Zustand könnte man in dem einen oder anderen Punkt vielleicht noch weiter gehen. Ich würde die demokratischen Probleme - obwohl ich keineswegs Herrn Zuleeg zustimmen kann- nicht so hart sehen wie Sie. Ich glaube, bei partizipatorischen Prozessen, Mitbestimmung, Bürgerinitiativen und dergleichen wird man eine lockere Hand haben können; vielleicht wollten Sie das auch gar nicht negieren. In Fällen, in denen Personen mitbestimmen sollen, und zwar nicht nur in der starken Form der sozialen Selbstverwaltung, sondern in denen Personen auch nur befragt werden sollen - Personen also, die es angeht -, da wird man nicht so streng sein müssen. Aus dieser dynamischen Sicht möchte ich auch noch hinzufügen, daß mich etwas gestört hat, daß das Problem hinsichtlich der betroffenen Personen zu sehr einseitig vom "Ausländer" bei "uns", also von der Kongruenz der "Inländer" mit dem „Staatsangehörigen" her, gesehen wurde. Ich glaube, daß man sehr viel stärker die Vielfalt möglicher Positionen von Inländern und Ausländern sehen muß. Und da haben wir ja in Deutschland a priori ganz besonders komplizierte Verhältnisse, weil wir z. B. „Deutsche" und „Staatsbürger" haben.

Alles in allem hat mir das Wort "Vaterland“ in der ganzen Diskussion bisher gefehlt. Es geht mir um das Problem einer elementaren, leistungsfähigen Einheit, die für den Krisenfall bereitstehen muß - für mich selbst und für die Mitbürger. 
Nun zu einem weiteren Punkt, den ich streifen möchte: ich glaube, daß man stärker betonen muß, wie stabil oder labil überhaupt die Grenze der Ein- und der Ausbürgerung ist. Wir haben gerade hier kraft Art. 116 GG über das Wiedervereinigungsgebot - jedenfalls wie es das Bundesverfassungsgericht interpretiert -, aber auch kraft der Grundrechtsschranken des Art. 16 GG betreffend Ausbürgerung, Aberkennung der Staatsangehörigkeit und dergleichen, ganz besonders starre Verhältnisse. Wir haben auch kein sehr flexibles Einbürgerungsrecht. Ich glaube, von daher muß bei der Situation der Einwohner in der Bundesrepublik berücksichtigt werden, daß der Dauerzustand in der Offnungssituation vielleicht zu stärker differenzierenden Regelungen - wie sie Herr Isensee etwa konzipiert hat - führt.

Tomuschat: Unsere Diskussion ist schwierig geworden, da man nicht recht weiß, wo man diskutieren soll, ob auf der Ebene des Verfassungsrechts, derjenigen des einfachen Gesetzesrechts oder derjenigen der Rechtspolitik. Es geht vieles ineinander über.

Bekanntlich existiert das Recht nicht unabhängig von denjenigen, die über sein Schicksal befinden. Insofern hatte bisher das Ausländerrecht ein gar schweres Schicksal zu tragen. Da sich die Wissenschaft seiner nur recht wenig angenommen hatte, war es in die Hände der Praktiker gefallen, die dieses Recht aus einer ganz spezifischen Sicht heraus behandelt haben, nämlich aus der Berufserfahrung desjenigen, dem täglich eine Vielzahl von pathologischen Fällen vorliegt. Das hat zu einer gewissen Reaktion geführt. Es sind literarische Stimmen laut geworden, die sich ganz offen als Anwälte einer Gruppe von Entrechteten verstanden haben. Man ist dabei wohl gelegentlich nicht nur über die faktischen Realitäten, sondern auch über die rechtlichen Realitäten hinausgegangen. Das Ausländerrecht muß aus der Dilemmasituation heraus. Mir scheint, daß die beiden Referate des Vormittags gute Ansätze geboten haben, um in einer reflektierten Weise Maß und Mitte in diesen doch recht heiklen Fragen des Verfassungsverständnisses und der Rechtspolitik zu finden.

Ein zweites möchte ich noch hinzufügen, und das betrifft den Art. 25. Ich knüpfe insoweit an Herrn Isensee an, glaube aber nicht, daß er gesagt hat, was ich hier ausführen will. Man hat der deutschen Staatsrechtslehre manchmal vorgeworfen - vielleicht nicht immer zu Unrecht -, daß sie etwas grundgesetzintrovertiert sei. Den beiden Referaten des Vormittags kann man diesen Tadelsvorwurf gewiß nicht machen. Andererseits 
muß das Bewußtsein erhalten bleiben, daß das Grundgesetz ein Rechtskörper ist, der auf eigenen Beinen steht. Man darf das Grundgesetz nicht dadurch aushöhlen - vielleicht ein etwas starkes Wort -, daß man Ergebnisse der Rechtsvergleichung oder Regeln des Völkerrechts an es heranträgt und ihm unterschiebt. Ich halte Herrn Doehrings These für gefährlich, daß es Art. 25 als lex specialis gestatte, selbst bei Grundfreiheiten, die als Menschenrechte ausgestaltet sind, zu differenzieren, konkret gesprochen: zu Lasten der Ausländer Beschränkungen anzuordnen. Ein Beispiel nur zur Wiederlegung: Das Völkerrecht gestattet auch, den Status der eigenen Staatsangehörigen abzusenken bis auf einen menschenrechtlichen Mindeststandard. Es kann aber wohl nicht gut angehen, daß man auf dem Wege über Art. 25 unsere Grundrechtsverbürgungen vom Sockel stößt. Dann hätten wir nämlich, nachdem wir den Art. 24 als Integrationshebel kennengelernt haben, den Art. 25 gleichsam als Grundrechtssturzhebel.

Nun ein dritter Punkt. Bei der Diskussion über das Wahlrecht scheint mir die Realität nicht immer klar erkannt zu sein. Soweit man sich mit der bisherigen Praxis befaßt, stellt sich als Ergebnis heraus, daß die Ausländer in erster Linie daran interessiert sind, in ihrem eigenen Heimatland weiter politisch mitbestimmen und mitwirken zu können, und zwar vom Boden der Bundesrepublik aus. Damit verlagert sich natürlich die Debatte auf das Gebiet des $\S 6$ des Ausländergesetzes. Das ist eine andere Debatte, sie ist hier nicht geführt worden.

Was die Frage angeht, ob Wahlrechte auch Ausländern zugestanden werden könnten, so meine ich, daß Herr Isensee vielleicht - was das Kommunalrecht angeht - etwas zu überspitzt argumentiert hat, indem er zunächst den Topos der Staatlichkeit aufgebaut und daraus dann wieder "stringent" abgeleitet hat, daß es schlechthin ausgeschlossen sei, Ausländern auch nur in den Gemeinden das Wahlrecht einzuräumen. Wenn man sich überlegt, was in den Kommunen entschieden wird, so sind das im wesentlichen Fragen der Daseinsvorsorge, und zu den Einrichtungen der Daseinsvorsorge leisten die Ausländer in gleicher Weise wie die Deutschen ihren finanziellen Beitrag. Sieht man nun hinter der Diskriminierung der Ausländer die materielle Erwägung, daß der Ausländer ja auch nicht in gleicher Weise mit Pflichten belastet sei, dann muß man für die Gemeindeebene folgern: Der Ausländer hat den gleichen Pflichtenstatus, und deshalb ist es sicher nicht inopportun oder nicht ungerechtfertigt, ihm auch ein gleiches Maß an Rechten einzuräumen. Dabei wäre natürlich sehr vor- 
sichtig zu verfahren, und es bedarf gründlicher tberlegung, wie man sicherstellen kann, daß die Ausländer nicht lediglich den Parolen irgendwelcher nationalen Gruppenführer folgen und ihre Stimme bei den Wahlen nicht aus eigener Uberlegung abgeben, sondern Wahlempfehlungen folgen, die man vorher für die jeweilige Gruppe ausgegeben hat.

Vorsitzender: Vielen Dank, Herr Tomuschat. Es wollte jetzt Herr Herzog Stellung nehmen. Ich würde dann vorschlagen, daß wir doch auch den $\S 6$ Ausländergesetz noch etwas näher betrachten sollten. Es ist mit Recht gesagt worden, da $B$ er in den Referaten zwar in das Blickfeld genommen worden ist, aber vielleicht könnte hier noch einiges vertieft werden, auch in Richtung der praktischen Konsequenzen der beiden Referate, deren Positionen ja doch wohl stärker auseinandergehen, als es vielleicht zunächst den Anschein hatte.

Herzog: Ich möchte zu zwei Themen Stellung nehmen, die schon in verschiedenen Diskussionsbeiträgen, wenn auch in ganz unterschiedlicher Richtung, angesprochen worden sind.

Zunächst unterstreiche ich mit allem Nachdruck die Entschiedenheit, mit der Herr Isensee die Zulassung zum deutschen Staatsgebiet und die Anwendung der deutschen Grundrechte auf Ausländer unterschieden hat. Diese Unterscheidung ist für meine Begriffe unumgänglich.

Allerdings muß ich auch hier, wie so oft, vor einer Uberinterpretation des Grundgesetzes warnen, wie sie etwa Herr Zuleeg vertreten hat. Die Probleme, die wir gerade in der Frage der Gastarbeiter haben, sind viel zu kompliziert, als daß man sie mit einer Verfassungsinterpretation lösen könnte. Wenn ich recht sehe, so kann eine wirklich überzeugende Lösung nur in der Richtung erwartet werden, daß für Gastarbeiter mehrere Statusformen mit ganz unterschiedlichen rechtlichen Konsequenzen eingeführt werden. Nur ein Beispiel: In der Bundesrepublik leben heute schon zahlreiche Gastarbeiterfamilien. Die Kinder dieser Familien bedürfen einer besonderen schulischen Betreuung. Hier wird die Notwendigkeit der Differenzierung besonders deutlich: Ein Gastarbeiterkind, dessen Familie mittelfristig wieder in ihr Heimatland zurückkehren soll, wird möglichst in Sonderklassen zu unterrichten sein, die die Entwurzelung aus dem Heimatland soweit wie möglich verhüten; ein Kind, dessen Familie auf Dauer in Deutschland bleiben soll, muß dagegen soweit wie irgend möglich gefördert werden, um den deutschen Bildungsansprüchen gerecht zu werden. Diese Dinge sind so kompliziert, daß man ihre Lösung von der politi- 
schen Führung und vom Gesetzgeber, aber nicht vom Verfassungsinterpreten verlangen muß.

Und zweitens: Ich möchte Herrn Isensee fragen, ob sein Versuch, neben seiner fundamentalen Unterscheidung weitere Stufen zu entwickeln, jenseits deren überhaupt nicht mehr zwischen Ausländern und Deutschen unterschieden werden darf, wirklich geglückt ist; es geht hier um die These $10 \mathrm{~b}$ und um den zweiten Satz der These 20. Zu These $10 \mathrm{~b}$ steht offensichtlich die Stufentheorie des Bundesverfassungsgerichts zu Art. 12 GG Pate. Untersucht man diese Rechtsprechung genau, so zeigt sich, daß man heute überhaupt nicht mehr von einer Stufentheorie, sondern bestenfalls noch von einer Theorie der schiefen Ebene sprechen kann, die Abgrenzungen, wie sie Herr Isensee vorschlägt, wahrscheinlich nicht mehr zuläßt. Zwischen dem, was Herr Isensee in seiner These $10 \mathrm{~b}$ und dem dazu gebildeten Beispielsfall vertritt, und der wirklich unhaltbaren Entscheidung des Bundesverwaltungsgerichts, die er genannt hat, liegt $m$. E. ein breiter Spielraum, der viel sorgfältiger untersucht werden müßte, als es Herr Isensee in diesem - zugegebenermaßen - Randbereich seines Referats getan hat.

Isensee: $\mathrm{Zu}$ dem Bedenken dagegen, ob das Modell einer zunehmenden Status-Verfestigung tragfähig sei: Ein Modell kann nicht jedem Einzelfall gerecht werden. Die Distinktionen zwischen Berufszulassung und Berufsausübung lassen sich nicht lupenrein treffen. Das Gebot der Gleichstellung des Ausländers in der jeweiligen sozialen Rolle löst nicht alle einzelnen Abgrenzungsschwierigkeiten.

Formen der grundrechtlichen Status-Verfestigung können auch außerhalb des Ausländerrechts aufgewiesen werden. Ein Beispiel liefern die Rechtsfiguren des Monopolergänzungs- und des Monopolersatzberufes im Wirkungskeis der Finanzmonopole. In der Verwaltungsrechtsprechung ist das Argument aufgetaucht, daß dort, wo die Grundrechte die Verstaatlichung und damit die Einführung eines Berufsverbots zuließen, sie erst recht beliebige Berufsbeschränkungen erlaubten. Dieser A-fortiori-Schluß wird aus gutem Grund überwiegend verworfen: Von einer rechtsstaatlich geordneten Rechtsversagung kann nicht auf rechtsstaats-freie Rechtsminderung geschlossen werden.

Wenn der Staat in grundrechtsfreier Entscheidung dem Ausländer einen Lebensbereich öffnet, so muß er die grundrechtsgebotenen Konsequenzen ziehen und die Gleichstellung mit dem Inländer gewährleisten. Die Rechtsfolgen der Zulassung soll- 
ten deshalb rechtzeitig bei der Entscheidung über die Zulassung in den Blick genommen werden. So sind sogleich bei der Erteilung der Aufenthalts- oder der Arbeitserlaubnis die gesellschaftlichen Bedürfnisse und die Möglichkeiten des nationalen "Energiehaushalts" in Rechnung zu stellen. Die staatliche Lenkungsgewalt sollte planmäßig in einem Stadium eingesetzt werden, in dem sie noch nicht zu stark grundrechtlich gebunden ist.

Das Selbstbindungs-Konzept enthält ein Moment des Allesoder-Nichts. Es wäre eine pseudo-humanitäre Lösung, wollte man an Stelle der Nichtzulassung zu einem Lebensbereich oder der Gleichstellung in dem Lebensbereich eine dritte Lösung wählen: die Zulassung mit verminderter Rechtsstellung. Diese Lösung widerspräche der Rechtsstaatlichkeit wie dem Sozialstaatsgebot. Sie höbe die Rechtsgleichheit wie die soziale Gleichheit auf.

Vorsitzender: Ich schlage vor, hier eine gewisse Zäsur zu machen, da dies ein besonderer Punkt zu sein scheint, über den schon vor Beginn der eigentlichen Diskussion intensiv gesprochen worden ist. Zunächst darf ich Herrn Bachof bitten.

Bachof: Zunächst $\mathrm{zu}$ dem von Herrn Isensee betonten und von Herrn Herzog unterstrichenen Unterschied von Gebietszulassung und Gebietszugehörigkeit: Auch ich stimme dem zu, halte aber die Anknüpfung an den Aufenthalt im Gebiet für zu eng. Es gibt noch andere Kontaktierungen der deutschen Staats- und Rechtsordnung, die einen Grundrechtsschutz für Ausländer auslösen müssen. Nehmen wir einmal den ausländischen Künstler oder Wissenschaftler, der ein Werk in der Bundesrepublik ausstellt oder ein Buch in der Bundesrepublik veröffentlicht; nehmen wir einen Jugoslawen, der einen Brief nach Dänemark schreibt, welcher die Bundesrepublik passiert. Nehmen diese Ausländer etwa nicht an dem Grundrechtsschutz des Art. 5 bzw. des Art. 10 GG teil? Ich meine, sie nehmen teil! Herr Isensee hat das Beispiel des mit einer Deutschen verheirateten Ausländers gebracht - man könnte auch an das nichtdeutsche Kind eines Deutschen denken - und hat gemeint, aus solcher Beziehung könne man (nur) einen Grundrechtsreflex für den Ausländer herleiten. Mir scheint, das sind mehr als bloße Reflexe, jedenfalls wenn Herr Isensee diesen Begriff im Sinne der herkömmlichen Unterscheidung von Rechtsreflex und subjektivem Recht verstanden wissen will. Ich halte in solchen Fällen nicht nur einen Reflex, sondern den vollen Grundrechtsschutz für gegeben.

Die Unterscheidung zwischen der Zulassung und dem dadurch erlangten Status ist sicher richtig, aber der Anknüpfungspunkt 
"Aufenthalt" ist zu eng. Es gibt eben noch andere als die durch den Aufenthalt ausgelösten Kontakte zur deutschen Rechtsund Staatsordnung, die des Grundrechtsschutzes bedürfen. Das mögen neben Kontakten gebietlicher Art auch solche personaler Art sein, z. B. bei der Ehe und beim Kindschaftsverhältnis. Daher müssen wir den Anknüpfungspunkt der "Gebietszulassung“ wohl erweitern. Das möchte ich jedenfalls als Frage aufwerfen.

Isensee: Die Frage hätte von mir erbeten sein können; sie ist eine willkommene Ergänzung. Der Aufenthalt ist Voraussetzung eines umfassenden Grundrechtsstatus. Daneben gibt es partielle grundrechtlich relevante Gebietsberührungen von Ausländern.

Bachof: Es geht nicht nur um Gebietsberührungen, sondern auch um Berührungen personaler Art; z. B. wenn zwischen einem Ausländer und einem Deutschen ein grundrechtsgeschütztes Verhältnis begründet wird oder entsteht, wie Ehe oder Kindschaftsverhältnis. Auch solche Beziehungen des Ausländers zur deutschen Rechtsordnung müssen bedacht werden.

Isensee: Hier muß die partielle Inlandsberührung näher dargestellt werden. Eines ist klar: Wenn ein Ausländer vom Ausland her einen Brief in das Bundesgebiet schickt, erlangt er im Geltungsbereich des Grundgesetzes den Schutz des Briefgeheimnisses. Wenn ein im Ausland lebender Ausländer ein Grundstück im Bundesgebiet erworben hat, genießt er den unverkürzten Schutz des Art. 14 GG wie der Deutsche. Wenn aber die Bundesrepublik dem Gebietsfremden den Grundstückserwerb untersagt, wie es § 23 AWG unter bestimmten volkswirtschaftlichen Voraussetzungen ermöglicht, so liegt kein Grundrechtseingriff vor. Hier ist lediglich die Gebietszulassung verweigert. $\mathrm{Da} B$ der Gesetzgeber diese Abweisung des Gebietsfremden für grundrechts-irrelevant hält, zeigt § $23 \mathrm{AWG.}$ Diese Norm genügt nämlich der Junktimklausel des Art. 14 GG nicht. Dagegen kann ein solches Veräußerungsverbot in Grundrechte des deutschen Veräußerers eingreifen. Soweit der Grundrechtsschutz des Gebietsansässigen auch für den Gebietsfremden Vorteile bringt, liegt ein Grundrechtsreflex vor.

Das Zwei-Phasen-Modell läßt sich also auch auf partielle Gebietsberührungen anwenden. Es fehlt hier allerdings meistens an einem manifesten Zulassungsakt. Die Zulassung wird in der Regel global und stillschweigend erteilt.

Ein im Ausland lebender ausländischer Publizist oder Wissenschaftler hat kein Grundrecht, im Bundesgebiet Werke zu veröffentlichen. Sind die Arbeiten aber erst einmal in Deutschland 
eingeführt, so gelten das Zensurverbot und die übrigen Freiheitssicherungen. - Auf der anderen Seite steht den deutschen Gebietszugehörigen und Staatsangehörigen das Informationsgrundrecht zu. Dieses Recht bezieht sich - das hat das Bundesverfassungsgericht entschieden - auch auf allgemein zugängliche Quellen, die im Ausland belegen sind, also etwa auf ausländische Presseerzeugnisse. Somit gewinnt der gebietsfremde Publizist einen Reflex des Informationsgrundrechts, das dem Inländer zusteht.

Doehring: Ich möchte noch einmal zu einigen Bemerkungen Stellung nehmen, die Herr Tomuschat gemacht hat und auch anknüpfen an das, was Herr Isensee gesagt hat. Ich bin in einigen Kardinalpunkten mit Herrn Isensee gar nicht einer Meinung. Und das ist folgendes: Ich kann mich eben doch nicht der Meinung anschließen, daß dann, wenn die Zulassung des Ausländers geschehen ist, er in Bezug auf die jedermann erteilten Grundrechte undifferenziert $\mathrm{zu}$ deutschen Staatsangehörigen behandelt werden muß. Ich habe da große Bedenken. Ich möchte nochmals betonen, daß ich Art. 25 nicht dazu verwenden will, alles aus den Angeln zu heben, sondern ich kann das Problem auch ganz anders darstellen. Ich will das einmal an einem Beispiel erklären: Wir haben im Rahmen der International Law Association jahrelang an einem Vorschlag gearbeitet für eine internationale Asylrechtskonvention. Viele Staaten sollten sich dem anschließen. Die Staaten sollten sich verpflichten, Asyl zu gewähren. Eine solche Konvention - das ist uns bei diesen internationalen Arbeiten klar geworden kommt nur zustande, wenn in dieser Konvention gleichzeitig steht, daß den Asylberechtigten die Meinungsfreiheit eingeschränkt werden muß, damit sie also dann nicht in dem aufnehmenden Staat unbegrenzt politisch tätig werden; sonst machen das die anderen Staaten nicht mit. Wenn man aber sagt: Der Fremde ist als Asylberechtigter zugelassen, jetzt hat er den Schutz des Art. 5 wie ein Deutscher, dann gibt man Steine statt Brot. Man gibt nämlich kein Asylrecht mehr, wenn die Konvention gar nicht zustande kommt. Andere Staaten haben solche Bedenken in dieser Beziehung bestimmt nicht. Ich glaube, wir sind der Staat, der sich weitaus am meisten überhaupt Gedanken darüber macht.

Also, ich wollte nur davor warnen, solche Rechte wie ein Benefiz auszudehnen; das könnte auch zurückschlagen. Es könnte so zurückschlagen, daß man überhaupt kein Asyl gewähren kann. Bei der Alternative, entweder abweisen oder zu- 
lassen und dann mit vollen Grundrechten, weist man sie eben zum Schluß doch ab.

Frowein: Die Zwei-Stufen-Lehre in diesem Zusammenhang macht sich natürlich sehr gut, enthebt uns aber nicht der Frage der dogmatischen Absicherung und der positiv-rechtlichen Begründung. Herr Isensee, Sie haben zu Anfang davon gesprochen, daß Grenznormen der Grundrechte entwickelt werden müssen. Die müssen positiv-rechtlich entwickelt werden. Ich glaube, daß Sie sich dieser Frage nicht deutlich genug gestellt haben.

Man kann wohl nicht so undifferenziert sagen - und hier verweise ich zum Teil auf Herrn Bachof - , daß derjenige, der noch keine Gebietsberührung hat, auch ohne grundrechtliche Sicherung ist, soweit es um die Zulassung für ihn geht. Auch bei der Entscheidung über seine Zulassung ist er durch die im echten Sinne staatsbegrenzenden Grundrechte, vor allem Art. 3, nach meiner Ansicht geschützt. Sie müßten den Nachweis führen, daß es den positiv-rechtlichen Schutz durch die Nicht-Inländer-Grundrechte hier nicht geben sollte. $\mathrm{DaB}$ das praktisch ist, kann ich an einem kleinen Beispiel klarmachen: Ein Ausländer hat deutsche Verwandte, durch Eheschließung mit einer Deutschen oder als Kind von Deutschen, er will einreisen aus einem ganz familiären Grunde. Er wird vor einer willkürlichen Verweigerung der Einreise - darüber besteht nach meiner Meinung kein Zweifel - durch den Art. 3 geschützt, was entsprechende prozessuale Konsequenzen hat. Weiterhin bin ich mit einigen Vorrednern nicht der Ansicht, daß nach Zulassung undifferenziert Möglichkeiten der Unterscheidung zwischen Ausländern und Inländern nicht mehr bestehen. Auch das ist positiv-rechtlich begründbar. $\mathrm{Da}$, wie Sie mit Recht gesagt haben, Art. 3 Abs. 3 die Ausländereigenschaft nicht enthält, aber allein Art. 3 Abs. 1 und Art. 3 Abs. 3 für die Ausfüllung von Grundrechtsvorbehalten ihrerseits Grenzen sind, können Grundrechtsvorbehalte sehr wohl ausländerdifferenzierend ausgestaltet werden. Lassen Sie mich wieder ein Beispiel geben: Alle deutschen Landespressegesetze legen, wenn ich es richtig in Erinnerung habe, fest, daß Ausländer Journalisten, aber nicht verantwortliche Redakteure sein können. In meiner Sicht wäre das ein Fall, der in Threm Stufensystem schwer unterzubringen wäre. Ich halte das aber für eine verfassungsrechtlich zulässige und sehr sinnvolle Regelung.

Noch ein letzter Punkt: Ich halte es auch nicht für richtig, so zwischen den demokratischen und den rechtsstaatlichen Kompetenzen zu unterscheiden, wie Sie es im allerletzten Teil getan 
haben. Ich halte es für verfassungsrechtlich zulässig und durch unser Grundrechtssystem, Art. 5 Abs. 2 und andere, gedeckt, daß wir zum Beispiel das Erscheinen von Ausländerzeitungen verbieten, die zielgerichtet der Auseinandersetzung mit bestimmten ausländischen Regierungssystemen dienen. Dinge dieser Art haben wir in Ansätzen zum Teil schon erlebt. Wenn ich recht sehe, wäre das auch nach Ihrem letzten Punkt V $19 \mathrm{~b}$ sehr schwer einzufangen. Das geht mir zu weit. Hier haben wir sowohl in den Grundrechten als auch von Art. 25 GG her Schutzmöglichkeiten.

Isensee: Das System des Verfassungs-Kollisionsrechts kann natürlich im Rahmen eines Referats nicht entwickelt werden. Dieses Kollisionsrecht muß stark differenzieren. Die dogmatische Zukunftsaufgabe ist noch nicht wirklich in Angriff genommen.

Zum konkreten Fall der ausländischen Journalisten, die nicht verantwortliche Redakteure werden dürfen: Hier geht es zunächst nicht um die Pressefreiheit, die allerdings nicht als Deutschen-Grundrecht ausgestaltet ist. Es geht um die Berufsfreiheit des Journalisten - und diese ist dem Ausländer nicht grundrechtlich gewährleistet. Erst wenn ihm der grundrechtsfreie Zugang zur Berufsausübung aufgetan wird, erschließt sich die Presse als Berufsfeld. Die partielle Zulassungssperre zu Presseberufen ist daher zulässig.

Zum Fall des einreisewilligen Ausländers, der familiäre Bindungen zum Inland hat: Hier ist der Rückgriff auf den allgemeinen Gleichheitssatz überflüssig, weil ein sachbezogenes besonderes Gleichstellungsgebot in Art. 6 GG eingreift. Das Grundrecht von Ehe und Familie fordert bei der Entscheidung über die Einreiseerlaubnis Beachtung - aber nicht um des gebietsfremden Ausländers, sondern um seiner deutschen Familienangehörigen willen. Der gebietsfremde Ausländer genießt keinen selbständigen Grundrechtsschutz, sondern er partizipiert am Grundrechtsschutz der Familienmitglieder, die als deutsche Staatsbürger oder Gebietszugehörige Grundrechtsträger sind.

Bachof: Herr Froweins Beitrag scheint mir deutlich gemacht zu haben, daß der Ausdruck „Zulassung“ mißverständlich ist. Wer als Ausländer unfreiwillig in das deutsche Bundesgebiet gelangt, etwa durch einen Terroristenakt - z. B. Verschleppung oder Flugzeugentführung - erhält ja sicherlich keine „Zulassung " im üblichen Wortsinn! Aber selbstverständlich - das wäre wohl auch Herrn Isensees Meinung - genießt er trotzdem Grundrechtsschutz, wenn er einmal da ist. Die Aufenthalts- 
"Zulassung" darf also nicht verstanden werden als Erfordernis eines Verwaltungsakts, es muß vielmehr auch jeder andere Kontakt zum deutschen Staatsgebiet oder zur deutschen Rechtsordnung genügen. Zu Ihrem Beispiel, Herr Frowein: Das nichtdeutsche Kind eines Deutschen hat bereits diesen "Kontakt", es bedarf keiner besonderen „Zulassung" mehr, sondern da ist die Verbindung zur deutschen Rechts- und Staatsordnung schon vorhanden. Deshalb ist der Ausdruck „Zulassung" mißverständlich, weil zu eng.

Oppermann: Ich knüpfe unmittelbar an das an, was eben gesagt wurde und möchte noch einmal von der Bemerkung von Herrn Herzog ausgehen, der auf die These $10 \mathrm{~b}$ von Herrn Isensee rekurrierte. Mir ist bei den ganzen Vorstellungen der „Zulassung", der "unmittelbaren Kontakte“, die hier eben wieder anklangen, nicht so ganz dogmatisch wohl. Man müßte stärker positiv-rechtlich vom Charakter der Grundrechte ausgehen bei der Frage 10 und da ist der Unterschied zwischen den Jedermann-Grundrechten und den Deutschen-Grundrechten in diesem Zusammenhang doch recht fundamental. Deswegen ist mir bisher noch nicht deutlich geworden, wie der Ausländer - wie es in Ihrer These $10 \mathrm{~b}$ mit der Stufentheorie anklingt - in den Status der Deutschen-Grundrechte hineinwachsen soll. Auch der Versuch, über Art. 3 Abs. $1 \mathrm{zu}$ arbeiten, überzeugt nicht.

Das Deutschen-Grundrecht kann der Ausländer nur auf dem Wege erreichen, da $\beta$ er eines Tages eingebürgert wird. Umgekehrt habe ich viel Sympathie für den Gedanken von Herrn Doehring, daß man auch bei den Jedermann-Grundrechten nicht jede Möglichkeit der Differenzierung von Art. 25 her gesehen von vornherein ausschließen sollte. Wenn man sich die Fälle im einzelnen ansieht, ist es nämlich durchaus die Frage, ob man den Ausländern ein großes Geschenk damit macht, sie von vornherein aus unserer verfassungsrechtlichen Sicht voll und ganz mit den verfassungsrechtlichen Wohltaten - hier der Jedermann-Grundrechte, vielleicht sogar der Deutschen-Grundrechte - zu versehen, sobald sie auf deutschem Boden angelangt sind. Oder sollen sie - wie manchmal in der Diskussion über die Grundrechtsmündigkeit bei Kindern und Heranwachsenden angenommen - allmählich in den grundrechtlichen Status hineinwachsen? Herr Isensee, es ist die Frage, ob es sich dabei nicht um eine Art Danaer-Geschenk für den Ausländer handelt. In sehr vielen wirtschaftlichen und sozialen Situationen kann sich das Problem stellen, daß der Ausländer, je stärker er mit den Deutschen assimiliert wird, beispielsweise auf dem Tarifgebiet oder in ähnlichen Bereichen, Gefahr läuft, in 
Zeiten der Krise dann auch - gerade weil er nur im vollen Status bleiben kann oder gar nicht bleiben kann - eher über die Grenze nach Hause geschickt zu werden. In den Jahren 1966/ 67 zeichnete sich das damals kurzzeitig in manchen Ansätzen schon ab. Sicherlich wird man den Ausländern soviel wie möglich soziale und wirtschaftliche Gleichstellung wünschen. Aber in manchen Situationen kann es für den Ausländer vorteilhafter sein, wenn er in einem geminderten wirtschaftlichen und sozialen Status im Lande bleiben kann und es dem Gesetzgeber nicht verfassungsrechtlich verboten ist zu differenzieren. Dies wollte ich zur Unterstützung der Sicht von Herrn Doehring zu dieser Frage sagen.

Leisner: Der Ernst, mit dem der Status der Ausländer in dieser Vereinigung heute diskutiert wird, ist nicht nur erfreulich, wie alles, was hier geschieht, er ist auch berechtigt. Denn wenn die Entwicklung so beängstigend fortschreitet, wie es hier mehrfach beschworen worden ist, wenn eines Tages dann türkische Divisionen unsere Grenze schützen, werden wir nur unseren eigenen zukünftigen Status hier diskutiert haben.

Zunächst einige Worte über die Zulassung der Ausländer zu den Rechten des status activus. Vor allem zwei Einwände sind hier gegen die Konstruktion von Herrn Isensee vorgebracht worden. Einerseits sagt man, man dürfe den Volksbegriff nicht allzu eng fassen. Es müsse auf eine gewisse Schicksalsgemeinschaft abgestellt werden; diese Schicksalsgemeinschaft umfasse eben auch den zugelassenen Ausländer. Auf der anderen Seite wird - wenn auch das Prinzip nicht in Zweifel gezogen wird immerhin vorgebracht, man könne auf der Gemeindeebene eine andere Lösung gelten lassen. Beides scheint mir nicht berechtigt, und zwar aus folgenden Gründen:

Wir können und nicht über die bindenden Normen des Grundgesetzes hinwegsetzen, über die Verfassung, die da sagt, daß die Gewalt vom Volk ausgeht, von jenem politischen Volk, das eben gerade nicht die "Schicksalsgemeinschaft" ist. Und aus unserem Demokratieverständnis heraus ist es uns schlechthin verwehrt, diesen Volksbegriff bis zu den Ausländern auszudehnen. Die „Unentrinnbarkeit“ hat ihren guten Sinn, selbst wenn das Wort zu Mißverständnissen Anlaß geben mag. Unentrinnbarkeit heißt ja keineswegs, daß jemand nicht über die Grenze fahren oder nicht zurückkommen kann. Wir Deutschen sind aber unentrinnbar jedenfalls in dem Sinne an dieses Land gebunden - dem wir, vor allem völkerrechtlich, immer „zugerechnet" werden -, daß wir mit unserem $\mathrm{Pa} B$ unsere Nationalität, ja unsere ganze Nation mit uns tragen und daß wir auch 
darunter leiden, wenn wir etwa wieder nach Deutschland abgeschoben werden. Insoweit ist eine rechtliche und auch eine gewisse faktische Unentrinnbarkeit gegeben.

Ich meine auch nicht, da $\beta$ man den Begriff des Volkes als Grundlage des demokratischen Prinzips erweitern kann, sozusagen "unten", auf der Gemeindeebene, und zwar aus folgendem Grunde: Im Gemeindebereich herrscht ja nicht etwa nur eine Autonomie, die territorial begrenzt wäre und nur mit der Daseinsvorsorge zu tun hätte. Die Gemeinden sind voll demokratisiert durch Art. 28, der eng mit Art. 20 GG zusammenhängt, der von demselben Volksbegriff ausgeht wie Art. 20. Deswegen müssen dieselben Grundsätze bei Art. 28 wie bei Art. 20 GG gelten. Auch die Gemeinde ist insoweit wenigstens eine politische Gemeinschaft, so daß wir nicht das Wort "Volk" zur Schicksalsgemeinschaft ausufern lassen können. Ich würde mich dem Versuch widersetzen, auf Gemeindeebene einen anderen Demokratiebegriff gelten zu lassen als auf Bundes- oder Landesebene.

Und nun noch zur „Stufentheorie“: Im Anschluß an Herrn Herzog möchte ich mich sehr dafür aussprechen, daß diese Stufentheorie Grundlage unserer künftigen Ausländerdogmatik wird. Die scharfe Trennung zwischen dem Gebietskontakt auf der einen Seite und dem daraus folgenden Grundrechtsstatus auf der anderen - dieses System ist dogmatisch geschlossen, und es hat hinreichende Flexibilität, wenn man nur berücksichtigt, daß natürlich nicht auf der grundrechtsgeschützten zweiten Stufe das wieder rückgängig gemacht werden darf, was auf der ersten Stufe gegeben worden ist. Mit anderen Worten: Wir müssen sehr vorsichtig sein, daß nicht der Ausländer erst mit großer Geste frei zugelassen wird, und man ihm dann erklärt, nach einem halben Jahr müsse er wieder gehen. Das wäre eine Aushöhlung der „zweiten Stufe“, des Grundrechtsschutzes.

Nicht zu teilen sind aber Bedenken, die einige Vorredner über das „Hineinwachsen in die zweite Stufe“ geäußert haben. Wenn ich Herrn Isensee richtig verstehe, so wollte er doch damit keineswegs sagen, daß etwa mit Zeitablauf immer neue Rechte hinzukommen sollten, und daß dann nach einigen Jahren der Ausländer eigentlich dem Deutschen vollständig gleichgestellt werde, in einer mehr oder weniger kontrollierbaren Weise. Das würde ja schon der Rechtsstaatlichkeit widersprechen. Der Sinn der Stufentheorie ist vielmehr: Wenn der Ausländer einmal zugelassen ist, hat er den Grundrechtsstatus des Ausländers. Und die Vorredner mögen doch bedenken, daß dieser immer noch genug Differenzierungsmöglichkeit bietet: Einerseits gilt 
das Differenzierungsgebot des Art. 3 Abs. 3 für die Ausländer nicht, so daß ihnen gegenüber auch nach Zulassung noch differenziert werden kann, und zum anderen sollen ihnen ja auch durchaus nicht - wenn ich Herrn Isensee recht verstanden habe - die Deutschen-Rechte zugebilligt werden. Damit aber, so glaube ich, ist das System flexibel genug und könnte zur Grundlage unserer Dogmatik werden.

Doehring: Herr Leisner, würden Sie sagen, daß der einfache Gesetzgeber nicht in der Lage sei, für die Kommunen das Wahlrecht an die Ausländer zu geben, da Art. 28 Abs. 1 Satz 2 mit dem Wort „Volk“ das sperrt?

Leisner: Ich wollte genau das sagen; ich halte das für verfassungswidrig.

Erbel: Herr Isensee, eine Frage habe ich zur These $4 \mathrm{~b}$ betreffend die Verfügung über die Zulassung zum Aufenthalt und dem daraus erwachsenen Grundrechtsstatus: Bei meiner wirklich freundlichen Bewunderung für die Begriffsschärfe. mit der Sie Thre Ausführungen gestaltet haben, verwundert mich doch etwas diese Fassung. Es heißt dort:

Die Begründung eines Grundrechtsstatus des Ausländers ist die Folge der Zulassung seines Aufenthalts.

Ich war bisher und bin auch noch der kindlichen oder, wenn man so will, der treuherzigen naturrechtlichen Auffassung, daß der Mensch diese elementaren Rechte, die Grundrechte - in der amerikanischen Verfassung heißt es, die angeborenen Rechte - eben von Geburt aus als Mensch sozusagen mit sich herumträgt. Ich verstehe nicht ganz, wieso die Kontaktnahme mit dem Staatsgebiet und die Zulassung - ich weiß nicht, ob das vorhin nicht im Sinne eines Verwaltungsaktes gemeint war, was noch eine merkwürdigere Konstruktion wäre - also diese Zulassung - wie beim König Midas die Sachen in Gold verwandelt wurden - hier plötzlich den grundrechtlichen Status begründet. Müßte man nicht genauer sagen, daß vielleicht die Ausübung dieser Grundrechte aktualisiert wird?

Isensee: Eine Unterscheidung vorweg: Die überstaaatlichen Menschenrechte, die als naturrechtliche Vorgegebenheiten jeder Staatsorganisation anerkannt werden, sind nicht identisch mit den Grundrechten, die das Grundgesetz als positivrechtliche Normen enthält. Die innerstaatlichen, positivrechtlichen Grundrechte gelten nur in den räumlichen und personellen Grenzen, die der Staatsordnung innerhalb der Völkergemeinschaft ge- 
steckt sind. Die grundrechtliche Garantenstellung der Bundesrepublik ist daher auch begrenzt.

Ob die Grundrechte der deutschen Verfassung für den Ausländer erst mit der Gebietsberührung entstehen oder ob sie auch auf den in Neuseeland wohnenden Neuseeländer angelegt sind, sich aber erst beim Gebietskontakt aktualisieren - das ist eine Frage der dogmatischen Konstruktion, von der das praktische Ergebnis nicht abhängt.

Das Stichwort "Gebietskontakt" darf ich ganz kurz aufnehmen: Der Aufenthalt als solcher ist ein realer Zustand. Aber ein realer Zustand kann rechtlich geregelt werden. Die Zulassung des Aufenthalts durch den Staat ist ein Willensakt und gehört damit in den Bereich des Normativen. Wenn der Fremde, der unerlaubt das Staatsgebiet betritt, den Schutz der Grundrechte erlangt, so unterliegt doch der Realakt der Einreise als solcher der rechtlichen Bewertung. Vollends stellt sich beim Rechtsakt der Gebietszulassung das Problem, wieweit er rechtlich, vor allem auch verfassungsrechtlich determiniert ist.

Saladin: Ich möchte anknüpfen an den überzeugenden Schluß des Referats vun Herrn Isensee. Wenn er sagt, das Grundgesetz enthalte keine ausländerpolitische Konzeption, so finde ich das durchaus richtig. Das bedeutet im Grundsatz, daß dem Gesetzgeber hier ein außerordentlich weiter Spielraum gelassen ist, und daß somit die Möglichkeit $\mathrm{zu}$ sehr vielfältigen Differenzierungen besteht, die allesamt vor dem Grundgesetz Bestand haben Dem Gesetzgeber ist die Verantwortung für die Auswahl unter diesen Möglichkeiten vom Grundgesetz nicht abgenommen.

Wenn Sie, Herr Isensee, in Ihrer These $18 \mathrm{c}$ von den typischen Lasten sprechen, die aus der demokratischen Mitgliedschaft im Staatsverband erwachsen, so möchte ich immerhin darauf hinweisen, daß solche Belastung durch andersartige Verpflichtungen, vor allem humanitäre (von den fiskalischen ganz abgesehen), aufgewogen werden könnte. Und wenn Sie in Ihrer These $18 \mathrm{~b}$ erklären, das demokratische Prinzip schließe das aktive wie das passive Wahlrecht für Ausländer aus, d. h. für Personen, "die nicht Staatsbürger auf Lebenszeit sind", so wäre dazu zu erwähnen, daß ja in der Bundesrepublik, wie auch in der Schweiz, Aufenthaltsbewilligungen ohne zeitliche Befristung verliehen werden (Schweiz: „Niederlassung“, Art. 6 des Bundesgesetzes über Aufenthalt und Niederlassung der Ausländer, vom 26. März 1931). Und wenn der Gesetzgeber dies zuläßt, dann heißt das doch, daß wir den betroffenen Ausländern eine außerordentlich enge Verbindung, ja 
eine eigentliche "Schicksalsgemeinschaft" mit dem Gastland gestatten. Und dann wäre es doch nur konsequent, wenn man sich um eine optimale Assimilierung solcher Ausländer bemühte. Das hieße dann nach meinem Dafürhalten auch, daß man versuchte, jedenfalls diese Kategorie von Ausländern an der politischen Willensbildung partizipieren zu lassen - mindestens an gewissen Akten der Willensbildung. - Eine weitere Differenzierung, von der noch gar nicht gesprochen wurde, wäre in dem Sinne denkbar, daß die Ausländer im politischen Willensbildungsproze $\beta$ zwar nicht Entscheidungs-, wohl aber qualifizierte Anhörungs-(,Mitsprache"-)rechte erhielten. All diese Möglichkeiten sollten, wie mir scheint, noch viel eingehender geprüft werden, als das bisher geschehen ist.

Böckenförde: Herr Doehring hat uns in seinem Referat, wenn ich das recht verstanden habe, sehr deutlich die Grenzmarkierungen aufgezeigt und festgemacht, wie sie sich vom Völkerrecht her für die Gestaltung des Ausländerrechts im staatlichen Bereich ergeben. Ich habe dabei den Eindruck gewonnen, als ob diese völkerrechtlichen Markierungen zur unausgesprochenen Voraussetzung immer noch die Tatsache haben, daß der Fremde, von dem das Völkerrecht spricht, der Gast ist, der in einem anderen Staat lebt und Gastrecht genießt. Von daher werden auch die sehr weitgehenden Gestaltungsmöglichkeiten und deren Begrenzungen, soweit sie vorhanden sind, gefunden.

Meine Frage ist, ob diese Voraussetzung eigentlich noch auf die Wirklichkeit zutrifft, mit der wir es heute zu tun haben. Ich möchte das an zwei Punkten kurz erläutern. Erster Punkt: Die Gastarbeiter-Wirklichkeit ist meines Erachtens nicht mehr damit adäquat $\mathrm{zu}$ erfassen, daß es sich hier um Gäste handelt, die dem Fremdenrecht als einer Ausformung des Gastrechts unterstehen. Es handelt sich auch im Hinblick auf unsere eigene Lage nicht mehr darum, daß hier Fremden durch Einräumung bestimmter Rechtspositionen gewisse Wohltaten und ein nicht geschuldetes Entgegenkommen gewährt werden. Unsere Gesellschaft ist nach der Strukturentwicklung, die sie genommen hat, heute schon auf die Gastarbeiter angewiesen; sie erbringen für die Gesellschaft lebenswichtige Funktionen, die diese Gesellschaft aus sich heraus immer weniger zu erbringen in der Lage ist. Muß das nicht im Sinne der allem Recht eigenen Reziprozität auch Auswirkungen auf den völkerrechtlichen Status dieser „Fremden“ haben?

Zweiter Punkt: Die Inhaber des EWG-Niederlassungsrechts. Da müßte man doch fragen, ob diese Personen nicht mehr nur Quasi-Fremde sind, die einen Status haben, der sich nicht mehr 
nahtlos in das bisherige völkerrechtliche Fremdenrecht einfügt. Ist hier nicht auch völkerrechtlich eine Differenzierung angebracht, die das zum Ausdruck bringt?

Schließlich noch ein anderer Punkt: Wenn ich Sie recht verstanden habe, so sagten Sie, daß DDR-Bürger von der BRD nach Ihrer Auffassung analog zum Fremdenrecht behandelt werden sollten. Da muß ich entschieden widersprechen. Bei aller Problematik des Grundlagenvertrages und des BVerfGUrteils dazu scheint mir unaufgebbar zu sein, daß Bürger der DDR, sowie sie im Herrschaftsbereich der Bundesrepublik leben, den vollen Inländerstatus haben. Vielleicht war das von Ihnen anders gemeint. Denn es kann meines Erachtens gar keine andere Lösung geben. Dies ist die Realität, die von Gesamtdeutschland noch vorhanden ist und auch effektiv gehalten werden muß.

Doehring: Vielleicht darf ich gleich replizieren. Herr Böckenförde, Sie haben das völlig richtig verstanden, um auf die DDR zurückzukommen. Ich hatte gesagt, eine analoge Anwendung des Fremdenrechts kann geboten sein, und zwar zu ihren Gunsten. Ich erinnere an den Ihnen auch bekannten Hanke-Fall. Wenn ein Volkspolizist drüben schießt und kommt hierher und wird hier bestraft, weil er drüben etwas getan hat ( - wofür er bestraft wird, wenn er es nicht getan hätte -), dann muß ich das internationale Strafrecht analog anwenden. Sonst schädige ich ihn gerade mit der - wiederum - Wohltat der $\mathrm{Zu}$ erteilung aller Rechte, aber auch aller Pflichten eines bundesrepublikanischen Staatsbürgers. Das will ich nicht. Da gehen doch die Menschenrechte vor. Deshalb zumindest die analoge Anwendung in diesen Fällen. Wo die analoge Anwendung als Schutzfunktion nicht nötig ist, wende ich unser Recht uneingeschränkt an. Ich glaube, da haben wir uns völlig verstanden.

Böckenförde: Das würde also gelten, soweit er auf dem Territorium der DDR ist. Wenn er in die Bundesrepublik überwechselt, darin sind wir uns einig, hat er sofort den Inländerstatus.

Doehring: Ja, der fliehende Volkspolizist kommt hierher, und er wird hier vor Gericht gestellt, weil er drüben geschossen hat. Jetzt will ich das internationale Strafrecht mit den $\$ \S 3$ und 4 des Strafgesetzbuches analog wie bei einem Fremden anwenden, weil ich sonst mit ihm verfahre, wie etwa mit einem Marokkaner, der über die algerische Grenze geht, nicht verfahren würde. Das ist der ganze Grund. Sonst, soweit möglich, bekommt er selbstverständlich alle Rechte, die überhaupt für 
einen Deutschen denkbar sind. Darüber sind wir uns, glaube ich, beide völlig einig. Die von mir gebrachte analoge Anwendung ist eine Schutzfunktion.

Zweiter Punkt zur EWG: Das ist Vertragsrecht, daran kann ich mit allgemeinen Völkerrechtsregeln überhaupt nichts ändern. Das sind ganz andere Bindungen. Es wird in den Verträgen davon gesprochen, daß die Staatsangehörigen der Mitgliedsstaaten gleichbehandelt werden; das ergibt selbstverständlich einen anderen Status. Deshalb habe ich auch Gewohnheitsrecht und Vertragsrecht sauber getrennt. Wir hatten die EWG ausgeklammert, weil das sonst zu weit führen würde; es ist ein Kapitel und ein großes Gebiet für sich.

Sie sagen "Gast". Wir sprechen auch von Gastarbeitern. Warum eigentlich, wenn wir mit dem Begriff des Gastes dann doch nicht Ernst machen wollen. Im übrigen ist es schließlich so, daß wir nicht allein auf der Welt sind. Das Problem der Gastarbeiter ist weltweit, und die Völkerrechtsregeln, die für Nichtstaatsangehörige, also Fremde, gelten, sind nun einmal Inhalt der Verfassung nach Art. 25. Wenn wir mit Besonderheiten anfangen, kommen wir aus der Differenzierung überhaupt nicht mehr heraus. Ich möchte daher etwas strikt an dem traditionellen Fremdenbegriff festhalten; so lange der sich nicht geändert hat, so lange die Verfassung den Art. 25 hat, ist er da und ist der zu behandelnde Begriff. Das ist meine Auffassung.

Hans Meyer: In zwei Punkten scheint mir das Referat von Herrn Isensee nicht ganz befriedigend $\mathrm{zu}$ sein, und zwar in bezug auf jene Gruppen, die vorhin mißverständlich als Minderheiten bezeichnet worden sind, d. h. jene Gruppen von Ausländern, die nicht Bildungsreisende oder Teppichhändler sind, die ihre soziale Existenz vielmehr in der Bundesrepublik verankert haben und langjährig hier wohnen.

Eine wichtige Frage ist, wie es mit der Einbürgerung steht. Hier ist mehrmals auf die Lösung der Einbürgerung verwiesen worden, die den vollen rechtlichen Status für den Ausländer vermittle. Die Gretchenfrage ist aber doch: Hat der Ausländer einen Anspruch auf Einbürgerung? Ich meine, daß ein solcher Anspruch besteht, wenn die Bundesrepublik einen Ausländer zehn Jahre voll in das Wirtschaftsleben integriert hat.

Der zweite Punkt betrifft die Partizipation. Sowohl Herr Leisner als auch Herr Isensee haben formell über Art. 28 argumentiert. Es ist schwer, etwas dagegen zu sagen, wenn man nicht vielleicht folgendes überlegt: Immerhin ist nicht vom 
"Staatsvolk" die Rede und es fehlt ein formaler Bezug zur Staatsangehörigkeit. Man könnte daran denken, ob nicht eine Aufweichung für den Sonderfall möglich ist, daß ganze Volksteile hier auf die Dauer leben und langsam aber sicher integriert werden. Ich darf daran erinnern, daß die Mehrheit der Lehre dem Demokratiebegriff in Art. 28 für die Gemeinde nicht die gleiche Dignität einräumt wie dem für die Landes- oder Bundesebene, wenn z. B. dem gemeindlichen Parlament das autonome Satzungsrecht verweigert wird.

Wenn aber eine solche Aufweichung nicht möglich erscheint, dann müßte man - das ist natürlich keine Frage der Grundrechte oder der Verfassungsauslegung, sondern eine rechtspolitische Frage - andere Formen der Partizipation finden, und zwar recht bald, da die Probleme dringend sind. Es gibt eine Reihe von Fällen, in denen sich Ghettos bilden, wo also z. B. der Begriff der öffentlichen Ordnung in unserem Sinne nicht mehr gilt, wo auch die deutschen Ordnungsbehörden nicht mehr in der gedachten Weise funktionieren, wo sich vielmehr das Ghetto selbst organisiert, die Ordnung hält. Wenn wir das vermeiden wollen, müssen wir, und zwar durch eine wirksam gestaltete Partizipation, Möglichkeiten eröffnen. Es geht um die Frage, ob es nicht viel vernünftiger ist, diese Ausländer in unsere normale demokratische Struktur einzubinden.

Merten: Eine kurze Zwischenfrage: Herr Meyer hat gesagt, er würde einem Ausländer bei einem zehnjährigen Aufenthalt in der Bundesrepublik einen Anspruch auf Einbürgerung einräumen. Nun wüßte ich als gesetzestreuer Jurist bei einem Anspruch gern auch die Anspruchsgrundlage. Woher kommt sie? Und warum sind es gerade zehn Jahre und nicht neun, acht oder sieben Jahre?

Hans Meyer: Ich will mich nicht auf zehn Jahre festlegen; aber eine Grenze wird man setzen müssen. Und die Grundlage würde ich darin sehen, daß diese Leute zehn Jahre lang ihre soziale Existenz bei uns verankert und für die Bundesrepublik Deutschland das geleistet haben, was auch der normale Staatsbürger geleistet hat. Den Anspruch könnte man auf Art. 1 oder auf Art. 3 stützen; in diesem Punkte hätte ich keine Hemmungen.

Oppermann: Noch ein Wort zum EWG-Vertrag, der bei Herrn Böckenförde und auch bei Ihnen, Herr Doehring, anklang. Man muß hier ganz deutlich sagen, daß der EWG-Vertrag in diesem Zusammenhang nicht ein völkerrechtlicher Vertrag wie jeder andere ist, sondern - Sie haben das auch angedeutet, 
Herr Doehring, indem Sie auf Art. 24 neben Art. 25 rekurrierten - daß er ein Vertrag ist, der auf einen Endzustand hinarbeitet - man kann dabei von einem europäischen Bundesstaat reden oder von einem Zweckverband im Sinne Ipsens jedenfalls auf einen staatsrechtlichen oder staatsähnlichen Endzustand, in dem ein größeres Gemeinwesen entsteht. In diesem Gemeinwesen können die "Marktbürger" eines Tages mehr oder weniger wieder zu Staatsbürgern werden, die sich dann ihrerseits als Inländer nach außen hin abgrenzen. Insofern muß man einen deutlichen Unterschied zwischen dem allgemeinen völkervertragsrechtlichen Zustand machen und dem, was sich aus der EWG ergibt. Daher war es doch ein wenig schade - was ich aus arbeitsökonomischen Gründen vollkommen verstehe -, daß man den EWG-Vertrag in beiden Referaten ausgeklammert hat. $\mathrm{Er}$ ist in diesem Zusammenhang eine besonders interessante $Z$ wischenstufe. Es gibt ja auch ein Bleiberecht für EWG-Ausländer im Inland in einer EWG-Verordnung, das in dieser Form zum ersten Male ausdrücklich statuiert wurde. Insofern gibt es in der EWG sehr viele status-begründende Berechtigungen für Marktbürger, die scheinbar Herrn Doehring widersprechen. Er kann sich aber mit der Begründung rechtfertigen, daß die Europäische Gemeinschaft einen Sonderfall darstellt, weil es hier nicht um den völkerrechtlichen „Fremden“ geht, sondern um Angehörige eng verbundener Staaten, die allmählich mehr oder weniger personalbinnenmarkt-ähnlich miteinander zusammenwachsen sollen.

Fritz Münch: Ich möchte den beiden Referenten mit einigen kurzen Bemerkungen beitreten. Zum Wort „Minderheiten“ ist eingewandt worden, daß die Minderheiten doch aus Staaatsangehörigen bestehen. Mir scheint es wichtig zu sein, daß die Minderheiten typischerweise fest angesiedelte traditionelle Volksgruppen sind, jedenfalls in Europa. Aber wenn wir genauer hinschauen, haben wir zwischen dem Staatsangehörigen und dem klassischen Ausländer des vorigen Jahrhunderts, auf den Herr Kewenig mit Recht hingewiesen hat - also dem isolierten Staatsfremden, noch eine ganze Reihe von Kategorien.

Neben den Staatsangehörigen haben wir in Deutschland jedenfalls die deutschen Volkszugehörigen, die Flüchtlinge nach Art. $116 \mathrm{GG}$; dann gibt es die Konventionsflüchtlinge und die displaced persons, denen wir gewissermaßen ein Heimatrecht zugebilligt haben; dann gibt es in Einwanderungsländern große Einwanderergruppen, die die Absicht haben - und das unterscheidet sie von den Gastarbeitern - sich dauernd niederzu- 
lassen und Staatsangehörige zu werden; endlich gibt es die Gastarbeiter, die mir in der Tat heute noch lediglich eine quantitative Ubersteigerung des klassischen Ausländers zu sein scheinen, wenn sie auch besondere Probleme aufwerfen. Aber worauf es wirklich ankommt, ist der Grad der Solidarität, die diese Gruppen zu unserem Staat haben. Am größten ist er gewiß bei den volksdeutschen Flüchtlingen und Vertriebenen; das ist aus Art. 116 GG zu folgern. Ich würde auch bei den Konventionsflüchtlingen und displaced persons darauf rechnen, daß sie Solidarität mit uns haben. In einem Einwanderungsland sind die typischen Einwanderer wohl auch als solidarische Gruppen anzusehen. Bei den Gastarbeitern müßte das noch überprüft werden. Ich weiß nicht, wie weit sie jetzt mit uns solidarisch sind. Der Natur der Sache nach würde es meines Erachtens gerade von diesem Punkt abhängen, welche besonderen Rechte man ihnen gibt und wie weit man sie rechtlich integriert. In einem Einwanderungsland hat Heinz Kloss kurz vor dem Kriege eine große Studie über die kulturelle Autonomie und die kulturelle Pflege von Einwanderergruppen durch die USA und deren Gliedstaaten zusammengestellt; sie ist 1963 erst erschienen (Das Nationalitätenrecht der Vereinigten Staaten von Amerika).

Zu Art. 25: Mir scheint, daß über Art. 25 GG mit Hilfe von Völkergewohnheitsrecht auch Grundrechtssätze interpretiert werden können. Das ist beim Asylrecht angedeutet, als es darum ging, Attentäter vom Asyl auszuschließen (BGHStr. 3, 394; 8, 64 f.; BVerwGE 4, 237 f.). Die These 13 von Herrn Doehring scheint mir etwas zu scharf formuliert zu sein oder Mißverständnisse aufwerfen zu können. Wenn die nach Art. 25 erzeugten Rechte und Pflichten am Verfassungsrecht tejlnehmen, dann ist dennoch nach der Rechtsprechung des Bundesverfassungsgerichts ausgeschlossen, da $B$ sie zu Verfassungsbeschwerden Anlaß geben können.

Mußgnug: Ich möchte nur eine konkrete Frage an Herrn Isensee richten: Wie steht es mit einem Ausländer, der hier zum Beamten auf Lebenszeit ernannt worden ist, dann aber irgend ein mittelschweres Vergehen begeht (also etwa Verkehrsgefährdung, einen Warenhausdiebstahl, eine Unterhaltspflichtverletzung etc.), das bei einem deutschen Bamten disziplinarisch noch mit einer Laufbahn- oder Gehaltsstrafe geahndet würde? Für Ausländer schaffen solche Delikte jedoch bereits einen Ausweisungstatbestand. Nur verbeamtete Ausländer befinden sich in einer besonderen Lage. Würden sie ausgewiesen, so würde ihnen das den Schutz ihres Beamtenstatus 
rauben, der ja in der Verfassung garantiert ist. Oder erlaubt der Gleichheitssatz hier eine disziplinarrechtliche Differenzierung dergestalt, daß die Tat eines inländischen Beamten mit einer Laufbahnstrafe geahndet, die des Ausländers aber, weil er einen Ausweisungstatbestand geschaffen hat, mit der Entfernung aus dem Dienst? Wenn ich es nicht falsch sehe, liefert das die Probe aufs Exempel für Herrn Isensees These von den zwei Stufen des Grundrechtsschutzes für Ausländer.

Isensee: Ich darf die vielen Einwände gegen das Zwei-Phasen-Modell an dem Beispiel, das Herr Mußgnug entwickelt hat, aufgreifen. Es stellen sich zwei Fragen: Wieweit geht die unerläßliche Status-Sicherung durch Gebietszulassung? Welche Grundrechtsverzichte kann der Ausländer erbringen?

Vorweg aber eine Klarstellung: Die Status-Verfestigung des Ausländers im Bereich der Deutschen-Grundrechte bedeutet nicht die unmittelbare Zuweisung eines Deutschen-Grundrechts, sondern nur die materielle Gleichstellung auf der Basis des allgemeinen Gleichheitssatzes. Diese Gleichstellung ist kein Rechtsautomatismus, der aus der Einreise folgt, sondern eine Möglichkeit, die sich mit den staatlichen Zulassungsentscheidungen aktualisiert.

Gegen dieses Gleichstellungs-Konzept wird eingewendet, der Staat erwiese dem Ausländer möglicherweise keine Wohltat, wenn er sich auf die Wahl zwischen Abweisung oder Gleichstellung beschränke. Der Gesichtspunkt der Wohltat ist in dieser Runde übrigens als neuer grundrechtsdogmatischer Topos kreiert worden. Ich weise auf die Geburtsstunde hin.

Ich möchte dagegen die konventionelle Sicht verteidigen, daß der Rechtsstaat um seiner selbst willen zur Rechtsgleichheit verpflichtet ist, ohne Rücksicht auf die individuellen Empfindungen der Betroffenen, mag es sich nun um den Bürger auf Lebenszeit handeln oder (wenn das Reizwort "Untertan" vermieden werden soll) um den ausländischen subditus temporarius. Wenn ein Türke lieber Sklave in Mannheim als Kaufmann in Trapezunt ist und wenn er für den Fall der Einreiseerlaubnis zu jedem Grundrechtsverzicht bereit ist, so mag ein Aufenthaltsrecht mit minderem Grundrechtsstatus in seinen Augen eine Wohltat sein. Aus rechtsstaatlicher Sicht ist es unerträglich. - Wenn der Staat des Grundgesetzes zwischen Steinen und Brot zu wählen hat, so reicht er, wenn er das Brot der Grundrechte nicht teilen kann (oder will), den Stein der Abweisung. Aber er gibt nicht eine Mischung aus Brot und Steinen. - 
Nun zu der Probe aufs Exempel - zum Disziplinarfall des ausländischen Beamten: Hier sind die beamtenrechtliche und die aufenthaltsrechtliche Ebene zu unterscheiden. Auf beamtenrechtlicher Ebene ist jeder gleich zu behandeln. Wenn ein Ausländer in den öffentlichen Dienst aufgenommen worden ist, so unterliegt er denselben dienstrechtlichen Regelungen, bis hin zu denen des Disziplinarrechts. $O b$ ein Ausländer aber verbeamtet werden soll, ist eine freie Entscheidung des Dienstherrn, die durch Art. 33 Abs. 2 und 3 GG nicht eingeschränkt wird. - Nun stellt sich die Frage, ob mit der Verbeamtung nicht notwendig eine Status-Sicherung auf aufenthaltsrechtlicher Ebene verbunden ist. Die Frage ist zu bejahen. Wer zum Beamten auf Lebenszeit ernannt und damit der Residenzpflicht unterworfen worden ist, hat damit auch ein entsprechendes Aufenthaltsrecht erlangt und ist gegen Ausweisung gesichert. Es ist daher ausgeschlossen, daß ein Dienstvergehen neben der disziplinarischen Sanktion auch die Ausweisung nach sich zieht.

Ich möchte das Problem noch an einem anderen Beispiel verdeutlichen. Wenn ein Ausländer, der die Aufenthaltserlaubnis für ein Jahr besitzt, einen Gewerbebetrieb im Bundesgebiet aufmacht und sich so eine grundrechtlich gesicherte EigentumsPosition erarbeitet, so erlangt er damit noch kein Aufenthaltsrecht auf Dauer. Bei der Status-Sicherung ist zu unterscheiden: Bei einem Beamtenverhältnis auf Lebenszeit müssen auch die aufenthaltsrechtlichen Voraussetzungen lebenslänglich gewährleistet sein. Bei freiberuflicher Tätigkeit im Rahmen einer Aufenthaltserlaubnis von einem Jahr ist auch die Berufstätigkeit im Bundesgebiet nur für ein Jahr gesichert. Die beliebte Argumentation, daß dem Ausländer nunmehr ein länger währendes Aufenthaltsrecht zukommen müsse, damit er seine Grundrechtsposition genießen oder über effektiven Rechtsschutz verteidigen könne, ist nicht haltbar. Hier werden Grundrechtsvoraussetzungen und Grundrechtsinhalte durcheinander gebracht.

Scholz: Herr Isensee, Sie haben sich hinsichtlich Ihrer ZweiPhasen-Lehre eben etwas in eine defensive Position begeben. Ich möchte Sie dagegen unterstützen; mich hat Ihre Auffassung sehr bestochen.

Andererseits meine ich, daß in der Diskussion über der rechtsstaatlichen und der demokratischen Dimension die sozialstaatliche Dimension der Rechtsstellung des Ausländers etwas zu kurz gekommen ist. Bei der demokratischen Dimension wurden wohl einige Pferde von hinten aufgezäumt. Verfassungsrechtlich möchte ich hier vor allem Herrn Leisner zustimmen. Die Vorstellung vom Ausländer als Gemeindebürger mit 
demokratischem Aktivstatus knüpft doch an kommunalpolitisch längst überwundene Romantik an. Die wirklich zentralen Fragen liegen dagegen - Herr Zacher hat vorhin schon darauf hingewiesen - im sozialpolitischen Bereich. Die maßgebenden Stichworte heißen hier: Stellung des Ausländers in den Gewerkschaften, in den Verbänden, Rechtsstellung des Ausländers im Betrieb, in der Betriebsverfassung und im Arbeitskampf. In letzterer Hinsicht darf ich nur an die jüngsten wilden Streiks gerade von ausländischen Arbeitnehmern erinnern. In all diesen Bereichen bedarf es sozialstaatlicher Gesetzesmaßnahmen zur Verbesserung des sozialen Status des Ausländers. Dem Gastarbeiter steht zwar das Grundrecht der Koalitionsfreiheit zu, aber wie steht es um seine aktiven Mitgliedschaftsrechte in den Gewerkschaften? Sie sind faktisch außerordentlich beschränkt. Demgemäß liegen hier die Probleme und nicht etwa bei der Frage nach einem aktiven Bürgerrecht des Ausländers in der Gemeinde.

Ich bedaure es auch ein wenig, daß das Europarecht nicht stärker berücksichtigt wurde. Gerade hier wird deutlich, wo die zentralen Fragen des sozialen Ausländerstatus liegen: in den ökonomischen und sozialen Fragen von Freizügigkeit, Arbeitsplatzwahl und sozialer Sicherheit. Diese sozialstaatlichen Statusfragen bilden die zentrale Problematik der Rechtsstellung des Ausländers überhaupt. Und bei der Lösung auch dieser Fragen bietet Ihre Zweiphasenabgrenzung, Herr Isensee, methodisch wirklich wichtiges Rüstzeug.

Vorsitzender: Vielleicht sollten wir den Weg in Richtung der Zwei-Phasen-These Herrn Isensees mit Blick mehr auf die konkreteren Sachbereiche weiterverfolgen. Zunächst noch eine Stellungnahme von Herrn Böckenförde:

Böckenförde: Ich möchte unmittelbar anknüpfen an Herrn Scholz, auch im Hinblick auf das Gemeindewahlrecht. Das Problem scheint mir darin zu liegen, daß der sozialstaatliche Status, von dem Sie, Herr Isensee, gesprochen haben, gerade weil seine Realisierung nicht durch Ableitung von Rechtsansprüchen aus Art. $20 \mathrm{GG}$, sondern nur im Wege politischer Entscheidung erfolgen kann, für die Ausländer einer Absicherung bedarf, also eines status processualis. Wir geben ihnen diese Absicherung ja auch im Rahmen der Koalitionsfreiheit. Die Ausländer können sich gewerkschaftlich organisieren, sie sind Mitglieder der Sozialversicherung und haben dort die Rechte, die die inländischen Mitglieder der Sozialversicherung haben. Das Problem liegt darin, daß die Infrastrukturmaßnahmen, die für die Ausländer wesentlich mit zur Realisierung des sozial- 
staatlichen Status gehören, weitgehend auf der Gemeindeebene vollzogen und realisiert werden. Die Frage ist, ob man die Gemeinde hier nicht in ihrer Doppelfunktion sehen muß, einmal als Träger der mittelbaren Staatsverwaltung, um Leistungen der Daseinsvorsorge zu erbringen und den Sozialstaatsauftrag effektiv zu machen, und zum anderen auch, was sicher nicht unterschätzt werden darf, als örtliche BürgerGemeinschaft mit demokratisch strukturierter Willensbildung.

Sicher sprechen gewichtige Gründe dafür, das Wahlrecht zu den Gemeindevertretungen nicht auf die Ausländer auszudehnen; die sind schon angeführt worden. Aber dann müssen wir überlegen, ob nicht die Ausländer berechtigt sein sollen - ich denke jetzt insbesondere auch an die statusrechtlichen Verfestigungen in der EWG, also an die Marktbürger, die hier, wenn und solange sie Arbeit finden, ein lebenslanges Niederlassungsrecht haben -, die Belange, die in ihrem sozialstaatlichen Status begründet sind, in einer anderen geeigneten Form verfahrensrechtlich geltend zu machen und sich zu Gehör zu bringen. Es würde zu weit führen, hier im einzelnen durchzuspielen, was da geschehen kann. Vielleicht kann man an eine Funktionsteilung derart denken, daß es im Hinblick auf bestimmte Infrastrukturprobleme eine andere Art von Gemeinde gibt als die politische Gemeinde. Wir haben das auch jetzt schon in Form eigener Schul-Gemeinden, WasserversorgungsVerbände und ähnlicher funktional bestimmter und radizierter Quasi-Gemeinden.

Nun noch ein Punkt zu Threr These 20, Herr Isensee, im Hinblick auf die Meinungsfreiheit. Sie haben - wenn ich Sie recht verstanden habe - die Meinungsfreiheit ausschließlich als rechtsstaatliches Grund- und Freiheitsrecht interpretiert und das demokratische Element, das in diesem Grundrecht enthalten ist, unter die rechtsstaatliche Interpretation strikt unterordnen wollen. Sie haben damit ein sehr wichtiges Problem deutlich gemacht, das sich bei den drei Grundrechten der Art. 5, 8 und 9 immer stellt. Hier haben wir die eine Tendenz, die diese Grundrechte nur oder primär demokratisch interpretieren will mit all den bekannten Folgerungen, die sich aus einer solchen Unterordnung des rechtsstaatlichen unter den Primat des demokratischen Elements ergeben. Sie sind jetzt den umgekehrten Weg gegangen. Ich halte das nicht für möglich. Diese drei Grundrechte müssen in ihrer Doppelfunktion, die sie aus sich selbst heraus haben, gesehen und auch interpretiert werden. Von daher würde ich es für zulässig halten, daß bei politischen Meinungsäußerungen der Ausländer differenziert wer- 
den kann, obwohl das ein Jedermann-Recht ist. Von Ihrem Interpretationsansatz kommen Sie zu genau dem gleichen Problem bei Art. 8 und 9 im Hinblick auf die Versammlungsfreiheit und die Vereinigungsfreiheit. Beide sind zugleich ja rechtsstaatliche Freiheits- und demokratisch-politische Mitwirkungsrechte. Wenn Sie allein die rechtsstaatliche Seite sehen und diese pars pro toto setzen, kommen Sie im Sinne ihrer eigenen Thesen vor die Alternative: ganz oder gar nicht, wobei Sie sich durch Leitsätze $7 \mathrm{ff}$. den Weg zum "gar nicht" selbst verlegt haben. Mit § 6 II AusländerG und § 14 I VereinsG kommen Sie auf diese Weise in große, kaum überwindbare Schwierigkeiten. Ich meine also, der Doppelcharakter dieser Grundrechte muß wirklich festgehalten werden und auch in der Interpretation eine Differenzierung ermöglichen.

Leisner: Ich möchte noch einmal auf die Bedeutung der Unterscheidung der beiden Phasen, über die schon viel gesprochen worden ist, hinweisen, eine Bedeutung, die weit über das Ausländerrecht hinausgeht und für das Verfassungsrecht von besonderer Wichtigkeit ist. Was hier Herr Isensee vor allem ausschalten will, ist doch dies, daß zunächst die Voraussetzung verhältnismäßig leicht bejaht wird, dann aber, wenn es um die Rechtsfolge geht, und wenn man zur Kasse gebeten wird, das Geschenkte mit der anderen Hand wieder zurückgenommen wird. Wie man die Grenzen zwischen den beiden Phasen zieht - darüber mag durchaus diskutiert werden. Bedeutsam ist nur, daß eine strenge Trennung besteht. Wie wichtig diese Erkenntnis für das gesamte Verfassungsrecht ist, zeigt sich an vielen anderen Stellen unserer Grundrechtsdogmatik, wo ähnliche Mißbräuche, wie sie im Ausländerrecht heute festzustellen sind, ebenfalls auftreten, z. B. im Bereich des Art. 14 GG: Es ist etwa problematisch, ob ein bestimmter Eingriff Sozialbindung oder Enteignung ist. Um darüber nicht lange streiten zu müssen, rechnet man ihn mit großer Liberalität der Enteignung zu. Nachher aber sagt man: Wir können das ja gar nicht bezahlen, laßt uns also "bei den Rechtsfolgen einsparen“ und die Enteignungsentschädigung absenken. Mit anderen Worten: Hier wird das bei den Rechtsfolgen wieder aufgehoben, was man vorher bei den Voraussetzungen gegeben hat. Ähnliche Fälle lassen sich aus dem Beamtenrecht und anderen Bereichen anführen. Ich glaube also, daß die strenge Unterscheidung, wie sie hier versucht worden ist, vor allem auch methodisch und dogmatisch für das gesamte Recht von Wichtigkeit ist, gleich, wie man im einzelnen nun die Grenzen zieht. 
Vorsitzender: Die Zeit ist jetzt beschränkt. Obwohl die Diskussion nur eine begrenzte Reihe von wichtigen Punkten eingekreist hat, müssen wir nun abbrechen. Wir wollen aber doch den beiden Referenten die Möglichkeit eines Schlußwortes geben. Zunächst Herr Isensee.

Isensee (Schlußwort): Ich darf mich auf eine Nachlese der Argumente beschränken. Die Diskussion zeigt eine seltsame Widersprüchlichkeit der Argumentationsrichtungen - eine Widersprüchlichkeit, die gleichsam dem objektiven Rechtsgeist der Siebziger Jahre entspricht. Auf der einen Seite soll das demokratische Prinzip, zumindest auf kommunaler Ebene, über das verfassungsrechtlich Vorgesehene hinaus ausgeweitet werden. Auf der anderen Seite sollen die Grundrechte, die nach dem Verfassungstext jedermann zustehen, im Zeichen desselben demokratischen Prinzips auf Verbandsangehörige beschränkt werden. Dort, wo die Verfassung ein Recht gibt, soll es qua Demokratiegebot zurückgenommen, dort aber, wo es die Verfassung versagt, qua Demokratiegebot eingeräumt werden.

Es war eine Entdeckung, daß in den traditionellen liberalen Grundrechten ein status activus, eine demokratische Komponente, ein Integrationsauftrag enthalten sind. Aus diesen verfassungstheoretischen Erkenntnissen werden aber illegitime Folgerungen gezogen, wenn der Verfassungstext über die Verfassungstheorie korrigiert und die rechtsstaatlichen Grundrechtsgehalte von den demokratischen Ideen der Integration und der Offentlichkeit überwältigt werden. Die Argumente des "politischen" oder "demokratischen" Gehalts, des Öffentlichkeitsbezugs oder des Integrationseffekts haben keine normative Trennschärfe. Sie können den Grundrechtsstatus des Ausländers nicht begründen, erweitern oder schmälern.

Wenn die Bereiche der demokratischen und der (rechtsstaatlich-)grundrechtlichen Legitimation nicht auseinander gehalten werden, ist es gleichgültig, wo man die Gemeinde verfassungsdogmatisch einordnet. Die heutige Demokratisierungsbewegung, die auf die Verleihung des Kommunalwahlrechts an ausländische Gemeindeeinwohner drängt, läßt in der Gemeinde eine staatsheterogene, gesellschaftliche, "soziale“ Komponente -ein Legitimationsprinzip des 19. Jahrhunderts - wieder aufleben. Sie macht die Einbindung der Gemeinde in den demokratischen Staat wieder rückgängig. Die Entwicklung der Gemeinde von der gesellschaftlichen Selbstverwaltung zur mittelbaren Staatsverwaltung war in der Weimarer Republik bereits abgeschlossen, wie es Hans Peters Monographie "Grenzen der kommunalen Selbstverwaltung in Preußen" zeigt. 
Die Verleihung des Wahlrechts an ausländische Gemeindeangehörige wird auch mit dem Argument gerechtfertigt, daß die kommunale Gebietskörperschaft die Sozialstaatlichkeit verwirkliche. Die sozialstaatliche Zuständigkeit der Gemeinde läßt aber keine Folgerung zu auf den Zuständigkeitsträger und sein demokratisches Fundament. Ich darf nur wiederholen, daß weder der status positivus noch der status passivus des Individuums den status activus als Kompensation fordert.

Es heißt, die Sonderstellung des Ausländers im unrichtigen Zusammenhang zur Geltung bringen, wenn ihm auf der einen Seite das Wahlrecht eingeräumt, auf der anderen Seite die grundrechtlich gesicherte politische Freiheit, vor allem die Meinungsfreiheit verkürzt wird. In diese Richtung geht der Vorschlag, den wahlberechtigten Ausländer im Wahlkampf irgendeiner Zensur zu unterwerfen, wie sie das allgemeine Grundrecht des Art. 5 GG an sich nicht zuläßt.

Damit ist das Stichwort „Partizipation“ fällig. Partizipation ist kein Verfassungsbegriff, sondern ein vorrechtlicher Gedanke der in verschiedenen Verfassungsrelationen bedeutsam werden kann. Die Gewährleistung der allgemeinen Meinungsfreiheit, ohne Unterscheidung nach ihrer „demokratischen“ oder „rechtsstaatlichen" Komponente, ist ein grundgesetzlicher Partizipationstitel für den Staatsfremden. Er erhält damit die Möglichkeit, an der politischen Willensbildung teilzunehmen. Die „demokratischen" Rechte werden ihm nur vorenthalten, soweit es um das geschlossene, organisierte Entscheidungsverfahren, nicht aber soweit es um den offenen, unorganisierten Prozeß der Vorklärung des politischen Willens geht.

Im übrigen ist es unverständlich, weshalb die stolze Entdekkung der demokratischen Komponente in den Freiheitsrechten zumeist nur zur Restriktion der Meinungsfreiheit führen soll. Der Wirkungszusammenhang des Privaten und des Offentlichen im politischen Gemeinwesen gilt für jedes Grundrecht. So ist das „liberale“ Elternrecht höchst „politisch“, weil die privatautonome Entscheidung über die Erziehungsziele die Grundlage der demokratischen Differenzierung der künftigen Aktivbürgerschaft bildet. -

Soweit dem Ausländer konkrete sozialstaatliche Ansprüche oder ein verfassungsrechtlicher Einbürgerungsanspruch zugesprochen wird, stellt sich die Frage, wo denn die sedes materiae liegt: im objektiven Geist der heutigen Rechtsgemeinschaft? in einem kosmopolitischen Weltgeist? oder in einem philanthropischen Nebel? - Gerade um des demokratischen Verfassungsprinzips willen ist vor allzu kühnen Verfassungsdeduktionen 
und Verfassungsprojektionen zu warnen: Sie spiegeln als längst verfassungsrechtlich fixiert vor, was erst in der demokratischen Diskussion gesucht werden muß. Sie heben die demokratische Auseinandersetzung auf, ehe sie begonnen hat.

Ich möchte mich mit jener Entschuldigung zurückziehen, mit der Kant das Fremdenrechtskapitel seiner Arbeit „Zum ewigen Frieden" einleitet: daß hier "nicht von Philanthrophie, sondern vom Recht" die Rede sei. So bitte ich um Verständnis dafür, $\mathrm{da} \beta$ die Bemühungen nur dem philanthrophischen Minimum gegolten haben, das die Verfassung gewährleistet.

Vorsitzender: Es ist betrüblich, da $B$ wir darüber nicht noch weiter diskutieren können. Bitte, Herr Doehring.

Doehring (Schlußwort): Ich möchte die Möglichkeit eines Schlußwortes dazu benutzen, noch einmal klarzumachen, daß ich der wohl nicht überwiegenden Auffassung bin, wonach man mit dem normativen Gefüge der Verfassung im Fremdenrecht ganz gut zurecht kommt. Allerdings, wie gesagt, nehme ich zur Lösung der Probleme das Völkerrecht zu Hilfe. Das will ich noch einmal an einem kleinen Fall erklären, den ich sonst in meinem Referat gebracht hätte. Der Fall beinhaltet eine ganz einfache Frage. Wir haben das Wehrpflichtgesetz mit seinem $\S 2$, wonach Ausländer zum Wehrdienst herangezogen werden können, wenn ihr Heimatstaat das mit Deutschen auch macht. Man kann streiten, ob diese Vorschrift nicht aus mehreren Gründen verfassungswidrig ist; das ist nicht ganz unbestritten, soll aber dahingestellt bleiben. Der deutsche Gesetzgeber hat davon Gebrauch gemacht, hier das völkerrechtliche Recht auf Repressalie einzusetzen. Der andere Staat soll dadurch gezwungen werden, nun das gleiche zu machen und also Deutsche nicht zum Wehrdienst heranzuziehen. Das ist der Sinn des $\S 2$. Der $\S 2$ sagt aber noch etwas anderes aus; er besagt, unter den gleichen Voraussetzungen könnt ihr hier Fremde behandeln, wie der andere Staat es drüben mit Deutschen macht. Jetzt nehmen Sie an, im Ausland wird ein deutscher Geistlicher zum Wehrdienst eingezogen. Die Frage ist: Wir wären hier normalerweise durch $\& 11$ des Wehrpflichtgesetzes gehindert, Geistliche einzuziehen. Im $\S 2$ steht aber, daß die gleichen Voraussetzungen, die im Ausland gelten, auch bei uns beachtet werden dürfen. Was soll sich denn nun durchsetzen, $\$ 11$ oder $\S 2$ ? Ich persönlich bin der Meinung, hier setzt sich die Repressalie im Völkerrecht gemäß Art. 25 auf Verfassungsebene als Rechtfertigungsgrund durch; wir dürfen das. Denn wir haben auf einfacher Gesetzesstufe zwei Vorschriften, die offenbar miteinander nicht in Ubereinstimmung zu bringen sind. Das wird 
aufgelöst durch die Erlaubnis der Verfassung. Schwieriger wäre die Frage - hier wird der Fall etwas ausgedehnt - : ein Deutscher wird im Ausland eingezogen; er hat keine Möglichkeit zur Verweigerung des Wehrdienstes aus Gewissensgründen. Der Angehörige des anderen Staates hier will sich aber auf Gewissensgründe berufen. Soll der Ausländer unter denselben Voraussetzungen eingezogen werden können, wie der Deutsche drüben und also ohne das Recht zur Wehrdienstverweigerung? Hier meine ich, daß sich Art. 25 nicht durchsetzt. Denn wir haben letzthin auf der gleichen Ebene des Art. 25 auch die Wesensgehaltsgarantie des Art. 19 Abs. 2. Zwar haben wir den Gesetzesvorbehalt bei der Kriegsdienstverweigerung, aber er muß die Wesensgehaltsgarantie als Verfassungsnorm beachten. Also, meine ich, müßte sich der Fremde auch auf Gewissensgründe berufen können. Ich wollte nur noch einmal zeigen, da $\beta$ man bei diesem Normenkonflikt eine Auflösung durch diesen - wenn man so will - Trick mit dem Art. 25 schlüssig erreicht. Wenn ich Art. 25 so benutze, habe ich gar nicht so große Schwierigkeiten, mit dem Fremdenrecht zurechtzukommen. Alles andere sind politische Fragen für den Gesetzgeber, nämlich wie er die sozialen Fragen regeln will. Ich kann auch zur Zeit nicht sagen, wie das zu regeln ist. Dazu müßte ich Statistiken über die soziale Gestaltung haben und vieles andere mehr. Der Gesetzgeber müßte eingreifen; das sehe ich ein. Nur solange das nicht geschieht, müssen wir mit den Normen fertig werden, die wir hier haben. Ich meine, man wird in meinem Sinne auch damit fertig.

Damit bin ich am Ende meiner Ausführungen. Ich danke allen, die sich an der Diskussion so anregend beteiligt haben.

Vorsitzender: Ich darf damit die Beratungen des heutigen Tages schließen. 